\title{
QL
}

430.5

P37W64

1905

Uberreicht vom Verfasser

MOLL.

\section{Embryologie von Physa fontinalis L.}

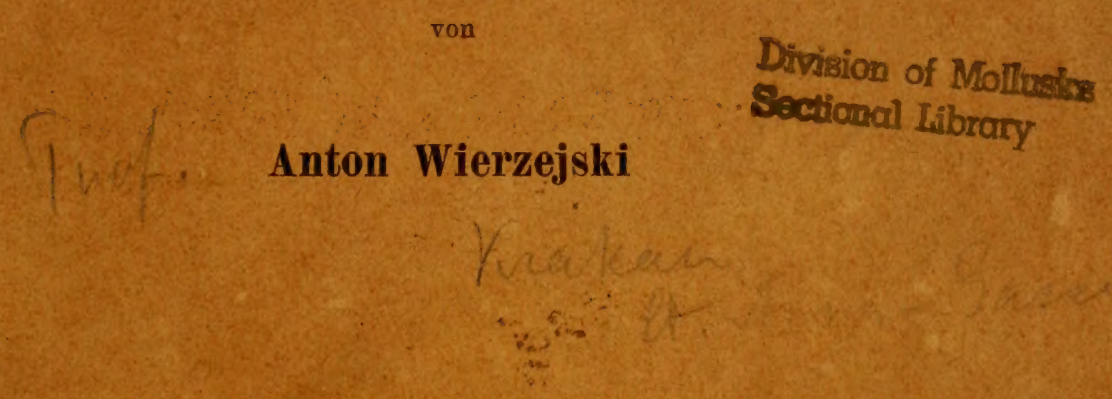

Mit 10 Tafeln, 6 Furchungstabellen und 9 Figuren im Text

Sonderabdruck aus: Zeitschrift für wissenschaftliche Zoologie , Bd. LXXXIII

Leipzig

Wilhelm Engelmann

1905 


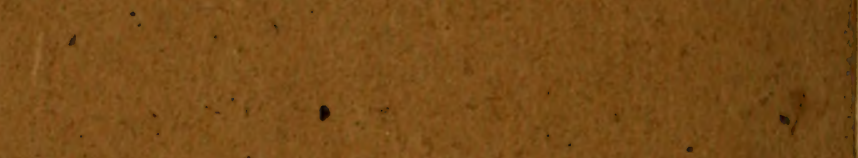

6.

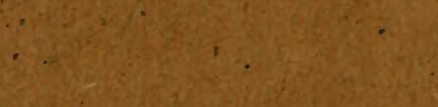

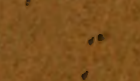

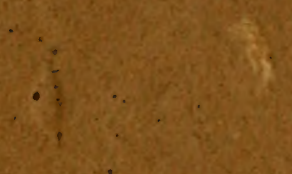

$x_{x \rightarrow 3}$

ensisios

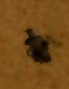

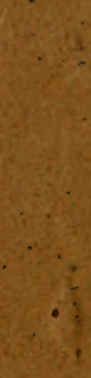

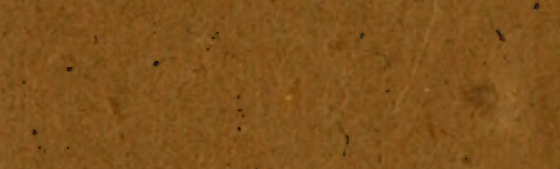

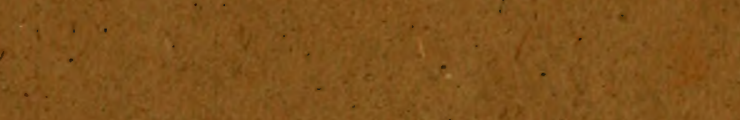

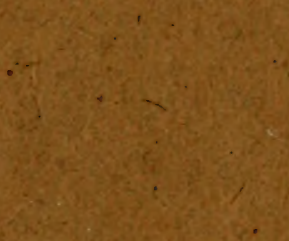
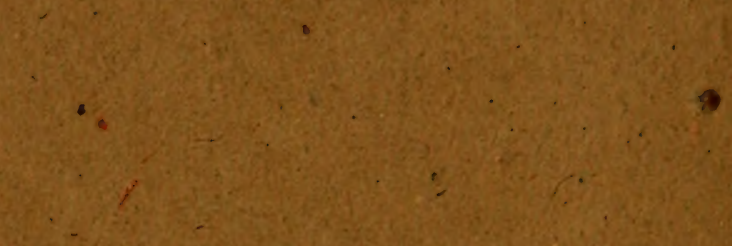

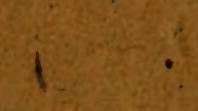
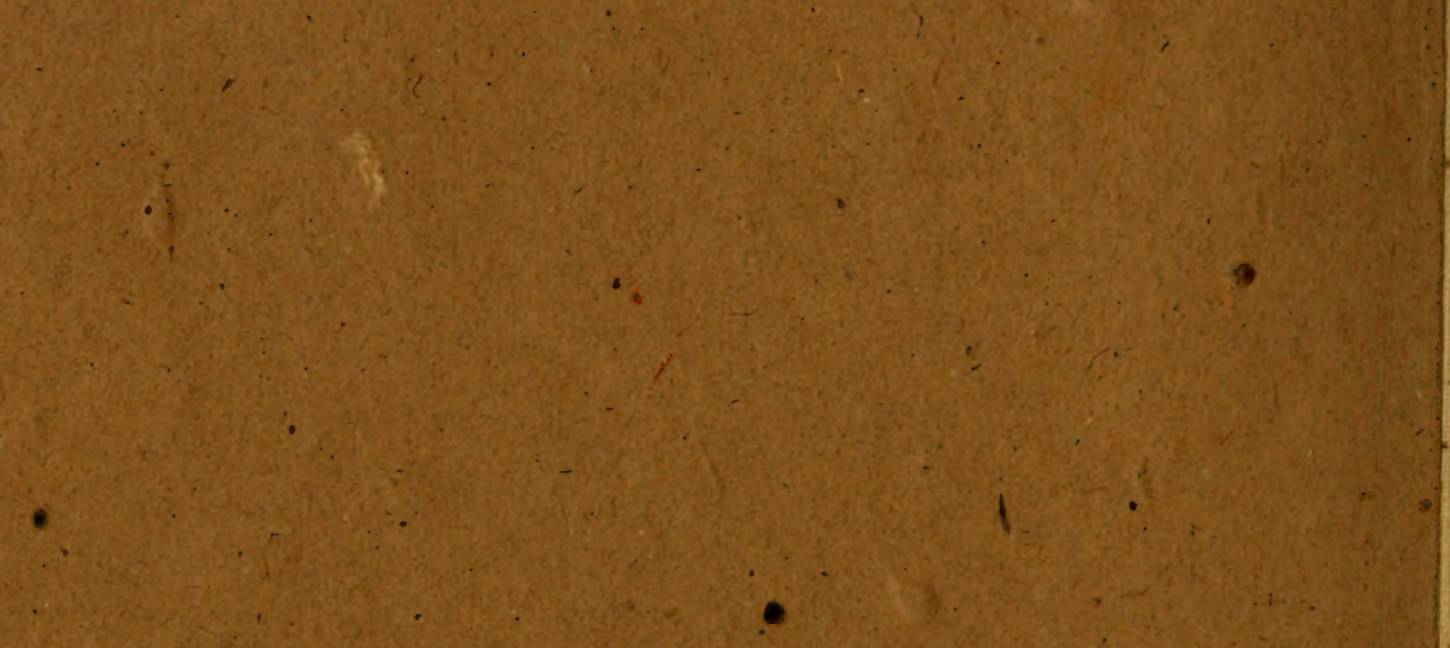

e.

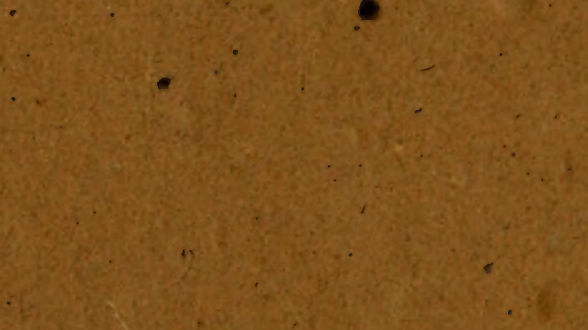

$\sin$
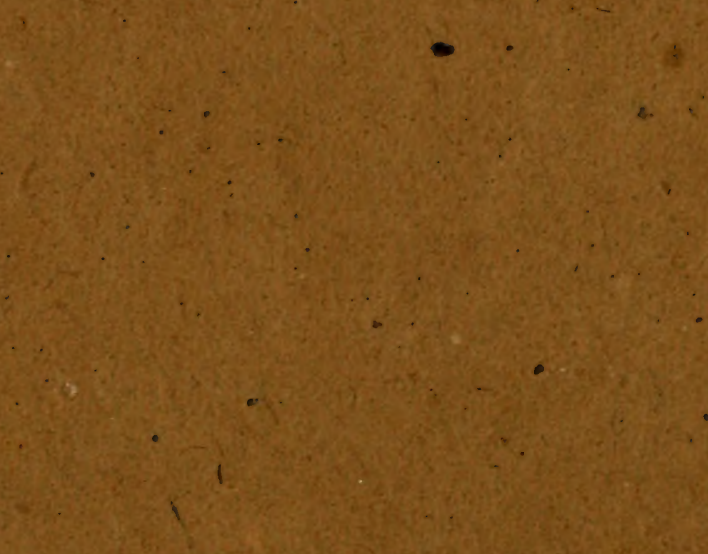

i. 


\section{Dtvision of Mollusks Sectional Library}

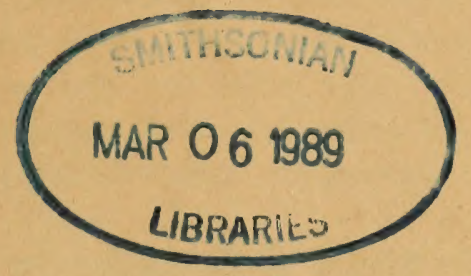

Anton Wierzejski.

Mit Tafel XVIII-XXVII, 6 Furchungstabellen und 9 Textfiguren. 


\section{Inhaltsüibersicht.}

1. Einleitung

2. Material und Methode $\ldots \ldots \ldots$

3. Nomenklatur . . . . . . . . . . . . . . . 511

4. Abnormitäten; ungefurchtes Ei . . . . . . . . 513

I. Furchung . . . . . . . . . . . . . . . . . . . 518

5. Furchungsgeschichte bis 123 Zellen .......... 518

Der umgekehrte Furchungsmodus . . . . . . . . . 523

Allgemeines über die Ectosomen . . . . . . . . . . 534

6. Geschichte des ersten Quartetts . . . . . . . . . . . 552

a. Das Kreuz . . . . . . . . . . . . . . . 552

b. Die Trochoblasten . . . . . . . . . . . 562

c. Bemerkungen über das sogen. Apikalorganء. . . . . 562

7. Geschichte des zweiten Quartetts . . . . . . . . . . 564

8. $>$, dritten,...... .569

9. Zahl der Ectomerenquartette . . . . . . . . . . 577

10. Entoderm . . . . . . . . . . . . . . 579

11. Primäres Mesoderm . . . . . . . . . . . . . . . . . 584

12. Furchungshöhle. . . . . . . . . . . . 589

II. Vergleichende Betrachtungen . . . . . . . . 598

13. Spiralfurchung . . . . . . . . . . . . . . . 598

14. Allgemeine Betrachtungen über das sekundäre Mesoderm . . . . 604

15. $>>$ s primäre $>\ldots 611$

16. Rudimentäre Zellen . . . . . . . . . . . . . . 625

17. Gastrulation . . . . . . . . . . . . . 633

III. Entwicklung der Organe . . . . . . . . . . . . 640

18. Larvale Organe. . . . . . . . . . . . . . 640

a. Velum . . . . . . . . . . . . . . . 640

b. Urniere .................. . . . . . 643

c. Nuchalzellen . . . . . . . . . . . . 658

19. Definitive Organe. . . . . . . . . . . . 663

a. Nervensystem . . . . . . . . . . . . . . . . . 663

b. Darmkanal . . . . . . . . . . . . . 665

c. Definitive Niere . . . . . . . . . . . . 685

IV. Résumé. . . . . . . . . . . . . . . 692

Literatur . . . . . . . . . . . . . . . . . . . 696

Erklärung der Abbildungen . . . . . . . . . . . . 698 


\section{Einleitung.}

Als ich mich vor einigen Jahren mit der Embryologie von Physa zu befassen begann und zunächst den Reifungs- und Befruchtungsvorgang bei derselben in Gemeinschaft mit v. KosTANECKI verfolgte und als es uns gelang positive Resultate zu erzielen ('96), fühlte ich mich veranlaßt, die Untersuchung auf den ganzen Furchungsprozeß bei dieser Form auszudehnen. Sie schien aus dem Grunde besonders interessant zu sein, weil es sich schon beim Studium der Anfangsphasen der Furchung herausstellte, daß sie zu den wenigen Gasteropoden gehört, bei denen der sog. sumgekehrte * Furchungsmodus festgestellt wurde.

Ferner hat die weitere Forschung gezeigt, daß das Mesoderm von Physa nicht ausschließlich aus den Urmesodermzellen, sondern außerdem noch aus zwei Zellen der Ectodermgeneration seinen Ursprung nimmt. Ein analoger Befund war damals nur bei Unio (LiLlit, '93) bekannt und gleichzeitig machte ihn auch ConkLIN ('97) bei Crepidula.

Die Ergebnisse meiner Untersuchungen über den Furchungsprozeß bis zur Anlage des soeben erwähnten Mesoderms, das ich als »sekundäres « bezeichnete, wurden im Jahre 1897 in einer vorläufigen Mitteilung veröffentlicht. Es handelte sich nunmehr eine in Aussicht gestellte ausführliche, durch Tafeln erlänterte Darstellung folgen zu lassen.

Verschiedene Umstände haben jedoch dazu beigetragen, daß die Veröffentlichung dieser Arbeit bis dato aufgeschoben werden mußte. Unter andern war es der Vorsatz die Descendenz möglichst genau bis zur Anlage der Organe zu verfolgen, ein Vorsatz, dessen Ausführung sehr zeitraubend ist, während der Erfolg nicht immer unsern Erwartungen entspricht. Denn, wenn es auch gelingt in der Aufdeckung der Zelldescendenz bis zu Stadien mit relativ sehr hoher Blastomerenzahl vorzudringen, so stehen wir dennoch den späteren Stadien zumeist ratlos gegenuiber und sind leider außer stande bei der Organogenese die Schicksale einzelner Zellterritorien mit mathematischer Sicherheit der Anfangsstadien zu verfolgen.

Es wäre aber verfehlt, wollten wir nur aus diesem Grunde unsre Untersuchungen bei einer bestimmten Phase abbrechen, denn ohne eine wenigstens annähernde Kenntnis dieser Schicksale wären wir bei Feststellung der Beziehungen zwischen einzelnen Blastomeren, den Keimblättern und Organanlagen bei verschiedenen Formen ganz und 
gar auf Vermutungen angewiesen. Wenn es also oft unmöglich ist das Ideal derartiger Forschung zu erreichen, d. i. die Geschichte der individuellen Blastomeren durch alle Phasen der Entwicklung des Keimes bis zur Ausbildung von definitiven Organen zu verfolgen, so ist es allerdiegs sehr wünschenswert, dieselbe bis zu den weitesten Grenzen kennen zu lernen. Sicherlich wären viele embryologische Irrtilmer vermieden, wenn sich die Ableitung der Organe auf die sichere Grundlage der Zelldescendenz gestuitzt hätte.

Von dieser Überzengung ausgehend habe ich in meinen Untersuchungen die Descendenz sogar soleher Blastomeren bis zu weit fort gerückten Furchungsstadien zu verfolgen versucht, deren Rolle beim Aufbau des Keimes untergeordnet zu sein scheint, denn man kann es im vorhinein nicht wissen, welche Dienste die Kenntnis der Descendenz eines Zellterritoriums beim Studium der Organogenese erweisen kann.

Das Hauptaugenmerk wurde jedoch der Descendenz der beiden Mesodermanlagen zugewendet, welche bekanntlich in der neneren Literatur Gegenstand lebhafter theoretischer Erörterungen geworden sind. Für das Studium ihrer wechselseitigen Beziehungen ist Physa gerade ein sehr gïnstiges Untersuchungsobjekt. Außerdem wurde auch der Descendenz des Entoderms und des ersten Quartettes große Sorgfalt gewidmet. Wofern es beim Studium der Zelldescendenz gelungen ist bis zur Anlage der Organe auf sicherer Basis vorzudringen, wurde auch die Entwicklung der letzteren in den Kreis meiner Beobachtungen einbezogen. Vor allem handelte es sich um diejenigen Organe, welche aus dem mittleren Keimblatte ihren Ursprung nehmen. Ein systematisches Studium der Organogenese wurde bei unsrer Form nicht bezweckt, deshalb hat der betreffende Teil dieser Arbeit keinen Anspruch auf eine erschöpfende Darstellung der gesamten Organogenese.

Was die allgemeinsten Fragen der modernen Morphogenie anbelangt, bin ich im Laufe meiner Untersuchungen zur Überzengung gelangt, daß das vorliegende Material noch viel zu spärlich und in mehrfacher Beziehung zu wenig kritisch ist, als man darauf weittragende theoretische Spekulationen namentlich in phylogenetischer Richtung stützen könnte. Dieser Umstand macht es uns zur doppelten Pflicht für wiederholte und vielseitige Erforschung der individuellen Entwicklung zu sorgen, um eine möglichst breite und solide Basis für weitgehende theoretische Betrachtungen zu gewinnen. Freilich hätte die Erfüllung dieser Pflicht nach Ansicht derjenigen Forscher, 
welche nur dem Experiment einen wissenschaftlichen Wert zuschreiben, eine bloß untergeordnete Bedeutung, wir huldigen aber mit Conklin, Lillie u. a. der Überzeugung, daß eine tunlichst gründliche Erkenntnis der Tatsachen der normalen Entwicklung zum Verständnis der morphogenetischen Prozesse wesentlich beitragen kann.

Krakau, Ende März 1905.

\section{Material und Methode.}

Physa fontinalis L. kommt bei Krakau in allen stehenden Gewässern, sogar in tieferen Wassergräben ziemlich häufig vor. Sie hält sich während der Laichzeit am liebsten an Stellen auf, welche mit Elodea canadensis dicht bewachsen sind und kann mit dieser Pflanze mit einem Netz ans Ufer gezogen und meistens in großer Anzahl abgelesen werden.

Die Eiablage beginnt im Freien, wenn der Frühling zeitlich anbricht, bereits im April, sonst erst im Mai und dauert bis in den September fort. Am regsten ist sie wohl im Mai und Anfang Juni, später nimmt die Laichproduktion stetig $a b$, so daß man im August nur sehr vereinzelte Gelege findet, im September dagegen laichen wahrscheinlich nur Tiere jüngerer Generationen. In Aquarien beginnen die Schnecken schon im März zu laichen, wenn der Februar ausnahmsweise so warm war, daß die Eisdecke in den Teichen zeitweise verschwunden ist und sich Gelegenheit dargeboten hat, geschlechtsreife Tiere zu sammeln.

Der Laich wird, sowohl im Freien als auch in Aquarien, in glashellen Gallertklumpen von unregelmäßig oblonger Form und äußerst wechselnder Größe an verschiedene im Wasser untergetanchte Gegenstände abgesetzt, am liebsten an Elodea canadensis, Lemna, Myriophyllum, sonst auch an faulende Blätter, Baumreiser, glatte Steine und in der Gefangenschaft ausnahmsweise auch an die Glaswände der Behälter.

Die hyalinen Gallertklumpen der einzelnen Gelege enthalten eine sehr wechselnde Zahl von rundlichen, ebenfalls durchsichtigen Eikapseln, von einer einzigen bis über 20, durchschnittlich aber etwa 10 Stiick. Lebensfrische Laichtiere setzen unter normalen Bedingungen zahlreiche und dabei recht große, vielkeimige Laichklumpen $a b$, während Exemplare mit erschöpfter Keimdrüse oder in ungüinstigen Lebensbedingungen, z. B. in ungeniigend durchlïfteten Aquarien, vorwiegend kleine, bloß wenige, oder ein einziges Ei enthaltende Gelege liefern. Manchmal sind dieselben sogar ganz leer, oder nur mit kleinen Spermaballen versehen. Hat man einmal diese Tatsache, sei es an Zuchttieren, sei es in der freien Natur, festgestellt, so wird man nie in Verlegenheit sein, zu entscheiden, welcher Laich sich zu entwicklungsgeschichtlichen Untersuchungen am besten eignet. Sobald man nämlich im Aquarium bemerkt, daß die Gelege rapid kleiner und keimärmer werden, so ist es ein Zeichen, daß man entweder die Zuchttiere in frisches Wasser bringen, oder ihnen reichlichere Nahrung ${ }^{1}$

1 Das beste Nahrungsmittel sind für Physa halb vermoderte Baumblätter, etwa Ulmen- oder Erlenblätter, die in loser Schicht den Boden des Aquariums bedecken und von äsenden Tieren gern aufgesucht werden. 
darbieten muß, oder dieselben überhaupt durch frisch gesammelte ersetzen. Manchmal erweisen sich auch frisch gebrachte Tiere zur Zucht und Laichgewinnung unbrauchbar, wenn sie in verdorbenem Wasser lebten oder von ihren gewöhnlichen Parasiten (Chaetogaster) zu stark befallen wurden. Meinerseits wurde stets für frischen, sowohl von freilebenden wie von Zuchttieren stammenden Laich gesorgt und zwar erfolgte die Fixierung möglichst bald nach dem Einsammeln.

Zum Fixieren wurden verschiedene Flüssigkeiten gebraucht, je nach dem Zweck, zu welchem das Material konserviert werden sollte. Für Schnitte wurden die von der Gallerte auf mechanische Weise mittels Präpariernadeln befreiten Eikapseln mit einer konzentrierten Sublimatlösung (mit oder ohne Zusatz von Eisessig) in der üblichen Weise behandelt; dagegen für das Studium der Eier in toto, wurden letztere nur auf etwa 2-4 Minuten in eine konzentrierte Sublimatlösung gebracht, und sobald das Eiweiß milchig getruibt und fast ganz undurchsichtig geworden ist, rasch mit destilliertem Wasser oder 15\% igem Alkohol abgespült und in einer von diesen Flüssigkeiten belassen. Schon nach etlichen Minuten gelingt das Herausschälen der gelben Eikeime aus den Kapseln mittels Nadeln sehr leicht und man iiberträgt die freigelegten Stiicke in $30 \%$ igen Alkohol, wo sie einige Stunden zu verbleiben haben, worauf sie in steigendem Alkohol mehrere Stunden gehärtet werden. Die Anwendung der Jodtinktur halte ich bei der Kleinheit der Objekte für überfliissig.

Auf diese Art konservierte Embryonen eignen sich ganz besonders zur Untersuchung der äßßeren Gestalt, sowie zum Studium gewisser Zellstrukturen und Organanlagen, desgleichen auch zum Schneiden; weniger giinstig sind sie dagegen für das Studium der Zelldescendenz.

Auch die Flemmingsche Fliissigkeit liefert ganz gute Resultate und wird in ähnlicher Weise gebraucht wie Sublimat. Es werden namentlich die von der Gallerte befreiten Eier ganz kurz mit einer mittelstarken Lösung derselben behandelt, mit Wasser abgespült und nach Verlauf von 15-30 Minuten in der ïblichen Weise mit Nadeln herausgeschält, worauf sie zunächst in $30 \%$ igen Alkohol auf etwa 12 Stunden kommen und dann die stärkeren Alkohole durchlaufen werden ${ }^{1}$.

Das in Flemmingseher Flüssigkeit fixierte Material eignet sich wenig zum Studium der Zelldescendenz, weil die Zellgrenzen nicht scharf genug hervortreten, ist aber sonst sehr brauchbar, weil in demselben die äußere Form der Embryonen sowie die feinsten Plasmafortsätze vorzïglich erhalten bleiben.

Außer den genannten Fixierungsmitteln habe ich auch einige andre Versuchsweisen angewendet, so z. B. die von Coskuin bei seinen CrepidulaStudien und von Holmes bei Planorbis mit dem besten Erfolg benutzte KLEINENBERGsche Pikrinschwefelsäure. Da ich indessen weder bei Anwendung dieser noch bei andern Säuren völlig zufriedenstellende Resultate erzielen konnte, habe ich schließlich der PERÉNyIschen Fliissigkeit, welche mir stets die besten Dienste leistete, vor allen andern den Vorzug gegeben. Bei Anwendung der letzteren hat sich mir in der Praxis folgendes Verfahren als das einfachste und sicherste ergeben.

Die zu fixierenden Eierklumpen werden mit der Gallerte, so wie den Gegenständen, an denen sie haften, z. B. Blättern und Stengeln von Elodea,

1 Diese Methode wird von mehreren Forschern empfohlen (ScHмid, '90, KoFOID, 195 u. a.). 
in die zur Hälfte mit Wasser verdünnte Perényische Flüssigkeit ${ }^{1}$ geworfen, in welcher sie bloß so lange zu liegen haben, bis das Eiweiß der Eikapseln, welches unter der Einwirkung der Fixierungsflïssigkeit momentan ganz undurchsichtig geworden ist, bald aber sich wieder aufhellt, neuerdings sich milchig zu truiben beginnt. Dieses Verhalten des Eiweißhofes ist um so leichter zu beobachten, als die Gallerthülle völlig hyalin verbleibt. Soll die Fixierung, besonders aber das nachherige Herausschälen der Eier, gelingen, so muß man genau achtgeben, daß der Augenblick, in welchem die abermalige Trübung des Eiweißes sich einzustellen beginnt, nicht verpaßt werde, da es erfahrungsmäßig der richtige Zeitpunkt ist, die Einwirkung des Fixierungsmittels zu unterbrechen und dasselbe durch $15 \%$ igen Alkohol zu ersetzen. Letzterer wird zwei- bis dreimal in kurzen Intervallen gewechselt. Nun kann man sogleich die Eikapseln von der Gallerte zu befieien beginnen. Dieses geschieht am leichtesten, wenn die einzelnen Gallertklïmpchen auf eine trockene schwarze Porzellanplatte gebracht werden und die weißlichen Eikapseln mittels Nadeln herauspräpariert werden. Je genauer die zähe Gallerthülle entfernt wird, desto besser gelingt nachher das Sprengen der Eikapseln selbst. Die herauspräparierten Eikapseln gelangen abermals in $15 \%$ igen Alkohol und können darin etwa $1 \frac{1 / 2}{2}$ bis höchstens 2 Stunden verbleiben. Sobald man ïbrigens bemerkt, daß das opake Eiweiß in den merklich aufquellenden Kapseln durchscheinend zu werden beginnt, kann man das Herausschälen der Eikeime unverzüglich vornehmen. Diese Aufgabe setzt allerdings einige Übung und Geschicklichkeit vorans, doch sind die wenigen und einfachen Kunstgriffe in der Praxis sehr bald erlernt. Die Hauptbedingung des Gelingens liegt in der richtigen Fixierung und der davon abhängigen Konsistenz des Eiweißes. Das Sprengen der Kapselhüllen wird wesentlich erleichtert, wenn man sich möglichst scharfer und starrer Nadeln bedient und allen Alkohol um das Ei herum entfernt, da sonst die schlïpfrige Kapsel der Nadelspitze fortwährend entweicht. Außerdem soll man es peinlich vermeiden, den frei ausfließenden Keim mit der außerordentlich klebrigen Kapselmembran in Berührung zu bringen, da er an ihr so fest haften bleibt, daß die Isolierung desselben in unversehrtem Zustand in der Regel mißlingt. Jetzt werden schnell mit einer feinen Pipette einige Tropfen $15 \%$ iger Alkohol zugesetzt, der Keim behutsam aufgefangen und in ein Uhrschälchen mit 30\% igem Alkohol iibertragen. Letzterer muß während der Arbeit öfters gewechselt werden, weil er beim Übertragen der Eier fortwährend verdünnt wird. Es ist überhaupt zu bemerken, daß der schwache Alkohol nicht zu lange auf die Objekte einwirken darf: da sie sonst leicht maceriert werden und an den Uhrschälchen kleben bleiben. Es ist daher besonders dem minder Geübten und langsamen Arbeiter anzuraten, stets nur kleine Portionen des Laiches auf einmal in Arbeit zu nehmen. Die ganze Operation des Herausschälens wird selbstverständlich unter dem Präpariermikroskop ausgeführt.

Die in 30\% igem Alkohol anfbewahrten Keime werden nach etwa 12 Stunden in steigendem Alkohol gehärtet und schließlich in $96 \%$ igem aufbewahrt.

Von manchen Forschern (Koford, HoLmes) wird zum Auflösen der Gallerte und des Eiweißes eine 0,75\% ige Kochsalzlösung empfohlen. Da die Keime bei

${ }_{1} \mathrm{Da}$ in der gewöhnlichen Mischung nach der neneren Erfahrung gewisse Bestandteile des Zellplasmas aufgelöst werden, so wurde als Stammlösung die

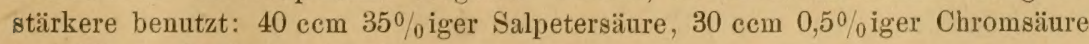
und $30 \mathrm{~cm} 96 \%$ igen Alkohol. 
längerer Einwirkung der Salzlösung mehr oder weniger anfquellen, empfiehlt Holmes, derselben einige Tropfen der Fixierungsfliissigkeit zuzusetzen. Ich habe diese Methode versuchsweise angewendet, konnte aber die Auflösung des Eiweißes ohne Schädigung des Keimes nicht zu stande bringen. Praktischer dürfte das von CHILD empfohlene Verfahren sein, welches darin besteht, daß die Gallerte erst nach Fixierung in einem beliebigen Säuregemisch (Chromsäuregemische ausgenommen) und nach Härtung in Alkohol aufgelöst wird. Nach seiner Erfahrung löst sich dieselbe in jeder sehr verdünnten Säure auf. Da jedoch das in den Eikapseln enthaltene Eiweiß nach der Härtung nicht löslich ist, so habe ich diese Methode für Physa bloß dann anwenden können, wenn es sich um ein zum Schneiden bestimmtes Material handelte.

Für meine Untersuchungen habe ich daher hauptsächlich ein in der oben angegebenen Weise in PerÉnyischer Flüssigkeit fixiertes Material verwendet, weil es sich zum Studium der Zelldescendenz ganz besonders eignet. Es treten nämlich an gelungenen Präparaten alle gewünschten Details, wie Zellgrenzen, Kerne, Mitosen, Zwischenkörper u. dgl. mit großer Klarheit und Schärfe hervor und zwar sowohl in Oberflächenbilde als auch in den tieferen Schichten der Embryonen.

Zur Tinktion der Präparate habe ich vorwiegend kristallinisches Hämatoxylin gebraucht.

Neben dem kristallinischen wurde auch öfter das DeLAfieldsehe Hämatoxylin verwendet und zwar sowohl in neutraler als auch in einer sehr schwach angesänerten Lösung. Letztere wird sowohl von ConkLiv als auch von HoLmes sehr warm empfohlen und liefert in der Tat ganz hïbsche und dauerhafte Tinktionen, wenn die Präparate in KLeinenbergseher Pikrinschwefelsäure fixiert worden sind. Weniger empfehlenswert habe ich diese Tinktionsmethode für Physa gefunden, deren Laich in PERḱnyischer Flüssigkeit fixiert wurde. Das saure Hämatoxylin gibt nämlich besonders bei älteren Furchungsstadien deshalb keine günstige Färbung, weil es die im Plasma enthaltenen Eiweißkïgelehen ebenfalls färbt, wodurch das Präparat an Durchsichtigkeit einbüßt. Die erwähnten Eiweißelemente kommen auch in dem Falle störend zum Vorsehein, wenn man die mit Desafieldschem Hämatoxylin tingierten Präparate mit saurem Alkohol nachbehandelt.

Es braucht kaum hervorgehoben zu werden, daß man sich bei embryologischen Untersuchungen mit einer einzigen oder zwei Tinktionsmethoden nicht begnügt, sondern der beabsichtigten Wirkung entsprechend deren mehrere in Anwendung bringt, zumal für Schnitte. Doch selbst die exakteste Tinktion lïßt zuweilen den Embryologen im Stich und man ist genötigt, zur Metallimprägnation zn greifen.

Es wurde namentlich von HoLmes (1900) in dessen Untersuchungen über Planorbis die Silbernitratmethode fleißig und mit gutem Erfolg angewendet, was mich veranlaßt hat, seinem guten Beispiel zu folgen. HoLMes verfährt folgendermaßen. Er überträgt die Eier aus den Eikapseln direkt in eine $0,7 \tilde{5} \%$ ige Silbernitratlösung, setzt sie in einem Uhrschälchen darch längere Zeit dem direkten Sonnenlicht aus, kontrolliert von Zeit zu Zeit unter dem Mikroskop und sobald das Mosaik der Zellengrenzen mit gewünschter Schärfe zum Vorschein kommt, spült er das Präparat mit destilliertem Wasser gehörig $\mathrm{ab}$, setzt einige Tropfen von $0,5 \%$ iger unterschwefliger Natriumlösung auf bloß 3-4 Sekunden hinzu, damit der Silberniederschlag nicht ganz aufgelöst werde, und wïscht schließlich mit konzentrierter Pikrinsäure aus. Diese dient zugleich 
als Fixierungsmittel und übt keine nachteilige Wirkung auf das imprägnierte Präparat ans.

Die Holmessche Methode gibt bei einiger Übung sehr befriedigende Resultate. Das Versilbern an und für sich bereitet keine Schwierigkeiten. Dagegen verlangt das Auswaschen mit Natriumhyposulfit große Vorsicht und Geschicklichkeit, wenn das Präparat nicht verdorben werden soll. Bei zu kurzer Einwirkung ist die Reduktion unzureichend, bei lingerer Daner wird das Präparat zu stark entfärbt und durch Quellung verdorben. Diese Methode hat überhaupt ihre Launen, welche man durch Erfahrung zu beseitigen lernen muß. Präparate, die zu lange in der Silbernitratlösung dem Sonnenlichte ausgesetzt waren, sind zu dunkel und briichig; im entgegengesetzten Fall bleiben die Zellgrenzen verschwommen. Ebenso geht es mit der Reduktion des Silbers. Im allgemeinen gelingt die Versilberung bei älteren Stadien viel leichter als bei jiingeren.

Ich habe diese Übelstände zu umgehen versucht und dabei ebenfalls gute Resultate erzielt. Ich bringe die Eier samt den Eikapseln in eine $0,75 \%$ ige Silbernitratlösung und belasse sie unter fortwährendem Umrühren in derselben so lange im direkten Sonnenlicht, bis die Eischale sich zu brännen anfängt. Dies ist der richtige Zeitpunkt, wo die Konturen deutlich hervorzutreten beginnen und das Eiweiß eine günstige Coagulation erleidet. Dann werden die Keime in der Silberlösung herausgeschält und entweder mit schwachem Alkohol ausgewaschen, oder, falls die Konturen noch wenig deutlich sind, in der Nitratlösung nochmals der Sonne ausgesetzt und fleißig koutrolliert, bis das Liniennetz derselben mit gewünschter Schärfe zum Vorschein kommt, endlich werden die Keime in steigendem Alkohol gehärtet und in Balsam montiert.

Für jüngere Stadien hat die Metallimprägnation einen geringen Wert, für Anfangsstadien ist sie sogar entbehrlich. Bei älteren Keimen dagegen, mit gut differenzierter Intercellularsubstanz, liefert sie sehr instruktive Bilder. An gelnngenen Präparaten treten namentlich einzelne Zellterritorien mit markanter Schärfe und Klarheit hervor; wie HoLmes richtig angibt, werden gewisse Zellen dunkler abgetönt wie die andern, infolgedessen die Trochoblasten und die Zellen der Kopfblase stets durchsichtig bleiben, während die dunklere Kreuzfigur sich von der hellen Umgebung vorzïglich abhebt und die sofortige Orientierung des Keimes ermöglicht. Besonders huibsche Bilder erlangt man bei Gastrulastadien und jungen Larven. Obgleich hier bereits Hunderte von Zellen vorhanden sind, treten die Grenzen jeder einzelnen mit schematischer Klarheit hervor, so daß der Fortgang der Zellvermehrung in den einzelnen Organanlagen mit größter Genauigkeit verfolgt werden kann. In dieser Beziehung leistet die Methode tatsïchlich die besten Dienste und läßt sich durch keine andre ersetzen.

Die meisten Embryologen empfehlen zum Aufbewahren des konservierten Materials den Kanadabalsam. Selbst ältere Balsampräparate sollen sich zur allseitigen Untersuchung qualifizieren. Man braucht nur einen 'Tropfen Xylol an Rande des Deckglases zuzusetzen, um den Balsam wieder flüssig zu macheu und das Objekt nach beliebiger Richtung rollen zu können. Es ist schon richtig; daß der an den Deckglasrïindern eintrocknende Balsam sich nach Verlauf von einigen Tagen und selbst Wochen leicht verfliissigen lïßt. Sollen aber die Priiparate nach Monaten behufs Untersuchung unter Deckglas gerollt werden, dann reicht selbst reichlicher Xylolzusatz nicht aus, und das Objekt wird bei dem ersten Rollversuche ruiniert. Ich habe es deshalb vorgezogen, meine Präparate entweder in reinem Nelkenöl aufzubewahren oder in einem Gemisch 
von Nelkenöl und Kanadabalsam ', welches nicht so schnell eintrocknet wie der bloß in Xrlol aufgelïste Kanadabalsam. Derartige l'rijuarate miissen zwar ron Zeit zn Zeit nachgefiillt werden, man hat aber den Vorteil, dals sie ohne bedeutenden Zeitverlust stets gebranchsfillig bleiben, allenfallsig auf ein andres Objektglas iibertr: gen oder in Bedarfifalle nachgefïrbt werden künnen. Trotz dem großen Brechungsindex des Nelkenöls eignen sich in demselhen authewahre Präparate von Furchungsstadien nnd Embryonen ganz geut sowohl zum stulium als auch zur Anfertigung ron Camerazeichnungen. da sowohl die äuberen Konturen gnt fixierter und gefïbter Objekte, als auch die tiefer gelexrenen Zellen schr scharf hervortreten.

Es mag noch erwïhnt werden, daß ich statt der als Fiißchen der Deckgläser allgemein empfohlenen Capillarrihrchen Papierstreifen ron entsprechender Stairke benutzte, welche mit syndetikon an zwei entgegengesetzte Riinder des Deckglases festgekleht wurden. Ich habe stets eine serie lerart präparierter Deckglïschen im Torrat gehalten. Diese anch ron How Ms angewandten Papierstreifen erwiesen sich bei weitem praktischer als die frlastihichen. da letztere beim Verschieben des Deckglases nach allen Richtungen ihre Lage verïndern, sehr oft dem Keime zu nahe kommen. oder gar herausgleiten und außerhalb des Deckglases geraten, wobei das Präparat zugrunde geht.

Wir widmen noch einige Worte der Untersuchung selbst. Sie wurde an einem ungemein reichen Material rorgenommen. welches ich mïglichst eingehend auszunutzen bestrebt war. Es wurde sowohl eine Lnzahl ron I'raiparaten,

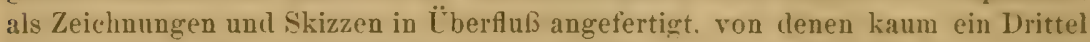
in den beigegebenen Tafeln Aufuahme finden konnte. Daß eine so peinliche Griundlichkeit geboten war. werden mir wohl alle Embryologen zugeben. welche die Zelldescendenz genau zu erforschen bemiiht warn. Die Erfahrung lehrt, daß bei derartigen Studien die Schwierigkeit darin litgt, eine der Wirklichkeit entsprecheude, kontinuierliche Reihe von Furchungsstadien festzustellen. Denn einerseits gibt es gleichalterige Furchungsstadien mit verschiedener Zellenzahl, anderseits Keime mit der nämlichen Zellenzahl, welche in sonstigen Bezichungen so rerschieden sein kömnen, daß man ohne zahlreiche und selır naturgetreue Zeichnungen nicht imstande ist. die genugsam untersuchten Phasen richtigerweise aufeinander zu beziehen und den f'ortgang des Furchungs]rozesses klarzulegen. Sonst führt das beiläntige Zusammenstellen ähnlicher Stadien auf spekulativer Grundlage zu Fehlschliissen, welche besonders beim studium der Organogenie zn verhängnisvollen Irrtümern Anlaß geben künnen.

Es eribrigt noch hervorzuheben. daß sowohl nach meiner Erfahrung als anch derjenigen ron Jexwasas und ('HuL das kinstliche Licht beim Studium des Furchungsprozesses bei weitem giinstiger ist als das Tageslicht. ferner, daß optische Schnitte viel sicherere Resultate geben als wirkliche Serienschnitte. Man kann selbstrerstïnllich auch letztere unter keiner Bedingung enthehren und so habe auch ich cine stattliche Anzahl von Schnittprïparaten angefertigt und selhe in mehreren Fällen zu Rate gezogen. Doch habe ich mich bald iiherzengt. daß sie in organogenetischen Fragen an und für sich nicht entscheidend sein künnen und die meisten Embryologen diirften mir in dieser Hinsicht bei-

1 Wie ich soeben mit Genugtuung erfahre. wurle diese Nethode auch von IIEAD "97, bei seinen Studien über marine Anneliden zur Aufbewahrung der Keime mit Vorteil angewendet. 
stimmen. Demgemäß wird man im Abschnitte über den Furchungsprozeß nur ausnahmsweise Schnitte abgebildet finden.

Was die Auswahl und Zahl der Abbildungen anbelangt, stößt der Leser embryologischer Arbeiten öfters auf Schwierigkeiten, wenn der Verfasser mit denselben zll sparsam war und die abgebildeten Entwicklungsstadien zu große Lïcken aufweisen oder gar nur fragmentarisch vorgeführt werden. Im Interese des Lesers war ich daher bestrebt, den Text durch eine tunlichst liickenlose Serie der Furchungsbilder zu erläutern. Außerdem wurde von jedem Stadium sowohl die animale, als die vegetative Keimhälfte abgebildet, wobei sümtliche Figuren in streng derselben Weise orientiert wurden, um das Aussuchen korrespondierender Teile zu erleichtern und das Herauslesen des Entwicklnngsganges aus den Figuren allein zu ermöglichen. Dei Übersichtlichkeit halber wurden histologische Details, wie z. B. die feinere Struktur der Kerne, sowie die plastische Schattierung weggelassen. Um so größerer Nachdruck ist auf die Schärfe der Konturen der einzelnen Blastomeren und auf eine ausgiebige Zellensignification gelegt worden. Dadurch wird man wohl imstande sein, selbst ohne den Text zu Hilfe zu ziehen, aus den Abbildungen die Entwicklungsgeschichte der Physa in ihren Hauptziigen herauszulesen.

Dieses wenige zur Rechtfertigung der relativ großen Zahl der Tafeln und ihrer Einfachheit.

\section{Nomenklatur.}

In meiner vorläufigen Mitteilung über die Mesodermbildung bei Physa ('97) habe ich ein System befolgt, welches von Koford ('94) in dessen Limax-Arbeit in Anwendung gebracht wurde. Jenes System besitzt unverkennbare Vorziige und hat tatsächlich mehrfach Annahme gefunden, wie z. B. von Jennings ('96), nach dessen Ansicht dasselbe von allen andern vorgeschlagenen Systemen den Vorzug verdient. Im Laufe der Untersuchung habe ich indessen allmählich die Überzeugung gewonnen, daß das zwei Jahre vorher von WiLson (92) eingeführte System der Furchungsnomenklatur in bezug auf Übersichtlichkeit und Bequemlichkeit so große Vorteile bietet, daß ich schließlich die Kofordsche Signifikation aufgegeben und die Nomenklatur WiLsons angenommen habe. Die letztere bietet vor allem diesen Vorteil, daß sie nicht nur die Entomeren und Ectomeren auf den ersten Blick als solche zu erkennen erlaubt, sondern auch die Abstammung der Zellen von den betreffenden Quartetten anzeigt, was besonders bei der Ableitung der einzelnen Organe von Wichtigkeit ist. Bestimmend war für mich außerdem der Umstand, daß man sich in den bedeutendsten einschlägigen Publikationen der letzten Jahre (Conklin, Child, Holmes, Mead, Carazzi u. a.) fast allgemein dieses Systems bedient hat, so daß es geboten schien, auch den vorliegenden Ergebnissen eine Fassung zu geben, welche einen Vergleich der behandelten Ontogenie mit verwandten Furchungstypen 
wesentlich erleichtert. Dies um so mehr als in der letzten Zeit RoBERT ('03) auch die Ergebnisse derjenigen Embryologen, die andre Bezeichnungssysteme befolgten, in die Ausdrucksweise der von uns gewählten Nomenklatur vibertragen hat.

Es ist nicht das ursprügliche System WILsoxs, welches ich anwende. Ich habe vielmehr mehrere, nitunter wichtige Verbesserungen und Änderungen bericksichtigt, welche von einzelnen Autoren in Vorschlag gebracht wurden. So halte ich vor allem die ron CoxKLIN ('97) eingeführte Neuerung für einen wesentlichen Fortschritt. die Zahl des Quartetts, welchem die Blastomere angehört, nicht im Exponent sondern als Koeffizient auszudrücken, wodurch die Nomenklatur in eine binäre umgewandelt wurde. Ferner habe ich nach dem Vorgange einiger neuester Autoren die Koeftizienten auch den Makromeren beigegeben, so daß man durch Signifikate auch bei diesen Zellen sofort unterrichtet ist, wie viel Zellgenerationen dieselbeu bereits geliefert baben. Desgleichen habe ich der Einheitlichkeit halber bei Bezeichnung eines Tochterzellenpaares nur die Lage desselben im Keime, nicht aber deren Größe in Betracht gezogen, so daß eine dem animalen Pol näher gelegene Zelle selbst dann eineu kleineren (unpaaren) Exponent erhält, wenn sie auch bedentend kleiner wäre, als ihre Schwesterzelle.

Die Prinzipien des WiLsoxschen Systems an dieser Stelle nochmals auseinanderzusetzen, halte ich für therflissig, da sie bereits von Coxklix und andern Autoren genïgend erörtert und klargelegt wurden und die Einzelheiten in deren Arbeiten nachgeschlagen werden können. Es sei nur für die in der Literatur minder bewanderten Leser bemerkt, daß die Bezeichnung der Blastomeren von den vier ersteren Zellen den sog. Makromeren $A-D$ ihren Ausgang nimmt. Die abgeschnürten Mikromerenquartette heißen $1 a-1 d, 2 \_$ $-2 d$ usw. Die Tochterzellen dieser Quartette erhalten Exponente, deren Ziffernzahl zugleich die Zahl der Generationen ausdrickt. Die Zelle $1 a$ liefert somit $1 a^{1}$ und $1 a^{2}$, die Zelle $1 a^{1}$ liefert $1 a^{11}$ und $1 a^{12}, 1 a^{11}$ gibt $1 a^{111}$ und $1 a^{112}$ usw. Nur bei den Descendenten der sogenannten Urmesodermzelle erleidet diese allgemeine Bezeichnungsregel eine kleine Modifikation.

Die Ausdrlicke »läotrop * und »dexiotrope werden in der allgemein fur die Richtung der Spirale angewendeten Weise gebraucht. 


\section{Abnormitäten.}

Wie dies bei den meisten embryologisch untersuchten Mollusken, bei Neritina (Blochmann), Umbrella (Heymons), Crepidula (Conkrin), Planorbis (HoLmes), Trochus (ROBERT) u. v. a., beobachtet wurde, kommen auch bei Physa Fälle von abnormer Entwicklung nicht selten vor und würden es sicher verdienen, als Gegenstand einer besonderen Untersuchung behandelt zu werden, insofern sie uns erwünschte Aufschliisse über den Einfluß verschiedener Faktoren auf die Entwicklung geben können. Die Abnormitäten betreffen sowohl normal gebildete, d. i. bloß einen einzigen Keim enthaltende, als auch anormale d. i. mehrere Keime enthaltende Eikapseln.

Unter den ersteren kommen besonders in frihen Stadien der Furchung teratologische Gebilde vor; weit seltener in vorgeschrittenen Entwicklungsphasen. Die von mir beobachteten Unregelmäßigkeiten betreffen entweder die.Größe der Blastomeren, indem schon die erste Eiteilung auffallend inäqual ausfällt, oder es treten Hemmungen und Unregelmäßigkeiten in dem Teilungsprozeß selbst auf. So gelangte ein Fall zur Beobachtung, wo ein zweizelliges Stadium fünf gut ausgebildete Kerne besaß, von denen zwei in der einen drei in der andern Blastomere lagen; alle Kerne waren gleich groß und lagen dicht nebeneinander in der Nähe des animalen Poles. In einem andern Fall mit drei Blastomeren ist die Teilung der einen Eibälfte offenbar unterblieben und es waren in der betreffenden, merklich größeren Zelle zwei aneinandergedrückte Kerne zu sehen; die beiden andern Zellen, welche der zweiten geteilten Eihälfte entsprachen, waren völlig normal, nur in der Größe etwas ungleich. Es wurden auch multipolare Spindeln oft beobachtet und zwar nicht nur im ungefurchten Ei, was meistens auf Überfruchtung (Polyspermie) zuriickgefuihrt wird, sondern auch in einzelnen Blastomeren älterer Stadien, z. B. eines 4 zelligen und eines 24 zelligen, wo sich diese Erscheinung eher durch lokale, pathologische Zustände in der Beschaffenheit der Centrosomen, bzw. des Cytoplasmas der betreffenden Zellen erklären läßt.

Auch unter Larven waren öfters mißgebildete Exemplare zu finden, mit buckligen Höckern oder mit enormer Kopfblase und verkümmertem Körper, auch solche ohne Entoderm und Mesoderm. Anenterische Larven sind aus dem Grunde besonders interessant, weil sie mit gesteigerter Energie rotieren und im Innern lose Brocken von Zell- und Dotterelementen enthalten.

In die zweite Kategorie gehören Eikapseln mit zahlreichen Eiern. Während solche mehrkeimige Kapseln bei gewissen Schnecken normal sind, wie z. B. bei Umbrella, wo die einzelnen Eikapseln 30-40 Keime umfassen, ist das Verhalten bei Physa entschieden teratoloyisch und gehört zu selteneren Ausuahmen. Es konnten dann in einer gemeinsamen Hiille 2, 6, 11, 14, ja in einem Falle sogar 20 Eikeime gezählt werden. Die Gallertklumpen bleiben dabei normal und enthalten gewöhnlich neben den mehrkeimigen auch gewöhnliche Kapseln mit einzelnen Eiern. In dem erwähnten extremen Falle enthielt das ganze Gelege 14 Eikapseln, von denen eine keinen Keim enthielt, 10 mit je einem, eine mit 2 , eine mit 3 und eine mit 20 Keimen besetzt waren. In der letzteren befanden sich 19 Keime im 24 zelligen Stadium und schienen in ihrer Entwicklung keine Störung erlitten zu haben, bloß ein Keim ist in der Entwicklung etwas zurickgeblieben. Die gemeinschaftliche Eikapsel war verhïltnisuäßig sehr groß, so daß die Keime bis zum Larvenstadium geniigenden I'latz in ihr gefunden hätten; 
erst bei weiterer Entwicklung diirfte sich ein Mangel an Raum und Sauerstoff fühlbar gemacht haben. Leider bin ich auf diese Abnormitit erst nach Fixierung des Materials aufmerksam geworden. Aus einigen Überresten zerbrickelter Zellen darf geschlossen werden, daß die Zahl der Eikeime in jener Kapsel urspriinglich noch größer war. In den beiden ïbrigen Kapseln mit 2 und 3 Keimen waren normale 32 zellige Stadien zu sehen. Besondere Erwihnung verdient ein Fall wo 17 Keime in einer Kilpsel vereint waren. Von einer ge-

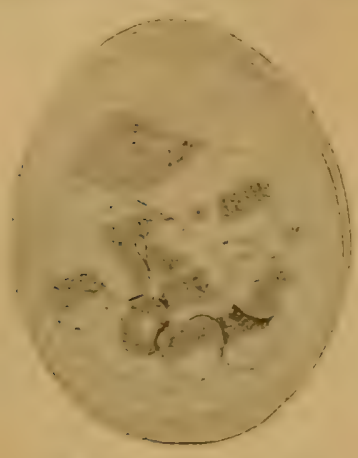

Textfig. 1. Abnormität. meinschaftlichen Dotterhülle umschlossen lagen sie dicht nebeneinander; sieben Exemplare waren in normaler Weise bis zum Veligerstadium vorgeschritten; zwei in gleicher Entwicklungsphase begriffene Stiicke waren mit einem Teile der vegetativen Hälfte miteinander verwachsen und die übrigen haben zwei Drillingagruppen auf :ihnliche Weise erzengt; beide letzteren waren bis auf die Verwachsungsstelle vollkommen normal ausgebildet (Textfig. 1). Auch in dieser Kapsel befanden sich an einem Pole Überreste von zerbröckelten Keimen angesammelt, die anf eine ursprünglich größere Zahl von Embryonen hindeuten, welche aber auf verschiedenen Entwicklungsstufen im Kampf ums Dasein erlegen sind. Je weiter nämlich die Entwicklung fortschreitet, desto mehr Raum und Luft mïssen einzelne Embryonen beans]ruchen, um fortkommen zu könuen, desto mehr Exemplare miissen zugrunde gehen.

Die Ursachen der Erzeugung von mehrkeimigen Eikapseln künnen sowohl in der Einwirkung üußerer als auch innerer Faktoren gesucht werden. Erstere wirken direkt auf das Wohlbetinden der Tiere und indirekt auf den Vorgang der Erzengung des Laiches, letztere liegen in irgend welcher Afficierung des ganzen fieschlechtsapjarates oder lokaler, momentaner Stürung seiner Funktion. Ohne letztere Annahme würde es schwer zu verstehen sein, warum in einem und demselben Gelege die Melurzahl der Kapseln normal und bloß einige wenige abnorm gebildet sind? .

$\Pi$ as die anormale Entwicklung von Keimen in normalen Eikapseln betrifft, so kann die Einwirkung äußerer Faktoren experimental nachgewiesen werden. Für Physa ist dies zum Teil geschehen, denn es wurde gar oft die Erfahrung gemacht, daß der Laich von Tieren, die alssichtlich in ungrinstige Lebensbedingungen gebracht, oder bereits erschïj,ft. oder von Parasiten befallen waren, sich zunehmend auormal entwickelt. Außerdem wurde das Gelege im s'eewasser von verschiedener Konzentration geziichtet und dalei interessante Resultate erzielt. iiber die ich seinerzeit eingehender zu berichten. gedenke. Das tWesentlichste müge schon hier in aller Kiirze verzeichnet werden. Setzt man zum Siißwasser 5\% Seewasser hinzu, daun geht die Furchung noch ohne merkliche Stürung vor sich. In $10^{\prime}{ }_{0}$ iger Mischung begimen bereits teratologische Furchungsbilder aufzutreten und werden um so hïufiger, je melır man das Siißwasser mit Salzwasser versetzt. Es hat sich indessen gezeigt, daß die Keime selbst eine $25 \%$ ige Misclıung vertragen, wenn sie dazu durch ganz

${ }_{1}$ Bemerkenswert ist der Umstand, daß bei Trochus ROBERT; niemals melir als ein einziger Embrjo in einer Schale angetroffen wird. 
allmählichen Zusatz von Seewasser nach und nach vorbereitet werden. Die Entwicklung wird unter der Einwirkung der Salze allerdings stark verzögert. So habe ich im Salzwasser, im Juli, kaum nach 19 Tagen unvollkommen ausgebildete Larven erhalten, während die vollständige Ausbildung unter normalen Bedingungen gewöhnlich nur 4 Tage in Anspruch nimmt. Die Beweglichkeit der Veligerlarven wird ebenfalls durch die Anwesenheit des Salzes beeinträchtigt und verlangsamt. Ältere Stadien, mit Kopfblase und fertigem Velum, unterliegen auch bei fortdauerndem Verweilen in Salzlösungen trotz ausgiebigster Durchlüftung dem Zerfall, es lösen sich unregelmäßige Zellhaufen ab, um selbständig im Eiweiß der Kapsel zu rotieren, selbst einzelne Wimperzellen, wahrscheinlich isolierte Velarzellen - scheinen ihre Bewimperung zu ergänzen und bewegen sich selbständig nach Art von Infusorien. Diese Vorgänge erinnern einerseits an die Experimente HeRBsts über die Disjunktion des Blastomerenverbandes in modifizierten Salzlösungen, anderseits, was noch wichtiger ist, entsprechen sie genau den Erscheinungen, welche zuweilen bei Keimen unter normalen Lebensbedingungen auftreten und auch von ConkLIN (97) für Crepidula angegeben wurden. Daß aber auch hier vieles von der individuellen Beschaffenheit und Prädisposition der Eizellen abhängt, ergibt sich aus dem verschiedenen Verhalten der Keime desselben Geleges in derselben Salzmischung. Die einen gehen ziemlich bald zugrunde, die andern gedeihen gut bis zur vollkommenen Ausgestaltung. Verschieden sind desgleichen die Umordnungsund Umdifferenzierungsprozesse, die sich an einzelnen Keimen im Seewasser vollziehen. Manchmal scheint der Organismus gezwungen zu sein, sich einzelner Teile seines Bildungs- und Nährmaterials in Form von Dotterstiicken . und Plasmakliimpchen zu entledigen, um in dem veränderten Medium das physiologische Gleichgewicht zu bewahren.

In diesem Zusammenhange möge noch bemerkt werden, daß es unter den abgelegten Eiern stets einen Prozentsatz unbefruchteter gibt und daß auch dieser Prozentsatz merklichen Schwankungen unterworfen ist. Auch hier finden unsre oben auseinandergesetzten Annahmen ihre Bestätigung. Während in Gelegen von frischen, lebenskräftigen Tieren taube Eier nur ganz vereinzelt rorkommen, nimmt ihre Zahl gegen das Ende der Laichperiode beständig zu. Dasselbe habe ich an einer befruchteten Acera bullata ans der Adria beobachtet, die sich wochenlang im Aquarium hielt und den Laich reichlich abgab. Gegen das Ende der Eiablage wurden sterile Eikapseln von Tag zu Tag häufiger.

Das ungefurchte Ei.

Das Ei von Physa ist glänzend hellgelb, fast durchsichtig mit stark vacuolisiertem Plasma, zwischen dessen Maschen die Dotterkörnchen gleichmäßig verteilt erscheinen. Es hat eine länglich eiförmige Gestalt, mißt im langen Durchmesser $0,08-0,1 \mathrm{~mm}$ und ist von einer feinen, elastischen Membran umbüllt, welche den Cytoplasma so dicht anliegt, daß sie erst nach Einwirkung von Reagentien sich abhel,t und als eine Membran erkannt werden kann. Ob es aber eine Dottermembran im gewöhnlichen Sinne dieses Wortes ist, kann ich nicht entscheiden. Von ihrer Anwesenheit auf späteren Stadien kann man sich leicht ïberzeugen, indem sie nach Erreichung 
des Gastrulastadiums und beim Beginn der stärkeren Ausbildung der Kopfblase gesprengt und vom Embryo sehr bald samt dem Richtungskörperchen abgestreift wird ${ }^{1}$. Den Vorgang selbst habe ich oftmals beobachtet; das feine Häutchen gleitet nämlich seitwärts vom Keim gleichsam wie von einem schlupfrigen, langsam anschwellenden Körper berunter. Damit wäre auch der Mechanismus des Abwerfens beiläufig erklärt. Das abgeworfene Ḧ̈utchen kann man schon bei schwacher Vergrößerung und ohne Anwendung von Reagentien im Eiweiß leicht auffinden, wo es stets als ein feines, glänzendes, gefaltetes Häutchen bis in die spätesten Stadien unverändert verharrt.

Die Existenz einer besonderen Dottermembran scheint mit der Tatsache unrereinbar zu sein, daß die Blastomeren während der Furchung verschiedene Evolutionen machen, einzelne derselben sich uiber das allgemeine Niveau erheben und allseitige Verschiebungen erleiden, sie muß aber bei Physa mit Rücksicht auf das soeben beschriebene Abwerfen eines Häutchens unbedingt angenommen werden, da man es sonst als ein späteres Ausscheidungsprodukt des ganzen Keimes betrachten müßte, was wohl kaum zulässig ist.

Über das Vorkommen einer Dottermembran bei den Gastropodeneiern lauten die Angaben der Autoren sehr verschieden. In einigen Fällen ist sie ganz sicher nachgewiesen worden z. B. bei Paludina (Töxniges), in andern soll sie fehlen z. B. bei Umbrella (Hexmoxs), Limax (Koford), Neritina (Blochmans), Trochus (Robert) usw. Bei den Lamellibranchiern scheint sie allgemein vorzukommen, zumal bei Süßwasserformen; eine Ausnahme bildet Dreissensia, bei der MEIsenhemmer keine Dottermembran finden konnte. Bei den Annelideu wird sie für Arenicola (CHILD) ganz bestimmt angegeben, bei den Rotatorien konnte sie bei Asplanclina ron Jexwixgs nicht nachgewiesen werden und dieser Autor äußert sich über ihr Vorkommen sehr skeptisch.

Bei der Schwierigkeit der Feststellung der Dottermembran sowohl am ungefurchten $\mathrm{Ei}$ als auch an frühen Entwicklungsstadien ist es erklärlich, daß diesbezuigliche Angaben oft unbestimmt oder negativ lauten.

Wir wenden uns zu der vielfach diskutierten Frage nach der Orientierung des Eies. Die polare Differenzierung desselben durfte nach den bisherigen Beobachtungen als eine allgemeine Erscheinung bei Mollusken und Anneliden betrachtet werden.

1 Derselbe Vorgang findet auch bei Limnaca stagnalis statt. Nach eigner Beobachtung. 
Bei Physa äußert sie sich in einer Ansammlung des Bildungsplasma am oberen Pole, in der Lage der Richtungsspindel in der Polarachse, sowie der Pronuclei nahe dem animalen Pole. Distinkte Achsen von ungleicher Länge, wie sie bei gewissen Anneliden (Arenicola, Stemaspis) und bei Asplanchna Jennings beobachtet wurden, wo nämlich die Polarachse bedentend kürzer als eine der Querachsen ist, sind bei unsrer Art in der Konfiguration des Eies selbst nicht ausgedriickt. Es scheint aber keinem Zweifel zu unterliegen, daß das Ei schon vor der Befruchtung vollkommen orientiert ist, und nicht erst nach dem Eindringen des Spermatozoons, da dasselbe nach Beobachtungen an Physa, Arenicola u. a. an beliebiger Stelle stattfinden kann.

Betreffend die Beziehung der Hauptachse des Eies zu den Achsen des künftigen Embryos gelten für Physa die für andre Gastropoden festgestellten Normen, d. i. sie entspricht beiläufig der dorsoventralen Achse des künftigen Embryos.

Über die Vorgänge der Reifung und Befruchtung des Eies von Physc habe ich gemeinschaftlich mit Kostanecki in einer bereits oben erwähnten, ausführlichen Arbeit ('96) berichtet, glaube somit dieses Kapitel übergehen zu können. Ergänzend mag nur hinzugefuigt werden, daß in den meisten Eikapseln sich regelmäßig viele Spermatozoen eingeschlossen finden, öfters ganze Bündel derselben. Man beobachtet in den meisten Eiern, ja sogar an sehr vorgerỉckten Furchungsstadien bis zur Gastrulation einzelne Spermien mit den Köpfen gegen die Ei- bzw. Keimoberfläche gerichtet, in welcher Stellung sie sich ganz unversehrt erhalten. In dieser Tatsache scheint das verhältnismäßig häufige Auftreten polyspermer Abnormitäten eine Erklärung zu finden.

Es mag noch bemerkt werden, daß in mehreren Fälleu die Teilung des Chromatins in einem der Richtungskörperchen festgestellt wurde, was bereits in der oben zitierten Arbeit betont wird.

Es mag noch hinzugefügt werden, daß der Richtung der Polstrahlen bei Ausbildung der Richtungsspindeln besondere Aufmerksamkeit gewidmet wurde, um zu erfahren, ob diese Richtung nicht etwa die Richtung der künftigen Spiralfurchung bereits andeutet. In den vielen Präparaten, die daraufhin untersucht wurden, konnte indes eine deutliche Ablenkung der rein meridional ausstrahlenden Fasern nicht festgestellt werden ${ }^{1}$.

1 Vgl. die anders lautenden diesbezïglichen Angaben von Kostanecki und SIEDIECKI ('96). 


\section{Furchung.}

\section{Furchungsgeschichte bis 123 Zellen.}

Der Furchungsprozeß beginnt bei Plysa etwa 3 Stunden nach der Ablage des Eies und man findet durchschnittlich bereits nach 4 Stunden die erste Teilung rollzogen ${ }^{1}$. Man darf aber weder fur diese noch für die nachfolgenden Teilungen festgesetzte Termine erwarten, da eine mehrjährige Erfahrung mich zur Geniige tiberzeugt hat, daß der Gang der Furchung von vielen äußeren und innereu Einflüssen abhängig und infolgedessen äußerst großen Schwankungen unterworfen ist. Beispielshalber wollen wir anfüren, daß für die Entwicklung vom Ei bis zur vollkommen ausgebildeten Schnecke im kalten Friihjahr 190230 Tage, während im Juni desselben Jahres uur 15 Tage erforderlich waren; ein Gastrulastadium entwickelt sich manchmal schon binnen 24 Stunden, wogegen ein andres Mal in dieser Frist kaum ein Stadium von 24-28 Zellen erreicht wird. Man sieht, welch bedeutende Unterschiede im Tempo des Furchungsprozesses die Temperatur allein hervorzurufen vermag². Außer derselben wirken aber auch andre Faktoren bald beschleunigend bald verzögernd auf den Furchungsprozess ein. So wirken heller Sonnenschein, milde Luft, gutes Wasser unbedingt beschleunigend, wogegen regnerisches Wetter, iiberhaupt niedriger Barometerstand unbedingt verzögernd einwirken. Nebenbei läßt sich die Abhängigkeit des Furchungsganges von inneren Faktoren nicht leugnen, mögen dieselben in der Struktur der Keime selbst oder in der Qualität und Quantität des sie umgebenden Eiweißes, dem Bau der Kapseln, der Befruchtung und andrer uns ebensowenig bekannter spezifischen Eigenschaften der einzelnen Gelege und Keime liegen. Nur den Einflusse dieser inneren Faktoren ist die Tatsache zuzuschreiben, daß oft unter genau denselben Bedingungen sehr große Lnterschiede im Furchungsrlhythmus auftreten, die man schlechtweg individuclle schwankungen zu nennen pflegt. Mit Riticksicht auf diese Schwankungen, mag ihre Ursache in den außeren oder inneren Faktoren liegen,

1 Bei Physa heterostropha beginnt nach Cramptox die Furchung erst 5 Stunden nach der Eiablage und 2 Stunden nach dem Ausstoßen des Richtungskörperchens.

2 Die Abhängigkeit der Furchungsvorgänge von der Temperatur ist nicht nur von mehreren Autoren Fol, Kofoid, CARAzzi u. m. a.; fuir Mollusken nachgewiesen worden, sondern iiberhaupt als eine im Tierreich allgemein verbreitete Erscheinung erkannt. 
haben wir es unterlassen die Zeitpunkte zu notieren, in denen dieses oder jenes Stadium erreicht wird und wo wir es ausnahmsweise tun, sind es immer die aus unzähligen Beobachtungen gewonnenen Durchschnittszahlen. Es stellte sich nämlich heraus, daß nach derartigen Zeitangaben die entsprechenden Entwicklungsstadien sich gar nicht identifizieren ließen, und daß sie somit ohne praktischen Wert sind. Einen wissenschaftlichen Wert hätten sie nur dann, wenn man die Abhängigkeit der Dawer einzelner Entwicklungsphasen von den äußeren oder inneren Faktoren genau abzuschätzen imstande wäre.

Um die strenge Aufeinanderfolge der einzelnen Stadien, die Kontinuität der Entwicklung kennen zu lernen, gibt es keinen andern Weg als denjenigen der Erfahrung.

Im besondern mag hier ein Faktor genannt werden, dessen Einfluß auf die Furchung nach den neulich vorgenommenen Experimenten (Hertwig, Roux, 0. Schultze) vielfach diskutiert wurde, nämlich die Schwerkraft. Bei Physa scheint jedoch dieser Faktor gar keine richtende Wirkung auf den Furchungsprozeß auszuüben, da der Laich nach vielfachen Beobachtungen sowohl in der freien Natur als auch im Aquarium in allen möglichen Richtungen an Blättern und Stengeln von Wasserpflanzen abgelegt wird, ja die einzelnen Keime in einem und demselben Eiklumpen nach beliebiger Richtung gegeneinander und gegen die Richtung der Schwerkraft orientiert sind, ohne daß infolgedessen ein Unterschied in der Entwicklung hätte bemerkt werden können ${ }^{1}$. Es mag die geringe Größe des Eies zweifellos anch seine Struktur die Ursache sein, daß es keine fixe Stellung während der Entwicklung zu nehmen braucht.

Über anormale Furchungserscheinungen handelt ein vorausgeschicktes Kapitel, hier wollen wir bloß bemerken, daß es dem Geiibten keine Schwierigkeit bereitet, die anormalen Bilder auf den ersten Blick zu unterscheiden.

Indem wir nun zur Schilderung des Furchungsprozesses selbst übergehen, mag bemerkt werden, daß er in den Anfangsstadien besonders eingehend am lebenden Objekt studiert wurde. In betreff der Darstellung selbst mag bemerkt werden, daß ich es angezeigt fand, den beschreibenden Teil von den vergleichenden und theoretischen Auseinandersetzungen vollständig zu trennen und die nachein-

1 Dieselbe Beobachtung machte MEAD ('95) für die Anneliden Amphitrite, Clymenella and Nereis und WheELER ('95) für das Ei von Blatta. 
anderfolgenden Entwicklungsstadien stets in ihrer Gesamtheit zu betrachten, da ich aus eigner Erfahrung weiß, wie schwer sich die Lektüre einer embryologischen Abhandlung gestaltet, wenn die Schilderung der tatsächlichen Befunde durch vergleichende Exkurse, Diskussionen über das Schicksal einzelner Blastomeren oder Quartette $\mathbf{a}$. dgl. unterbrochen wird.

\section{Die erste Teilung.}

Das in Teilung begriffene Ei hellt sich zanächst an der animalen Hälfte stark auf, indem sich der ganze Dotter auf der vegretativen konzentriert und einen scharf umschriebenen Kontur zeigt. Kurz vor dem Erscheinen einer Einsenkung am animalen Pole rerlängert sich die animale Hälfte des Eies sehr stark in der Kichtung eines Querdurchmessers, wodurch das $\mathrm{Ei}$ die kugelige Gestalt mit derjenigen eines stumpfen mit der konvexen Basis nach oben gerichteten Kegels rertauscht. Infolge der am animalen Pole beginnenden Einschnürung gewinnt das Ei eine herzförmige Gestalt und sind an demselben in dieser Phase drei Achsen von ungleicher Länge zu unterscheiden. In der längeren ron den beiden Querachsen liegt nunmehr die Theilungsspindel horizontal, ganz nahe am animalen Pole. Indem sich die Furche vertieft, werden die Spindelfasern nach dem regetativen Pole gleichsam herahgedrängt; man sieht sie nämlich am konservierten Yaterial anfangs stark nach dem letzteren ausgebogen, später winklig geknickt. Indessen hat bereits die Regeneration der Kerne begronnen, welche noch immer ihre Lage in der Nähe des animalen Poles zu behaupten streben. Bald wird der Zusammenhang der Spindelfasern mit den letzteren gelockert, es ist dies der Zeitpunkt der Ausbildung des $Z$ wischenkïrpers, welcher aber nicht genau in der Hauptachse liegt, sondern merklich seitwärts und zwar nach links während der Zelldurehschnürung verschoben wird Fig. 1). Mit Rücksicht darauf, daß die beiden ersten Blastomeren nur äußerst selten einen Größenunterschied zeigen, ist die Entscheidung, welche ron denselben der vorderen und welche der binteren Eihälfte entspricht, unmöglich, folglich läßt sich auch die Richtung, nach welcher die Verschiebung des Zwischenkürpers erfolgt, nur nach den Ausnabmsfällen bestimmen. Diese linkseitige Verschiebung des Zwischenkïrpers marg vielleicht die Vorbedingung fur die nächste dexiotrope spirale Teilung andenten.

Während die geschilderten Vorgänge der Kernteilung sich abspielen, sieht man die Furche das ganze Ei umgreifen, die Ver- 
bindungsbrücke zwischen beiden Eihälften wird immer schmäler, sie entfernen sich gleichzeitig mit ihren animalen Hälften ziemlieh weit voneinander, ziehen sich zusammen, runden sich ab und gewähren voriubergehend den Anblick zweier bloß in einem Punkte zusammenstoßender Kugeln. Die Verbindungsbriicke zwischen denselben ist hauptsächlich durch den Zwischenkörper bewerkstelligt und liegt nicht in der Ebene des Äquators der beiden Blastomeren, sondern bedeutend tiefer gegen den vegetativen $\mathrm{Pol}$ zu. Der ganze Vorgang dauert durchschnittlich 15 Minuten, das Ei scheint dabei eine Drehung um $90^{\circ}$ auszuführen. Nach einer kurzen Pause beginnen die kugeligen Blastomeren in einer rasch zunehmenden Kontaktfläche miteinander zu verschmelzen, so daß sie für einige Zeit das Stadium des ungefurchten Eies vortäuschen, indem sie sich zu einer einzigen vollkommenen Kugel zusammenschließen. Erst bei stärkeren Vergrößerungen überzeugt man sich, daß man es mit einem Zweierstadium zu tun hat und zwar an der feinen Grenzlinie zwischen den Zellen, welche im großen Kreise das Ei umzieht, sowie an den zwei durchschimmernden Kernen, die jetzt nahe dem animalen Pole liegen. Die animalen Hälften sind wieder ganz hell, der Dotter konzentriert sich an den beiden vegetativen Zellhälften. Die Grenzlinie tritt alsbald sehr scharf hervor, denn zwischen den eng verbundenen, nunmehr halbkugligen Blastomeren wird bald Flïssigkeit ausgeschieden, die zuerst einen schmalen, linsenförmigen, ron Pol zu Pol ausgedehnten Raum ausfüllt, bald aber fast kugelig wird, währenddem die Blastomeren selbst sich zu hohlen Kugelschalen umgestalten, welche mit sehr feinen, vollkommen durchsichtigen Rändern miteinander an der Keimesoberfläche zusammenhängen. Die Kerne sind jetzt wandständig ${ }^{1}$. In senkrecht zu der Teilungsebene geführtem optischen Schnitt geben die beiden Blastomeren derzeit das Bild zweier mit ihren Hörnern verwachsenen Mondsicheln. Es ist aus den zwei ersten Blastomeren eine zweizellige Blastula entstanden mit kolossaler Furchungshöhle. Um bis zu dieser Phase zu gelangen, braucht das Ei etwa 50 Minuten. Wir wollen gleich bemerken, daß von nun an durch eine lange Reihe von Furchungsstadien das Auftreten und Verschwinden der Furchungshöhle zur Regel wird. Wir nennen dieselbe nach dem Vorgange Kofords » die periodisch wieder-

${ }_{1} \mathrm{Da}$ das Gasteropodenei in dieser interessanten Phase bereits von andern Autoren wie Kofold, Fr. Schмid genau abgebildet wurde, so unterlasse ich, die betreffende Abbildung zu geben. 
kehrende Furchungshöhle" ( an ephemeral recurrent cleavage cavity ) und werden dieselbe in einem besonderen Abschnitt näherer Erwägung unterziehen.

\section{Die zweite Teilung. Von 2-4 Zellen (Fig. 2-4).}

Sobald die Kerne der beiden zu einer Kugel zusammengeschlossenen Blastomeren röllig ausgebildet sind und die Furchungshöhle ihr Maximum erreicht hat, tritt das $\mathrm{Ei}$ in die Phase der nächsten Teilung ein. Es sammelt sich nämlich um die beiden Kerne ein feinkörniges Plasma, in welchem bald die Centrosomenstrahlung sichtbar wird, die Furchungshöhle verschwindet plötzlich wie auf einen Ruck, die Blastomeren werden voriibergehend dunkler und beginnen sich in der Richtung der ersten Furchungsebene zu verlängeru, gleichzeitig bilden sich neue Teilungsspindeln aus, welche anfänglich vollkommen horizontal und der ersten Teilungsebene parallel liegen. Später sind sie im entgegengesetzten Sinne schief gegen die Horizontalebene eingestellt und zwar so, daß je zwei in der Diagonale gegenüberstehende Spindelpole in einem höheren und je zwei in einem tieferen Niveau sich befinden. Diese Lageveräinderung wird aus der Fig. 2 ohne weiteres rerständlich, sie zeigt zugleich seichte Einkerbungen an den in Teilung begriffenen Blastomeren, sowie eine bajonettartige Knickung ihrer Verbindungslinie: die fribzeitige Andeutung der oberen Querfurche. Am lebenden Objekt fällt außerdem noch ein ziemlich weiter Hohlraum zwischen den beiden Blastomeren auf.

Betrachtet man den lebenden Keim unmittelbar nach der Ausbildung der Furchungsspindeln, wobei man den animalen Pol nach oben und die erste Furchungsebene parallel zum Beobachter orientiert, so bemerkt man nach einigen Minuten, daß sich seine Lage ändert. Der animale Pol entzieht sich lang'sam dem Blicke und man bekommt eine schiefe Seitenlage zur Ansicht. Bei tiefer Einstellung überzeugt man sich jetzt, daß die bereits merklich eingeschntirten Zellen nicht mehr in paralleler, sondern in gekreuzter Stellung sich befinden. Sie haben nämlich eine Drehung in der Vertikalehene in entgegengesetzten Sinue ausgeführt und zwar etwa um einen Winkel von $35^{\circ}$. Nach einer kurzen Weile kehrt der Keim in die urspriingliche Lage zurick und man kann jetzt ganz genau feststellen, daß infolge dieser Drehung das vordere rechte und das hintere linke Teilprodukt sich über die Horizontalebene erhoben hat. Diese höher liegenden Blastomeren, die wir mit $A$ und $C$ bezeichnen, verbinden 
sich bei weiterer centralwärts gerichteten Verschiebung am animalen Pole miteinander, die beiden tiefer liegenden $B$ und $D$ am vegetativen. Beide Verbindungslinien auf die Äquatorialebene projiciert, kreuzen sich unter einem schiefen Winkel.

Wie aus der obigen Darstellung des Teilungsaktes selbst, sowie aus den Fig. 2 und 3 zu entnehmen ist, erfolgt die Abschnürung der oberen Blastomeren in dexiotroper Richtung, ein Umstand, der die ganze Furchung bei Physa als spiralig umgekehrt, »reversed cleavage * CRAMPTONs, charakterisiert.

Der ganze Vorgang von dem Erscheinen der Furchungsspindeln an bis zur völligen Ausbildung des Viererstadiums dauert etwa 25 Minuten.

Die weiteren Vorgänge führen nunmehr zur Ausbildung dès Ruhestadiums (Fig. 3) und bestehen darin, daß die Kerne bedeutend anschwellen und ein weiter Flüssigkeitsraum entsteht, worauf die vier Blastomeren sich zu einer vollkommenen Kugel zusammenschließen. Die Zusammengehörigkeit der Tochterzellen ist noch in dieser Phase durch den Zwischenkörper nachweisbar (Fig. 4), so daß ein Irrtum in der Signifizierung derselben ausgeschlossen ist. Was das Größenverhältnis der vier ersten Blastomeren betrifft, ist zu bemerken, daß ausnahmsweise $D>B$ und sich schon jetzt als die künftige Urmesodermzelle kundgibt.

Der umgekehrte Furchungsmodus.

Bevor wir zur Darstellung des weiteren Furchungsprozesses übergehen, wollen wir aus weiter unten anzufithrenden Gründen den Begriff des umgekehrten Furchungsmodus an dieser Stelle näher erläutern.

Wenn wir bei dem Vorgange der zweiten Teilung eines Gasteropodeneies denjenigen Augenblick einer scharfen Beobachtung unterziehen, wo bereits die Abschnürung der vier Blastomeren angedeutet ist, wenn wir dabei das Ei mit dem animalen Pole nach oben und mit der ersten Furchungsebene parallel zum Beschauer, d. i. von links nach rechts, orientieren, wenn wir ferner die erst angedeuteten Blastomeren im Sinne des Uhrzeigers mit den Buchstaben $A, B, C, D$ uns bezeichnet denken, so sind nach den bisherigen Beobachtungen zwei Fälle möglich: entweder erheben sich die alternierenden Zellen $A$ und $C$ uber $B$ und $D$ oder aber $B$ und $D$ uber $A$ und $C$. In beiden Fällen bilden sich nach vollendeter Abschnürung zwischen je einem Paare die sog. Kreuz- oder Polarfurchen, die sich unter 
einem annähernd rechten Winkel schneiden, aber im ersten Falle fuihren die oberen Blastomeren eine Drehung nach links aus, im zweiten nach rechts (vgl. Textfig. 2 ( u. b). Vergleicht man ferner die Ruhestadien der so gebildeten Vierergruppen, so sieht man, daß ihre Polarfurchen eine entgegengesetzte Lage haben. Man pflegt diesen Gegensatz in der Lage und der gegenseitigen Bewegungsrichtung mit dexiotroper und läotroper Spirale zu bezeichnen. Zur Erlïuterung dieser etwas schwer verständlichen Verhältnisse und zum Verständnisse der spiralen Furchung überhaupt mag noch hinzugefiigt werden, daß infolge der oben beschriebenen Verlagerung der Blastomeren die beiden ersten Furchungsebenen aus der Vertikale heraustreten und die Gestalt der Fliigel einer vertikal gestellten Schiffsschraube annehmen. Im optischen Horizontalschnitt betrachtet, erscheint infolgedessen jede von ihnen S-förmig geschweift und die
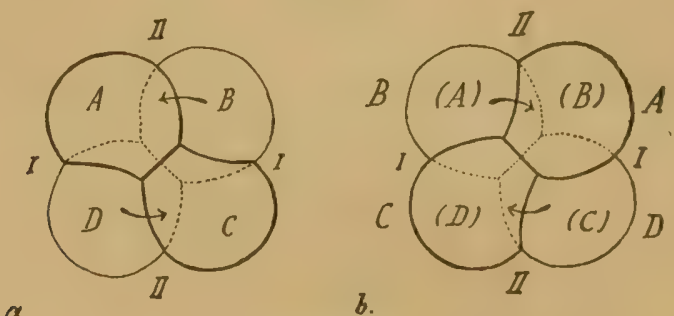

Textfig. 2.

$a$, Schema der normalen (läotropen) Furchung; $b$, Schema der umgekehrten (dexiotropen) Furchung.

sphärisch dreieckigen Berührungswände der Blastomeren geben ein mathematisch getreues Abbild der Schraubenwindung ab (Fig. 3 und 4, Textfig. 2).

Bei Physa und einigen wenigen linksgewundenen Gasteropoden$\operatorname{arten}^{1}$ ist nach dem Obigen die erste Spirale dexiotrop, während sie bei andern, rechtsgewundenen Gasteropoden läotrop ist. Der erste Furchungsmodus kommt nur ausnahmsweise vor und wird deshall) dem zweiten gegenïber als umgekehrte Furchung, „reversal cleavage* Cramptons, bezeichnet. Wir müssen schon an dieser Stelle hervorheben, daß bei der normalen Furchung die Urmesodermzelle, welche stets hinten links und tiefer als die zweite hintere Zelle gelegen ist, beim gewöhnlichen läotropen Furchungsmodus hinten links zu stehen kommt (bei der Ansicht vom vegetativen Pole ans rechts), während

${ }^{2}$ Bei drei Physa-Arten: Ph. heterostropha, Ph. fontinalis, Ph. hypnorum, drei Planorbis-Arten und Ancylus ricularis Say, im ganzen also bei sieben Arten. 
sie bei der umgekehrten Furchung hinten rechts liegt. Demgemäß ist auch die Lage der drei übrigen Blastomeren, bzw. Quadranten, eine umgekehrte und aus diesem Grunde hat Crampton (1894) in seiner Arbeit über Physa heterostropha diese Quadranten zwar mit denselben Buchstaben, aber in entgegengesetzter Ordnung, d. i. von rechts nach links, signifiziert, um homologe Teile des künftigen Keimes mit demselben Namen zu belegen, wobei die Urmesodermzelle stets als Zelle $D$ bezeichnet wird. Bei Anwendung dieser umgekehrten Bezeichnung wird sich die Zelle $D$ stets mittels der vegetativen Polarfurche mit der Zelle $B$ verbinden, während das erhöhte Zellenpaar stets die Indices $A$ und $C$ erhält.

Unsre Auffassung des Gegensatzes in der dextralen und sinistralen Spiralfurchungsform stimmt mit derjenigen CRAMPTONs vollkommen überein und konsequent stimmt auch unsre bildliche Darstellung dieses Gegensatzes mit der seinigen überein 1.

Anders scheint ConkLiv ('97) diesen Gegensatz zu beurteilen. Denn einerseits hat er in seiner Crepidula-Arbeit in beiden Furchungstypen die Quadranten in derselben Ordnung, d. i. im Sinne der Bewegung des Uhrzeigers signifiziert, anderseits gibt er für Crepidula adunca (p. 15, Diagr. 2, a) an, daB die Blastomeren $B$ und $D$, welche nach Cramptons und unsrer Auffassung am vegetativen $\mathrm{Pol}$ zusammenstoßen und dort eine Polarfurche ergeben, am animalen Pol zusammenhängen und somit $A$ und $C$ überlagern. Diese Angabe ist um so auffälliger, als bei zwei andern Crepidula-Arten die Zellen $A$ und $C$ die Zellen $B$ und $C$ überlagern, bzw. am animalen Pol zusammenhängen, wie dies für die meisten Gasteropoden als Regel gilt. Ohne uns auf die Verhältnisse bei Crepidula adunca, die möglicherweise eine Ausnahme bildet, näher einlassen zu wollen, heben

1 In meiner vorläufigen Mitteilung wurden die beiden vorderen Quadranten mit $b$ und $c$ anstatt mit $a$ und $b$ bezeichnet, welcher Irrtum keineswegs auf einer falschen Bezeichnung der Richtung der Spirale, wie es RoBERT S. 224 vermutet, sondern einfach auf einem Schreibfehler beruht. Es wäre selbst bei richtiger Bezeichnung der Quadranten die Ableitung des sekundären Mesoderms von den Quadranten $b$ und $c$ ebenfalls falsch gewesen, da die Mesodermanlage asymmetrisch wäre, was bei Physa nicht der Fall ist. Die Orientierung des Viererstadiums war in meinen Zeichnungen von Anfang an ganz korrekt und die obige kritische Auseinandersetzung wurde lange vor dem Erscheinen der RoBertschen Trochus-Arbeit abgefaßt, wiewohl sie erst jetzt in die Öffentlichkeit gelangt. RoBERT führt für seine Ansicht keine weiteren Gründe an, als daß ihm die Nomenklatur Cramptons rationeller erscheint. Casteel (Fiona 04), der sich demselben in dieser Beziehung anschließt, stiitzt seine Ansicht auf den inversen Bau der Eizelle der sinistralen Gasteropoden. 
wir an dieser Stelle hervor, daß allem Anschein nach HoLmes durch ConkLins Darstellung beeinfluBt wurde und unbeklimmert um Schemen C'RAMPToss die vier ersten Blastomeren bei I'lanorbis, welche ebenso wie bei den drei Physa-Arten umgekehrte Furchung (mit rechts liegender Lrmesodermzelle) besitzt, anstatt in umgekehrter Richtung, in einer fur den normalen Typus der Spiralfurchung angenommenen Richtung von links nach rechts signifiziert. Um also die Blastomere $D$ an die rechte Seite zu bringen, mußte er die betreffende Figur um $90^{\circ}$ nach links umdrehen. Infolgedessen wurde jedoch die Lage der andern Blastomeren in unrichtiger Weise rerändert, so zwar, da $B$ die Zellen $A$ und $D$ nach hinten, dagegen $B$ und $C$ nach vorn zu liegen kamen, was unbedingt falsch ist, da doch, wie es RoliEi'T ('03) S. 224 ganz zutreffend bemerkt, nach der ersten Teilung in der vorderen Eihälfte $A$ und $C$ and in der hinteren $B$ und $D$ enthalten sind, die nach ibrer Abtrennung bei der zweiten Teilung in denselben Eihälften verbleiben und nicht von vorn nach hinten oder umgekehrt herïberwandern können, wie sich dies HoLues rorgestellt haben mochte. Seine Signifizierung der Blastomeren in der Ordnung von links nach rechts schien uns nichtsdestoweniger in einer gewisseu Hinsicht doch einige Berechtigung zu haben. Um uns zu überzeugen, ob dies wirklich der Fall ist, haben wir folgenden Versuch gemacht. Wir bezeichneten bei Physa die vier ersten Blastomeren in derselben Ordnung, wie es HoLMes tut und versuchten nach der für diese Form durch genaue Beobachtung festgestellten Norm das 24-zellige Furchungsstadium zu konstruieren, doch sind wir dabei zu dem sonderbaren Resultate gelangt, daß wir nicht nur einzelne Zellen von unrichtigen Yutterzellen ableiten, sondern auch an der vegetativen Seite die Makromeren $A$ und $C$, anstatt $B$ und $D$ mit der Polarfurche verbinden mußten. Da man aber in den betreffenden Figuren bei Holues ('900) (Taf. XVIII, Fig. 10) dennoch $B$ mit $D$ verlounden findet, so macht es unser Versuch wabrscheinlich, daß derselbe gewisse Teilungsrichtungen, z. B. diejenige beim Übergang rom 12-zelligen in das 16-zellige Stadium die Teilung des ersten Ectomerenquartettes, vielleicht ohne dessen gewahr zu werden, als dexiotrop, statt läotrop aufgefaßt hat.

Sein Verfahren erweist sich somit, sowohl theoretisch erwogen als anch praktisch nachgeprift, als unrichtig.

Über die Ursachen der entgegengesetzten Drehungsrichtung beim dexiotropen Furchungsmodus wird in einem späteren Kapitel gehandelt. An dieser Stelle möchten wir des Zusammenhanges halber 
noch dem Probleme der Identität des vierzelligen Furchungsbildes bei verschiedenen Tiergruppen einige Worte widmen.

Das vierzellige Furchungsbild mit den typischen gekreuzten oder parallelen Polarfurchen kommt bekanntlich nicht nur in der Ontogenie der Mollusken und Anneliden ganz allgemein vor, sondern es wurde auch bei Formen mit holoblastischen Eiern in allen übrigen Tiergruppen nicht selten beobachtet.

Die allgemeine Verbreitung und die vollkommene Identität dieses Furchungsbildes bei systematisch weit entfernten Typen legte den Gedanken nahe, daß seiner Ausbildung dieselben Ursachen zugrunde liegen, die aber keineswegs auf eine spezifische "vitale "Natur der Organismen, sondern auf allgemeine, physikalische Notwendigkeit zurückzuführen wären. Es erschien somit seit langem als eine sehr verlockende Aufgabe, den Vorgang physikalisch zu analysieren. Nachdem die darauf gerichteten Bemühungen neulich von RoBERT ('03) in seiner Trochus-Arbeit S. 45 u. ff. eingehend besprochen worden sind, halten wir es für überflüssig, auf dieselben nochmals einzugehen, zumal sich aus der Zusammenstellung der bisher geäußerten Ansichten keine neuen Gesichtspunkte gewinnen lassen. Es mag also nur zusammenfassend festgestellt werden, daß bislang trotz der gelungenen Experimente eine eindeutige Erklärung nicht erzielt wurde. Selbst RoвerT, dem es wohl zum erstenmal gegliickt ist, alle bisher bekannten Varietäten des vierzelligen Furchungsbildes, sowie der nächstfolgenden Stadien bis zum 16-zelligen ${ }^{1}$ mit aller Genauigkeit an Seifenblasen nachzubilden, ist $z u$ der Einsicht gelangt, daß man "un tout autre ordre d'actions que les forces purement physiques * annehmen muß, um die Orientierung der ersten Furchungsebenen, sowie die relative Länge und Lage der Polarfurchen zu erklären. Dies ist auch unsre Überzengung. Ohne die selbstrerständliche Einwirkung rein physikalischer Momente, wie dieselben bei keinem materiellen Geschehen ausgeschaltet werden können, in Abrede zu stellen, sehen wir uns ebenfalls genötigt, anzunehmen, daß die Furchung, von den frühesten Stadien angefangen, durch die spezifische Beschaffenheit der Eizelle geleitet wird. Das Walten rein physikalischer Momente einmal angenommen, müßte man auch die komplizierte Anordnung der Zellen in den späteren Stadien aus dem Spiele äußerer Faktoren herleiten, da dieselbe in sehr zahlreichen

1 Vgl. 1. c. die photographischen Aufnahmen Taf. XII, Fig. 1-12. 
Fällen ebenfalls identisch ist. Wir brauchen nur auf das 24-zellige Furchungsbild, auf die regelmäßige Alggabe von drei sog. Ectomerenquartetten, auf die Kreuzfigur u. dgl. mehr hinzuweisen. Wir möchten also beim Zustandekommen auch der einfachsten Furchungsbilder der Capillarität als solcher lediglich einen sekundiir determinierenden Einfluß eiuräumen. Wer den Vorgang der Vierteilung Schritt für Schritt verfolgt und die Drehung der Spindeln, sowie die starke Lageverschiebung der eingeschntirten Zellen scharf beobachtet hat, der wird gewiß unsre Auffassung billigen.

Im übrigen halten wir diese Frage für gegenstandslos, nachdem es auf experimentellem Wege unmittelbar nachgewiesen werden konnte, daß das Zellplasma beim Teilungsprozesse eine aktive Rolle spielt 1.

Nach diesem Excurs kehren wir zur weiteren Darstellung des Furchungsprozesses zurtick.

Das erste Quartett von Ectomeren. Von vier bis acht Zellen (Fig. 5, 6).

Das soeben beschriebene Ruhestadium ist nur von kurzer Dauer (etwa 30 Minuten), worauf die Furchungshöhle verschwindet, die Blastomeren sich in die Länge strecken und am vegetativen P'ole roneinander entfernen. Zugleich verschieben sie sich gegenseitig in entgegengesetzter Richtung des Uhrzeigers von rechts nach links, was sowohl rom animalen Pole aus als auch in der Seitenansicht zum Ausdruck kommt (Fig. 5). Durch diese aktive Bewegung der Blastomeren wird die Lage ihrer Tochterzellen frïh vorbereitet. Die Teilungsspindeln erscheinen in den vier Blastomeren selten srnchron, meist successire, ohne bestimmte Ordnung einzuhalten, und stimmen in ihrer schiefen, ron rechts nach links geneigten Lage mit der Drehungsrichtung der Blastomeren iiberein. In der Phase der Abschnürung selbst stehen die kleinen, knospenähnlichen Tochterzellen merkwürdigerweise eine Zeitlang genau iber den Mutterzellen; erst nach vollzogener Teilung und Rekonstruktion der Kerne gelangen sie in ihre definitive, in bezug auf die Mutterzellen liotrope Lage (Fig. 6\%. Nach kurzer Zeit schließen sich die acht Blastomeren zu einer Kugel zusammen und es kommt wieder zur voribergehenden Ausbildung der »ephemerischen "Furchungshöhle. Die vier neugebildeten Zellen

1 Vgl. T. Garbowski, Über parthenog. Entw. der Asteriden. Extr. Bull. Ac. Sc. Cracovie 1904. 
$1 a-1 d$ haben eine Verschiebung gegen ihre Mutterzellen erfahren, ihre Polarfurche bildet mit derjenigen des vegetativen Poles einen Winkel von ungefähr $30^{\circ}$.

Einer sehr eigentümlichen Erscheinung müssen wir noch gedenken, bevor wir zur Schilderung der weiteren Furchung ibergehen. Während sich nämlich die Teilungsspindeln für die Teilung in acht Zellen anlegen, wird der ganze Dotter, ebenso wie auf früheren Stadien, gegen den vegetativen $\mathrm{Pol}$ zurïckgedrängt, wo er sich auf einer scharf umschriebenen Stelle konzentriert. Betrachtet man nun einen Schnitt von einem solchen Stadium unter starker Vergrößerung, so bemerkt man, daß in der einen Sphäre, und zwar derjenigen, die gegen die vegetative Eihälfte zugekehrt ist, zahlreiche Körnchen verschiedener Größe angesammelt sind, die während des Diasterstadiums bis an die Oberfläche der Zelle verdrängt werden(Fig. 1 u. 5, Taf.XXVII). An der andern Sphäre sind sie gar nicht zu finden. An Totalpräparaten sieht man in dieser Phase am vegetativen Pole knapp unter der Oberfläche in jeder der vier Makromeren einen Fleck von unregelmäßigem Kontur, der fast genau über der Kernspindel, bzw. über dem Kern (vor der Ausbildung der letzteren) liegt (Fig. 2, Taf. XXVII). Diese vier Flecken sind nach Ablauf der Teilung ganz charakteristisch gruppiert, wie dies aus der Fig.4, Taf. XXVII, zu entnehmen ist. Es liegen nämlich, sowohl an diesem Stadium wie an allen nächstfolgenden bis zum 24zelligen, zwei derselben längs der vegetativen Polarfurche ausgebreitet, während die zwei andern sich in den Ecken befinden, welche an beiden Enden der Polarfurche durch die Grenzlinien der Makromeren $A$ und $C$ gebildet werden (Taf. XXVII, Fig. 6).

Ohne an dieser Stelle auf die nähere Beschreibung dieser, unsres Wissens bei Mollusken zum ersten Male beobachteten Gebilde ${ }^{1}$ einzugehen, wollen wir sie mit Rücksicht auf ihr ähnliches Verhalten während der Zellteilung mit analogen Körnchengruppen bei Cyclops mit Häcker ('99) »Ectosomen" nennen.

Die Ectosomen erscheinen zwar bereits in der Übergangsphase vom 2-4zelligen Stadium, jedoch nur als verstreute Körnchen, die leicht der Beobachtung entgehen; am vierzelligen Ruhestadium sind sie am vegetativen Pole nur schwach angedeutet, erst währeud der Vorbereitungsphase zur Teilung in acht Blastomeren treten sie mit aller Schärfe zum Vorschein, weshalb wir über dieselben crst jetzt zum ersten Male berichten. Von dem achtzelligen Stadium an bis

1 Dieselben wurden bereits von mir im Jahre 1900 beschrieben. Vid. Refer. Dr. Garbowski's Zool. Centralbl. 1901. p. 120.

Zeitschrift f. wissensch. Zoologie. LXXXIII. Bd. 
zum 24 zelligen erscheinen sie, wie bereits erwähnt wurde, in derselben Lage und mehr oder weniger auch in derselben Gestalt jedesmal während der Übergangs- und Ruhestadien (vgl. Taf.XXVII, Fig. 4 u. 6).

Das zweite Quartett von Ectomeren. Von acht bis zwölf Zellen (Taf. XVIII, Fig. 7,8).

Bei mehreren Gasteropoden folgt in der Regel auf das Stadium von acht Zellen unmittelbar dasjenige von 16 Zellen, während das 12 zellige Stadium nur eine vortibergehende Erscheinung bildet. Bei Physa müssen wir nach zahlreichen Beobachtungen die Ausbildung eines 12 zelligen Rubestadiums als Regel, dagegen den direkten Übergang vom 8-16zelligen Stadium als Ausnahme betrachten. Unsre Fig. 7, 8 führen eben einen solchen Ausnahmsfall vor. Man sieht, daß die Abschnürung des zweiten Quartetts $2 \|-2 d$ kaum erfolgt, als das erste Quartett bereits Spindeln ausgebildet hat. Sonst finden wir dieses Quartett meistens in Ruhe zu einer Zeit, wo das zweite Quartett seine Kerne bereits rekonstruiert hat.

Die Zellen des zweiten sind kleiner als die Makromeren, jedoch bedeutend größer als die des ersten und werden in dexiotroper Richtung abgegeben ${ }^{1}$ (Fig. 7, 8).

Teilung des ersten Ectomerenquartetts von 12-16 Zellen. Taf. XVIII, Fig. 7-10.

Das 16 zellige Stadium wird durch die inäquale, läotrope Teilung des ersten Quartetts $(1 a-1 d)$ in $1 a^{1}, 1 a^{2}-1 d^{1}-1 d^{2}$ erreicht. Bald nach der Abtrennung der neuen Blastomeren bildet sich eine geräumige Furchungshöhle aus und es tritt eine längere Ruhepause ein, während welcher sich die nächsten Teilungen vorbereiten. Das Ei gewinnt während derselben abermals eine beinahe vollkommen kugelige Gestalt, die Außenwände der den Keim zusammensetzenden 16 Blastomeren scheinen eine ununterbrochene Kugeltï̈che zn konstituieren; ihre feinen Konturen werden nur bei entsprechender Beleuchtung erkannt. Am vegetativen Pole treten jetzt neben der Polarfurche die bereits oben erwähnten Ectosomen in sehr deutlichen Konturen und in ihrer charakteristischen Lage zum Vorschein.

Bevor wir zur Schilderung des weiteren Furchungsprozesses ubergehen, wollen wir noch auf die Bemerkung zurickkommen, welche wir bei Beschreibung der zweiten Teilung über die Art und Weise

${ }_{1}$ Nach dem Übergang in das Ruhestadium erscheinen auch hier in den Makromeren die schon erwähnten charakteristischen Ectosomen. 
der Signifikation der Makromeren gemacht haben. Wir haben nämlich dort gesagt, daß Holmes die Teilung des ersten Ectomerenquartetts bei Planorbis in unrichtiger Weise als dexiotrop anstatt läotrop aufgefaßt hat. Dieser Irrtum ist leicht zu entschuldigen, da die bei Beurteilung der Furchungsrichtung als maßgebend geltenden Prinzipien sehr oft irre leiten, wie dies jedermann an sich selbst erfahren haben mag. Ohne uns in eine nähere Auseinandersetzung dieser Prinzipien einlassen zu wollen, möchten wir an dieser Stelle bloß mit Nachdruck betonen, daß für uns neben der Richtung der Spindelachse besonders die Richtung maßgebend war, in welcher die Tochterzelle verschoben wird, was am besten erst während der Metakinese oder sogar nach vollzogener Teilung beurteilt werden kann, wie dies ConkLIN ('97) ganz zutreffend S. 59 hervorhebt. Nach diesen Anhaltspunkten haben wir uns auch im vorliegenden Falle gerichtet und halten unsre Auffassung der Teilungsrichtung im ersten Quartette für ganz korrekt.

\section{Das dritte Quartett von Ectomeren. Teilung des zweiten Quartetts. Von 16-24 Zellen (Taf. XVIII, Fig. 12-15).}

Es gelangen jetzt acht Zellen auf einmal zur Teilung; die vier Makromeren $2 A-2 D$ und die Ectomeren $2 a-2 d$. Die Teilung kann in zwei Modifikationen vor sich gehen: Entweder teilen sich zunächst bloß die Makromeren und es entsteht vorübergehend ein 20 zelliges Stadium, was als eine Ausnahme, oder aber teilen sich die genannten acht Zellen gleichzeitig, was als Regel gelten kann. Es wird auch im letzteren Fall die Synchronie nicht ganz genan eingehalten, da die Makromeren in der Regel sich bereits in der Metaphase befinden, bevor noch die Zellen des zweiten Quartetts ihre Spindeln ausgebildet haben. Trotz dieser Verspätung holen sie aber schließlich die Makromeren in der Teilung ein. Letztere ist in allen acht Zellen inäqual und läotrop. Der wichtigste Erfolg dieser Teilung ist die Abgabe des dritten und zugleich letzten Quartetts von Ectomeren.

Aus der Tatsache, daß die Abgabe des ersten Quartetts in lïotroper, die des zweiten in dexiotroper und des dritten wieder in läotroper Richtung erfolgt, ergibt sich eine Alternierung der Spirale, die für alle Gasteropoden charakteristisch ist.

Als seltene Ausnahme von dem soeben beschriebenen Teilungsmodus fand ich einen direkten Übergang vom 12zelligen Stadium zum 24 zelligen. Es bilden nämlich alle 12 Zellen fast gleichzeitig: die Spindeln aus, jedoch wird die definitive Teilung keineswegs auf 
ein Tempo rollzogen, sondern in kurzen Intervallen, so daß ohne Einschiebung eines distinkten Ruhestadiums ein 16, 20 und 24 zelliges Stadium schnell aufeinander folgen. Diese Modifikation ändert gar nichts an dem Endresultate, nämlich an der Art und Weise der Anordnung der 24 Blastomeren. Ihre Lagrebeziehungen bleiben dieselben. Nach vollzogener Teilung der beiden unteren Quartette haben nämlich die 24, nunmehr in sechs Etagen liegenden Zellen eine solche Stellung angenommen, daß jede von ihnen vom animalen Pole ans sichthar ist. Es ist dies die müglichst günstige Lage derselben sowolıl gregeneinander als auch gegen die Lmgehung.

Beim Übergang in das Ruhestadium ändert sich das Aussehen der Furchungshöble rollständig. Während sie kurz nach der letzten Teilung sehr geräumig war, beginnt sie jetzt bald anscheinend zu schwinden, in der Wirklichkeit aber wird sie in mehrere Spalträume zerlegt, indem seitens aller 24 Zellen lange Fortsätze nach dem C'entrum des Keimes ausgesandt werden, die insgesamt den centralen Gipfeln der vier Makromeren zustrelıen. Letztere sind die massivsten, besitzen eine stumpfkegelförmige Gestalt und lassen zwischen einauder keine freien Spalträume iil)rig. Die Makromeren repräsenttieren in diesem Zeitpunkte die Hauptreservoire der deutoplasmatischen Substanz, während die übrigen 20 Blastomeren bloß feinkürniges Plasma enthalten. Der Keim ist somit von der animalen Hälfte hell, von der regretativen dunkel. Sol,ald sich die erwähnten Furtsätze in der Mitte des Keimes begeguet hahen, wird ein merkwïrdiger I'rozeB eingeleitet. Die Ectosomen, welche his zu diesem Zeitpunkte ihre charakteristische Lage an den Seiten und Ecken der Polarfurche behauptet haben (Taf. XXVII, Fig. 6 ; und in allen bisherigen Geuerationen unmittelbar unter der Oberfläche zu sehen waren, verschwinden auf einmal und begimnen, wie dies aus den Fig. 7-11, Taf. XXVII, zu ersehen ist, ihre Wanderung von der Oberfliche gegen das Centrum des Keimes, und zwar in der Richtmor der Hauptachse. Alle Bilder sprechen für eine passive Verlagerung derselben. Man findet nämlich die Kïrnchengruppen an Schnitten naheliegender Phasen fast immer in derselben Form auf verschiedenen Etappen zwischen der vegetativen Oberfläche des Eies und der Spitze der vier centralen, von den Makromeren gebildeten Kegel (Taf. XXVII, Fig. 7-11). Der Transport der Kömchen scheint langsau vor sich zu gehen, da man sunst diese Geljilde nicht so oft zu Gesicht hek:ime. Sie erreichen die nach dem Eicentrum konvergierenden Spitzen der Makromerenkegrel fast gleichzeitig, scheinen somit ihren kurzen Weg mit glei- 
cher Geschwindigkeit zurïckzulegen, da man sie an verschiedenen Punkten jener Strecke mehr oder weniger zu gleicher Zeit findet. ${ }^{1}$. Am Endziele, d. i. an der Spitze der vier Makromerenkegel, angelangt, lassen sie sich hier ganz deutlich mittels aller kernfärbenden Stoffe nachweisen, jedoch nur während einer kurzen Zeit, denn alsbald verschwinden sie vollständig und definitiv. Offenbar gehen sie in eine andre Form über, höchstwahrscheinlich werden sie aufgelöst und auf einige oder alle Zellen des Keimes mittels deren zentripetaler Fortsätze verteilt. $\mathrm{Ob}$ auf alle oder bloß auf einige, konnte nicht entschieden werden, da sie sich nach ihrem Verschwinden nicht mehr durch Tinktionsmittel als distinkte Körnchen nachweisen ließen. Aus der Erscheinung, daß in dem Sammelpunkte der Fortsätze aller 24 Blastomeren ein stark vacuolisierter Raum Taf. XXVII, Fig. 11) entsteht, der wie es scheint, hauptsächlich aus den Endstiicken der von den acht centralen Zellen ausgehenden Fortsätze gebildet wird, ist zu folgern, daß jene Fortsätze wahrscheinlich die rätselhaften Einschlüsse in sich aufnehmen. So viel wenigstens an entsprechend tingierten Präparaten bemerkt werden konnte, färben sich die centralen Spitzen jener Zellen, besonders die massiveren Fortsätze der vier apicalen Zellen $1 a^{\prime}-1 d^{\prime}$ intensiv mit Fuchsin (Taf. XXVII, Fig. 10), ähnlich wie das Plasma tätiger Driisenzellen; man sieht ferner, daß nach Färbung mit Nethylenblau-Fuchsin diese Spitzen in einer bestimmten Phase einen blauen Ton annehmen, ebenso wie die verschwundenen Körnchen. Diese Bilder sprechen zugunsten der Ansicht, daß bloß einige Zellen und vorzüglich diejenigen des ersten Quartetts, welchen die wichtige Aufgabe der Erzeugung des ganzen Kreuzes obliegt, einen Stoff aufnehmen oder richtiger von den vier Makromeren übernehmen, der für ihre spätere Funktion von Belang ist. $O b$ es ein Nährstoff oder irgendein spezifischer Stoff ist, läßt sich schwer entscheiden, desgleichen ob er von den Makromeren bloß dargereicht oder g'egen einen andern ausgetauscht wird. Die tinktionellen Eigenschaften der in Rede stehenden Dotterelemente weisen darauf hin, daß wir hier mit einem ron den gewöhnlichen hellgelben Dotterkörnchen des Physa-Eies entschieden verschiedenen Stoffe zu tun haben, durch dessen Aufnahme bzw. Abgabe gewisse Zellen des 24 zelligen Stadiums sich qualitativ ändern,

1 An manchen Schnitten sieht man sie in Gestalt von Körnchenkugeln, an andern als unregelwäßige vom vegetativen $\mathrm{Pol}$ gegen das Centrum hinziehende Körnchenstreifen (Fig. 8). 
daß wir somit einen exquisiten Differenzierungsprozeß der Blastomeren vor uns haben.

Die oben beschriebenen Vorgänge liefern zugleich den Beweis, daß das 24-zellige Ruhestadium unter allen wohl das längste und in mancher Hinsicht sehr charakteristische, bloß in bezug auf den Furchungsprozeß als eine Ruhepause angesehen werden kann, denn vom physiologischen Standpunkte aus scheint es die Phase einer gesteigerten Tätigkeit aller Zellen zu sein. Als Resultat der letzteren kaun nicht nur die erwähnte Differenzierung der Ento- und Ectomeren, sondern auch diejenige der Urmesodermzelle $3 D$ angesehen werden. Diese Zelle zeichnet sich nämlich sehr bald durch ihre Vorwölbung am vegetativen Pole unter den übrigen drei Makromeren aus, desgleichen an Schnitten durch ihren sehr massiven, stumpfkegelförmigen centralen Fortsatz, der ron Fortsätzen der Ectomeren umgeben wird (Taf. XXVII, Fig. 10. Von einer strengen Sonderung der drei Keimblätter ist auf diesem Stadium noch keine Rede, indem - wie wir an entsprechenden Stellen Gelegenheit haben werden zu zeigen sowohl die sogenannte Urmesodermzelle als mehrere andre Zellen noch fremdes Material mitfuhren, dessen sie sich erst bedeutend später entledigen. Für die regen Wechselbeziehungen unter den Zellen sprechen außer den beschriebenen Vorgängen die außerordentlich zarten, plasmatischen, die Blastomeren miteinander verbindenden Briicken, die besonders in diesem Stadium an Präparaten, die in Flemmixg'scher Mischung oder in Sublimat fixiert waren, mit großer Deutlichkeit wahrzunehmen sind. Auch an späteren Stadien ist aus den zahlreichen stärkeren und zarteren Verbindungsbahnen, die zwischen einzelnen Blastomeren und ganzen Zellengruppen für lïngere oder kürzere Dauer hergestellt werden, zu schließen, daß ein reger Verkehr zwischen den Teilen des Keimes stattfindet.

\section{Allgemeines tiber die Ectosomen.}

Um mit den Ectosomen gleich hier abzuschließen, müssen wir denselben noch einige rergleichende Beobachtungen widmen.

Ähnliche Gebilde sind bereits in andern Tiergruppen beobachtet worden. Jexnings ('96) beschreibt bei Asplanchna distinkte sphärische Körnchen, welche am Stadium von acht Zellen noch unregelmäßig im Dotter einer einzigen Zelle $d^{t .1}$ (unsre $1 D$, zerstreut liegen, später aber bei jeder Teilung auf der freien ventralen Oberfläche der Mutterzelle sich konzentrieren. Erst kurz nach Erreichung des 32-zelligen Stadiums, in welcher Phase die siebente Teilung von $d$ stattfindet, 
beginnt ihre Wanderung von der ventralen vorderen nach der dorsalen hinteren Fläche der Zelle $d^{7.1}$. Das Endziel dieser Wanderung wird bald bei der achten Teilung dieser Zelle erreicht, wobei die von diesem Autor als »clouds of granules « bezeichneten Körnchengruppen in die kleinere Descendentin $d^{8.2}$ heriberwandern und anfangs einen äquatoriellen Ring um den Kern derselben bilden, sich aber bald in zwei polständige Gruppen auflösen. Diese Zelle wird von Jennings als die Entodermzelle betrachtet.

Die weiteren Schicksale der »clouds of granules s sind Jennings unbekannt geblieben, desgleichen wird über ihre Abkunft keine Angabe gemacht, außer daß sie als Konzentrationen im Dotter ent- stehen. Ihre Bedeutung für den Furchungsprozeß liegt nach Jennings in dem handgreiflichen Differenzierungsvorgang in den sie einschließenden Zellen.

Mit den Körnchengruppen von Asplanchna können nach HäCKEk die von ihm als "Ectosomen « bei Cyclops beschriebenen Gebilde verglichen werden. Es sind dies zahlreiche, rundliche, verschieden große Körnchen, welche »jeweils um den einen Pol der zur Keimbahn gehörigen Teilungsfigur geschart sind und eine große Affinität zu roten Farbstoffen bekunden, während die Chromosomen blaue Farbstoffe aufnehmen «.

Sie erscheinen zum erstenmal im Asterstadium der ersten Furchungsteilung an der Basis der einen Sphäre, verteilen sich darauf außerhalb derselben in ihrem ganzen Umkreise und verbleiben hier noch während des Diasterstadiums. Nach der Neubildung der Tochterkerne treten an ihre Stelle einige größere Brocken auf, welche in der Nachbarschaft der Kerne zwischen den Dotterschollen eingebettet sind. Während der Ruhestadien verschwinden die Brocken vollständig.

Ganz dieselbe Erscheinung wiederholt sich an allen späteren Stadien bei der Teilung der Keimbahnzellen, und erst bei den zwei letzten Teilungen, aus denen die primäre Urgenitalzelle und die beiden definitiven Urgenitalzellen hervorgehen, ändert sich das Bild insofern, als die Ectosomen, nicht wie in allen vorhergehenden Teilungen, um den einen Spindelpol geschart, sondern im ganzen Umkreis der Teilungsfigur im Cytoplasma verbreitet sind.

HäcKER faßt die Eetosomen als Abkömmlinge der Nucleolen auf und dementsprechend die Vorgänge in den Keimbahnzellen als Ausdruck einer eigentiumlichen Differenzierung ibrer Kerne, deren Chromatinsubstanz andre Qualitäten als die der ührigen Kerne besitzt. 
Diese Auffassung fubrt zur Annahme seines besonderen Kermplasmas der Keimbahnzellen und einer durch äußerliche Vorgäinge nachweisbaren Kontinuität des Keimplasmas«.

Auf die Erklärung Ḧ̈скERs der einseitigen Lagerung der Ectosomen im Umkreis der einen Sphäre wollen wir hier nicht näher eingehen und verweisen auf die diesbeziiglichen Ausfuhrungen desselben S. 237-238.

Die Ectosomen von Physa sind denjenigen von C'yclops eben nur in bezug auf diese einseitige Lagerung im Umkreis der einen Sphäre ähnlich, weshalb wir für dieselben die Bezeichnung HäcKERs adoptiert haben. Sie unterscheiden sich sonst von den letzteren in mehrfacher Beziehung. Wie aus Fig. 1, Taf. XXVII, zu erseher ist, liegen sie im Asterstadium nicht an der Basis der Sphäre wie bei C!yclops, sondern außerhalb derselben im Dotter eingebettet, dagegen sind sie während der Neubildung der Tochterkerne in der Spluäre selbst gruppiert (Fig. 5). Ferner verschwinden sie während der Ruhestadien der Kerne nie vollständig, sondern treten im Gegenteil sehr deutlich hervor (Fig. 6). Schließlich zeigen sie eine Neigung zur Aufnahme und Festhaltung blauer Farbstoffe wie die Chromosomen Methylenblau, Hämatoxylin, Eisenhämatoxylin und nicht wie diejenigen von Cyclops zur Aufnahme von roten Farbstoffen. Mit Rücksicht auf diese letztere Eigenschaft diirften sie also eher als $\mathrm{A}$ hkömmlinge des Chromatius als diejenigen der Nucleolen angesehen werden.

Wenn also zwischen den Ectosomen ron Cyclops und Physa eine äußerliche $\ddot{A}$ bnlichkeit nicht zu verkennen ist, so scheinen es doch spezifisch andre Gebilde zu sein, worauf auch ihre ganz verschiedenen Endschicksale hinweisen. Bei Cyclops gehen sie nämlich, wie bereits erwähnt wurde, in den Lrgenitalzellen, bei Physa in den Ectodermzellen auf. Sehr charakteristisch für die Ectosomen der letzteren Form ist der Umstand, daß sie in den Entodermzellen, bzw. der Entomesomere nur so lange verbleiben lis das dritte Quartett von Ectomeren abgegeben worden ist. Erst jetyt folgt gleichsam der Schlußakt der Differenzierung des Entomesoderms, die in der Entfernung eines überflissigen Stoffes sich kund gibt. Auch bei Asplancha ist es die Mutterzelle des Entoderms, welche schließlich die sclouds of granules * aufnimmt, deren Endschicksale jedoch unbekannt sind.

Es ist nicht ausgeschlossen, daß es sich in beiden Fällen nur um eine besondere Erscheinung des Stoffwechsels handelt. Zurzeit 
können wir freilich iaber das Wesen der Körnchengruppen nichts Positives aussagen.

Es mag noch zum Schluß hinzugefiugt werden, daß die bei Physa fontinalis beobachteten Vorgänge sich genau in derselben Weise bei Physa hypnomum abspielen, woraus gefolgert werden darf, daß die Erscheinung der Körnchengruppen unter den Gasteropoden verbreitet ist. Vielleicht gehören in dieselbe Kategorie die von Blochmann bei Neritina beobachteten, stark lichtbrechenden Körnchen, welche bereits in den beiden ersten Furchungszellen erkennbar sind und bis zu ihrem Übergang in die Velarzellen verfolgt werden konnten. In der Arbeit FujITAs ('04), die ich soeben erhielt, finde ich in den Fig. 8-14, welche das 4-16zellige Furchungsstadinm von Siphonaria lepida darstellen, an dem vegetativen Pole je vier an der Polarfurche liegende Körper eingezeichnet, über welche leider weder der Text noch die Tafelerklärung irgend einen Aufschluß gibt. Nach der Lage und den charakteristischen Umrissen dieser Gebilde zu schließen, glaube ich ganz bestimmt annehmen zu können, daß sie unsern Ectosomen vollkommen identische Gebilde sind. Ist dies tatsächlich der Fall, alsdann findet unsre obige Vermutung, betreffend die Verbreitung der Ectosomen im Molluskenkreise eine neue Stuitze. Es ist auch höchst wahrscheinlich, daß schon FoL (1880) die Ectosomen bei Planorbis marginatus beobachtet hat, denn er bemerkt S. 115, daß am 16-zelligen Stadium sich das reichliche Pigment des Eies an der Oberfläche der vier Makromeren ansammelt, um sich bei der weiteren Furchung aufzulösen.

\section{Von 24-29 Zellen. Teilung von $2 a^{\prime}-2 d^{\prime}$ und $3 D$}

(Taf. XVIII, Fig. 16).

Die nächste nach der Ruhepause folgende Teilung betrifft die Zellen $2 a^{\prime}-2 d^{\prime}$ und ist inäqual und dexiotrop. Die kleineren oberen Descendenten $2 a^{\prime \prime}-2 d^{\prime \prime}$ kommen hinter die Polzellen $1 a^{\prime}-1 d^{\prime}$ in die Liicken zwischen je zwei Tochterzellen des 1. Quartetts $1 a^{2}-1 d^{2}$ zu liegen (Fig. 16). Sie sind zu jener Zeit die kleinsten Zellen im Keime, die zugleich durch ihr helles Plasma auffallen. Es mag schon an dieser Stelle hervorgehoben werden, daß sie bemerkenswerterweise bis in die späten Larvenstadien ungeteilt bleiben. Da sie nachher an den Enden der Arme des aus den vier Apicalzellen des 1. Quartetts $\left(1 a^{\prime}-1 d^{\prime}\right)$ sich aufbauenden Kreuzes liegen, so werden sie als •Endzellen* des Kreuzes oder viel häufiger mit dem englischen Terminus "tip-cells" bezeichnet. Die andern Descendenten 
$2 a^{12}-2 d^{12}$ nehmen indessen an der Ausbildung des Kreuzes gar keinen Anteil.

Während die geschilderte Teilung im Gange ist, sieht man die Makromere $3 D$ sich ebenfalls zur Teilung anschicken. Als Mutterzelle des Urmesoderms macht sie sich, wie erwähnt, schon im Stadium ron 24 Zellen durch ihren sehr stark ausgebildeten Centralfortsatz, sowie durch die Herrorwölbung über das Niveau der drei ibrigen Makromeren leicht kenntlich. Jetzt zieht sie sich kugelig zusammen, wölbt sich noch stärker über das Niveau des Keimes hervor und bildet eine Spindel aus. Ihre Teilung wird aber erst in der nachfolgenden und nur ausuahmsweise in dieser Phase durchgefiihrt, so daß ein Stadium mit 29 Zellen zu selteneren Ausnahmen gehört.

\section{Von 28-33 Zellen (Taf. XVIII, Fig. 16-19).}

Bereits während der Teilung der oberen Zellen des 2. Quartetts bereiten sich schon die unteren nämlich $2 a^{2}-2 d^{2}$ zur Teilung und und legen Spindeln an, die anfangs beinahe rertikal liegen, später erst nach links geneigt erscheinen. Die Teilung ist inäqual und lïotrop, indem die verhältnismäßig sehr kleinen Tochterzellen $2 \alpha^{2: 2}$ $-2 d^{22}$ nach dem vegetativen Pole zu abgeschnirt werden und jede derselben sich später an die korrespondierende Makmore anlehnt, dieselbe halbmondförmig umfassend. Diese Zellen verdienen insofern unsre Aufmerksamkeit, als sie ähnlich den Endzellen des Kreuzes sehr lange ungeteilt bleiben, unterscheiden sich jedoch ron den letzteren dadurch, daß sie sich doch bei etwa 72 \%ellen teilen und zwar in einzelnen Quadranten in verschiedener Weise, worauf wir noch später zu sprechen kommen.

Beror noch die soeben beschriebene Teilung zu Ende kommt, geht die Makromere, ron der schon im früheren Absatz die Rede war, in Teilung iber. Diese ist (iihnlich wie bei Planorlis) im hohen Grade inäqual und dexiotrop. Die kleine Tochterzelle, welche fast genau an den regetativen Pol zu liegen kommt, wird trotz ihrer geringen Größe als Makromere $(4 D)$ bezeichnet, wobei der Umstand entscheidet, daß sie von nun an als reine Entodermzelle mit den übrigen Entodermzellen $3 A-3 C$ ) die regetative, entodermale P'olrosette bildet, während die große Tochterzelle $4 d$ zum Urmesoderm wird.

Die Furchungshïhle ist in diesem Stadium verhältnismäßig klein und spaltförmig. 
Teilung des dritten Quartetts $3 a-3 d$ und der Apicalzellen $1 a^{\prime}-1 d^{\prime}$. Von 33-41 Zellen (Taf. XVIII u. XIX, Fig. 18-22).

Am Übergange vom 33 - bis zum 41 - oder 44 -zelligen Stadium kommen in den betreffenden Zwischenstadien alle möglichen Kombinationen vor, so daß man genötigt ist recht viele Skizzen zu entwerfen, um sich in den verschiedenen Kombinationen der Teilung gehörig orientieren zu können. Die Ausbildung der Spindeln in einzelnen von den acht in Teilung begriffenen Zellen beginnt schon oft vor Erreichung des 33-zelligen Stadiums, welehes somit keineswegs als ein distinktes Ruhestadium angesprochen werden darf. Die frühzeitig angedeutete Teilung schreitet in den genannten Quartetten in ziemlich raschem Tempo fort und ist in jedem derselben inäqual, jene des I. Quartettes beginnt gewöhnlich früher als die des III. Es resultieren aus der Teilung des ersteren vier kleine Zellen $\left(1 a^{1.1}-1 d^{1,1}\right)$, die am Apicalpole verbleiben und die wir bei der weiteren Darstellung des Furchungsprozesses unter dem Namen „Apicalzellen " anführen werden. Die Abschnuirung derselben erfolgt in lïotroper Richtung; am spätesten teilt sich $1 d^{1}$. Die Mutterzellen $1 a^{1.2}-1 d^{1.2}$, welche jetzt die Mittelstellung zwischen den Apicalzellen und den Tipzellen einnehmen, werden wir von nun an als "Basalzellen « des Kreuzes ansprechen. Die Kreuzfigur tritt in dieser Entwicklungsphase schon sehr deutlich bervor und ist sehr symmetrisch, wie ïberhaupt der ganze Keim zu dieser Zeit eine sehr hübsche radiale Symmetrie zur Schau trägt (Fig. 21).

Die vier großen Zellen des dritten Quartetts $(3 a-3 d)$ teilen sich ebenfalls inäqual, aber sonderbarerweise ganz discordant; sie schnüren nämlich ihre kleineren Tochterzellen nach verschiedenen Polen ab. Die beiden vorderen Quadranten $3 a, 3 b$ teilen sich läotrop, die größeren Mutterzellen verbleiben am vegetativen Pole, während die kleineren Tochterzellen $3 a^{1}, 3 b^{1}$ nach dem animalen geschoben werden; dagegen teilen sich die beiden hinteren Quadranten $3 c, 3 d$ in dexiotroper Richtung und ihre Tochterzellen $3 c^{2}, 3 d^{2}$ bleiben an der vegetativen Seite des Keimes, während sie selbst an die animale zu stehen kommen. Betrachtet man nach vollzogener Teilung dieser vier Zellen den Keim vom vegetativen Pole, so sieht man, daß die untere Etage des jetzt aus acht Zellen bestehenden dritten Quartetts, nämlich die Zellen $3 a^{2}-3 d^{2}$ nur paarweise einander gleich sind (zwei größere, zwei kleinere); dasselbe Verhältnis sieht man vom animalen Pole an den Zellen der oberen Etage dieses 
Quartetts (Fig. 22, 23). Wir haben diese auffallende Discordanz in der Teilung aus dem Grunde hervorgehoben, weil sie mit der späteren Rolle dieser Zellen im Einklang steht. Namentlich sind die Zellen $3 \iota^{2}, 3 \iota^{2}$ Anlagen des sekundären Mesoderms, während die Zellen $3 c^{1}$ und $3 d^{1}$ einen Teil des Ectoderms zu bilden haben. Schließlich wäre noch zu bemerken, daß infolge der soeben beschriebenen ungleichen Verteilung der Descendenten des dritten Quartett\$ die Polarachse sich etwas nach vorn zu neigen beginnt.

Teilung der Makromeren (Entomeren) $3 d-3 C$. Von $41-44$ Zellen (Taf. XIX, Fig. 23).

Bekanntlich hat sich die Makromere $3 I$ bereits am Stadium ron 33 Zellen im hohen Grade inäqual geteilt. Wie erinnerlich, wurde die polständige Mikromere $(4 D)$ als Makromere aufgefaßt. Die Teilung der ubrigen drei Makromeren $3 A-3 C$ wird in derselben Weise jedoch in läotroper Richtung vollzogen, jede zerfällt nämlich in eine Mikromere und eine Makromere; die ersteren rerbleiben am vegetativen Pole, bilden daselbst nit $4 D$ die Polrosette und werden ebenfalls als Makromeren $(4 A-4 c)$ bezeichnet, wogegen sich die eigentlichen Jakromeren $4 a-4 c$ ron diesem Pole entfernen. Die aus der Teilung hervorgegangenen sieben Zellen bilden zusammen mit $3 I$ die Entodermplatte, welche sowohl durch ihre Lage im Centrum des regetatiren Poles, als durch die Iudurchsichtigkeit und den hellgrelben Ton der sie zusammensetzenden Zellen von der Lmgebung alssticht. Die apicale Rosette oder die sogenannten Makromeren werden aber alsbald unkenntlich, indem sie lange Fortsätze nach der Furchungshöhle aussenden und bloß ein Teil ihres Plasmas an der Keimolerfläche sichtbar ist. Sie erscheinen demnach sehr abgeflacht, ilıre Grenzen sind rerwischt, so daß sie sehr leicht uihersehen werden künnen.

Von 44-52 Zellen (Taf. XVIII, Fig. 26, 27).

Teilungr der Zellen des ersten (Zuartetts (Trochol)lasten): $1 a^{2}$, $1 b^{2}$, des zweiten Quartetts $2 a^{1.2}-2 d^{1.2}$ und $2 d^{2.1}$, sowie der Lrmesodermzelle $4 d$.

Von den sieben obengenannten Ectomeren heginnen zunächst diejenigen des ersten Quartetts sich zu teilen. Es sind die vorderen Trochoblasten $1 a^{2}$ und $1 b^{2}$; ihre Spindeln liegen fast genau meridional, die Teilung erfolgt in einer zum Meridian senkrechten Richtung und ist ungefähr aqual Fig. 26\%. Die vier Descendenten 
wachsen in der Folge sehr schnell, ihr ganzes Plasma konzentriert sich in langen centripetalen Fortsätzen, an der Oberfläche bleibt nur eine dünne Schicht mit einem unbeträchtlichen Plasmahofe um den Kern. Infolgedessen zeichnen sie sich durch eine auffallende Durchsichtigkeit aus, und da sie keiner weiteren Teilung bis in die spätesten Furchungsstadien unterliegen, so liefern sie sehr bequeme und sichere Orientierungspunkte. Es sind dies außerdem die am meisten plastischen Zellen, welche, ohne sich zu teilen, sich den stets zunehmenden Dimensionen der betreffenden Keimbezirke aupassen.

Gleichzeitig mit der soeben beschriebenen, beginnt auch die Teilung im zweiten Quartett und zwar zunächst in den vier Zellen $2 a^{1.2}-2 d^{1.2 *}$. Ein Blick auf die Fig. 26, 28 belehrt, daß dieselbeu symmetrisch hinter ihren Schwesterzellen, d. i. den Tipzellen liegen. Ihre Spindeln sind dexiotrop orientiert, die Teilung ist inäqual, die oberen Tochterzellen $2 a^{1.2 .1}-2 d^{1.2 .1}$ sind kleiner als die unteren. Bei der Auffassung dieser Teilungsrichtung als dexiotrop werden die unteren Zellen $2 a^{122}-2 d^{122}$ wegen ihres beträchtlicheren Umfangs als Mutterzellen angesehen und rornehmlich der Umstand beachtet, daß im Moment der Teilung die Tipzellen durch die Tochterzellen nach rechts abgedrängt werden. Jedenfalls aber müssen wir bemerken, daß nach der definitiven Einstellung der geteilten Zellen schwer zu entscheiden wäre, wie die Teilungsspindeln eigentlich orientiert waren, da man in einzelnen Quadranten die Descendenten bald in dexiotroper bald in läotroper Richtung oder aber genau iubereinander gelagert findet.

Die Urmesodermzelle, welche schon am 44-zelligen Stadium stark vorgebuchtet war und etwa am Stadium von 46 Zellen eine horizontal orientierte Spindel ausgebildet hat, teilt sich fast gleichzeitig mit den Zellen des zweiten Quartetts vollkommen äqual und bilateral Fig. 27, 29). Wir bezeichnen die Tochterzellen mit $M_{1}, M_{2}$. Sie verbleiben noch längere Zeit durch den Zwischenkörper miteinander verbunden, sind anfangs beinahe kugelig, ziehen sich aber bald in die Länge und versinken mit einem Teile ihres Leibes in die Furchungshöhle.

Während die besprochenen Teilungen vor sich gehen, schicken sich auch einige Zellen des dritten Quartetts zur Teilung an, desgleichen die Zelle $2 d^{2.1}$, während an die zu derselben Etage gehörenden Zellen $2 a^{2} \cdot 1-2 c^{2} \cdot 1$ erst bedeutend später die Reihe kommt.

* $2 d^{12}$ teilt sich zuerst (in 4 Fällen beobachtet), es bildet sogar noch am Stadium von 41 Zellen eine Spindel aus. 
Die kleinere Tochterzelle $2 d^{2.1}{ }^{1}$ wird nach links abgeschntirt, eigentlich rein äquatorial. Wie erinnerlich hat in der Serie $2 a^{12}-2 d^{12}$ die letztere auch die Teilung zuerst begonnen. Diese frihzeitige Teilung des Quadranten $d$ steht gewiß in inniger Beziehung zur gleichzeitigen Teilung der Urmesodermzelle.

$$
\text { Von 52-69 Zellen (Taf. XIX, Fig. 29-35). }
$$

Teilung der drei Zellen des zweiten Quartetts $2 a^{2.1}-2 c^{2.1}$. der sechs Zellen des dritten Quartetts $3 a^{2}-3 d^{2}$ und $3 a^{2}, 3 b^{2}$, der drei Entodermzellen $4 a-4 c$, der drei Basalzellen des Kreuzes $1 a^{1.2}-1 c^{1.2}$, schließlich der beiden Urmesodermzellen $M_{1}, M_{2}$, zusammen 17 Zellen.)

Das Stadium von 52 Zellen ist keineswegs als ein irgendwie charakterisiertes Ruhestadium zu bezeichnen, wir haben es bloß als eine Phase gewählt, in der die Furchungen mehrerer Zcllen gleichzeitig vollzogen werden, - heben aber nachdruicklich hervor, daß nach ihrem Abschlusse kein Ruhestadium folgt, im Gegenteil bereiten sich mehrere andre Zellen zur Teilung vor - ein Beweis, daß die Furchung bereits in einem sehr raschen Tempo fortzuschreiten begonnen hat. Wir ersehen nämlich aus der oben gegebenen Übersicht der in Teilung begriffenen Zellen, daß ihrer auf einmal 17 an die Reihe kommen. Zwar erfolgt ihre definitive Teilung nicht synchron, sondern in größeren oder kleinen Intervallen, wobei aber zu bemerken ist, daß eine strenge zeitliche Aufeinanderfolge der Teilungen nicht eingehalten wird, weshalb auch die Ordnung, in der wir dieselben darstellen, nur annähernd bestimmt werden konnte, zumal anch indiriduelle Schwankungen vorkommen. Es leuchtet somit ein, daß man auf so vorgeriickten Stadien die Zusammenstellung von Keimen mit gleicher Zellenzahl auf große Schwierigkeiten stößt, welche nur bei genauer Beobachtung der Teilungsakte sellsst iberwunden werden können. Vor allem teilen sich die drei Zellen des zweiten Quartetts $2 a^{2.1}-2 c^{2.1}$ in spirallikotroper Richtung (Fig. 30). Bei Bestimmung dieser Richtung diente uns die definitive Lage der kleineren Tochterzellen und ihr Verhalten gegen die angrenzenden Tipzellen zur Richtschnur. Nachdem diese Teilnngen sich in den drei obengenannten Quadranten vollzogen haljen, besteht das zweite Quartett aus 24 Zellen, welche in den einzelnen Quadranten in je vier Etagen so rerteilt sind, daß in der obersten die Tipzelle des Kreuzes, in den zwei nächstfolgenden unteren je ein Paar und zu unterst wieder je eine Zelle liegen; drei von den untersten schließen sich den Entodermzellen, die vierte $\left(2, d^{2,2}\right)$ dem Yesoderm an. 
Von der Seite gesehen präsentieren sich die Zellgruppen dieses Quartetts als im Äquator verbreitete und gegen die Pole hin zugespitzte Streifen, welche die Kreuzarme mit dem Entoderm und Mesoderm verbinden (Fig. 32).

Die Teilung der sechs obengenannten Zellen des dritten Quartetts findet in verschiedenen Zeitpunkten und bei wechselnder Zellenzahl statt. Zunächst teilen sich bloß die vier Zellen: $3 a^{2}, 3 b^{2}, 3 c^{1}$, $3 d^{1}$ (Fig. 29), welche bereits auf dem Stadium von etwa 48 Zellen einzelnweise die Teilungsspindeln auszubilden begonnen haben, doch wird die Teilung erst am Stadium von 57 Zellen in allen vieren rollzogen (Fig. 31). Dieselbe ist äqual und bilateral, die acht Descendenten $\left(3 a^{21}, 3 a^{22}, 3 b^{21}, 3 b^{22}, 3 c^{11}, 3 c^{12}, 3 d^{11}, 3 d^{12}\right)$ liegen nach der Teilung nebeneinander, die der Quadranten $a$ und $b$ am regetativen Pole, diejenigen der Quadranten $c$ und $d$ am animalen. Die zwei Zellen $3 a^{1}, 3 b^{1}$ teilen sich ebenfalls in ungleichen Terminen, bald schon am Stadium von 64 Zellen, bald erst kurz vor Erreichung des 69zelligen Stadiums (Fig. 35). Ihr mitotischer Zustand dauert nur ganz kurz, weshalb es einige Miihe kostet sie auf der Teilung zu ertappen. Sie ist bilateral und äqual, ebenso wie die Teilung der unter ihnen liegenden Zellen desselben Quartetts. Das dritte Quartett ist nach den beschriebenen Teilungen sehr symmetrisch zusammengesetzt, enthält nämlich in den vorderen Quadranten acht, in den hinteren sechs, im ganzen somit 14 Zellen. Die beiden hinteren Quadranten zählen deshalb um zwei Zellen weniger als die rorderen, weil ihre untersten Glieder $3 c^{2}$ und $3 d^{2}$ ungeteilt geblieben sind und noch lange in Ruhe zu verbleiben haben.

Die drei Entomeren bereiten sich schon auf einem Stadium von etwa 55 Zellen zur Teilung. Bald ist es die rechte, bald die linke, bald die rordere, in der man zuerst eine Spindel ertolickt, seltener in allen dreien zugleich (Fig. 31, 33). Vor der Ausbildung der Teilungsspindeln erhebt sich jede derselben iiber das allgemeine Xireau des Keimes, infolgedessen wird während des ganzen Teilungsprozesses die Furchungshöhle bedeutend vergrößert. Die Spindeln sind in verschiedenen etwas läotropen Richtungen unmittelbar nach ihrem Entstehen orientirt, die einzelnen Zellen werden zwar aus ihrer früheren Lage abgedrängt, trotzdem erfolgt die Teilung ganz harmonisch äqual und bilateral. Die neu gebildeten sechs Zellen bilden in einer bestimmten Phase samt den zwei Urmesodermzellen einen achtzelligen Kranz um die vier Polzellen (Makromeren). Anfänglich sind sie noch abgerundet und stark vorgebuchtet, sehr bald 
aber gewimnen sie eckige Konturen und die freien Flächen werden kleiner, da sie mit der Hauptmasse ihres Plasmas in die Furchungshöhle versunken sind (Fig. 36).

Die Teilung der diei Basalzellen des Kreuzes $1 a^{1 \cdot 2}-1 c^{1 \cdot 2}$ ist in hohem Grade inäiqual und leicht läotrop Fig. 30, 32, 35), eigentlich ist sie radial, da die beiden Descendenten in derselben Ebene verbleiben und sich hintereinander stellen. Erwähnenswert ist der Umstand, daß die streifenförmigen kleineren Descendenten $1 a^{122}-1 e^{122}$, welehe zwischen ihre Mutterzellen und die Tipzellen eingezwängt erscheinen, während der ganzen Entwicklung ungeteilt verbleiben. Sie werden als die äußeren Mittelzellen bezeichnet. Merkwürdig verspätet sich die Teilung der Basalzelle im hinteren Arme $1 d^{1 \cdot 2}$ und ist, wie wir ans Fig. 39 ersehen, fast aiqual. Dak Kreuz ist auf dieser Entricklungsphase aus vier Basalzellen, drei Mittelzellen, vier Tipzellen und vier Apicalzellen zusammengesetzt. Zwischen seinen Armen liegen nach rorn beiderseits des Armes $b$ die vier Trochoblasten, nach hinten je eine Zelle beiderseits des Armes $d$. Alle diese sechs Zellen zeichnen sich sowohl durch ihre sehr bedeutende Größe als auch durch ihre Durchsichtigkeit aus (Fig. 32).

Die Urmesodermzellen, welche bereits am 64-zelligen Stadium die Teilungsspindeln in schief nach den Polen convergenter Richtung auszubilden beginnen (Fig. 34, teilen sich diesmal sehr inäqual. indem sie ihre verhältnismäßig sehr kleinen Descendenten $\left(m_{1}, m_{1}\right.$, Fig. 36) gegen den regetativen Pol genal unter die Makromere 4 I abschnitren. Da sich diese kleinen Zellen bald abflachen und zum großen Teil ron $4 L$ iberlagert werden, so lassen sie sich nur an sehr gelungenen Präparaten auffinden. Der Keim brancht zur Erreichung der soeben beschriebenen Zellenzahl ctwa 70 Stunden sehr viel Zeit nimmt in der Phase ron 58--69 Zellen die Abfurchung. der drei Entodermzellen in Anspruch.

Bevor wir uns der Schilderung von weiteren Teilungsvorgängen zuwenden, wollen wir auf die Symmetrie des Keimes, wie sie anf dem erreichten Stadium von 69 Zellen zutage tritt, in Betracht ziehen. Auf der animalen Eilä̈lfte füllt vor allem die für Mollusken und Anneliden so charakteristische Kreuzfigur auf (Fig. 32), deren Zusammensetzung wir bereits kennen, auf der vegetativen bemerkt man eine überraschend ähnliche Gruppierung der Zellen (Fig. 33, 36). namentlich fällt die aus den Makromeren zisammengesetzte Polrosette auf, welche den Apicalzellen des Kreuzes entspricht. Die parig. in den Hauptradien gruppierten Ento- und Mesomeren ent- 
sprechen ihrer Lage und ihrem Verbältnisse zu den Polzellen nach den Basal- und Medianzellen des Kreuzes. Ihre Teilung war jedoch bilateral, während die der korrespondierenden Kreuzarme radial ist und erst später in bilaterale übergeht. Der daraus resultierende Unterschied besteht darin, daß jene vegetativen Zellen sich eng aneinander anschließen, während die radial geteilten Kreuzarme freie Interradialräume zwischen sich lassen.

An die Basalzellen der Kreuzarme reihen sich zunächst je eine Mittelzelle (den Arm $d$ ausgenommen) und nach ihnen je eine den Kreuzarm abschließende Zelle des zweiten Quartetts an. Diesen Endzellen der Kreuzarme entsprechen an der vegetativen Eihälfte in ganz analoger Weise gelagerte Zellen, die ebenfalls dem zweiten Quartette angehören (d. i. $2 a^{22}-2^{22}$ ) und wie die ersteren bis in schr späte Entwicklungsstadien ungeteilt bleiben. Zwischen den Kreuzarmen des animalen Poles liegen ebenso sechs Zellen, wie an der vegetativen Eihälfte und zwar in der nämlichen Anordnung, d. i. zu beiden Seiten des vorderen Armes je zwei, zu beiden Seiten des hinteren je eine, nämlich die Zellen $1 c^{2}, 1 d^{2}$ an der animalen, und $3 c^{2}, 3 d^{2}$ an der vegetativen Kreuzfigur. Die Armenden der beiden Kreuze werden miteinander durch je vier am Äquator des Keimes gelegene Zellen des zweiten Quartetts verbunden. Die obengenannten zwischen den Kreuzarmen liegenden Zellen werden dagegen durch zwei im Äquator gelegene Zellenpaare des dritten Quartetts verbunden.

Somit läßt sich die gesamte Oberfläche des Keimes sowohl in der Richtung der animalen und vegetativen Kreuzarme, als auch durch Meridiane, die man sich in den Interradien denken würde, in vier Quadranten zerlegen. Dabei kommt auch die bilaterale Symmetrie in der Keimanlage besonders zum Ausdruck, indem an den beiden Eihälften die Zusammensetzung der vorderen und hinteren Interradien miteinander harmonisiert, während der in beiden Kreuzfiguren abweichend gestaltete hintere Arm $d$ in die Medianebene des Keimes zu liegen kommt und auf der vegetativen Seite sowohl die Urmesodermzellen als auch die Anlagen des sekundären Mesoderms und die Entodermzellen bilateral verteilt erscheinen.

Diese für das Verständnis des weiteren Ausbaues der Keimanlage wichtigen Lagerungsverhältnisse werden übrigens an andern Stellen unsrer Darstellung zur Sprache kommen. 
Von $69-82$ Zellen (Taf. XIX n. XX, Fig. 33-40).

Nach einer kaum angedeuteten Ruhepause, während welcher die Furchungshöhle durch lange Fortsätze der meisten Zellen bis auf enge Spalträume reduziert wird, beginnen wieder viele Zellen beiläufig zu gleicher Zeit ibre Teilung. Die vier Zellen des sekundären Mesoderms $3 a^{2 \cdot 1}, 3 a^{2 \cdot 2}$ und $3 b^{2 \cdot 1}, 3 b^{2 \cdot 2}$ (Fig. 36), ziehen schon am Stadium von etwa 70 Zellen ihre langen Fortsätze aus der Furchungshöhle zurtick, runden sich ab, wölben sich tiber das Niveau der Nachbarzellen vor und erzeugen in schiefer, nach dem vegetativen $\mathrm{Pol}$ convergierenden Richtung winzige Zellen, welche nach vollzogener Teilung sich den nächstliegenden vier Entodermzellen eng anschließen und dieselben halbmondförmig umfassen (Fig. 38). Diese vier kleinen Zellen (Mikromeren des sekundären Mesoderms) sind auffallend reich an Chromatin.

Fast gleichzeitig teilen sich an der animalen Eibälfte die sogenannten hinteren Trochoblasten $1 c^{2}$ und $1 d^{2}$ ungefähr äqual; ihre Teilungsspindeln sind meridional orientirt nach Art derjenigen bei der Teilung der vorderen Trochoblasten; die Descendenten kommen ebenfalls hintereinander (in den Interradialstrahlen des Kreuzes) zu liegen. In der Regel geht die Teilung von $1 c^{2}$ derjenigen von $1 d^{2}$ voran (Fig. 37).

Zugleich wird, wie im vorigen Kapitel erwähnt wurde, auch die Teilung der hinteren Basalzelle des Kreuzes $1 d^{1 \cdot 2}$ vorbereitet durch eine radial gerichtete Spindel, sie wird aber ausnahmsweise schon am Stadium von 75, in der Regel aber erst in demjenigen von 82 Zellen oder noch später vollzogen. Die beiden Tochterzellen sind anfänglich gleich groß (Fig. 39), später wächst jedoch die Basalzelle $1 d^{1 \cdot 2 \cdot 1}$ auf Kosten ibrer Schwesterzelle 1 $d^{1 \cdot 2 \cdot 2}$ (Mittelzelle), welche dadurch den entsprechenden Mittelzellen der übrigen Arme $\left(1 \mathrm{a}^{1 \cdot 2 \cdot 2}-1 c^{1 \cdot 2 \cdot 2}\right)$ an Größe fast gleich kommt.

Es beginnt ferner auch in den hinteren Zellen des dritten Quartetts $3 c^{1 \cdot 1}+3 c^{1 \cdot 2}$ und $3 d^{1 \cdot 1}+3 d^{1 \cdot 2}$ der Teilungsproze $\beta$, wobei weder ein bestimmter Zeitpunkt noch eine bestimmte Nacheinanderfolge eingehalten wird Fig. 36, 38, 40, 42). Der Teilungsmodus dieser Zellen ist demjenigen der vorderen zwei Paare dieses Quartetts, d. i. des sekundären Mesoderms, analog, sie schnüren nämlich ebenfalls zwei Paare von kleinen, chromatinreichen Zellen nach unten, d. i. gegen den vegetativen Pol, ab, welche den obenerwähnten Mikromeren an Größe fast gleichkommen und sich den Zellen $3 d^{2}, 3 c^{2}$ nnmittelbar anschließen (Fig. 42). 
Am vegetativen Pole teilt sich in dieser Entwicklungsphase eine von den vier oben mit den Tipzells des Kreuzes verglichenen Zellen des zweiten Quartetts, nämlich $2 b^{2 \cdot 2}$ und zwar fast äqual und läotrop (Fig. 40). Ihre Descendenten werden beiderseits von den Zellen des dritten Quartetts eingefaßt. Schließlich teilt sich noch die Zelle $2 d^{2 \cdot 1 \cdot 2}$ in dexiotroper Richtung inäqual (Fig. 36), wobei die kleinere Tochterzelle höher zu liegen kommt.

Wir hätten somit nach Abschluß der oben besprochenen Teilungen ein Stadium mit 82 Zellen (Fig. 39, 40), die sich etwa folgendermaßen auf einzelne Quartette verteilen:

$$
\begin{aligned}
& \text { auf den ersten entfallen } 20 \text { Zellen } \\
& \text { - - zweiten - } 26 \text { - } \\
& \text { - - dritten - } 22 \text { - } \\
& \text { - vierten - } 10 \text { - }
\end{aligned}
$$

\section{Von 82-98 Zellen (Taf. XX, Fig. 38-44).}

Mit dem ron nun an im schnelleren Tempo fortschreitenden Furchungsprozesse wird die Anzahl der synchron in Teilung begriffenen Zellen naturgemäß immer größer. Die individuellen Unterschiede in der Aufeinanderfolge einzelner Teilungen werden immer bedeutender. Ruhepausen fehlen, man kann daher in der Darstellung der Furchungsstadien bloß die durchschnittlich am frühesten auftretenden Teilungen zur Richtschnur nehmen.

In den nun zu beschreibenden weiteren Teilungen kommen zunäehst sechs Entodermzellen $\left(4 a^{1}, 4 a^{2}-4 c^{1}, 4 c^{2}\right)$ an die Reihe; sie beginnen schon am Stadium ron etwa 80 Zellen einzeln die Spindeln anszubilden, seltener befinden sich alle sechs gleichzeitig in Mitose und noch seltener in derselben Phase (Fig. 38, 40). Vor der Ausbildung der Spindeln erheben sie sich stark uiber das Niveau der ruhenden Zellen und orientieren ibre Spindel, wie dies an vielen Präparaten festgestellt wurde, nach verschiedenen Richtungen, die Abschnürung erfolgt aber stets in der Richtung der Makromerenrosette, worauf die untereinander gleichen Descendenten einen Doppelkranz von je sechs Zellen um dieselbe bilden (Fig. 42! Von diesen zwölf Descendenten sind acht: $4 a^{2 \cdot 1}, 4 a^{2 \cdot 2}, 4 b^{1 \cdot 1}, 4 b^{1 \cdot 2}, 4 b^{2 \cdot 1}$, $4 b^{2 \cdot 2}, 4 c^{1 \cdot 1}, 4 c^{1 \cdot 2}$ in bezug auf den vegetativen Pol radial, die uibrigen vier mehr schief gestellt. Das Entoderm besteht jetzt aus zwölf 
Mikromeren und vier Makromeren $4 A-4 D$, und bildet eine von den umgebenden Ecto- und Mesodermelementen wohl abgegrenzte, durch ihre gelbliche Färbung sich abhebende Kuppe aus 16 Zellen.

Im nächsten Umkreise des Entoderms verharren alle Zellen, wenn auch nur fur kurze Zeit im Ruhestadium, dagegen beginut eine immer regere Teilung unter den oberen Zellen des zweiten Quartetts. Vor allem teilen sich um diese Zeit die Zellen $2 a^{2 \cdot 1 \cdot 2}$ und $2 \cdot 1 \cdot 2 \cdot 2$, die erstere ausnahmsweise am Stadium von 82 Zelleu, in der Regel aber viel später, die zweite bald unmittelbar nach dem 82-zelligen Stadium, bald erst später, etwa bei 95 Zellen. Die Abschnürung der Tochterzelle erfolgt nach links. Ferner teilt sich auch $2 d^{1 \cdot 2 \cdot 2}$ inäqual in $2 d^{1 \cdot 2 \cdot 2 \cdot 1}+2 d^{1 \cdot 2 \cdot 2 \cdot 2}$ in dexiotroper Richtung und zwar bald vollzieht es seine Teilung bereits am Stadium von $95 \mathrm{Zel}-$ len, bald ist es noch an demjenigen von 97 ungeteilt, wie dies in unsrer Fig. 43 der Fall ist. Wollten wir die ohnehin wankende Zeitfolge bericksichtigen, so miißten wir jetzt zur Besprechung der sich an der animalen Sphäre vollziehenden Teilungen schreiten, wir ziehen es aber vor, der Übersichtlichkeit halber zuvor diejenigen der vegetativen $z u$ beschreiben. Hier teilen sich oft unmittelbar nach den Entodermzellen vier Zellen fast zu derselben Zeit, namentlich die zwei Urmesodermzellen $M_{1} M_{2}$ und die zwei oben mit den Tipzells des animalen Kreuzes in Parallele gebrachten Zellen des zweiten Quartetts $2 a^{2 \cdot 2}$ und $2 c^{2 \cdot 2}$ (Fig. 42 ;. Die Mesodermzellen vergrößern sich vor der Teilung sehr bedeutend, treten etwas aus der Furchungshöhle heraus und bilden bald die rechte, bald die linke, oder beide zugleich die Spindeln aus, deren Achse schief nach oben und außen gerichtet ist. Die Abtrennung der nur etwas kleineren Tochterzellen $M_{1 \cdot 1}+M_{2 \cdot 1}$ erfolgt somit in der Richtung gegen die animale Eihälfte und gegen den Äquatorialgürtel, während die Mutterzellen $M_{1 \cdot 2}+M_{2 \cdot 2}$ in der Symmetrieebene bleiben. Das Urmesoderm besteht nach dieser Teilung aus sechs Zellen: vier Makromeren und zwei Mikromeren. Die vier Makromeren ragen anfangs noch teilweise aus der Furchungshöhle heraus, später sind nur noch die beiden mittleren $M_{1 \cdot 2}+M_{2 \cdot 2}$ an der Oberfläche noch einige Zeit sichtbar, rersinken aber bald ganz in die Furchungshöhle.

Die Teilung von $2 a^{2 \cdot 2}$ und $2 c^{2 \cdot 2}$ ist inäqual und läotrop, die kleineren Tochterzellen $2 a^{2 \cdot 2 \cdot 2}$ und $2 c^{2 \cdot 2 \cdot 2}$ bleiben im unmittelbaren Kontakt mit dem Entoderm. Wir erinnern daran, daß die gleichnamige Zelle dieses Quartetts $2 b^{2 \cdot 2}$ schon lüngst geteilt ist, wälurend $2 d^{2 \cdot 2}$ erst bedentend später sich teilen wird. 
An der animalen Eihälfte teilen sich am frühesten die drei Basalzellen des Kreuzes $1 a^{1 \cdot 2 \cdot 1}, 1 b^{1 \cdot 2 \cdot 1}, 1 c^{1 \cdot 2 \cdot 1}$. Davon teilen sich $a$ und $c$ fast äqual und ungefähr radial, die Zelle $c$ in der Regel später als $a$. Im vorderen Kreuzarme geht die Teilung stark inäqual vor sich, indem die ebenfalls radial abgeschnïrte neue Basalzelle $1 b^{1 \cdot 2 \cdot 1 \cdot 1}$ auffallend klein ausfällt und seltsamerweise in den spätesten Furchungsstadien ungeteilt bleibt (Fig. 41, 43).

Wir hätten somit nach Abschluß der genannten Teilungen Stadien mit 98 Zellen, welche gleichfalls keinen Ruhepunkt in der regen Zellvermehrung bedenten, denn bevor sie noch erreicht werden, sieht man schon weitere Zellen sich zur Teilung vorbereiten. Unsre Figuren 43 und 44, welche die dargestellte Phase illustrieren, weisen nur 97 Blastomeren auf, weil die Teilung von $2 d^{1 \cdot 2 \cdot 2}$ noch nicht vollzogen ist.

V on 98 bis 123 Zellen (Taf. XX, Fig. 38-50).

Wir beginnen die Übersicht der weiteren Teilungen vom vegetativen $\mathrm{Pol}$ aus. Es entstehen binnen einer sehr kurzen Zeit aus den drei Makromeren $4 A-4 C$ durch beiläufig äquale Teilung die drei Zellen des fünften Quartetts $5 a, 5 b, 5 c$, welche die Zahl der Entodermzellen auf 19 heben (Fig. 46). Der aus den neu entstandenen Zellen und der ungeteilten Makromere $4 D$ bestehende Hinterteil der Entodermscheibe hat eine stumpf dreieckige Gestalt und überragt zu dieser Zeit kappenartig die mittlerweile in die Furchungshöhle fast ganz eingesunkenen medianen Mesodermzellen.

Während die tibrigen Derivate des vierten Quartetts noch lange im Ruhestadium verharren, erscheint bereits auf einem Stadium von etwa 107 Zellen das sekundäre Mesoderm $\left(3 a^{2.1 .1}, 3 a^{2.2 .1}-3 b^{2.1 .1}\right.$, $\left.3 b^{2.2 .1}\right)$ in Teilung begriffen. Es handelt sich diesmal wiederum um Abschnürung von vier rudimentären Zellen, welche sich den bereits vorhandenen vier eng anschließen und in derselben Weise gebildet werden, jedoch bedeutend größer sind. Ihre Indices sind: $3 a^{2.1 .1 .2}$, $3 a^{2.2 .1 .2}, 3 b^{2.11 .12}, 3 b^{2.2 .1 .2}$, die der Mutterzellen: $3 a^{2.1 .1 .1}, 3 a^{2.2 .1 .1}, 3 b^{2.1 .1 .1}$, $3 b^{2.2 .1 .1}$. Die Spindeln der vier genannten Zellen haben eine convergente Richtung, d. i. in jedem von den beiden Quartetten, in welchen die genannten Zellen liegen, wird die Mikromere nach entgegengesetzter Richtung abgegeben, nämlich die eine dexio-, die andre läotrop (Fig. 38, 46, 48a).

Erst mit dieser Teilung vollzieht sich die definitive Sonderung des sekundïren Mesoderms als eines sellständigen Keimblattes. 
Diese Tatsache verdient insofern eine besondere Beachtung, als hiermit die vorderen Bildungscentren des Mesoderms in gewisse Parallele zu der Urmesodermzelle zu stehen kommen, welche letztere urspringlich ebenfalls fremdes Material mitführt und erst nach Erzeugung des ersten Mikromerenpaares sich zu reiner Mesodermanlage differenziert. Es stellt sich zugleich heraus, daß die Sonderung des Furchungsmaterials in einzelne Keimblätteranlagen erst auf einem sehr vorgerïckten Entwicklungsstadium stattfindet, während man sonst dieselbe für Gasteropoden schon im 24-zelligen Stadium als vollzogen darzustellen pflegt.

Nach diesem Exkurs zur Schilderung der weiteren Teilungen übergehend, heben wir hervor, $\mathrm{da}$ ß auch die Teilung der vier übrigen Makromeren des dritten Quartetts $\left(3 c^{1.1 .1}, 3 c^{1.2 .1}, 3 d^{1.1 .1}, 3 d^{1.2 .1}\right)$ ganz analog verläuft, wie die des sekundären Mesoderms. Denn auch diese Zellen haben auf dem Stadium von 84 Zellen vier Mikromeren abgeschnürt, welche ebenfalls reich an Chromatin sind und, wie die ersteren, sich an das Entoderm anlehnen. Die Übereinstimmung in ihrer weiteren Teilung (die ungefähr gleichzeitig mit derjenigen der zweiten Teilung der vier Zellen des sekundären Mesoderms beginnt) (Fig. 47, 48a), besteht darin, daß sie ebenfalls inäqual ist. Doch werden die kleineren Tochterzellen nicht mehr an die vegetative, sondern an die animale Eihälfte, und zwar die rechtsseitigen nach links und die linksseitigen nach rechts abgegeben. Der Zeitpunkt ihrer Teilung schwankt in ziemlich weiten Grenzen zwischen dem 117- bis 130-zelligen Stadium.

Bemerkenswert wäre die vorübergehende Asymmetrie des Keimes während der Abschnürung des zweiten Mikromerenpaares von den vier Zellen des sekundären Mesoderms. Man sieht eine ausgesprochene Tendenz zur Verschiebung des vorderen Teiles bald nach links, bald nach rechts, was indessen bald verwischt wird und fiir die Ableitung der Asymmetrie des fertigen Tieres belanglos ist.

An der animalen Seite teilen sich im ersten Quartette nur die Apicalzellen $1 a^{11}-1 d^{11}$ inäqual und annähernd radial (Fig. 43, 45, die hinteren Quadranten gewöhnlich zuerst. Die vier kleineren Zellen $1 a^{111}-1 d^{111}$ bilden wieder die Apicalrosette, die vier größeren (Intermedialzellen) $1 a^{112}-1 d^{112}$ liegen interradial zwischen den Kreuzarmen (Fig. 49).

Indem wir uns zum zweiten Quartette wenden, haben wir vor allem zu bemerken, daß der vordere Quadrant $b$ in völliger Ruhe verharrt. In den übrigen Quadranten teilen sich zunächst die 
drei Zellenpaare, welche unmittelbar unterhalb der Tipzellen liegen: $2 a^{1.2 .1}+2 a^{2.1 .1}, 2 c^{1.2 .1}+2 c^{2.1 .1}$ und $2 d^{1.2 .1}+2 d^{2.1 .1}$. Die Teilungen erfolgen nach verschiedenen Richtungen, jedoch in den beiden Seitengruppen harmonisch, außerdem teilt sich in den letzteren je eine Zelle der nächstfolgenden Etage: $2 a^{12.2}$ und $2 c^{2.1 .2}$ und zwar fast äqual. Es ist daran zu erinnern, daß die Teilung von $2 a^{2.1 .2}$ bereits in der friiheren Phase zu erfolgen pflegt. In dem hinteren Quadranten teilen sich noch zwei Zellen: $2 d^{2.1 .2 .2}$ und die regetativ gelegene Zelle $2 d^{2.2}$, beide ziemlich äqual und in derselben dexiotropen Richtung (Fig. 43-50). Von allen den hierangefuhrten Teilungsvorgängen wurden verschiedene Stadien mit Spindeln, Zwischenkörpern usw. beobachtet.

Mit der letzteren Teilung ist das 123-zellige Stadium erreicht, welches wir in den Fig. 49 und 50 vorführen. Es hat folgende $\mathrm{Zu}$ sammensetzung:

\begin{tabular}{|c|c|c|}
\hline im ersten & Quartette 27 & Zellen \\
\hline - zweiten & 41 & . \\
\hline - dritten & 30 & - \\
\hline - vierten & 18 & - \\
\hline - fünften & - & - \\
\hline und & & Makromeren \\
\hline
\end{tabular}

Die nun folgenden Hauptereignisse im fortschreitenden Furchungsprozesse betreffen die Teilungen im vierten Quartette, die erste Teilung der vier Zellen des sekundären Mesoderms, die Abschnürung: der vier weiteren Mikromeren von den vier Zellen des Urmesoderms und der Anfang der Querteilung in den Kreuzarmen, den hinteren Arm $d$ ausgenommen. Die Zelldescendenz läßt sich bei den erwähnten Teilungen noch genau feststellen, weniger leicht im zweiten Quartette, wo die einzelnen Quadranten bereits aus 11-12 Blastomeren zusammengesetzt sind. Bei ihrem weiteren Zuwachs wird es geradezu unmöglich, sowohl die Zahl als die Zusammengehörigkeit der Zellen zu kontrollieren. Da sich somit in einer bestimmten Phase die Gesamtzahl der Blastomeren nicht mehr mit der erwünschten Sicherheit angeben läßt, müssen wir auf die bisherige Darstellungsweise, die auf die gleichzeitige Schilderung des Furchungsganges in allen vier Quadranten Bezug nimmt und stets den Keim als Ganzes vorführt, verzichten. Wir wenden uns vielmehr zur Schilderung der Spezialgeschichte der einzelnen Quartette, wo wir iiber die weiteren Schicksale ihrer Komponenten, insofern sie noch sicher eruiert werden konnten, näher berichten wollen. (Furchungsübersicht s. hinter S. 560.) 


\section{Geschichte des ersten Quartetts.}

\section{a) Das Kreuz.}

Es wird bekanntlich bei der Furchung des Eies von Gasteropoden, Amphineuren (Ischnochiton Heath), Lamellibranchiaten, Anneliden (? Polycladen) eine sehr charakteristische Kreuzfigur am animalen Pole - vier Endzellen der Arme ausgenommen - ausschließlich aus Descendenten des ersten Quartetts gebildet. Dieselbe wird neulich einerseits mit Riicksicht auf ihre iibereinstimmende Form und Lage, anderseits wegen des nämlichen Ursprungs und gleicher Bestimmung als eine bei all' den genannten Gruppen homologe Bildung betrachtet. Es war somit eine wichtige Aufgabe, die Entwicklung der Kreuzfigur und mit ihr die Entwicklungsgeschichte des ersten Quartetts bei Physa möglichst genau zu verfolgen, um sichere Anhaltspunkte fur einen so vielseitigen Vergleich zu gewinnen. In erster Linie handelte es sich hierbei um die Lösung der schwierigen Frage nach der Beziehung einzelner Kreuzarme zu künftigen Organen, welche uns zum Teil gelungen ist.

Der Ursprung des Kreuzes läßt sich bis zum Furchungsstadium von acht Zellen zuriickverfolgen, an welchem das erste Quartett von Ectomeren $(1 a-1 d)$ noch die Elemente des Kreuzes, der Trochoblasten und der Kopfblase in sich vereinigt enthält. Diese Ectomeren erzeugen am 12-zelligen Stadium vier sog. Trochoblasten $\left(1 a^{2}-1 d^{2}\right)$, sowie die Polrosette $\left(1 a^{1}-1 d^{1}\right)$, ans welcher erst das ganze Kreuz hervorgeht (ausgenommen die vier Endzellen, die vom zweiten Quartette entspringen). Am 24-zelligen Stadium sieht man diese Rosettenzellen sich für ihre späteren, so wichtigen Schicksale beizeiten vorbereiten. Sie erreichten nämlich bereits in friheren Stadien eine beträchtliche Größe und treten jetzt mittels centripetaler Fortsätze in innige Beziehung zu den Makromeren, von welchen sie (wie bereits an betreffender Stelle des Näheren berichtet wurde) wahrscheinlich das gesamte Material an sog. Körnchengruppen übernehmen. Am 28-zelligen Stadium lehnen sich an dieselben vier andre vom zweiten Quartette stammende Zellen $2 a^{11}-2 d^{11}$ unmittelbar an, es sind dies sog. "Tip-cells", die wir ebenfalls bereits kennen gelernt haben. Bei 33 Zellen findet ihre erste Teilung statt (Fig. 18). Die acht Descendenten werden nach ihrer Lage als "Apicalzellen * und "Basalzellen * des Krenzes bezeichnet, welches jetzt aus 12 Zellen gebildet ist und recht klar am animalen Pole hervortritt (Fig. 21, 24). Seine Arme sind so orientiert, daß zwei derselben $b$ 
und $d$ in die Medianebene, dagegen die andern zwei $a$ und $c$ in die Qnerebene fallen; davon ist $b$ der vordere, $d$ der hintere, $a$ der rechte, $c$ der linke. Im Stadium von 57-65 Zellen findet die Teilung der drei Basalzellen $\left(1 a^{1.2}-1 c^{1.2}\right)$ statt (Fig. 30), $1 d^{1.2}$ teilt sich erst bei 82 Zellen (Fig. 39). Die nach außen abgegebenen Descendenten derselben werden als » äußere Medianzellen « bezeichnet; sie verbleiben bis in das Larvenstadium ungeteilt. Etwa am Stadium von 85 Zellen beginnt die abermalige Teilung der drei Basalzellen $1 a^{1.2 .1}-1 c^{1.2 .1}$ (Fig. 41), dagegen bleibt $1 d^{1.2 .1}$ längere Zeit ungeteilt. Die nach außen abgegebenen Descendenten erhalten den Namen sinnerer Medianzellen«. Auf die Teilung der Basalzellen folgt unmittelbar diejenige der Apicalzellen, welche bei etwa 116 Zellen zum Abschluß gelangt (Fig. 49). Von den acht Descendenten bilden die vier kleineren $1 a^{111}-1 d^{111}$ die Polrosette, die vier größeren kommen in die Winkel zwischen den Kreuzarmen zu liegen, daher ihr Name »Intermediatzellen «. In dieser Phase ist das Kreuz aus vier Apicalzellen, vier Intermediatzellen, vier Basalzellen, in drei Armen aus je zwei Medianzellen und im Hinterarme bloß aus einer, schließlich aus vier Tipzellen, zusammen aus $28 \mathrm{Zellen}$ zusammengesetzt. Die schöne, regel-

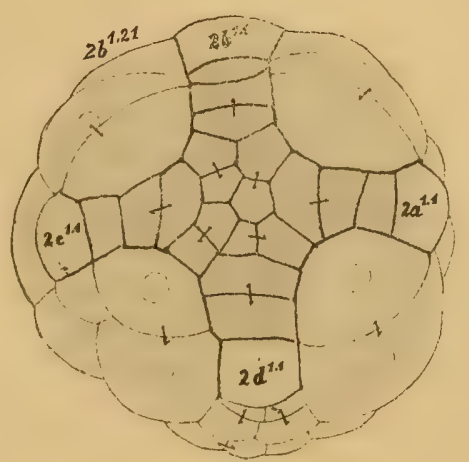

Textfig. 3.

23 zellige Kreuzfigur eines $117-123$ zelligen Stadiums. Silberpräparat. mäßige Gestalt der ganzen Figur tritt an Silbernitratobjekten besonders charakteristisch hervor (Textfig. 3).

Bis zu dieser Phase hatten wir die Geschichte des Kreuzes bloß zu rekapitulieren, nachdem wir dieselbe bis zum Stadium von 123 Zellen im vorigen Kapitel dargestellt haben. Wir gehen nun zur Fortsetzung derselben ïber.

Vor allem ist zu beachten, daß sich der bisherige Teilungsmodus insofern verändert, als die nächstfolgenden Teilungen nicht mehr senkrecht oder schief zu den Achsen der Kreuzarme, sondern parallel mit denselben verlaufen. Die Folge davon ist der Beginn einer Längsspaltung der Arme, die mit der Teilung der inneren Medianzelle $\left(1 b^{1,2,1.2}\right)$ anhebt. Dieselbe ist vollkommen äqual und bilateral, die Descendenten zeichnen sich durch ihre Größe und charakteristische Form aus (Fig. 52). Unmittelbar auf diese Teilung, häufig noch vor 
Abschluß derselben, folgt diejenige der Basalzellen $1 a^{1.2 .1 .1}, 1 c^{1.2 .1 .1}$, während die um eine Generation ältere Basalzelle des hinteren Armes $1 d^{1.2 .1}$ bald gleichzeitig, häufiger jedoch erst viel später geteilt wird (Fig. 56). Überhaupt unterliegt ihre Teilungsperiode recht bedeutenden Schwankungen. Zur selben Zeit macht sich auf dem animalen Pole eine auffallende Einsenkung bemerkbar, die an der Basis des hinteren Kreuzarmes am tiefsten ist. Nach der Teilung beider Glieder des hinteren Armes wird sie bedeutend geringer. Das Kreuz besteht jetzt aus 27 Zellen (Fig. 56).

Bald nach der Teilung der Basalzelle oder ausnahmsweise mit ihr zugleich teilt sich auch die einzige Medianzelle des hinteren Armes $1 d^{1.2 .2}$; nach einigen Präparaten durfte die Teilung der letzteren derjenigen der Basalzelle vorausgegangen sein. Sowohl die Teilung in den Querarmen als im hinteren Arm erfolgt ïqual und in der Längsachse derselben. Der hintere Arm setzt sich nunmehr ans fünf Zellen zusammen, d. i. der Tipzelle und vier zu einem Viereck mehr oder weniger regelmäßig gruppierten Zellen und diese Zellenzahl wird bis zur Anlage der Organe nicht mehr vermehrt. Die Längrsspaltung des hinteren Armes ist vom vergleichend embryologischen Standpunkte besonders interessant, da sie bei der so nahe rerwandten Limnäidengattung Planorbis nach HoLMes völlig ausbleibt.

Nun schreitet die Längsspaltung der Seitenarme fort; es teilen sich die inneren Medianzellen $1 a^{1.2 .1 .2}$ and $1 r^{1.2 .1 .2}$ in derselben Weise wie die Basalzellen, d. i. vollkommen äqual (Fig. 59j. Der karyokinetische Zusand dieser Zellen kommt zwar sehr selten zur Beobachtung, wurde aber doch an mehreren Präparaten gefunden. Ungefäbr zu gleicher Zeit teilt sich auch die äußere Medianzelle des vorderen Armes $1 b^{1.22} \mathrm{im}$ Sinne der Spaltung des Armes und äqual. Das Kreuz besteht sodaun, die Tipzellen inbegriffen, aus 31 Zellen und zwar vier Apicalzellen, vier Intermediatzellen, je sechs Zellen in den Seitenarmen, sechs im Vorderarme und fünf im Hinterarme ${ }^{1}$ (Fig. 61. Mit dieser Teilung ist die erste Längsspaltung der Kreuzarme vollendet. Sie erstreckte sich bloß in dem hinteren Arme durch dessen ganze Länge bis zur Endzelle, in den beiden Seitenarmen dagegen nur bis zur äußeren Medianzelle und im Vorderarme uur auf die beiden Medianzellen, demn die Basalzelle blieb ungeteilt. Vergleicht man das so-

\footnotetext{
${ }^{1}$ Dieser Arm ist in der Figur durch Einsenkung des apicalen Feldes ganz deformiert.
} 
eben beschriebene und in der genannten Figur abgebildete Stadium des Kreuzes mit dem jüngeren von 23 Zellen (wie in Textfig. 3), so überzeugt man sich, daß es seine ursprünglich schlanke und symmetrische Form bereits eingebüßt hat (vgl. Textfig. 4 und Taf. XXI, Fig. 61). Dies ist eben die Folge der bedeutenden Verbreiterung der Basis seiner Arme. Indem auch sein Centrum mit jedem Schritt der weiteren Entwicklung einen größeren Umfang gewinnt, wird seine typische Gestalt in noch höherem Grade alteriert. Bevor noch die bereits oben besprochene Teilung der äußeren Medianzelle des Vorderarmes eingeleitet wurde, sieht man manchmal eine von den inneren Medianzellen desselben Armes ausnahmsweise eine Spindel anlegen. In der Regel geschieht dies erst nach vollzogener Teilung:

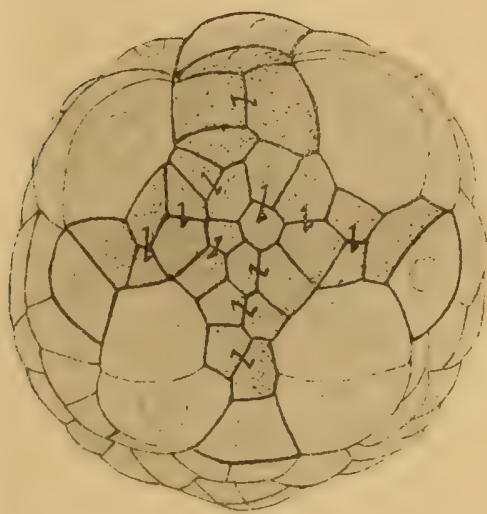

Textfig. 4.

30 zellige Kreuzfigur. Silberpräparat.

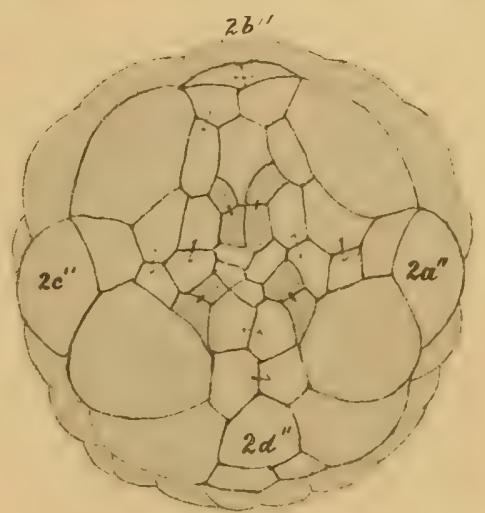

Textfig. 5.

Typische 37 zellige Kreuzfigur. Silberprăparat.

der äußeren Medianzelle. Die vollkommen ausgebildeten Spindeln konvergieren nach vorn gegen die Medianebene. Die Teilung erfolgt in der Regel synchron und ist beinahe vollkommen äqual. Die hinteren Descendenten $1 b^{1,2} 1.2 .1 .1$ und $1 b^{1,2,1.2 .2 .1}$ umfassen die Basalzelle von den Seiten und zugleich die anliegenden Intermediatzellen, und verbiuden sich mit ihren hinteren Enden mit den inneren Medianzellen der entsprechenden Seitenarme (Fig. 63). Dadurch wird der Kontakt der vorderen Intermediatzellen mit den Trochoblasten aufgehoben. Neben den beschriebenen Teilungen trägt zur weiteren Deformierung des Kreuzes auch die Teilung der Intermediatzellen bei. Sie findet in sehr wechselnder Nacheinanderfolge statt. Die Spindeln liegen mehr oder weniger radial. Die Gestalt der Descendenten ist ziemlich unregelmäßig. Die hinteren äußeren Zellen $1 c^{1.1 .22}$ und 
$1 d^{111,2,2}$ sind gewöhnlich größer als die ubrigen und gelangen zwischen die hinteren inneren Trochoblasten und die Ansätze der Seitenarme zu liegen, wobei sie von den stark aufgetriebenen Trochoblasten mehr oder weniger tiberdeckt werden. Dagegen sind die äußeren Intermediatzellen der vorderen Quadranten verhältnismäßig klein und stoßen keilförmig an die Basis des Vorderarmes an. Besondere Beachtung verdient der Umstand, daß nachher die Apicalzellen stets derart gruppiert werden, daß die Zelle $1 d^{1.1 .1}$ eine genau centrale Lage gewinnt und zwischen den Basalzellen des Hinterarmes zu stehen kommt. Zwischen $1 a^{1.1 .1}$ und $1 c^{1.1 .1}$ bleibt ein Rudiment der Polarachse nach wie vor erhalten. Das Kreuz besteht

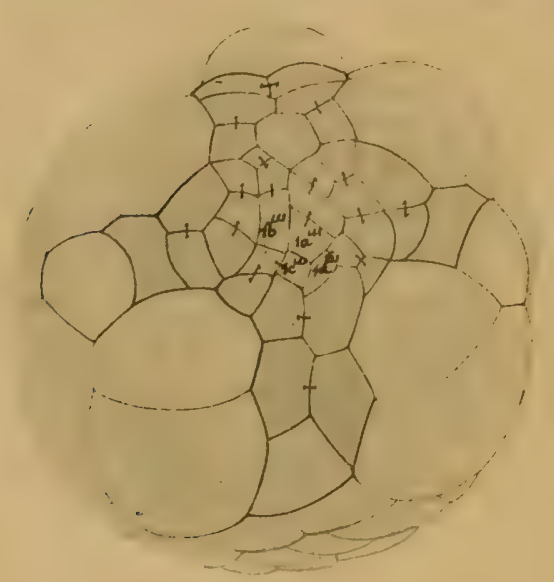

Textfig. 6.

Typische 39 zellige Kreuzfigur. Silberprāparat. nunmehr, die Tip-cells eingerechnet, aus 37 Zellen und wird in der Textfig. 5 nach einem Silbernitratpräparate in ziemlich typischer Ausbildung wiedergegeben (S. 555); die geteilten Intermediatzellen siud punktiert, die tibrigen Zellen in den Armen und die Polrosette der vier Apicalzellen sind ohne weiteres erkenntlich.

Nach der Teilung der Intermediatzellen zuweilen aber noch vor ihrem AbschluB (rgl. Taf. XXII, Fig. 68), beginnt die weitere Längsspaltung der Sei-

tenarme, indem in ihren Basalteilen, die infolge der ersten Spaltung bereits zweireihig geworden sind, neue Teilungen vor sich gehen. Der Keim zählt zu jener Zeit 170-180 Zellen. Den Anfang machen in der Regel die zwei vorderen Basalzellen $1 t^{1.2 .11 .2}$ und $1 c^{1.21 .1 .2}$. Sie teilen sich etwas schief und beinahe äqual und schließen sich mit den vorderen Basalzellen zu einer Querreihe zusammen. Das Kreuz besteht nach ihrer Teilung aus 39 Zellen (Textfig. 6), erhält aber bald wieder neuen Zuwachs, indem die Teilung von weiteren zwei Basalzellen unmittelbar an die Reihe kommt $\left(1 a^{1.211 .1}\right.$ und $\left.1 c^{1.211 .1 .1}\right)$ (Fig. 76). Die Zeit ihrer Teilung schwankt in geringfügigen Grenzen, und ist fast äqual. Nach ihrem Abschluß sieht man an der Basis der beiden Querarme einen aus vier Zellen zusammengesetzten Bogen, dessen konvexe Seite sich dem Centrum des Kreuzes zuwendet, während 
die konkare die in Teilung begriffenen Medianzellen $1 a^{1.21 .2 .2}$ und 1c.2.1.2.2 umfaßt. Die Teilung der letzteren wird bereits im Stadium von 39 Zellen angedeutet, jedoch erst am Stadium von 41 Zellen durchgeführt, worauf die Zahl der Komponenten des Kreuzes auf 43 steigt (Fig. 72). Davon entfallen auf die Seitenarme je 9, auf den Vorderarm 8, auf den Hinterarm 5 und auf die Apical- und Intermedialpartie 12 Zellen. Bei Betrachtung der zitierten Figur fällt die Umgestaltung des Kreuzes sofort auf. Seine Centralpartie wird zu einer umfangreichen stumpf viereckigen Platte, welche von dem von Haus aus kurzen Vorderarm sowie den Basalteilen der übrigen Arme gebildet wird. Die freien, nunmehr zweizelligen Endsticke der Querarme sind nach hinten umgebogen; der freie Teil des Armes $d$ wird gestreckter und verbleibt in der Medianebene. Gleichzeitig erfährt die Gesamtanlage des Kreuzes eine Verschiebung nach vorn. Alle diese hier geschilderten Verhältnisse veranschaulicht unsre nach einem Silberpräparat entworfene Fig. 72. Die Gestalt, die uns hier das Kreuz bietet, erinnert eher an ein ankerförmiges Gebilde. Zur Zeit dieser Umformung ist die gastrale Einstiulpung an der vegetativen Seite des Keimes bereits stark vorgeschritten. Es kommt auch bald zur Ausbildung der sogenannten Kopfblase und zur stärkeren Vermehrung des sekundären Mesoderms, welche Vorgänge auf die weitere Umformung des Kreuzes insofern von wesentlichem Einfluß sind, als es infolge derselben nach vorn geschoben und zugleich gleichsam in die Quere ausgedehnt zu werden scheint. Selbstrerständlich erfolgt diese Ausdehnung ausschließlich durch rasch vor sich gehende Teilungen sowohl an der Basis der Querarme als insbesondere in der Progenitur der Intermediatzellen.

Während wir somit imstande waren, die Entwicklung des Kreuzes bis zu seiner Zusammensetzung aus 43 Zellen mit aller Sicherheit zu verfolgen und eine genaue Evidenz der Chronologie der Zellteilungen zu führen, konnte seine weitere Entwicklung nicht mehr mit derselben Exaktheit verfolgt werden. Einerseits die zunehmende Kleinheit der Zellelemente, namentlich in der Mitte des Kreuzes, anderseits die Zerrung, welche die Kreuzfigur unter gleichzeitigem Einsinken der vorderen Partie erleidet, erschweren ungemein die Beobachtung. Trotzdem ist es uns gelungen, die Zelldescendenz noch weiter zu führen und die Endschicksale der wichtigsten Zellen und Zellgruppen zu erforschen.

Wir wenden uns zunächst zur Schilderung der weiteren Teilungen im Vorderarme. Die Basalzelle bleibt ungeteilt; dagegen 
teilen sich die vier Descendenten des inneren Medianzellenpaares und zwar, wie aus mehreren Präparaten hervorgeht, zuerst diejenigen der inneren, nachher die beiden äußeren. Die Teilung erfolgt in der Weise, daß sich zuerst die beiden hinteren Zellen $1 b^{1 \cdot 2 \cdot 1 \cdot 2 \cdot 1 \cdot 1}$ und $1 b^{1 \cdot 2 \cdot 1 \cdot 2 \cdot 2 \cdot 1}$ inäqual teilen, worauf erst die äquale Teilung der beiden vorderen $1 b^{1 \cdot 2 \cdot 1 \cdot 2 \cdot 1 \cdot 2}$ und $1 b^{1 \cdot 2 \cdot 1 \cdot 2 \cdot 2 \cdot 2}$ folgt (Fig. 73).

Die neu entstandenen Zellen, ebenso wie die äußeren Medianzellen verbreitern sich in der Folge immer stärker, unter gleichzeitiger Verkürzung, und bilden schließlich ein streifenförmiges Band, welches der Basalzelle quer vorgelagert ist, beziehungsweise sich neben derselben in die Breite erstreckt Fig. 74;. Diese ganze Zellgruppe ist bis zu einem Stadium, wo das ehemalige Kreuz bereits aus 70 Zellen zusammengesetzt ist, bis auf die Zellen zu erkennen. Die Tipzelle $2 b^{1 \cdot 1}$ teilt sich nur ausnahmsweise.

$\mathrm{Zu}$ gleicher Zeit mit der Zellenvermehrung im Arme $b$ vergrößert sich die Zahl der Zellen in den Seitenarmen und zwar sind es wieder die Basalzellen, an die zunächst die Reihe kommt. Zumeist teilen sich in beiden Armen vor allem die hinteren Zellen $1 a^{1 \cdot 2 \cdot 1 \cdot 1 \cdot 1 \cdot 1}$ und $1 a^{1 \cdot 2 \cdot 1 \cdot 1 \cdot 1 \cdot 2}$, bzw. $1 c^{1 \cdot 2 \cdot 1 \cdot 1 \cdot 1 \cdot 1}$ und $1 c^{1 \cdot 2 \cdot 1 \cdot 1 \cdot 1 \cdot 2}$ äqual, womit die dritte Generation der Basalzellen ihren Anfang nimmt. Indessen kann die Ordnung wechseln und ist oft in jedem Arme verschieden, wie dies aus der Fig. $73 \mathrm{zu}$ entuehmen ist. Hieran schlieBt sich auch die Teilung der hinteren Medianzellen der Seitenarme $1 a^{1 \cdot 2 \cdot 1 \cdot 2 \cdot 1}$ und $1 c^{1 \cdot 2 \cdot 1 \cdot 2 \cdot 1}$, die in demselben Sinne erfolgt, wie die bedeutend fruber stattfindende Teilung ihrer Schwesterzellen $1 a^{1 \cdot 2 \cdot 1 \cdot 2 \cdot 2}$ und $1 c^{1 \cdot 2 \cdot 1 \cdot 2 \cdot 2}$.

Die Gesamtzahl der Zellen im Kreuze steigt mit diesen Teilungen bis auf 57 . Sie verteilt sich in folgender Weise auf die einzelnen Teile desselben: die Mitte enthält 12, die Seitenarme je 14, der Vorderarm 12 und der Hinterarm bloß 5. In der Fig. 73 zählt das Kreuz bloß 53, da sich im rechten Arme nur 13, im linken 11 (anstatt 14) vorfinden ${ }^{1}$.

Bei weiteren Teilungen, welche wegen der Verschiebung der Kreuzfigur nach vorn nicht mehr genau kontrolliert werden können, gruppieren sich die Descendenten der Basal- und Medianzellen der Hauptsache nach in parallele halbkreisförmige Reihen. Die äuBeren Medianzellen der Seitenarme $1 a^{1 \cdot 2 \cdot 2}$ und $1 c^{1 \cdot 2 \cdot 2}$

1 Die zum zweiten Quartett gebörenden Tipzellen sind hier stets nitgezählt worden. 
und die Tipzellen der Arme ( $2 b^{1 \cdot 1}$ ausgenommen) bleiben b is zum Ende der Entwicklungsgeschichte des Kreuzes ungeteilt.

Während der so regen Furchung in den übrigen drei Armen sieht man die fünf ursprünglichen Zellen des Hinterarmes ungeteilt. Sie nehmen nur im Laufe der Entwicklung des Kreuzes bedeutend an Umfang zu und werden in ihrer ganzen Beschaffenheit den sie umlagernden vier Trochoblasten immer ähnlicher. Die regste Teilung findet wohl gegen das Ende der Geschichte des Kreuzes in den Intermediatzellen statt; leider konnte sie nicht bis ins einzelne verfolgt werden. Die Apicalzellen, welche bis zu einem Stadium von 45 bis 50 Zellen im Kreuze noch sicher ungeteilt nachgewiesen werden konnten, verbleiben allem Anschein nach auch weiterhin ungeteilt. Der helle Streifen, welcher sich in späteren Stadien als die vordere Fortsetzung des Armes $d$ zwischen die Basalteile der Querarme keilartig einzuschieben scheint, besteht nach iibereinstimmenden Beobachtungen an Physa und Planorbis aus den Basalzellen des Hinterarmes und den bedeutend vergrößerten und in die Quere gezogenen Apicalzellen (Fig. 74). Das Kreuz zählt bereits ungefähr 90 Zellen. Auf weiteren Stadien sieht man diese Zellen stets an Umfang zunehmen und in die Breite wachsen und die unmittelbare Folge davon scheint die zu sein, daß die Zellenplatte, in deren Mitte sie sich befinden, nach rechts und links auseinandergedrängt wird. Es ist dies die sogenannte Bilateralteilung des Kreuzes. Die seitwärts gedrängten Zellgruppen sind jetzt allseitig von hellen Zellen umlagert und heben sich als zwei rundliche flache Hügel von ihrer Umgebung immer schärfer ab, zumal in ihnen selbst die Zellfurchung äußerst rege fortschreitet und ein namentlich an Silberpräparaten auffallendes, engmaschiges Zellennetz hervorbringt (Fig. 77, $79 \mathrm{sp}$ ). Es sind dies die Anlagen der bereits älteren Embryologen bekannten Scheitelplatten ${ }^{1}$. Wir haben bei der Darstellung des Auseinanderweichens dieser Scheitelplatten bloß die Apicalzellen im Auge gehabt. Nun aber findet man vor denselben auf späteren Entwicklungsstadien - wie in Fig. 77-79 - noch einige andre durchsichtige und breitgezogene Blastomeren, deren Ursprung uns unklar geblieben ist. Bei Planorbis hat HoLxes diesbezüglich recht merkwürdige Verhältnisse beschrieben. Es soll sich nach ihm die Basalzelle $1 b^{1.2 .1 .1}$, die ebenso wie

1 An Silberpräparaten konnte die Zahl der das Kreuz zusammensetzenden Zellen bis zu mindestens 112 Zellen verfolgt werden. 
bei Physa die ganze Zeit passiv bleibt, durch sämtliche vor ihr gelegene Zellen, d. i. die Medianzellen und sogar durch die inzwischen geteilte Tipzelle nach vorn durcharbeiten, so daß sie schließlich mit den zwei Zellen des zweiten Quartettes $2 b^{2.1 .2}$ und $2 b^{1.2 .2}$, welche sonderbarerweise bis jetzt noch ungeteilt geblieben sind, sich verbindet. Bei dieser Wanderung soll diese Basalzelle einem Druck von hinten nachgeben. Wir wollen diese Darstellung nicht in Frage stellen. Die erwähnte Wanderung konnten wir indes bei Physa nicht ganz bestätigen, schon aus dem Grunde, weil dic Zelle $2 b^{1 \cdot 1}$ bei derselben in der Regel ungeteilt bleibt. Nach einer lückenlosen Reihe von Stadien, deren Zellgrenzen genau gezeichnet wurden, sieht man allerdings auch bei Physa, daß sich die Basalzelle $1 b^{1 \cdot 2 \cdot 1 \cdot 1}$ schließlich unmittelbar mit der Tipzelle verbindet (Fig. 72); von den Apicalzellen trennt sie in der Regel ein Intermediatenpaar. Mit Bezug auf Planorbis muissen wir aber hervorheben, daß die schließliche Umwandlung der Kreuzfigur bei beiden in Rede stehenden Arten in auffallend ubereinstimmender Weise verläuft.

Was das Schicksal der übrigen am Aufbau der Scheitelplatte nicht beteiligten Zellen des Kreuzes anbelangt, wäre noch zu bebemerken, daß sowohl die vier Zellen des Hinterarmes als auch die äußeren Medianzellen $\left(1 a^{1 \cdot 2 \cdot 2}\right.$ und $\left.1 c^{1 \cdot 2 \cdot 2}\right)$ und die Tipzellen der beiden Seitenarme neben den hinteren Trochoblasten zur Ausbildung der sog. Kopfblase verwendet werden. Die seitlichen Tipzellen rereinigen sich mit der Tipzelle $2 d^{1 \cdot 1}$ und umringen zusammen mit den besagten Medianzellen die Kopfblase an ihrer Basis (Fig. 78). In dem Maße, als die Kopfblase an Umfang zunimmt, werden sie schmäler und länger und die hintere Tipzelle wird unter dem Drucke der rasch anwachsenden Trochoblastzellen und infolge der zunehmenden Vorwölbung der ganzen Kopfblase stark in die Länge gezogen, bis sie streifförmig wird, wie dies aus Fig. 78 zu entnehmen ist.

In der beigegebenen Tabelle wird die Zellengenealogie der Kreuzfigur vorgeführt. Die in der oberen Rubrik angegebene Zellenzahl bezieht sich hier nur auf das erste Quartett; es sind somit die Tipzellen nicht mitgezählt. In der unteren Rubrik bedeuten die eingeklammerten Zahlen nur die durehschnittliche Zahl der Zellen in den betreffenden Stadien. 
Zu Seite 551.

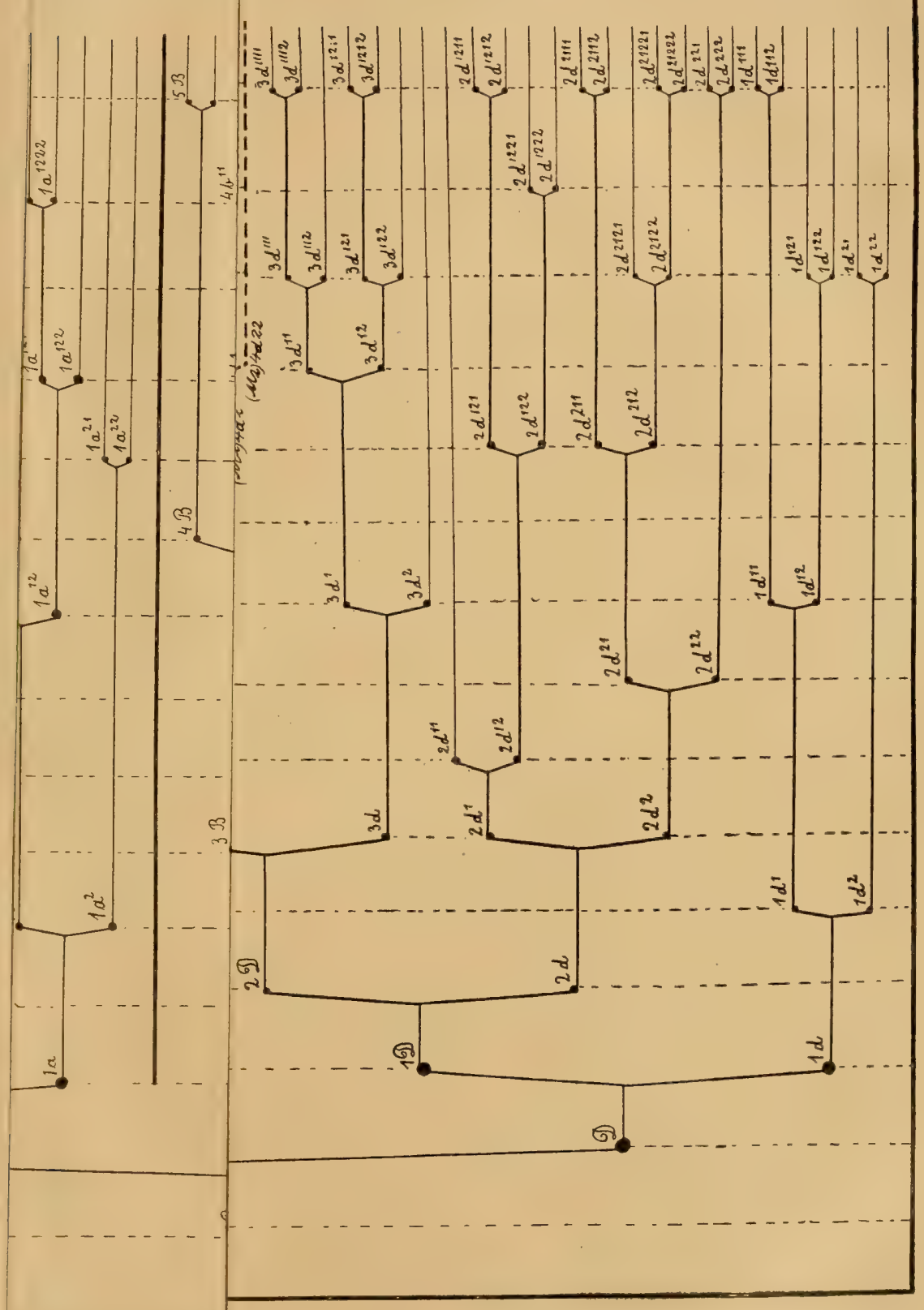

Verlag von Wilhelm Engelmann in Leipzig. 





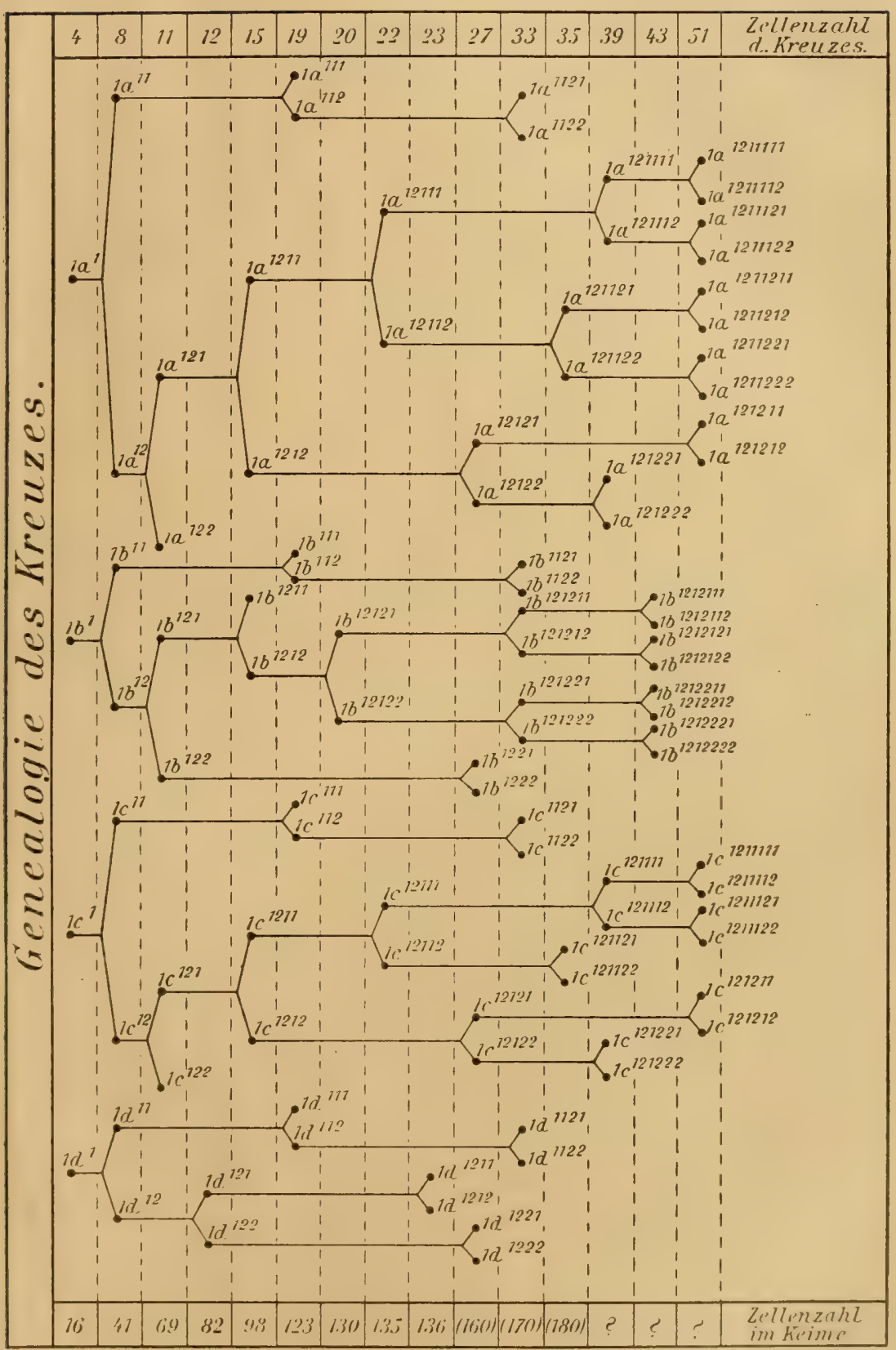

Anmerkung. Die zum Kreuze gehörenden sTipzellen" siud hier als Elemente des zweiten Quartetts nicht mitgezïhlt.

Zeitschr. f. wissensch, Zoologie. LXXXIII. Bd. 


\section{b. Die Trochoblasten.}

Die Geschichte des ersten Quartetts wäre unvollständig, wenn wir des Schicksals der acht ubrigen Glieder desselben $1 a^{2 \cdot 1}-1 d^{2 \cdot 1}$ und $1 a^{2 \cdot 2}-1 d^{2 \cdot 2}$ nicht Erwähnung tiiten. Wir haben hereits bei der allgemeinen Schilderung des Furchungsprozesses hervorgehoben, daß sie ihre Lage zwischen den Armen des Kreuzes unverindert hehalten und keine Teilung erfahren. Die den rorderen (zuadranten angehörenden Zellen bilden sich nachher zu Velarzellen um und lehnen sich ron der Seite an die Scheitelplatten. Die hinteren Trochoblasten liefern, wie soeben berichtet wurde, die Hauptbestandteile der Kopfblase.

c. Bemerkungen über das sogenannte "Apicalorgan *

Wir künnen die Geschichte des ersten Quartetts nicht abschließen ohne einer in theoretischer Beziehung sehr wichtigen Erscheinung zu gedenken, welche bereits in der einschlägigen Literatur öfters besprochen wurde, nämlich der charakteristischen vorübergehenden Einstülpung der apicalen Partie der Kreuztigur. Sie erscheint im Furchungsprozesse bei Plyysa zum ersten Male am Stadium von etwa 100 Zellen, zur Zeit, wo die Teilung der Polrosette in apicale und Intermediatzellen stattfindet. Es ist vornehmlich die Mitte des Kreuzes und der hintere Arm, die zunächst einsinken Fig. 49 . Mit der Zunahme der Zellenzahl im Kreuz nehmen auch immer mehr Zellen, die an die Polrosette angrenzen, an der Einsenkung teil. Während das Kreuz 30 bis 40 Zellen enthält (Fig. 68), kann die Einstullpung mitunter so tief werden, daß es zur Bildung eines förmlichen Trichters kommt und rom regetativen Pole aus gesehen erscheint die Stelle über der Einsenkung ganz durchscheinend; die ganze Konfiguration des Keimes taiuscht in einem solchen Falle eive vom animalen Pole ausgehende Gastralinvagination vor. In der Regel ist die Einsenkung ziemlich flach, muldenförmig; diese Nulde ist seitlich von den hinteren, stark vorragenden Trochoblasten, rorn ron den seitlichen Armen des Kreuzes und hinten rou der Tipzelle des hinteren Armes umrandet (Textfig. 7\%. An späteren Stadien ändert sich das Bild insofem als sich die Vertiefung mehr in die Länge zieht und die Gestalt einer flachen nach vorn verbreiterten Rinne gewinnt.

Beim Beginn der Entodermeinsenkung verschwindet die Vertiefung der Krenzmitte nicht, vielmehr erscheint sie infolge der 
starken Vorwölbung der inzwischen auseinandergerückten Querarme noch tiefer und wird zusammen mit der ganzen Kreuzanlage, namentlich Hand in Hand mit dem Vorderarme, nach vorn und unten verschoben. Es gibt eine kurze Phase in der Entwicklung des Keimes von Physı, wo sich gleichzeitig an beiden Hälften derselben eine Einsenkung befindet, wodurch er die Gestalt einer beiderseits excentrisch eingedrückten Scheibe gewinnt. Die Einsenkung an der animalen Hälfte verschwindet schon während der beginnenden Ausbildung der Kopfblase vollständig, die eingesenkte Partie bildet schließlich eine aus flachen durchsichtigen Zellen bestehende Brücke zwischen den beiderseitigen Kopfplatten.

Ähnliche Einstiulpung der apicalen Partie des Kreuzes ist bei Neritina (Blochmans), Trochus (Rober'r) beobachtet worden. Bei der letzteren Form ist sie derjenigen bei Physa sehr ähnlich; sie erreicht das Maximum bei 97 Zellen, ist bei 118 Zellen noch sehr deutlich, verstreicht aber bei 145 Zellen gänzlich. Nun hat A. RoBerT bei Trcehus striatus an der eingestïlpten Apicalfläche einige kurze, langsam schwingende Cilien gesehen, welcher Befund ihn zu weit gehenden vergleichenden Betrachtungen über ähnliche Einstülpungen und das sogenannte Apicalorgan bei Mollusken

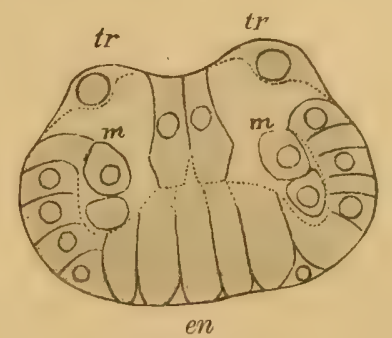

Textfig. 7. Optischer Querschnitt eines Stadiums
mit $31-10$ zelligem Kreuz. Schematisch. (Crepidula, Ischnochiton) und bei Anneliden mit31-10zelligem Kreuz. Schematisch. (Lepidonotus, Podarke, Capitella) und sogar

bei Polycladen führt. Die Befunde bei Physa liefern für einen Vergleich mit dem Apicalorgan keine Stiitze, da an der eingestuilpten Partie keine Cilien nachgewiesen wurden. Es ist aber nicht ausgeschlossen, (laß ihre Existenz bei gelegentlicher Nachuntersuchung wird festgestellt werden. Aber auch in diesem Falle wiirde dies für uns noch keinen Beweis für die Auffassung der Einstuilpung als eines rudimentären Sinnesorgans liefern, welches den Ahnen der heutigen Formenkreise gemeinschaftlich war. Nach einem Vergleich der Entstehungsweise und der Endschicksale der animalen Einstülpung gewinnt man den Eindruck, daß sich diese Vorgänge bei einzelnen Formen der Mollusken und Anneliden nicht unter eine Kategorie bringen lassen. Sie erheischen, wie Rojer' ganz richtig bemerkt, eine sehr eingehende minutiöse Untersuchung, bevor m:n an eine Erklärmg ihrer phylogenetischen Bedentung schreiten kann.

Betreffend die physiologisehe Bedentung des Einsinkens des 
Krenzcentrums bei Plysa bin ich zur Einsicht gelangt, daß sie auf Ernährungs- bzw. Differenzierungsvorgaingen beruhen dürfte, woftir in erster Linie ihr unmittelbarer Kontakt mit den Entodermelementen zu sprechen scheint (Textfig. 7).

\section{Geschichte des zweiten Quartetts.}

Die Entwicklung dieses Quartetts ist bereits bei der Darstellung des Furchungsprozesses bis zu einer Phase abgehandelt worden, wo es aus 41 Zellen und der ganze Keim aus 123 Zellen zusammengesetzt ist. Die einzelnen Quadranten haben dazumal folgende Zellreihen aufzuweisen:

\begin{tabular}{llll}
$2 a^{1.1}$ & $2 b^{1.1}$ & $2 c^{1.1}$ & $2 d^{1.1}$ \\
$2 a^{1.2 .1 .1}$ & $2 b^{1.2 .1}$ & $2 c^{1.2 .1 .1}$ & $2 d^{1.21 .1}$ \\
$2 a^{1.2 .1 .2}$ & - & $2 c^{1.2 .1 .2}$ & $2 d^{1.21 .2}$ \\
$2 a^{1.2 .2 .1}$ & $2 b^{1.2 .2}$ & $2 c^{1.2 .2 .1}$ & $2 d^{1.2 .2 .1}$ \\
$2 a^{1.2 .22}$ & - & $2 c^{1.2 .2 .2}$ & $2 d^{1.2 .2 .2}$ \\
$2 a^{2.1 .1 .1}$ & $2 b^{2.1 .1}$ & $2 c^{211.1}$ & $2 d^{21.1 .1}$ \\
$2 a^{2.1 .1 .2}$ & - & $2 c^{2.11 .2}$ & $2 d^{2.11 .2}$ \\
$2 a^{2.1 .2 .1}$ & $2 b^{2.1 .2}$ & $2 c^{2.1 .2 .1}$ & $2 d^{2.1 .2 .1}$ \\
$2 a^{2.1 .2 .2}$ & - & $2 c^{2.1 .2 .2}$ & $2 d^{2.1 .2 .2 .1}$ \\
- & - & - & $2 d^{2.1 .2 .2 .2}$ \\
$2 a^{2.2 .1}$ & $2 b^{2.2 .1}$ & $2 c^{2.2 .1}$ & $2 d^{2.2 .1}$ \\
$2 a^{2.2 .2}$ & $2 b^{2.2 .2}$ & $2 c^{2.2 .2}$ & $2 d^{2.2 .2}$ \\
\hline $11 a$ & $7 b$ & $11 c$ & $12 d=41$
\end{tabular}

Man ersieht aus der obigen Tabelle, daß der hintere Quadrant d den ubrigen in der Teilung vorausgeeilt, wogegen der vordere Quadrant $b$ zuriekgeblieben ist. Dies deutet auf ihre gan\% verschiedene Rolle beim Aufbau des Keimes hin. Der erstere hat die Hauptmasse des ectodermalen Materials zu liefern, während der letztere $b l o ß$ an der Ausbildung eines larvalen Organs, d. i. des Velums sich zu beteiligen hat.

Von den 41 oben aufgezïhlten Zellen haben $2 a^{1 \cdot 1}-2 d^{1 \cdot 1}$, die wir bereits als Tipzellen kennen gelernt haben, ihre Geschichte mit der Geburt ahgeschlossen, denn sie unterliegen bei Pliys weiteren Teilungen ${ }^{1}$, sondern vergrößern sich, wie wir es bereits wissen, sehr bedeutend während der Ausbildung der Kopflblase und drei derselben: $a, c, d$ gehen in die letztere ein, wihhrend die vierte

1 Es wurde zwar eine äquale, bilaterale Teilung von $2 b^{1.1}$ dreimal beobachtet, sie scheint jedoch nur ausnahmsweise vorzukommen. 
$b$ zu einem Bestandteile des Prototrochs wird (Fig. 72-74). Hiermit haben sie ihr Endschicksal erreicht. Die korrespondierenden Zellen am vegetativen Pole $2 a^{2 \cdot 2}-2 d^{2 \cdot 2}$ bilden bekanntlich den $\mathrm{Ab}$ schluß der mittleren Zellreihe entsprechender Quadranten, lehnen sich am vegetativen Pole unmittelbar an das Entoderm an und gewinnen dadurch an Wichtigkeit, daß die Descendenten dreier von ihnen: $2 a^{2 \cdot 2}-2 c^{2 \cdot 2}$ bei Einstülpung der Entodermplatte an die Lippenränder des Gastrulamundes zu stehen kommen und in einzelnen Fällen das Stomodäum mitbilden helfen. Daher ihr Name "Stomatoblasten". Wenigstens hat sie ConkLIN und HoLMES unter dieser Bezeichnung angeführt und mit den oberen Descendenten derselben Mutterzellen, d. i. mit $2 a^{2 \cdot 1}-2 c^{2 \cdot 1}$, die Wilson als Stomatoblasten bei Anneliden betrachtet, homologisiert. Sie entstehen bei Physa, Planorbis, Umbrella, Crepidula, Limax, Ciona, Ischnochiton und Unio in der Weise aus ihren Stammzellen, daß die letzteren in eine obere und eine untere Tochterzelle zerfallen, während bei Anneliden diese Teilung transversal verläuft. Unter den genannten Molluskengattungen wurde die weitere Teilung von $2 a^{2 \cdot 2}-2 c^{2 \cdot 2}$ bloß bei Ischnochiton, Planorbis, Trochus, Unio und Physa beobachtet. Bei letzterer und bei Planorbis zerfällt jede von ihnen in eine kleinere untere an die Entodermplatte unmittelbar anstoßende $\left(2 a^{2 \cdot 2 \cdot 2}-2 c^{2 \cdot 2 \cdot 2}\right)$ und eine verhältnismäßig sehr große obere Tochterzelle $\left(2 a^{2 \cdot 2 \cdot 1}-2 c^{2 \cdot 2 \cdot 1}\right)$, welche im weiteren Umkreise zwischen den Zellen des dritten Quartetts sich ausspannen (Fig. 46 u. f.). Die weiteren Schicksale der oberen Descendenten konnten bis zur nächsten Teilung derselben mit aller Genauigkeit verfolgt werden. Sie teilen sich nämlich alle äqual und bilateral, ihre Descendenten verbleiben lange Zeit hindurch nebeneinander und können auf sehr vorgerückten Stadien noch leicht wieder erkannt werden; $b$ macht in der Teilung den Anfang, ihr folgen erst bedeutend später $a$ und $c$ (Fig. 60, 62, 64, 69). Das Schicksal der unteren Descendenten ist für $a$ und $c$ schwierig zu erforschen, denn sie bleiben bis zum Beginn der Einstülpung ungeteilt, ziehen sich bedeutend in die Länge, ihr Kern wird chromatinreicher, schließlich teilen sie sich (Fig. 70), und gelangen unter den Umbiegungsrand der Blastoporuslippen. Ihre Endschicksale werden bei der Gastrulation besprochen. Für $2 b^{2 \cdot 2 \cdot 2}$ ist die Teilung ebenfalls unzweifelhaft und sehr leicht festzustellen gewesen, weil sie viel früher als diejenige von $a$ und $c$ erfolgt und zwar in radialer Richtung (Fig. 60).

Die Descendenten der mit den besprochenen gleichnamigen 
Zelle $2 d^{2.2}$, wher deren Teilung bereits an andrer Stelle berichtet wurde, rerhalten sich insofern anders als diejenigen von $2 a^{2.2}-2 c^{2.2}$, als die untere derselben $\left(2 d^{2.2 .2}\right)$ nur zeitweise mit der Entodermscheibe im Kontakt bleibt und zwar mit der Makromere $4 D$, jedoch infolge der Vergrößerung und Vermehrung der beiderseitigen Nachbarzellen des dritten Quartetts $3 c^{22}$ und $3 d^{2.2}$ mehr und mehr seitlich zusammengedriickt und schließlich ganz nach außen zurückgedrängt wird (Fig. 65. 67, 70) - ein deshalb charakteristisches Verhalten, weil es nach Holses in derselben Weise bei Planorbis wiederkehrt. Sie verbleibt noch lange ungeteilt zwischen den Zellen des dritten Quartetts der Quadranten $c$ und $d$, sogar bis zur Einstulpung des Entoderms.

Wir haben uns bei Betrachtung der Schicksale der Descendenten von $2 a^{2.2}-2 d^{2.2}$ länger aufgehalten, weil sie in vergleichend embryologischer Beziehung wichtig sind. Nun schreiten wir zur Darstellung der weiteren Veränderungen in vorderen Quadranten $b$, dessen vier Hauptzellen $2 b^{1.2 .1}, 2 b^{1.2 .2}$ und $2 b^{2.1 .1}, 2 b^{2.1 .2}$, so viel an unsern Präparaten festgestellt werden konnte, bis zu einem Stadium von ungefähr 120 Zellen in Ruhe verharren. Bei Planorbis unterliegen sie nach HoLses überhaupt keiner weiteren Teilung, sondern vergrößern sich vor der Ausbildung des Prototrochs, ziehen sich in die Quere und wehmen schließlich an der Zusammensetzung desselben wesentlichen Anteil. Der Quadrant $b$ zeichnet sich an späteren Stadien infolgedessen durch seine im Verhältnisse zur bedeutenden Breite geringe Kürze aus, was Holwes der Verschiebung des apicalen Poles nach vorn zuschreibt und in letzterer auch die Ursache des Ausbleibens der Furchung dieser vier Zellen erblickt, wobei er jedoch auch ihre Schicksale mitspielen läßt. Die Verschiebung des apicalen Poles nach vorn, welcher diejenige des vorderen Kreuzarmes folgt, scheint allerdings einen hemmenden Einfluß auf die Entwicklung in die Länge des im Wege stehenden Quadrauten $b$ auszuliben, zumal er auch gegen die regretative Hälfte hin keine gïnstigen Bedingungen furr eine unbehinderte Entwicklung findet. Jedoch würden diese Erklärungen keineswegs zur Beantwortung der Frage ausreichen: warum sich die Zellen dieses Quadranten nicht in querer Richtung teilen, sol,ald in derselben kein Druck hemmend entgegenwirkt?

Die Verhältnisse bei Pluysa und zum Teil auch bei Planorbis sprechen gegen die Erklïrungsweise HoLnes'. Was erstlich die * forward rotation of the apical pole betrifft, so erklürt sie keineswegs, warum der Quadrant $b$ (zweites Quartett) in denjenigen Phasen ungeteilt rerharrt, wo noch keine Vorwärtsverschiebung des apicalen 
Poles und folglich auch gar kein Druck existiert. Ferner stellt sich bei Physa heraus, daß nicht nur sämtliche vier in Rede stehenden Zellen eine und zwar äquale Teilung erfahren, sondern daß sich die Descendenten späterhin von neuem teilen.

Die Teilung von $2 b^{1 \cdot 2 \cdot 1}$ und $2 b^{2 \cdot 1 \cdot 1}$ findet zu verschiedenen Zeiten statt, manchmal recht früh, an etwa 130-zelligem Stadium, bei 25 Zellen in der Kreuzfigur, zumeist aber bedeutend später (Fig. 67, 68). Charakteristisch ist der Umstand, daß die sich teilenden Zellen vorher ihre ursprüngliche Lage aufgeben und nach den Seiten auseinanderweichen, so daß die Tipzelle $2 b^{1 \cdot 1}$ in unmittelbare Berïhrung mit dem vegetativen Schwesterpaare $2 b^{1 \cdot 2 \cdot 2}$ und $2 b^{2 \cdot 1 \cdot 2}$ gelangt. Der Vorgang ist aus der Fig. 67 ohne weiteres ersichtlich. Die Tochterzellen kommen in demselben Niveau nebeneinander zu stehen. Die Teilung von $2 b^{1 \cdot 2 \cdot 2}$ und $2 b^{2 \cdot 1 \cdot 2}$ erfolgt zu einer Zeit, als sich sowohl in der Entodermplatte als auch im Kreuze mindestens je 30 Zellen befinden (Fig. 60, 62). Hier verbleiben die Mutterzellen im gegenseitigen Kontakt in der Medianebene, die abgeschnürten Tochterzellen riicken mehr nach unten und liegen in den Ecken zwischen der inzwischen geteilten Zelle $2 b^{2 \cdot 2 \cdot 1}$ und den Zellen des dritten Quartetts von $a$ und $b$. Beiden Teilungen ist das Eine gemeinsam, daß sie bei äqualer Zelldurchschnürung mehr in die Breite gehen, wie wir das für den Vorderarm des Kreuzes kennen gelernt haben. Allenfalls ist hierbei ein Einfluß der besagten Verschiebung der oberen Partie des Keimes nach vorn mit im Spiele, die Teilung. selbst ist aber von demselben unabhängig. Somit könnte man nur den zweiten von HoLMes vermuteten Grund des Ausbleibens der Teilung der obengenannten vier Zellen bei Planorbis (falls kein Beobachtungsfehler vorliegt) als plausibel gelten lassen, daß nämlich im gewissen Grade auch ihre Schicksale dasselbe bedingen und erklären. Da aber ihre Schicksale für Physc dieselben sind, d. i. die Beteiligung an der Bildung des Velums, and dennoch eine Teilung stattfindet, so ist es höchstwahrscheinlich, daß sie auch bei Planorbis stattfindet.

Beziiglich dieser Teilungen wäre noch zu bemerken, daß die beiderseitigen Zellen sich nicht immer gleichzeitig teilen, sondern öfters eine von ihnen bereits geteilt ist, während sich der Keru der andern noch im Ruhestadium befindet.

In den korrespondierenden Zellen der seitlichen Quadranten A und $C$ findet die Teilung von $2 a^{2 \cdot 1 \cdot 1}, 2 a^{2 \cdot 1 \cdot 2}$ und $2 c^{2 \cdot 1 \cdot 1}, 2 c^{1 \cdot 2 \cdot 1} \mathrm{zu}$ recht verschiedener Zeit statt, häufig zugleich mit den Teilungen im 
Quadranten B. Es konnte an mehreren Präparaten festgestellt werden, daß sie bald schon am Stadium mit 19 Zellen, bald erst mit 23 Zellen im Kreuze erfolgt.

Die betreffenden Descendenten der soeben besprochenen Teilungen gruppieren sich halbmondförmig um die Tipzellen. Die Zelle $2 a^{1 \cdot 1}$ wird von außen von $2 a^{1 \cdot 2 \cdot 1 \cdot 1 \cdot 2}, 2 a^{1 \cdot 2 \cdot 1 \cdot 1 \cdot 1}, 2 a^{2 \cdot 1 \cdot 1 \cdot 1 \cdot 2}$ und $2 a^{2 \cdot 1 \cdot 1 \cdot 1 \cdot 1}$, die Zelle $2 c^{1 \cdot 1}$ von $2 c^{2 \cdot 1 \cdot 1 \cdot 1 \cdot 1}, 2 c^{2 \cdot 1 \cdot 1 \cdot 1 \cdot 2}, 2 c^{1 \cdot 2 \cdot 1 \cdot 1 \cdot 1}$ und $2 c^{1 \cdot 2 \cdot 1 \cdot 1 \cdot 2}$ umgtirtet. Diese Zellen werden etwa bei 38 Zellen im Kreuze gebildet, aber niemals zu gleicher Zeit. Die Art und Weise, in welcher die Teilungen in allen drei Zellen vor sich gehen, ist am besten aus der nebenstehenden Textfigur $8 \mathrm{zu}$ entnehmen, wo sich eben die vordere rechte Zelle

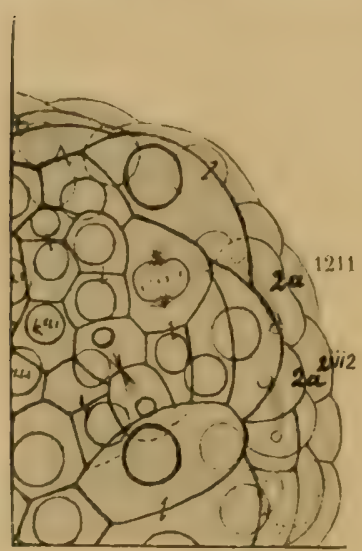

Textfig. 8.

Ansschnitt ans einer Figur mit $40 \mathrm{zel-}$ ligem Kreuz. $2 a^{1 \cdot 2 \cdot 1 \cdot 1}$ zerschniurt. Die Teilung der hinteren benachbarten Zelle $2 a^{1 \cdot 1 \cdot 2 \cdot 1}$ zeigt Fig. 59 am Stadium von 180 Zellen und 31-zelligem Krenze. Die vordere Mutterzelle an der linken Seite $2 c^{2 \cdot 1 \cdot 1 \cdot 1}$ teilt sich in ähnlicher Weise wie die rechte subäqual am 170-zelligen Stadium (Fig. 63). Die Teilung von $2 e^{1 \cdot 2 \cdot 1 \cdot 1}$ erfolgt zugleich mit $2 a^{2 \cdot 1 \cdot 1 \cdot 1}$ am ungefähr 180-zelligen Stadium.

Durch weitere Teilungen wird der erwähnte vierzellige Halbmond der seitlichen Tipzellen achtgliedrig. Genau wurde noch die Teilung der mittleren Zellen $2 a^{1 \cdot 2 \cdot 1 \cdot 1 \cdot 1}$ und $2 a^{2 \cdot 1 \cdot 1 \cdot 1 \cdot 2}$ verfolgt, ferner von $2 c^{2 \cdot 1 \cdot 1 \cdot 1 \cdot 2}$ und $2 c^{1 \cdot 2 \cdot 1 \cdot 1 \cdot 1}$, welche bei 35 Zellen im Kreuz stattfindet.

Im gleichen Schritt mit den aufgezählten Zellen teilen sich auch die benachbarten Descendenten der Zellen $2 a^{1 \cdot 2 \cdot 2}, 2 a^{2 \cdot 1 \cdot 2}$ und $2 c^{2 \cdot 1 \cdot 2}$, $2 c^{1 \cdot 2 \cdot 2}$. Die Zelle $2 a^{1 \cdot 2 \cdot 2 \cdot 1}$ teilt sich bei etwa 35 Zellen im Kreuze; das Zellenpaar $2 a^{2 \cdot 1 \cdot 2 \cdot 1}$ und $2 a^{2 \cdot 1 \cdot 2 \cdot 2}$, sowie die Zelle $2 c^{1 \cdot 2 \cdot 2 \cdot 1}$ teilen sich bei 38 Zellen im Kreuze (Fig. 65). Die an 2.2.2.1 angrenzende Zelle $2 c^{1 \cdot 2 \cdot 2 \cdot 2}$ teilt sich desgleichen äqual bei 27 Zellen im Kreuze, es wurde ferner auch noch die Teilung von $2 c^{1 \cdot 2 \cdot 2 \cdot 1}$ und $2 c^{1 \cdot 2 \cdot 1 \cdot 2}$ festgestellt. Diese und ihnen entsprechenden Teilungen beginnen erst zu jener Zeit, wo die Basalteile der Seitenarme des Kreuzes durch neue Zellaufteilungen $3-4$ zeilig zu werden beginnen.

Indem wir uns den Teilungsvorgängen im hinteren Quadranten $D$ zuwenden, müssen wir bemerken, daß zwar mehrere Teilungen in demselben an späteren Stadien zur Beobachtung gelangten, jedoch 
konnte nur für wenige die Descendenz sicher ermittelt werden, da bei gleichzeitiger, rascher Teilung in den Quadranten $C$ und $D$ im dritten Quartette öfters Verschiebungen stattfinden, welche die Orientierung stören. Die festgestellte Descendenz an einzelnen Zellen wurde in den Figuren 56-70 ersichtlich gemacht und in unsre genealogische Tabelle (s. hinter S. 576) aufgenommen.

Wie aus der letzteren ersichtlich ist, wurden im ganzen vom zweiten Quartette 77 Descendenten genetisch verfolgt. Die Unterschiede in der Zellvermehrung in den einzelnen Quadranten können am leichtesten an dieser Tabelle überblickt werden. Sie zeigt, daß der Quadrant $A$ aus 20, $B$ aus $15, C$ aus 23 und $D$ aus 19 Zellen besteht, daß also die Entwicklung in allen vier Quadranten ziemlich gleichmäßig abgelaufen ist. Der geringe Unterschied zwischen den beiden seitlichen Quadranten $A$ und $C$ hat für die Symmetrie des Keimes keine Bedeutung, dagegen zeigt die schwache Descendenz von $2 b$, welche am Stadium von etwa 180 Zellen oft kaum 10 Zellen beträgt, daß dieser Quadrant nur eine untergeordnete Rolle im Aufbau des Keimes spielt. In der Tat geht aus seinen Abkömmlingen ein Teil des Velums und der Wandungen des Oesophagus hervor, während die Quadranten $A, C$ und $D$, insbesondere aber der letztere, die Hauptmasse des somatischen Epithels liefern.

Sehr charakteristisch fur die Mutterzellen aller vier Quadranten ist die Erzeugung von kleineren Descendenten bei ihrer ersten Teilung, welche sich während der ganzen Entwicklung passiv verhalten. Es sind nämlich die Tipzellen, deren Verhalten und Endschicksale bereits oben besprochen wurden. Ein ähnliches Verhalten zeigen auch die unteren Descendenten von $2 a^{2 \cdot 2 \cdot 1}$ und $2 c^{2 \cdot 2 \cdot 1}$, welche bis zum Beginn des Verschlusses des Blastoporus ungeteilt bleiben.

\section{Geschichte des dritten Quartetts.}

Die exakte Erforschung der Entwicklung des dritten Quartetts, womöglich bis in die spätesten Phasen, hielt ich für eine sehr wichtige und dankbare Aufgabe. Es handelt sich nämlich hierbei nicht nur um sichere Anhaltspunkte für vergleichende Betrachtungen über das aus diesem Quartette entspringende »sekundäre Mesoderm ", sondern auch über seinen vermutlichen Anteil an der Konstituierung der Entodermanlage und der ektodermalen Organe. Übrigens bin ich außerdem betreffs des sekundären Mesoderms speziell bei Plysa eine Erweiterung und ausfuhrlichere Begründung derjenigen Angaben schuldig gewesen, die ich in der vorläufigen Mitteilung vom Jahre 1897 iuber 
dessen Lrsprung aus dem dritten Quartette verïffentlicht hahe. Es ist mir gelungen, die Descendenz bis zu 57 Zellen zu führen, alsn bis zu dieser verhältnismäBig hohen Zellenzahl eine sichere Basis für vergleichende Studien zu schaffen.

Über den fang der Entwicklung des in Rede stehenden Quartetts von seiner Anlage an his zu einer Phase, wo es hereits 30 Zellen zühlt, d. i. bis zu demjenigren Stadium. wo der ganze Keim aus 123 Zellen aufgebaut ist, haben wir bereits oben eingehend berichtet und wollen an dieser Stelle bloB an die Hauptpunkte erinnern. Wie aus der Übersicht del Furchung S. ¿ō1 ersichtlich ist, entstehen am Stadium ron 28-33 Zellen aus $3 a-3 d$ vier nene Zellen durch eine radiale und inäquale Teilung, welche uns hier insofern interessiert, als sie bei typischer Furchung discordant verliuft, so zwar, daß an der vegetativen Eihälfte zwei graße vordere Zellen zwei kleinen hinteren entsprechen Taf. XIX, Fig. 22-27) und an der animalen gerade das ('tegenteil stattfindet (Taf. XIX, Fig. 21, 24), ferner, daß die Furchungsrichtung beider Paare ebenfalls entgegengesetzt ist. In diesem Teilungsmodus sind bereits die Bedingungen fur den Unterschied in der weiteren Entwicklung der beiden Quadrantenpaare und somit auch des ganzen Keimes gegeben und die Rolle einzelner Glieder derselben rorgezeichnet. Aus den zwei großen vorderen Descendenten $3 a^{2}, 3 b^{2}$ soll sich nämlich das sekundiire Mesoderm in der Folge entwickeln, sie haben somit noch mehrere Teilungen durchzumachen, his sie schlieBlich als reine Mesodermzellen in die Furchungshïhle ihre weiteren Schicksale tibertragen. Dagegen verbleiben ibre kleineren, den beiden hinteren Quadranten angehörigen Altersgenossen $3 r^{2}, 3 d^{2}$ bis in sehr vorgertickte Entwicklungsstadien des Keimes in Ruhe, um endlich drei Paare von Nachkommen zu erzeugen. Ïhnlich verhält es sich mit den vier Zellen der oberen Etage. Die zwei vorderen kleineren machen verhältnismäßig wenige Teilungen, und diese erst ziemlich spät, durch; ihre Descendenten spielen eine untergeordnete Rolle am Aufbau des Keimes, wogegren die größeren hinteren Zcllen $3 c^{1}$ und $3 d^{1}$ ihrer späteren Rolle entsprechend mehrere Differenzierungsteilungen durchmachen.

Sehr charakteristisch für die nächstfolgenden Entwicklungsphasen des dritten Quartetts ist das frühe Auftreten der bilateralen Teilung in allen seinen Gliedern, ausrenommen zwei, d. i. $3 r^{2}$ und $3 d^{2}$. in welchen sie, wie erwähnt, erst viel später vor sich geht. Es sind wieder die korrespondierenden grö̈ßeren, aber in verschiedenen Etagen liegrenden Zellen, 1 ämlich $3 a^{2}, 31,2,3 c^{1}, 3 d^{1}$, die sich fust 
gleichzeitig äqual und bilateral teilen; die beiden vorderen liefern die beiderseitigen paarigen Anlagen des sekundären Mesoderms, die beiden hinteren hauptsächlich das Material für die somatische Ectodermplatte. Die vier Mesodermanlagen $3 a^{2.1}, 3 a^{2.2}, 3 b^{2.1}, 3 b^{2.2}$ lehnen sich dem Entoderm von den Seiten unmittelbar an, dessen vordere Begrenzung durch eine Zelle des zweiten Quartetts $2 b^{2} 2$ bewerkstelligt wird. Die hinteren ectodermalen Glieder stehen über den unpaaren Schwesterzellen $3 c^{2}, 3 d^{2}$, welche sich wieder an das Mesoderm und Entoderm anlehnen (Fig. 33).

Recht bald und ohne längere Vorbereitung folgt die bilaterale Teilung der beiden vorderen kleineren Zellen $3 a^{1}, 3 b^{1}$ (Fig. 36); ihre kleinen Descendenten $3 a^{1.1}, 3 a^{1.2}, 3 b^{1.1}, 3 b^{1.2}$ haben ein helles Plasma und kleine Kerne und lehnen sich oben an die entsprechenden Trochoblasten, inten an die entsprechenden Mesodermzellen an. Nach dieser Teilung bestehen die vorderen Quadranten aus je zwei Paaren, die beiden hinteren dagegen aus je drei Zellen, das ganze Quartett also aus 14 Zellen. Während die letztgenannte Teilung noch im Gange ist, bereiten sich schon die vier Mesodermanlagen zur neuen Teilung vor, welche aber diesmal schief gegen die vorhergegangene, bilaterale ausgefuhrt wird. Unsre Fig. 36 und 40 zeigen ihre Richtung und ihren Ausgang so genau, daß eine nähere Beschreibung überflüssig ist. Die kleinen im Absatze »Furchung " als zwerghafte Zellen bezeichneten Descendenten werden mit Chromatin reich ausgestattet und der nunmehr aus zehn Zellen bestehenden Entodermplatte zugefügt, mit der sie von nun an unzertrennlich verbunden bleiben. Nach vollzogener Teilung senden die Mesodermanlagen lange Fortsätze gegen die Furchungshöhle aus, mittels deren sie sich mit dem Entoderm fiir kurze Zeit in innigen Kontakt setzen.

Die hinteren paarigen Zellen $3 c^{1.1}, 3 c^{1.2}$ und $3 d^{1.1}, 3 d^{1.2}$ (Fig. 33), welche bisher mit den vorderen im Furchungsgange gleichen Schritt hielten, tun dies auch jetzt; sie schniiren nämlich, wie aus den Fig. 40-42 ersichtlich ist, ebenfalls gegen den vegetativen $\mathrm{Pol}$ zu zwerghafte und verhältnismäßig ziemlich chromatinreiche Zellchen ab und schwellen im Laufe dieses Vorganges ebenso wie die Mesodermanlagen vor dem Abschniiren ihrer kleinen Zellen mächtig au, was auf wichtige, innere, mit diesem Vorgange verbundene Prozesse hinzudeuten scheint. Vergleicht man die Art der Zusammensetzung: des dritten Quartetts in dieser Entwicklungsplase bei Plyysa und Planorlis (HoLmes), - bei letzterer Gattung mit Zuhilfenahme der Fig. 24, so fällt die tiberraschende Übereinstimmung im Erfolg der 
bisherigen Teilungen sofort auf. Indem wir an dieser Stelle diese Tatsache mit Nachdruck hervorheben und sie erst später für unsre Homologieschliisse ausnutzen wollen, fligen wir gleich hinzu, daß in der Weiterentwicklung des Mesoderms bei den erwähnten zwei Gattungen von nun an namhafte Differenzen auftreten, welche wir weiter unten eingehend besprechen.

Wir schreiten nun zur weiteren Übersicht der Zellenvermehrung im dritten Quartette bei Plıysa. Kaum, daß die soeben erwähnten zwerghaften Zellen seitens der hinteren zwei Makromerenpaare abgeschnürt worden sind, bereiten sich schon die beiden vorderen Paare $3 a^{2 \cdot 1 \cdot 1}, 3 b^{2 \cdot 1 \cdot 1}$ und $3 a^{2 \cdot 2 \cdot 1}, 3 b^{2 \cdot 2 \cdot 1}$ zur Abschnürung von zwei neuen, diesmal etwas größeren Mikromerenpaaren, die aber erst im Stadium von über 112 Zellen ganz vollzogen wird (Fig. 38, 46, 48). Diese zwei neuen Pare schließen sich den vorher erzeugten und an das Entoderm angefügten unmittelbar an. Die in hohem Grade inäquale und in kurzen Intervallen sich zweimal wiederholende Teilung der vier Mesodermanlagen deutet unsrer Ansicht nach auf einen recht erfolgreichen Differenzierungsprozeß hin. Es mag nebenbei erwähnt werden, daß zu gleicher Zeit das bisher durch ein einziges Zellenpaar repräsentierte Urmesoderm sich ebenfalls geteilt hat und somit eine vollkommene Harmonie in der Anlage der vorderen und hinteren Mesodermstreifen besteht. Jede von ihnen setzt sich aus je vier Makromeren zusammen, nur besitzt das Urmesoderm um ein Mikromerenpaar mehr, welches zwar nach dem Vorbilde des vom sekundären Mesoderm abgeschnürten ersten Paares von Zwergzellen entstanden ist und ebenfalls der Entodermscheibe angefügt wurde, ja sogar noch jetzt nicht ganz in die Furchungshöhle versunken ist, jedoch später in dieselbe vollständig versinkt, was mit den entsprechenden Zwergzellen des sekundären Mesoderms nicht der Fall ist. Werfen wir, bevor wir weiter gehen, noch einen raschen Blick auf die Zusammensetzung des dritten Quartetts etwa auf dem Stadium von 116-123 Zellen, so sehen wir, daß jeder vordere Quadrant aus je acht Zellen und jeder hintere aus je sechs bzw. sieben Zellen besteht, je nachdem sich bloß eine oder beide Makromeren zum zweiten Male geteilt haben. Im letzteren Falle beträgt die Gesamtzahl seiner Komponenten 30, d. i. diejenige Ziffer, zu der wir die Geschichte dieses Quartetts in der allgemeinen Darstellung des Furehungsganges bereits geführt haben.

Unsre weiteren Angaben über die Entwicklung dieses Quartetts muissen naturgemäß in zwei Rubriken zerfallen. In der ersten 
wollen wir die weiteren Schicksale der vier Mesodermzellen, welche wir von nun an kurz mit $S M$ bezeichnen wollen, behandeln, in der zweiten dagegen die Schicksale der übrigen Zellen. Wir haben die ersteren in dem Augenblicke verlassen, wo sie in die Furchungshöhle zu versinken begonnen haben. Betrachtet man sie in jener Phase im optischen Querschnitt, so sieht man (Fig. 51), daß sie mit ihren dicken Fortsätzen tief in der Furchungshöhle stecken, so daß nur kleine Teile ihrer änßeren Oberflächen hinter den Mikromeren von außen sichtbar sind (vgl. Fig. 57). Sehr bald aber, etwa zwischen dem 124- und 130-zelligen Stadium, treten sie wieder aus der Furchungshöhle mit einem großen Teil ihres Körpers an die Keimoberfläche heraus und dies ist der Zeitpunkt, wo sie die Teilungsspindeln ausbilden ${ }^{1}$. Die Teilung ist fast äqual (Fig. 54), eine von den Tochterzellen wird nach hinten und oben geschoben, die andre schaut, wie vorher die Mutterzelle, aus der Furchungshöhle heraus, alle acht stellen sich nach vollzogener Furchung und nach Übergang in das Ruhestadium so auf, $\mathrm{daB}$ sie eine in der Mitte ziemlich breit unterbrochene halbkreisförmige Doppelreihe bilden, wobei die Glieder derselben in schiefer Richtung hintereinander zu stehen kommen. Später wird aus dieser doppelten Reihe bloß eine einfache. Das Nähere ist aus den Fig. 58-66 zu ersehen. Wir wollen nur den Leser darauf aufmerksam machen, daß die beiden Mesodermanlagen, d. i. die vordere und die hintere, jetzt schon einen (mit Ausnahme einer Liicke im vorderen Keimbezirke) geschlossenen Ring bilden. Die neu entstandenen vier Zellen bilden die erste Generation der sekundären Mesodermzellen, welche wir mit $S M^{2}$ bezeichnen wollen2. Die nachfolgende Generation wird erst bedeutend später, etwa auf einem Stadium von etwa 160 Zellen angefangen, erzeugt. Während sich die acht Zellen zur Erzeugung einer neuen Generation vorbereiten, sieht man sie wieder in je zwei Doppelreihen gruppiert (Fig. 66). Der Vorgang der Teilung scheint längere Zeit in Anspruch zu nehmen und ist bei dieser hohen Zellenzahl im Keime schwer im einzelnen zu verfolgen, es kann jedoch als eine feststehende Tatsache angegeben werden, daß die Teilung eine beinahe vollkommen äquale

1 Das Versinken der Mesodermzellen in die Furchungshöhle und ihr Wiederauftauchen ist vom entwicklungsmechanischen Stande eine sehr interessante Erscheinung, welche nach unsrer Ansicht durch den Turgor der Zellen und ihre gegenseitige Pressung nicht erklärt werden kaun, soudern als aktiv angesehen werden muß.

$23 a^{21112}, 3 a^{22112}, 3 b^{21112}$ und $3 b^{22112}$. 
ist und, nach vielen Figuren zu schließen, nicht synchron vor sich geht, so daß man Stadien mit 10,12, 14, 16 Zellen findet, wo bald diese, bald jene, bald auf der rechten, bald auf der linken Seite geteilt ist (Fig. 66, 82).

Nachdem nun das sekundäre Mesoderm sich bis anf 16 Zellen vermehrt hat, hat auch der Keim eine hohe Entwicklungsstufe erreicht. Das erste Quartett zählt jetzt iiber 40, das zweite beiläutig 60, das dritte etwa 50 Zellen usw. Es braucht somit kaum erörtert zu werden, wie schwer sich die weitere Verfolgung der Schicksale des sekundüren Mesoderms bei einer so hohen Zellenzahl gestalten muß. Mich hat die weitere Descendenz deshalb interessiert, weil ich, aus den Verbältnissen bei L'nio schließend, in dem sekundären Mesoderm eine innige Beziehung zu einem larvalen Organe, d. i. zu der Urniere, zu finden hoffte. Diese Frage wollen wir im Kapitel $\nsim$ Lrniere näher besprechen. Hier mag in bezng auf die weitere Produktion von Descendenten des sekundären Mesoderms iiber 16 Zellen hinaus nur soviel bemerkt werden, daß in den nächstfolgenden Phasen die iqquale Teilung zweifellos noch weiter in allen 16 Zellen vor sich geht, jedoch wieder in einer sehr unregelmäßigen Aufeinanderfolge. In sehr rorgeriickten Stadien, namentlich während der Gastrulation, treten anffalleud inäruale Teilungen auf, es werden nämlich nach dem Vorbilde der Lrmesodermzellen seitens der Zellen des sekundirren Mesoderms chromatinreiche Mikromeren erzeugt Fig. 84 , denen wir in den allgemeinen Betrachtungen iber das Mesoderm bei Physa noch einige Worte widmen wollen.

Wir haben noch die weitere Entwicklung ron denjenigen Zellen des dritten Quartetts zu besprechen, welche dem sckundïren Mesoderm nicht angehören. Unsre Beobachtungen über ihre Teilungen lassen sich kurz zusammenfassen, denn es wurde nur die Teilung von 13 Zellen derselben sicher festgestellt. Die am hinteren Rande der Entodermplatte liegenden Zellen $3 c^{2}$ und $3 d^{2}$, welche bis zum Stadium von etwa $13 \pm$ Zellen in Ruhe verharren, teilen sich zweimal stark inäqual; am Gastrulastadium wurde noch eine dritte Teilung beobachtet. Die kleinen Descendenten licgen sodann unmittelbar an die Entodemplatte angeschlossen und nach außen von ihnen die Mikromeren andrer Mutterzellen der Quadranten $c$ und $d$. Die Richtung dieser Teilungen, sowie die Größe und Gruppierung der Descendenten ist aus den Fig. 57, 64, 69 ersichtlich.

Die paarigen Zellen in den vorderen Quadranten $3 a^{1 \cdot 1}, 3 a^{1 \cdot 2}$, $3 \zeta^{1 \cdot 1}$ und $3 l^{1 \cdot 2}$ teilen sich vollkommen iibereinstimmend radial und 
fast äqual auf einem Stadium von beiläufig 150 Zellen (Fig. 57). Ihre unteren Descendenten schließen sich unmittelbar den von den Mesodermanlagen erzeugten Mikromeren an und wachsen später stark in die Quere, was sich auch an ihren Schwesterzellen feststellen lïßt (Fig. 67). Ihre weiteren Teilungen erfolgen erst während des Verschlusses des Blastoporus, wenigstens ist eine derselben sicher festgestellt worden (Fig. 71). Von den vier Descendenten der Zellen $3 c^{1 \cdot 1 \cdot 1}, 3 d^{1 \cdot 1 \cdot 1}$ und $3 c^{1 \cdot 2 \cdot 1}, 3 d^{1 \cdot 2 \cdot 1}$ beginnen einige ihre weitere Teilung bereits bei 134-zelligem Keime, andre hingegen erst bei 134-150zelligem und zwar sind es die unteren Paare, an welche zunächst die Reihe kommt. Ihre fast äqualen Descendenten liegen anfangs in demselben Niveau nebeneinander, später werden sie etwas schief verschoben (vgl. Fig. 53, 57, 62).

Nach erreichten 170 Zellen bis zum Stadium von 180 Zellen findet die Teilung der oberen Paare statt, wobei sich keine bestimmte Aufeinanderfolge feststellen läßt (Fig. 63). Man beobachtet nämlich die Teilung oft an jüngeren Stadien, während sie an bedeutend älteren nicht vorkommt.

Die beigegebene Tabelle möge auch hier die genealogischen Beziehungen im dritten Quartett veranschaulichen. In derjenigen Entwicklungsphase, in der wir unsre Darstellung abschließen, etwa bei über 200 Zellen im ganzen Keime, steigt die Zellenzahl in diesem Quartette bis 58. Die Zahl 57 der Tabelle erklärt sich dadurch, daß die mutmaßlichen Descendenten der Zelle $3 d^{1 \cdot 1 \cdot 1 \cdot 2}$, deren Teilung nicht direkt gesehen werden konnte, nicht mitgezählt worden sind.

Vergleicht man die Tabelle mit den entsprechenden Figuren, so fällt der übereinstimmende Teilungsmodus in den vorderen und hinteren Quadranten sofort auf.

Auf die Abgabe der ersten kleinen Tochterzellen nach entgegengesetzter Richtung folgt nämlich fast synchron eine iqquale, bilaterale Teilung aller vier Mutterzellen und auf diese eine stark inäquale, deren Resultat die Bildung von kleinen Zellen ist, welche bis zur Gastrulation ganz untätig verbleiben. Die nächste Teilung ist wieder in allen vier Mutterzellen inüqual, es werden aber diesmal größere Tochterzellen abgeschnürt und wie bei der ersten Teilung. in entgegengesetzter Richtung. Auf diese zwei inäqualen folgt abermals eine äquale, ganz übereinstimmende Teilung in allen Mutterzellen.

Bei der weiteren Furchung treten schon Differenzen auf, entsprechend der verschiedenen Rolle, welche die Descendenten beider Quartettenpaare am Ausbau des Keimes zu spielen haben. Diejenigen 


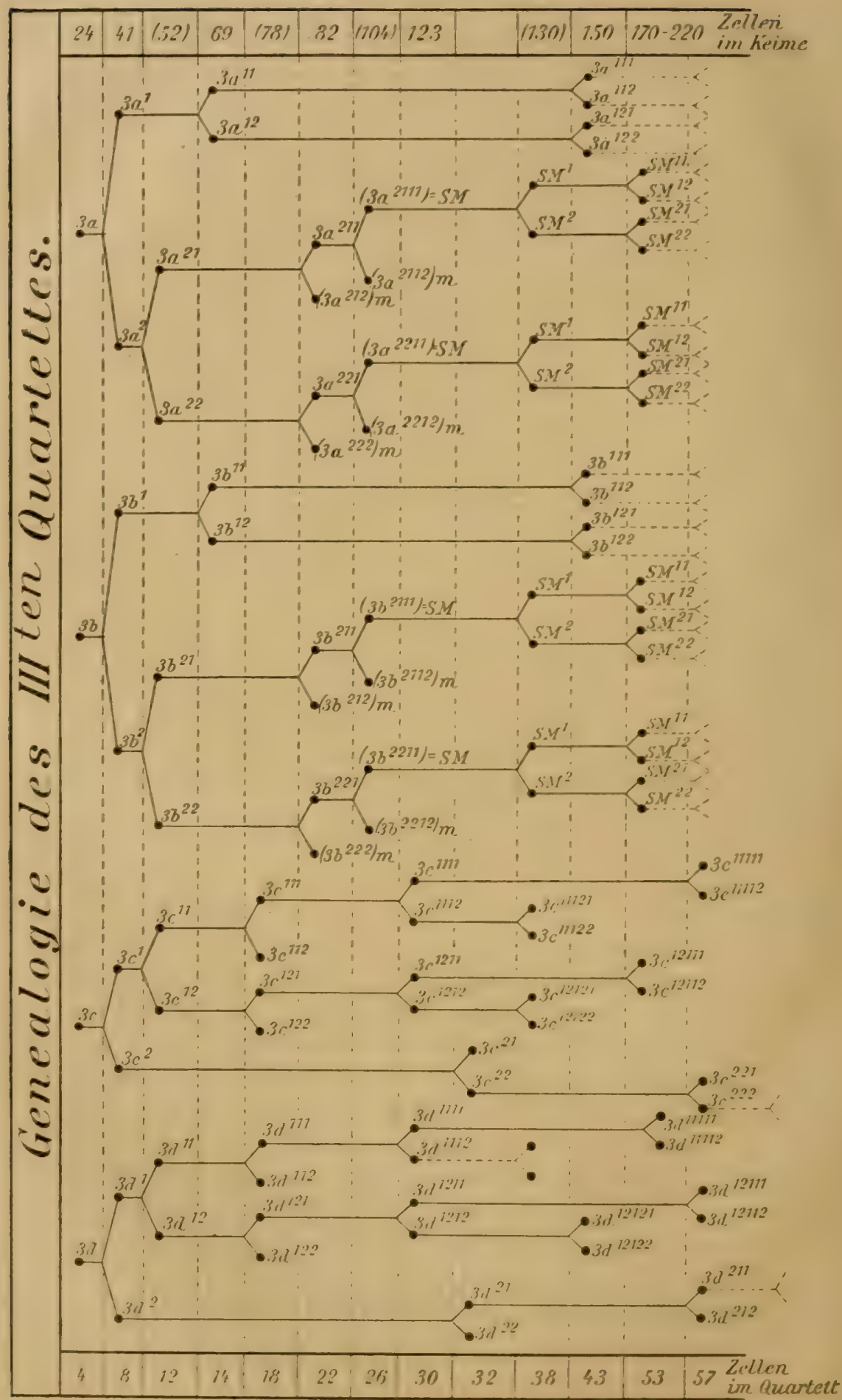




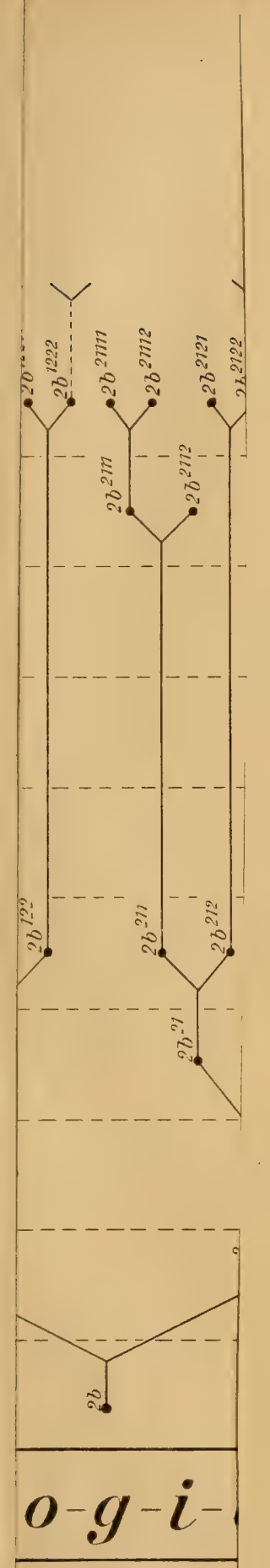





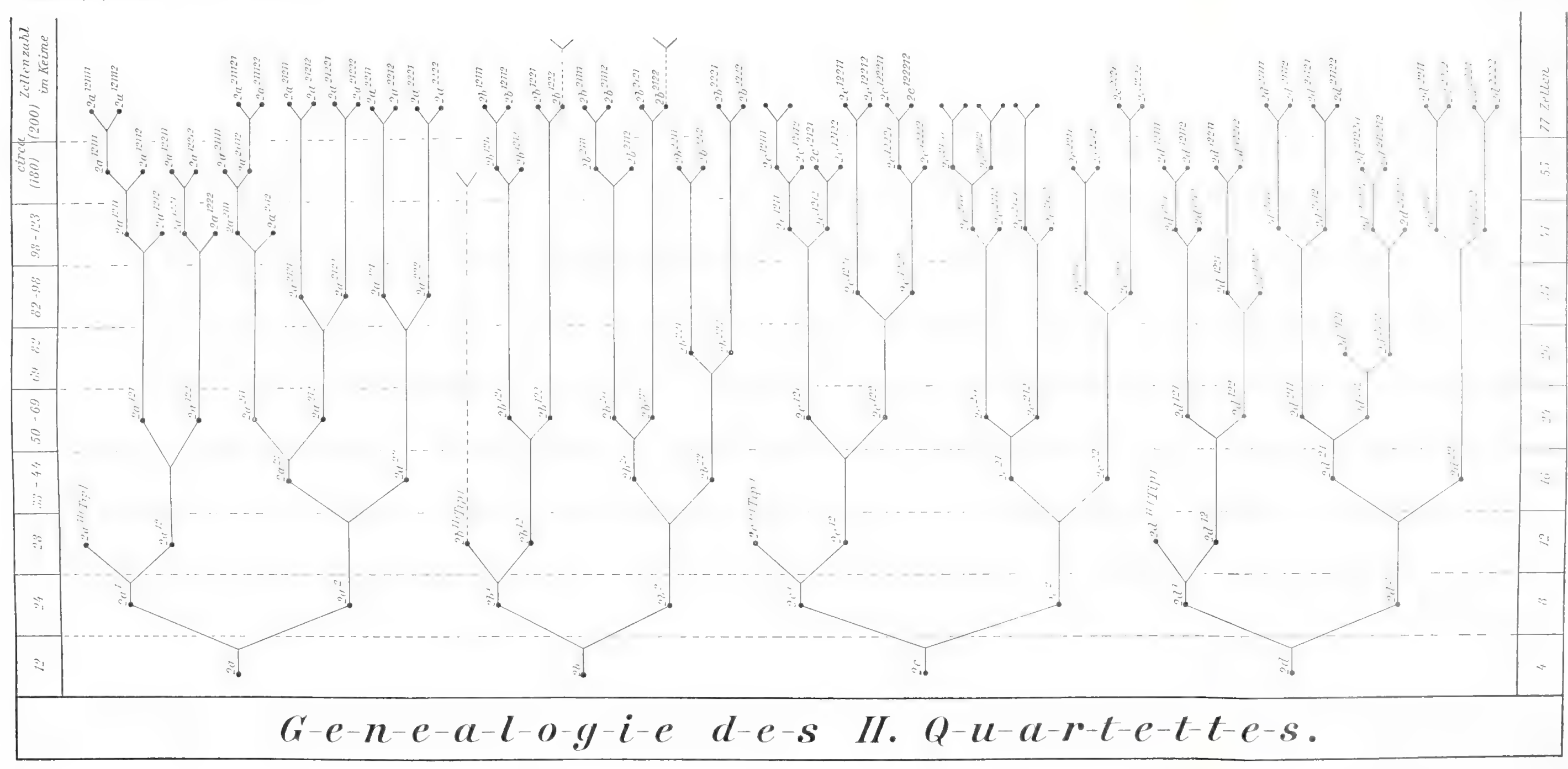



der vorderen bilden bekanntlich hauptsächlich das sekundäre Mesoderm, während diejenigen der beiden hinteren Quadranten nur das Ectoderm liefern,

Die Endschicksale der kleinen, an die vegetative Keimhälfte abgegebenen Descendenten werden an entsprechenden Stellen besprochen.

\section{Zahl der Ectomerenquartette.}

Bei Physa werden nur drei Ectomerenquartette gebildet. Nach den bisherigen Untersuchungen über den Furchungsprozeß der Anneliden und Mollusken kann man die Erzeugung von nur drei Generationen sogenannter Mikromeren oder Ectomeren als ein Furchungsgesetz ansehen. Demselben folgen in vollkommen gleicher Weise die holoblastischen Eier der Anneliden und Mollusken, gleichgültig ob die Furchung äqual oder inäqual, ob das Ei groß oder klein, ob es dotterreich oder dotterarm ist.

Die wenigen Ausnahmen von der allgemeinen Norm sind bereits von Conklin ('97) und neulich von RoBert ('03) eingehend besprochen worden und es geht sowohl aus den theoretischen Ausführungen dieser Forscher, als insbesondere aus einigen Beobachtungen ConkLINs an nächst verwandten Formen unzweifelhaft hervor, daß die betreffenden Angaben sowohl älterer als auch neuerer Forscher entweder auf ungenaue Beobachtung oder unrichtige Deutung zurückzuführen sind. Solange also keine unerschütterlichen Tatsachen dagegen sprechen, dürfen wir die Erzeugung von drei Ectomerenquartetten, nicht mehr und nicht weniger, als eine in der Ontogenie der Anneliden und Mollusken allgemein verbreitete und mit hartnäckiger Konstanz wiederkehrende gesetzmäßige Erscheinung annehmen.

ConkLin ('97) betrachtet dieselbe mit Recht als die merkwürdigste im ganzen Furchungsprozesse der genannten Tiergruppen und glaubt sie wäre darin begründet, daß jedes der drei Ectomerenquartette »ein Protoblast für bestimmte Körperregionen und Organe der Larve sei «. Nach dieser Auffassung würde auch die relative Größe einzelner Ectomerenquartette bei bestimmten Formen in einer engen Beziehung zur relativen Größe der aus denselben hervorgehenden Körperteile und Organe sowie zur relativen Zeit ihrer Ausbildung stehen.

Dieser Forscher nimmt ferner an, daß mit der Abgabe der dritten Generation von Ectomeren bereits eine definitive Sonderung des Eimaterials in distinkte Keimblätter durchgefubrt ist (\$but at 
this early stage we have two layers, ectoblast and mesentoblast perfectly differentiated = p. 61).

Mit der Auffassung der Ectodermquartette als Organanlagen sind wir vollkommen einverstanden, können aber die definitive Sonderung der Keimblätter auf diesem frihen Entwicklungsstadium aus dem Grunde nicht zugeben, weil bekanntlich die sog. Ectodermgeneration noch an bedeutend späteren, ja sogar sehr späten Stadien mesodermale Elemente, d. i. das sekundäre Mesoderm (Ectomesoblast) liefert, aus welchem nicht ausschließlich larvale sondern auch definitive Organe hervorgehen können und welches z. B. bei Physa die Hauptmasse des ganzen Mesenchyms liefert.

Es existiert also auf diesem friben Stadium von 24 Blastomeren durchaus nicht eine ganz reine Ectomerengeneration im Sinne CoNkLiss und andrer Forscher, sondern eine Generation von noch gemischten Elementen, welche erst später abgesondert werden. Wie im Abschnitte iiber das sekundäre Mesoderm näher erörtert wird, kann sogar die erste Ectomerengeneration nicht als rein ectodermal angesehen werden, da auch aus ihr mesenchymatische Elemente hervorgehen können (Thalassema).

Was die Makromeren betrifft hat CoNKLIN vollkommen recht, wenn er dieselben nach Abgabe von drei Generationen als reine Entomesoblasten betrachtet, denn sie liefern von nun an keine ectodermalen Elemente mehr, sie sind in der Tat "perfectly differentiated., wie dies bereits beim 24-zelligen Furchungsstadium näher erörtert wurde.

Wir glauben somit nicht irre zu gehen, wenn wir annehmen, daß die dreimalige Teilung der vier ursprünglichen Makromeren nicht so sehr die Erzeugung des äußeren Keimblattes, als vielmehr die eigne Differenzierung derselben zum Zwecke hat, die wesentlich in der Sonderung des deutoplasmatischen Materials and Konzentrierung desselben in den vier Makromeren besteht. Nach dieser Differenzierung und nach Abgabe des Urmesoderms von $D$, ibernehmen die Entodermzellen $A, B, C$ während der ganzen weiteren Furchung die Rolle von Nährzellen, welche sie auch fernerhin während der Konstituierung der Organe beibehalten. Wir fassen somit die typische dreimalige Teilung der vier urspringlichen Makromeren als eine Differenzierungsteilung auf. Zur Stiitze dieser Ansicht möchten wir auf ganz analoge Teilungen der primären und sekundüren Mesoblasten hinweisen, bei welchen zunächst ganz kleine, dann etwas größere Descendenten abgeschniurt werden, worauf sich die 
Mutterzellen äqual oder subäqual teilen. Die Makromeren $A, B$, $C, D$ erzeugen ebenfalls zunächst das ganz kleine erste Quartett, dann das etwas größere zweite und schließlich teilen sie sich subäqual, wobei das dritte Quartett gebildet wird. Derselbe Teilungsmodus läßt sich außer bei Physa noch bei vielen andern Formen feststellen.

Wir hätten somit in der gesetzmäßigen Erzengung von nur drei Ectomerenquartetten eher eine allgemeine Differenzierungserscheinung zu erblicken, als eine definitive Sonderung der Keimblätter. Der neutrale Charakter der Ectodermgeneration äußert sich nicht nur in der Tatsache, daß aus ihr das sekundäre Mesoderm entspringt, sondern auch darin, daß aus dem Ectoderm bei einigen Formen solche Organanlagen hervorgehen, die sonst vom Meso- oder Entoderm ihren Ursprung nehmen. Wir brauchen nur diesbezüglich auf die Verhältnisse bei Limax und Dreissensia hinzuweisen, wo der ganze Darm, das Herz, Perikard und die Geschlechtsdrüsen aus dem Ectoderm abgeleitet werden.

\section{Geschichte des Entoderms.}

Die Entwicklung des Entoderms beginnt erst mit dem Stadium von 28-29 Zellen, auf welchem die definitive Sonderung des mesoblastischen Materials vom entoblastischen stattfindet. Es teilt sich nämlich die hintere Makromere $3 D$ auffallend inäqual, wobei in die verhältnismäßig sehr große Tochterzelle $4 d$ das mesodermale, wogegen in die verhältnismäßig sehr kleine Mutterzelle $4 D$ das entodermale Material übergeführt wird.

Nach dieser Differenzierungsteilung besteht die Entodermanlage aus vier Makromeren von ungleicher Größe und ungleichem Alter, nämlich aus $4 D$ und $3 A-3 C$, aus denen sich das ganze Entoderm entwickelt. An seiner Erzeugung nimmt die kleinste von den Makromeren $4 D$ den geringsten Anteil, da sie sich während der regsten Teilung der drei übrigen ganz passiv verhält und erst nach vollkommener Ausbildung der Entodermplatte, oft erst beim Beginn ihrer Einstuilpung sich zum ersten Male teilt. Es beschränkt sich somit die Geschichte des Entoderms auf die Darstellung der Furchungsvorgänge in den drei Quadranten $A, B, C$, in welchen sie vollkommen harmonisch verlaufen, weswegen wir in der genealogischen Tafel (S. 582) bloß einen von ihnen (A) beriicksichtigt haben, nebstdem noch die zwei Teilungen von $4 D$.

Der nächste Schritt in der Entwicklung der genannten drei Makromeren wird erst auf dem Stadium von 41-44 Zellen'gemacht. 
Ihre Teilung wird durch kolossale Vergrößßerung ihrer Kerne und ein starkes Hervorquellen der Zellen sellsst eingeleitet und erfolgt ganz nach dem Vorbilde der Teilung von $3 D$, d. i. es werden in liatroper Richtung drei kleine Makromeren $4 A-4 C$ nach dem vegetativen Pole abgegeben, während die großen sogenannten Mikromeren $4 a-4 c$ hinter die entsprechenden Makromeren gegen die Peripherie zu liegen kommen. Aus den drei neuen Makromeren und der zuvor gebildeten $4 \mathrm{D}$ entsteht die Polrosette, in welcher $4 \mathrm{~B}$ und $4 \mathrm{D}$ unter Bildung einer Polarfurche im Centrum zusammenstoßen. Die Polrosette besteht nun aus kleineren und verhältnismäßig wenig Dotter enthaltenden Zellen, deren Konturen oft sehr schwer zu sehen sind, da sie an der Oberfläche abgeplattet sind und mit der Hauptmasse ihres Körpers in der Furchungshöhle stecken.

Während die letzte Teilung noch vollkommen nach dem spiralen Typus abläuft, kommt bei allen nachfolgenden der radiale immer deutlicher zum Ausdruck, namentlich sind es die median gelegenen Zellen, deren Teilung vollkommen bilateral ist. In den drei Zellen des vierten Quartetts folgen vor der Einstillpung der Entodermplatte drei Teilungen aufeinander, durch welche diese Zellen in 6, 12, 24 Descendenten zerlegt werden und um die Polrosette schließlich zwei Zellenkränze bilden. Das Charakteristische dieser Teilungen besteht darin, daß ibre Richtungen alternieren und daß sie ganz oder beinahe ganz äqual sind. Während der Ausbildung der Furchungsbilder bemerkt man zwar in den schief gegen die Medianebene und nach oben gerichteten Achsen der Spindeln eine Tendenz zur spiralen Teilung, namentlich in den seitlich liegenden Zellen, jedoch stellen sich die Schwesterzellen nach vollzogener Durchschniurung stets in dieselbe Ebene, bald hinter-bald nebeneinander. Nach jeder Teilung schicken die neu entstandenen Zellen lange Fortsätze in die Furchungshöhle aus, welche vor der Ausbildung der Spindeln für die nächstfolgende Teilung wieder eingezogen werden, worauf die betreffenden Zellen sich abrunden und über das Niveau der übrigen hervorquellen. Diese Erscheinung heruht auf einer aktiven Bewegung des Cytoplasmas und nicht etwa auf dem Turgor der Zellen, wie es mauche Forscher haben wollen 1 .

Was die Teilungsperioden selbst betrifft, so findet die Zerlegung der ersten drei Zellen des vierten Quartetts in sechs auf dem Stadium

1 Conklix beschreibt bei Crepidula die oberflichliche I age rler Nuclei der vier Makromeren gerade vor den Ectoblastzellen und ihre Bewegung um den animalen Pol. S. 153. 
von etwa 59 Zellen, die zweite in 12 Zellen anf dem Stadium von 81-92, die dritte in 24 auf dem Stadium von etwa 135-150 Zellen statt. Bereits nach der zweiten Teilung hat sich der krasse Gegensatz zwischen. den Mikromeren und Makromeren ausgeglichen, die Entodermscheibe besteht jetzt aus kleinen Zellen und hat die Gestalt einer flachen, muschelförmigen Platte mit sechs hinten konvergierenden Zellstrahlen angenommen (Fig. 46, 48, 50).

Auf dem Stadium von 105 Zellen wird das fünfte Quartett bloß aus drei Zellen $5 a-5 c$ erzeugt, da $4 D$ noch immer in Ruhe verharrt. Auf die Bildung von $5 a-5 c$ folgt erst die Zerlegung der bisher gebildeten 12 Zellen des vierten Quartetts in 24 und zwar erst am Stadium von 135 Zellen, wobei weder eine bestimmte Ordnung noch eine bestimmte Zeitfolge festzustellen ist. Deshalb ist die richtige $\mathrm{Be}-$ stimmung der 24 Descendenten mitunter mit Schwierigkeiten verbunden.

Betrachtet man ein Stadium, in welchem die Entodermplatte bereits aus 31 Zellen besteht, d. i. aus 24 des vierten Quartetts, drei des füntten und vier Makromeren, zumal ein solches, wo alle diese Zellen in Ruhe sind (Fig. 60), so fällt ihre Gruppierung nach Art von Zuwachsstreifen einer Muschelschale sofort auf. Die 24 Zellen des vierten Qnartetts bilden die zwei äußeren Kränze von je sechs Zellpaaren, der innerste Kranz besteht aus den Makromeren $A$ und $C$ und den drei Zellen des fünften Quartetts, das Centrum nehmen $5 B$ und $4 D$ ein.

Die weiteren Teilungen, welche uber 31 Zellen ausgehen, sind in ihrer Aufeinanderfolge und Descendenz schwer zu verfolgen, da öfters schon bei der genannten Zellenzahl die Entodermplatte sich einzustuilpen beginnt. Es konnte aber an genau orientierten Präparaten mit Sicherheit festgestellt werden, daß in vielen Zellen des vierten Quartetts bei Beginn der Einstiulpung noch eine vierte Teilung stattfindet, desgleichen, daß auch noch ein sechstes Quartett gebildet wird. Die Teilung der Makromere $4 D$, welche sich bis in die spätesten Stadien passiv verhalten hat, erfolgt bald vor Beginn der Einstiilpung, bald erst während derselben.

Über diejenigen Zellen des zweiten und dritten Quartetts, welche die Entodermplatte umgrenzen, ist bereits das Wesentlichste in der Geschichte dieser Quartette erörtert worden.

Die Genealogie des Entoderms wird in der umstehenden Tabelle vorgeführt.

Ein Vergleich der Entwicklung des Entoderms bei Physa mit demjenigen bei Planorbis ergibt eine wahrhaft iiberraschende Über- 
einstimmung, wenn nicht volle Identität des morphogenetischen Prozesses. Nicht nur die Aufeinanderfolge der eiuzelnen Teilungen in den betreffenden Quartetten, selbst der Zeitpunkt in der allgemeinen Entwicklung des Keimes, bis zu welchem die einzelnen Teilungen vor sich gehen, stimmt wunderbar bei beiden Formen tiberein. Nicht minder ließen sich in der weiteren histologischen Differenzierung der Entomeren viele identische Zuige aufweisen. Was aber besondere

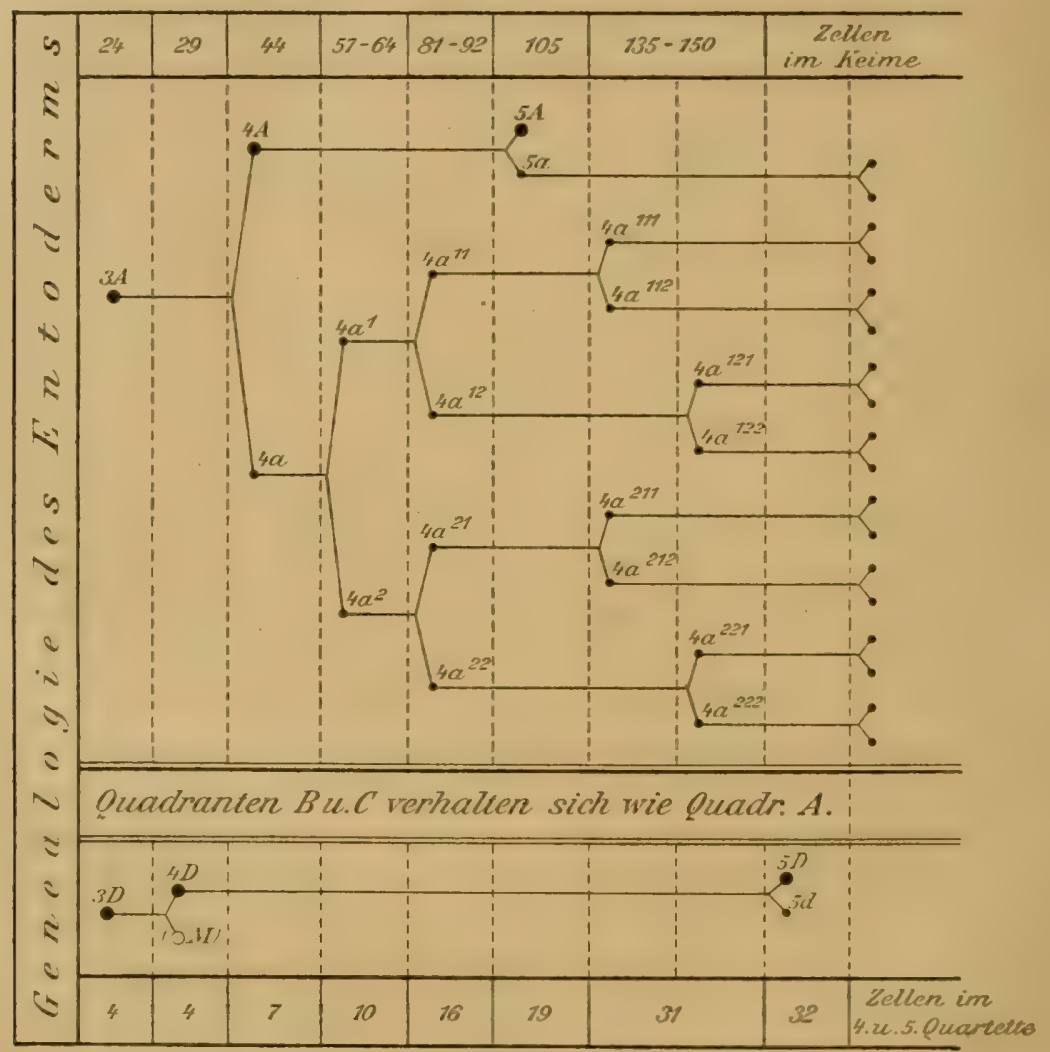

Erwähnung verdient, wäre, daß der Vorgang der Einstillpung bei beiden Gattungen rollkommen derselbe ist, worauf wir noch an entsprechender Stelle zurückkommen wollen. Anders scheint sich die Sache bei Crepidula zu verhalten, deren Eier mit einem sehr reich. lichen Dotter ausgestattet sind. Während nämlich bei Physa und Planortis bei Bildung des vierten Quartetts fast der ganze Dottervorrat aus den Makromeren in die Zellen dieses Quartetts ibertragen wird und die kleinen, am Pole rerbleibenden Mutterzellen, fast dotterfrei 
sind, findet bei Crepidula gerade das Gegenteil statt, da bei ihr die Zellen des vierten Quartetts nach der Peripherie abgeschnirt werden und dabei klein und dotterarm sind, während die Makromeren am Pole verbleiben und den ganzen Dotter in sich aufspeichern. Wenn man also ausschließlich die Größe und den Dottergehalt der entsprechenden Quartette in Betracht nehmen wollte, so würde man die Makromeren bei Physa und Planorbis anstatt den Makromeren den dotterarmen Zellen des vierten Quartetts bei Crepidula gleichstellen. Erstere gleichen den letzteren auch in bezug auf den weiteren Furehungsgang, weil sie ebenso wie jene nur wenige Teilungen durchmachen. Dagegen müßte man die dotterreichen Zellen des vierten Quartetts bei Physa und Planorbis den Makromeren bei Crepidula gleichstellen, da sie ebenso wie diese die Hauptmasse des entodermalen Zellmaterials liefern. Vergleicht man aber das Endschicksal der Makromeren bei Physa und Planorbis mit dem Endschicksal des vierten Quartetts bei Crepidula, so stellt sich ein prinzipieller Gegensatz heraus. Aus den ersteren wird ein Teil des Urdarmes, aus den letzteren das innere Ende des Stomodäums. Die Homologie dieser Zellen bleibt somit sehr fraglich.

Die Makromeren spielen bei Crepidula eine sehr wichtige Rolle in der Entwicklung des Keimes, indem nach ConkLin die erste erkennbare Ursache der Torsion in der Asymmetrie der Zellen $5 C$ und $5 D$ liegt; es teilt sich nämlich die rechtsliegende Zelle $5 C$ früher und liegt der Dorsalseite näher als $5 D$, wodurch eine leichte Drehung des hinteren Teils des Embryo verursacht wird, die linke Seite bleibt permanent kuirzer als die rechte, was den ersten Anstoß zur Asymmetrie des fertigen Tieres gibt. Bei Physa ist die identisch significierte Zelle infolge ihrer Lage und unbedeutenden Größe nicht geeignet eine nachhaltige Wirkung auf die Gestaltung des Keimes auszuüben.

Bei weitem größer ist die Übereinstimmung mit Umbrella, bei welcher einerseits $4 D$ kleiner ist als die übrigen Makromeren und diese kleiner als die Zellen des vierten Quartetts, ebenso wie bei Physa. In der Erzeugung des fünften Quartetts treten allerdings bedeutende Unterschiede auf, indem bei Umbrella sich zuerst $4 D$ teilt, was bei Physa erst beim Beginn der Gastrulation geschieht, ferner indem die Abschnuirung aller Zellen des fünften Quartetts nach vorn und hinten erfolgt, welche Teilung Herwoss als eine bilateral-symmetrische auffaßt, wiihrend bei Physa diese Teilung in einer zur Medianebene schiefen Richtung erfolgt. Abgesehen von 
diesem Lnterschiede ist die Entwicklung der Entomeren bei Physa und L'mbrella ganz übereinstimmend. Auch die Schicksale des fünften Quartetts und der Makromeren sind bei beiden Formen ziemlich dieselben.

\section{Primäres Mesoderm (Urmesoderm).}

Tir haben bereits bei der Darstellung des Furchungsprozesses auf den doppelten Ursprnng des Mesoderms bei Physa aufmerksam gemacht und die beiden Stammbäume desselben gesondert zu konstruieren getrachtet. Für den einen bildet den Ausgangspunkt die hintere rechte Makromere des 24 zelligen Stadiums $3 D$, fur den andern fanden wir zwei Ausgangspunkte in den beiden vorderen Quadranten des dritten Quartetts, nämlich $3 a^{2}, 3 b^{2}$. Das dem Makromerenquartett entstammende Mesoderm (Mesentoblast WiLsoss, Cuxiciss u. a., (ölomesoblast Eisigs) bezeichneten wir als sprimäres*, dasjenige aus dem dritten Eetomerenquartett als ssekundäres : Mesoderm. Da das letztere bei der Geschichte des dritten Quartetts behaudelt wird, so ziehen wir an dieser Stelle nur das erstere in Betracht.

Die Urzelle $4 d(M)$ entwickelt bei Physa während der Periode rom 28 zelligen Stadium an bis zur Gastrulation einen ziemlich stattlichen Stammbaum, dessen Hauptzweige zwar blof sechs Makromeren, dessen Nebenzweige aber etwa 20 Mikromeren ${ }^{1}$ bilden.

Der ganze Entwicklungsmodus ist aus der S. 585 beigegebenen Tabelle ersichtlich.

Die erste Teilung rou $4 d(M)$ findet bei $44-50$ Zellen statt, ist bilateral und beinahe vollkommen äqual. Die beiden Schwesterzellen $U_{1}$ und $I_{2} \quad 4 d^{1}$ und $4 d^{2}$ beginnen kurz darauf ziemlich tief in die Furchungshöhle einzusinken, tauchen aber bei 69 Zellen aus derselben wieder empor, um eiue weitere Teilung durchzumachen, welche zur Abschnürung des ersten Mikromerenpaares $m_{1}\left(4 d^{1.1}\right.$ und $4 d^{2.1}$ ) führt.

Letzteres wird nach rorn und unten abgegeben, kommt zwischen die Mutterzellen und die Makromere $4 \mathrm{D}$ zu liegen, verbleibt in dieser Lage während der ganzen Furchungsperiode bis zum Beginn der

1 Mit diesem Ausdruck bezeichnen wir die ans der auffallend inäiqualen Teilung hervorgehenden kleinen Zellen. welche bereits in der embryologischen Literatur mehrere Namen tragen: >Zwergzellen*, srudimentïr Zellen *, svestigial cellse usw. 
Einstülpung der Entodermplatte, wobei es gegen den animalen $\mathrm{Pol}$ verschoben wird.

Die dritte Teilung findet an Keimen mit 91-116 Zellen statt

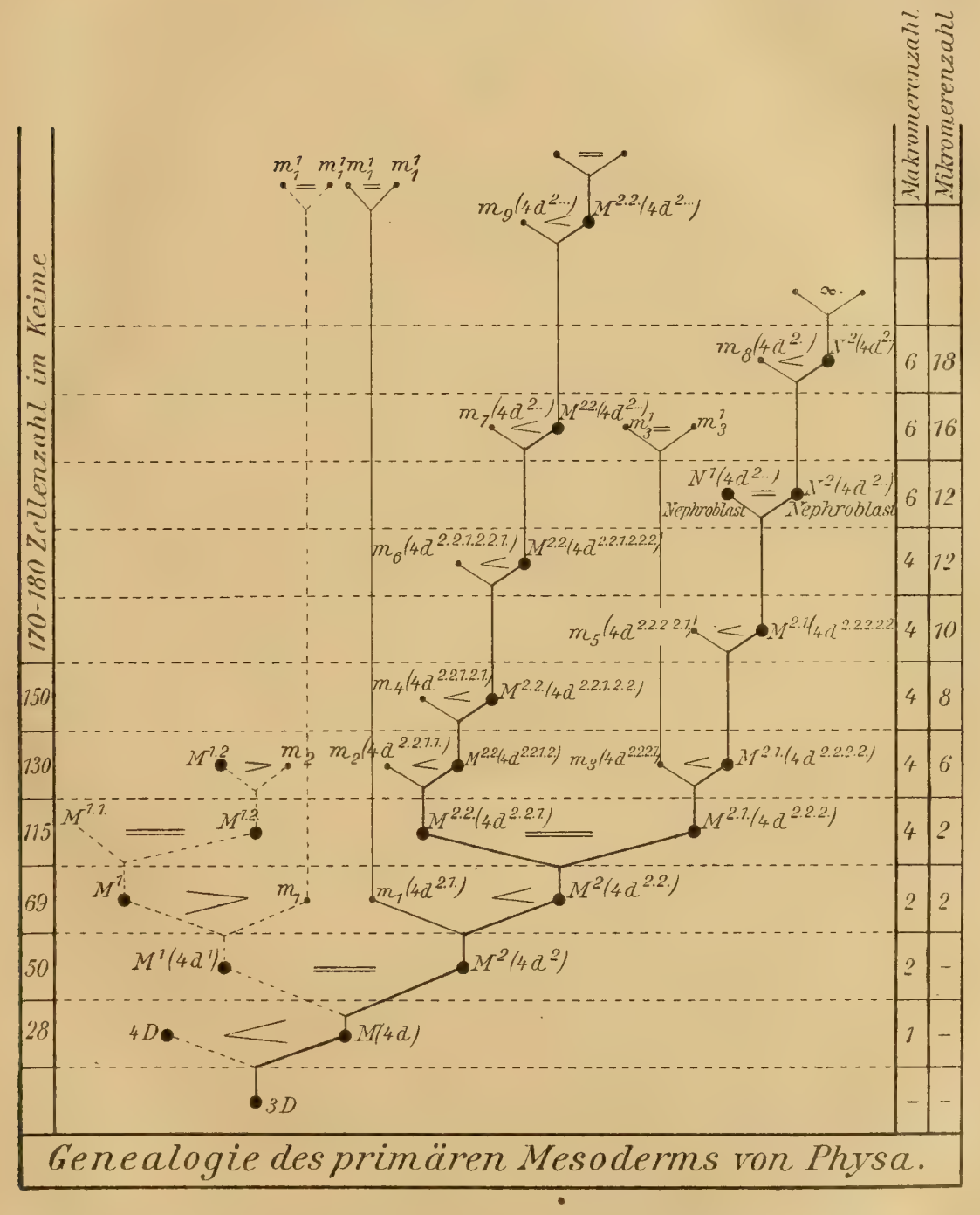

und ist wieder fast äqual (Fig. 48b). Die vier Makromeren $\mathbb{X}^{1.1}, M^{1.2}$, $M^{21}, M^{2.2}\left(4 d^{1.2 .1}, 4 d^{1.2 .2}\right.$ und $\left.4 d^{2.2 .1}, 4 d^{2.2 .2}\right)$ liegen unmittelbar nach ihrer Abtrennung übereinander; die unteren sind anfangs etwas kleiner als die oberen, der Unterschied wird aber bald ausgeglichen; die letzteren werden später seitwärts nach außen verschoben, während 
die unteren die mediane Lage behaupten. Während ihrer Teilung zeigen alle vier Descendenten denselben goldgelben Farbenton wie die Entomeren.

Am Stadium von etwa 124 Zellen teilen sich alle vier Makromeren gleichzeitig inäqual und im entgegengesetzten Sinne (Fig. 51 und 54); die medianen schnüren nämlich ihre winzigen, chromatinreichen Tochterzellen $\left(m_{2}\right)$ nach vorn, die seitlichen ihre mehr als doppelt größeren chromatinärmeren $\left(m_{3}\right)$ nach hinten $a b$. Letztere kommen zwischen und über die anstoßenden Makromeren zu liegen und verbleiben an dieser Stelle bis in die spätesten Stadien.

Nach der letzteren Teilung ist das ganze Urmesoderm aus vier Makromereu und sechs Mikromeren zusammengesetzt, von denen das Paar $m_{2}$ das kleinste ist. Die weitere Teilung beginnt an einem bereits sehr vorgerückten Stadium von etwa 150 Zellen und betrifft die beiden mittleren Makromeren, welche wieder ein recht kleines Mikromerenpaar in schiefer Richtung nach vorn und außen abschnüren (Fig. $54 \mathrm{~m}_{4}$ ). Kurz darauf, etwa bei 160 Zellen, teilen sich auch die beiden äußeren Makromeren, sie erzeugen aber diesmal ein winziges Mikromerenpaar $m_{5}$ in derselben Richtung, wie ihr erstes Paar $m_{3}$, d. i. nach hinten (Fig. 66). Dieses neue Mikromerenpaar kommt unter das erste Paar zu liegen und erscheint an späteren Stadien zwischen die anliegenden Makromeren förmlich eingeklemmt.

Es alterniert somit nicht nur das Mutterzellenpaar, sondern auch die Richtung, und das gilt auch für die nächste Teilung, denn es kommt jetzt wieder das mediane Paar an die Reihe, welches an einem Stadium von 170-180 Zellen ein neues, ganz kleines Mikromerenpaar $m_{6}$ nach rorn und außen abschnürt, dessen Glieder sich an das Paar $m_{4}$ anlehnen (Fig. 82).

Bis zu dieser Phase hat die Urmesodermzelle im ganzen nur vier Makromeren, dafür aber zwölf Mikromeren geliefert, welche teils vor den medianen, teils in den Winkeln zwischen diesen und den äußeren angeordnet sind. Die Feststellung der Aufeinanderfolge bei den weiteren Teilungen bietet bedeutende Schwierigkeiten, da der Keim sich bereits dem Gastrulastadium nähert.

Die nächste Teilung betrifft das äußere Makromerenpaar, welches schon während der Abschnürung des sechsten Mikromerenpaares auffallend an Größe zugenommen hat, wobei die Kerne sehr stark aufquellen und ein grobmaschiges Chromatinnetz ausbilden, in welchem ein großer Nucleolus aufgehängt ist. Es hat sich zugleich um die beiden Zellen ein weiter Flüssigkeitsraum gebildet, infolgedessen man 
sie bequem beobachten kann. Alsdann bemerkt man in denselben die Teilspindeln, welche eine horizontale Lage haben. Die Teilung erfolgt ganz äqual, die Schwesterzellen $4 d^{1.2 .2 .2 .2 .1}, 4 d^{1.2 .2 .2 .2 .2}$ und $4 d^{2.22 .2 .2 .1}, 4 d^{2.2 .2 .2 .2 .2}$ bleiben längere Zeit durch den Zwischenkörper miteinander verbunden und liegen bis zu ihrer völligen Abtrennung in derselben Ebene. In der Beschaffenheit ihres feinkörnigen, gelblichen Plasmas, sowie ihrer Kerne, gleichen sie vollkommen den medianen Makromeren und stechen von den vorn und seitwärts anstoßenden Elementen des sekundären Mesoderms, denen der gelbliche Farbenton ganz abgeht, deutlich ab. Da diese vier Zellen die Hauptanlagen der paarigen Urnieren bilden, so wollen wir sie von nun an als "Nephroblasten « bezeichnen und zwar die beiden hinteren mit $\lambda_{1}^{r}$ und die beiden vorderen mit $\mathrm{N}_{2}$. Ihre weiteren Teilungen werden somit an dieser Stelle nur insofern berücksichtigt, als es die zusammenhängende Darstellung der Entwicklung des ganzen Mesoderms erheischt.

Kaum ist die Trennung der beiderseitigen Nephroblasten erfolgt, als sich die beiden medianen Makromeren dem Gesetz der Alternierung folgend, zur Abschniurung eines neuen Mikromerenpaares $m_{7}$ vorbereiten. Dieselbe erfolgt, wie aus der Lage der Teilspindeln (Fig. 82) zu ersehen ist, in der Richtung gegen die inneren Winkel zwischen die medianen Makromeren und die Nephroblasten. Zu gleicher Zeit bemerkt man an einigen Keimen die Teilung des dritten Mikromerenpaares $m_{3}$, welches von den Mutterzellen der Nephroblasten erzeugt wurde und, wie erinnerlich, die übrigen Mikromeren an Größe übertrifft (Fig. 82). Die Descendenten, welche wir mit $m_{3}{ }^{1}$ bezeichnen wollen, sind einander gleich und liegen hintereinander zwischen den Makromeren $M^{12+\cdot}, M^{22+\cdots}$ und $N^{1}, N^{1}$. Ihre Teilung scheint indessen an diesem Stadium nur ausnahmsweise zu erfolgen, da sie nur selten zur Beobachtung gelangte.

Nach der Erzeugung des siebenten Mikromerenpaares folgen abermals zwei alternierende Teilungen. Namentlich schnüren zunächst die vorderen Nephroblasten $N_{2}$ ganz kleine Tochterzellen $\left(m_{8}\right.$, Fig. 85a) nach hinten und kurz darauf die medianen Makromeren ein neues Mikromerenpaar nach vorn ab. Es ist bereits ihr sechstes Mikromerenpaar und das neunte Paar in der Mikromerengeneration, weshalb wir es mit $m_{9}$ bezeichnen. Während der Abgabe der letzteren zwei Mikromerenpaare befindet sich der Keim bereits im Gastrulastadium. Der Stammbaum des Urmesoderms ist jetzt aus 6 Makromeren und 18 Mikromeren zusammengesetzt, von den letzteren gehören 12 den medianen und 6 den äußeren Makromeren. 
Es wurde rersucht, die Erzeugung von Mikromeren seitens der medianen Makromeren noch weiter zu verfolgen und es hat sich herausgestellt, daß noch ein siebentes, ja vielleicht noch ein achtes Paar erzengt wird, weil eine genane Zählung der Mikromeren an sehr vorgeriickten Stadien eine höhere Ziffer als 18 ergibt. Da wir aber die weitere Descendenz nicht mehr mit gewünschter Genanigkeit zu rerfolgen imstande waren, so haben wir es unterlassen, die vermuteten Teilungen in unsrer Tabelle ersichtlich zu machen.

Nach einer sehr großen Zahl von Beobachtungen und Zeichnungen zu urteilen, durften in der Regel die medianen Makromeren bis zum Gastrulastadium höchstens sechs bis sieben und die beiden äıßeren drei Mikromerenpaare erzeugen ${ }^{1}$. Es muß aber bemerkt werden, daß sich diese Maximalzahl an Stadien gleichen Alters nicht immer uachweisen läßt, woraus geschlossen werden darf, daß auch in der Sonderung des Mesoderms individuelle Schwankungen in der Zeitfolge und Zahl der Teilprodukte vorkommen können.

Außer den besprochenen Mikromeren, deren Descendenz direkt beobachtet worden ist, kommen an Gastrulastadien noch andre gauz kleine chromatinreiche Zellen zur Beobachtung, welche neben oder unmittelbar vor den vorderen Nephroblasten liegen und auch au andern Stellen unter den Mesodermzellen angetroffen werden. Ein Teil derselben gehört aber ganz bestimmt nicht dem Urmesoderm und auch nicht den hinteren Nephroblasten, sondern dem sekundären Mesoderm, dessen Komponenten um diese Zeit in einer sehr regen Teilung begriffen sind, die bald äqual, bald in hohem Grade inäqual ist und zur Bildung von Mikromeren fullurt, welche ihrer Beschaffenheit nach denjenigen des primären Mesoderms sehr ähnlich sind.

Indem wir uun unsre Darstellung der Entwicklung des primären Mesoderms abschließen, wollen wir bemerken, daß wir dieselbe in einer Phase unterbrechen, wo es geradezu unmöglich wird, die weitere Descendenz genau zu verfolgen.

Überblickt man nun die ganze Entwicklung des Urmesoderms, so fällt in derselben die Symmetrie auf, welche in dem konformen Fortgang der Teilung beider Teloblasten $M_{1}$ und $M_{2}$ bis in die spiitesten Furchungsstadien, zu welchen unsre Tabelle fithrt, zum Ausdruck kommt. Wir haben es deshalb fïr iberflissig erachtet, in derselben den symmetrischen zweiten Hauptzweig des Stammbaumes zur Anschanung zu bringen.

1 Die Erzeugung von Mikromeren findet noch während der Gastı ulation statt. 
Es eribrigt uns noch, unsre Beobachtungen über das weitere Verhalten des Mesoderms kurz anzuführen.

Von den sechs Makromeren werden die vier als Nephroblasten bezeichneten zum Aufbau der Urnieren verwendet, aus ihren drei hinteren Mikromerenpaaren entsteht eine ziemlich lange Kette von Zellen, die sich zwischen den medianen Makromeren und den hinteren Nephroblasten ausspannt. Die medianen Makromeren teilen sich erst an einem Stadium, wo bereits die Ausbildung der Kopfblase ziemlich weit vorgeschritten ist, zunächst äqual, dann mehrmals inäqual, und liefern die hinteren Mesodermstreifen (Fig. 93, 94b, c, 97).

Aus ihren Teilprodukten entstehen schließlich zwei symmetrisch an der Bauchseite der Larve liegende Mesodermplatten, in deren Zusammensetzung auch einzelne Mikromeren eingehen (Fig. 101). Die ersteren geben der bleibenden Niere den Ursprung.

Was die Mikromeren betrifft, so wurde vor allem dem ersten Paare besondere Aufmerksamkeit gewidmet, und es konnte festgestellt werden, daß es sich nach der Einstiilpung des Entoderms in der Richtung der Medianebene äqual teilt. Die vier Derivate liegen zwischen der hinteren Archenteronwand und dem Ectoderm (Fig. 84, 86).

Über ihre Beziehung zum Enddarm wird bei Darstellung der Ausbildung des letzteren berichtet. Von den übrigen, dem medianen Makromerenpaare entstammenden Mikromeren wird ein Teil ebenfalls zum Aufbau des Enddarmes verwendet, während ein andrer sich in der Furchungshöhle zerstreut; einige sieht man der Archenteronwand angepreßt, andre längs der Nephroblasten und mit denselben durch feine Fortsätze verbunden.

\section{Die Furchungshöhle.}

Im beschreibenden Teile wurde zwar die Furchungshöhle gelegentlich berïcksichtigt, da es sich aber in diesem Abschnitt um die Beurteilung ihrer morphologischen und physiologischen Bedeutung handelt, so wollen wir die Hauptpunkte noch einmal überschauen.

Wie bei andern daraufhin näher untersuchten Mollusken: Limax (Kofoid, Meisenhemer), Planorbis (Holmes), Dreissensia (Mersenheimer), Cyclas (Stauffacher) usw. erscheint die Furchungshöhle auch bei Physa zum erstenmal schon auf dem Stadium von zwei Blastomeren. Ihre Ausbildung beginnt unmittelbar nach der Zweiteilung während der Rekonstruktion der Kerne. Zunächst ist es ein enger, linsenförmiger Spaltraum, welcher schnell an Ausdehnung gewinnt und zu 
einem enormen Flüssigkeitsraume anschwillt, wobei die beiden Blastomeren sich zu flachen Kugelscheiben umbilden, welche sich nur mit ihren änßerst feinen Rändern zusammenschließen.

Vor der nächsten Teilung verschwindet dieser Flissigkeitsranm gänzlich, $s 0$ daß die in Teilung begriffenen Zellen flächenhaft einander anliegen. Ist dieselbe vollzogen, alsdann beginnt abermals die Ausbildung des Hohlraumes, der während des vierzelligen Ruhestadiums die stärkste Ausdehnung gewinnt.

Yon nun an wiederholt sich dasselbe Spiel vom Auftauchen und Verschwinden eines mit Flissigkeit erfülten Innenraumes auch während der Übergangs- und Ruhestadien vom 8-12 zelligen, vom 12-16 und 16-24zelligen Furchungsstadium, mit dem einzigen Unterschiede, daß der Hohlraum in allen späteren Stadien, vom achtzelligen angefangen, auch während des Teilungsaktes selbst nicht mehr verschwindet, ferner, daB er sich an späteren Stadien immer mehr an der animalen Keimbälfte lokalisiert, deren einzelne Zellen, wofern sie sich in Ruhe befinden, flacher und durchscheinend werden, während die vier Makromeren mit breiten Wandflächen verbunden bleiben.

Bei Physa ist die Furchungrshöhle am schönsten ausgebildet am 16zelligen Ruhestadium (Fig. 9 und 10) und unmittelbar nach der Konstituierung des 24 zelligen Stadiums, welches zeitweise eine ganz regrelmäßige Blastula vortäuscht Fig. 13). Indessen ist die enorme Furchungshöhle desselben nur von kurzer Dauer, denn beim Übergang in das liuhestadium wird sie bis anf unbedeutende radiär gestellte Spalträume an der animalen Hälfte reduziert, indem sämtliche Blastomeren mehr oder minder starke Fortsätze gegen die Mitte des Keimes ausschicken. Die vier Makromeren schließen wieder wie auf vorhergehenden Ruhestadien mit breiten Flächen zusammen. Es gilht auch am 24 zelligen Stadium eine Phase, in welcher die Furchungshöhle bis auf polständige Vacuolen reduziert wird.

An späteren Stadien rom 28 zelligen an ist zwar das Alternieren des Wachsens und Schwindens des Flissigkeitsraumes eine regelmäßig wiederkehrende Erscheinung, doch vermißt man dabei die konstante Regelmäßigkeit der Anfangsstadien. Vergleicht man nämlich die lange Reihe von Furchungsstadien bis zum Begiun der Einsenkung der Entodermplatte, so stellt sich heraus, daß die Hohlräume bald wïhrend der Teilung einzelner Blastomeren, bald während der Ruhepause entsteben, ohne daß fur ihr Auftreten und Verschwinden eine bestimmte Norm festgesetzt werden kann. Das Verhalten der 
Flüssigkeitsräume ist sogar an Stadien mit gleicher Zellenzahl öfters ganz verschieden, da solche auf verschiedene Weise zustande kommen können, wie dies an entsprechender Stelle hervorgehoben wurde.

An sehr weit vorgerückten Stadien über 150 Blastomeren treten weite, centrale Räume sehr selten auf, dafür erscheinen an verschiedenen Stellen des Keimes bald periodisch, bald konstant intercellulare Spalträume, die letzteren namentlich unter den acht Trochoblasten und zwischen den vorderen Zellen des zweiten und dritten Quartetts $\left(2 b^{121}\right.$ and $2 b^{122}, 2 b^{211}$ und $2 b^{212}$, zwischen $3 a^{11}$ und $3 a^{12}, 3 b^{11}$ und $3 b^{12}$ ), also zwischen und unter solchen Zellen, die entweder ganz ungeteilt bleiben, wie die Trochoblasten, oder sich erst an sehr späten Stadien teilen, wie die übrigen der obengenannten Zellen.

Im allgemeinen verhält sich die Furchungshöhle bei Physa in ihrer wechselnden Form und Ausdehnung, in ihrem periodischen Auftauchen und Verschwinden genau so wie diejenige von Limax (Kofoid, Meisenheimer), von Planorbis (Holmes), Dreissensia (MeisenHeiner) und Cyclas (Stauffacher), so daß wir dieselbe mit Kofoid am besten als eine ephemeral and recurrent cleavage cavity * kennzeichnen können. Die Übereinstimmung ist besonders in den Anfangsstadien sehr auffallend, an späteren Stadien treten entsprechend dem verschiedenen Furchungsmodus einige Unterschiede auf, die jedoch den allgemeinen Charakter der Furchungshöhle nicht wesentlich beeinträchtigen. Die Furchungshöhle von Physa und Planorbis erreicht nie eine so bedentende Ausdehnung wie diejenige von Limax, sie ist überhaupt bei den Landpulmonaten größer als bei den Wasserpulmonaten, worauf wir noch weiter unten zurückkommen.

Als ein gemeinschaftliches Kennzeichen für die Furchungshöhle aller obengenannter Formen kann wohl die Lokalisation derselben in der animalen Keimhälfte, ihr Fortbestand bis zum Gastrulastadium und direkter Übergang in die Leibeshọ̆hle, desgleichen die unmittelbare Kommunikation des centralen Flïssigkeitsraumes mit peripheren intercellularen Spalträumen angesehen werden, welche nach übereinstimmender Auffassung der Autoren mit jenen in enger morphologischer Beziehung stehen.

Mit Riucksicht auf das vollkommen übereinstimmende Verhalten der Furchungshöhle bei Physa, Limax und Dreissensia während der ganzen Furchungsperiode halten wir für ganz iiberflissig unsre Erörterung bis ins einzelne zu führen, da wir zur erschöpfenden Darstellung KoforDs, in welcher auch die betreffende Literatur berücksichtigt wird, sowie zu derjenigen Meisenuemens kaum etwas 
Wesentliches hinzufiigen könnten, desgleichen wäre es überflussig dieselbe durch Figuren zu erläutern, da wir fast genaue Kopien derjenigen geben würden, welche den betreffenden Arbeiten dieser beiden Autoren zugrunde liegen. Wir gehen somit zur Frage nach der Rolle der Kerne bei der Bildung von Flussigkeitsrïumen, sowie nach der physiologischen Bedeutung der Furchungshöhle uber.

Betreffend die erstere hat bereits MeIskxhenner in seiner LimaxArbeit '96. die enge Beziehung der Kerne zu den Excreträumen in einem besonderen Abschnitt eingehend besprochen und für ihre direkte Beteiligung am Excretionsprozesse mehrere Anhaltspunkte gewonnen. Lnter andern ist es die jedesmalige Annäherung derselben fast bis zur Berührung, die Ausbildung der ersten linsenförmigen Spalträume in ihrer unmittelbaren Nähe und gewisse Strukturveränderungen in den Nucleolen. Bei Physa wurden ähnliche Erscheinungen beobachtet, aber auch ohnehin würden wir an der wichtigen Rolle der Kerne bei der Bildung der Excretstoffe gar nicht im Zweifel sein, sobald es heutzutage als eine wobl begrindete Tatsache angenommen werden muß, daß der Kern bei den meisten Stoffwechselvorgängen in der Zelle in hervorragender Weise beteiligt ist. Seine vermittelnde Rolle bei der Verarbeitung des Dotters steht wohl außer Zweifel. Bedeutend wichtiger dürfte die ron MeisesHEIner aufgeworfene Frage sein, ob es sich bei der Bildung der Flüssigkeitsräume nicht etwa um die Differenzierung der Kerne selbst handelt? Für die Entscheidung dieser Frage fehlt noch zurzeit, wie dieser Autor richtig bemerkt, jeder Anhalt. Trotzdem halten wir es für höchst wahrscheinlicb, daß es sich bei der Bildung der Flïssigkeitsräume nicht ausschließlich um Stoffwechselvorgänge, sondern auch um gleichzeitige Differenzierung der Kerne handelt.

In physiologischer Beziehung werden die Hohlräume seit WARNECK 1850 mit den Ernährungs- und Excretionsprozessen in Beziehung gebracht. Koford ('95) betrachtet die Furchungshöhle ausschließlich als eine $\bowtie$ Excrethöhle , dagegen stellt Meisenhenmer ('96) die Ernährungsvorg:inge mehr in den Vordergrund. Dieselben beständen im Verbrauch des ursprünglichen Dotters und des von einzelnen Blastomeren aufgenommeneu Eiweißes. Wir stimmen dessen Ansicht ohne weiteres zu, denu wir fanden oft bei den beiden PhysstArten (Ph. fontinalis und $P h$. hypnorum) sowohl Eiweiß- als auch Dotterpartikelchen nicht nur in den Entodermzellen, sondern auch in einzelnen Ectodermzellen und in der Furchungshiohle ein fein granuliertes Gerinnsel, dessen Granula sich mit Hämatoxylin lebhaft 
tingieren. Ich glaube kaum, daß es Excretkörnchen sind, man diirfte sie vielmehr als fein rerteiltes Eiweiß betrachten. Wie dem tatsächlich sei, darüber können weder Tinktionen, noch die nicht ganz verläßlichen mikrochemischen Reaktionen näheren Aufschluß geben. Einstweilen müssen sich also unsre Vermutungen hauptsächlich auf morphologische Erscheinungen stiitzen. Dieselben bestehen bei Physa im unausgesetzten Ausschicken und Einziehen von Fortsätzen in der Ausbildung von feinen seitlichen Pseudopodien, im fortwährenden Wechsel der Konfiguration einzelner Blastomeren, welche wohl keinen andern Zweck haben können, als eine rege Wechselwirkung zwischen denselben zu ermöglichen. Es unterliegt für uns keinem Zweifel, daß dieser Wechselverkehr zwischen den Furchung:szellen nicht nur den Stoffwechsel sondern auch die Differenzierung derselben zum Zwecke hat.

Wir kommen nun zu einer andern Frage, welche unsres Wissens zuerst ron KoFoId (Limax) angeregt wurde, warum nämlich die Furchnngshöhle bei den Landpulmonaten bedeutend größer ist als bei den Suißwasserpulmonaten und bei letzteren größer als bei den marinen Formen. Koford sucht die erstere Erscheinung durch die Annahme zu erklären, daß die Quantität des Eiweißes und die Stärke der Eiweißhïllen auf den Excretions- und Respirationsprozeß hemmend einwirken. Infolgedessen muß bei den Landpulmonaten, deren Eier von einer mächtigen Eiweißhülle und einer sehr starken Membran umgeben sind, der enorme, periodisch wiederkehrende Fluissigkeitsraum entstehen. Dem gegeniiber hebt Meisenheiner ('01) hervor, daß Dreissensia in dieser Beziehung den Landpulmonaten Limax: eher ïbertrifft, trotzdem ihre Eier von einer schwächeren Eiweißhülle umgeben sind. Auch die weitere Annahme Kofords, daß nämlich das Süßwasser auf die Exosmose der Excretstoffe hemmend einwirkt, wird von Meisenhemer auf Grund der Befunde bei Dreissensic zuriickgewiesen. Die Experimente mit Physa, deren Eier KoFoID in Salzlösungen von verschiedenen Konzentrationen sich entwickeln ließ und dabei eine Reduktion der Excrethöhle beobachtete, weist Mensenhemer ganz richtig zurück, indem er darauf hinweist, „daß ein derart abnormes Medium, in dem sich die Eier befinden, den Organismus unbedingt schwächen und seine Lebenstätigkeit herabsetzen muß, wenn die Furchung dabei auch noch normal verläuft«. Nach eignen Versuchen an Physa-Eiern, welche in Seewasser von verschiedenen Konzentrationen bis zu $250^{\circ}$, gezichtet wurden, muß ich dessen Ansicht im volleu Maße bestätigen. 
Unter diesen abnormen Bedingungen äußert sich die Herabsetzung der Lebenstätigkeit der Keime besonders in dem Umstande, daß die Eier zur Erreichung einer bestimmten Entwicklungsstufe etwa viermal so viel Zeit beduirfen wie unter vollkommen normalen, wenn überhaupt die Entwicklnng nicht ganz gehemmt wird. Außerdem spricht dafuir auch ein bedeutender Prozentsatz abnormer Formen, welche trotz unguinstiger Bedingnngen doch zur Ausbildung der Schneckengestalt gelangen.

In der freien Natur verhalten sich die Seeformen in bezug auf die Ausdehnung der Furchungshöhle sehr verschieden. Bei einigen derselben ist sie, zumal in den Anfangsstadien, kaum angedeutet Nassa (BовRетzкi), Ĺmbrella (Heymors), bei andern sehr klein Aplysia (CARazzi), Polycera und Acera (nach eignen Beobachtungen), bei Crepidula (Coxklis) ist sie nur auf die Anfangsstadien beschränkt und bei Patella (Patten) und Trochus (RoBert) ziemlich weit 1.

In andern Gruppen, namentlich bei Cölenteraten und Echinodermen, erreicht die Furchungshöhle eine sehr bedeutende Ausdebnung. Es stellt sich somit heraus, daß die äußeren Bedingungen, im gegebenen Falle das Seewasser, an und fuir sich keinen bestimmenden Einfluß auf die Bildung und Ausdehnung der Furchungshöhle austiben, sondern daß bierbei bauptsïchlich innere Faktoren im Spiele sind. Unsrer Ansicht nach ist es nicht etwa die Quantität und Qualität des Dotters allein, anch nicht die Menge des den Keim umgebenden Eiweißes, sondern in erster Linie die eigenartige Struktur des Eiplasmas selhst, von welcher sowohl der spezifische Stoffwechsel, als auch der Gang der Entwicklung reguliert wird. Ohne diese Annahme könnte man nicht verstehen warum bei sonst gleichen Bedingungen die Furchungshöhle einmal enorm weit, ein andres Mal sehr eng ist oder gar nicht ausgebildet wird, ferner warum der Dottervorrat bald schneller bald langsamer verbraucht oder aber großenteils für die Larvenperiode aufgespeichert wird. Diese Erscheinungen hängen offenbar mit der spezifischen $\ddot{0 k o n o m i e ~ i n ~ d e n ~}$ einzelnen Ontogenien zusammen.

Zum Schlusse wollen wir noch der morphologischen Bedeutung der Furchungshöhle einige Bemerkungen widmen. Es wurde bereits erwähnt, daß KofoID (Limax) die Furchnngshöhle der Mollusken

1 Bei zwei mit Riicksicht auf die Quantitüt des Dentoplasmas extremen Formen Siplonaria lepida und Aplysiu sp. (Fvira '04) wird keine Furchungshöhle ausgebildet. wenigstens wird sie weder im Text erwïhnt noch in den Abbildungen ersichtlich gemacht. 
als eine „Excrethöhle" bezeichnet, welcher Ausdruck nach MeisexHEIMER mit Bezug auf die größere physiologische Bedeutung dieses Hohlraumes gut angebracht ist. Beide Autoren legen somit das Hauptgewicht auf die physiologische Bedeutung der Furchungshöhle und Kofold spricht ihr sogar jede Bedeutung für den Furchungsprozeß ab, wie dies aus folgender Äußerung hervorgeht: sthe existence of a cleavage cavity is dependent more upon the physiological necessities of the egg than upon the internal process of cell division, or the mechanical necessities of cleavage, and than is preeminently physiological than morphological .

Wir gestehen, daß wir diese Auffassung etwas unvermittelt finden und daß wir überhaupt nicht verstehen, wie Autoren, die sich mit den Schicksalen der Furchungshöhle und den Furchungsvorgängen eingehend befaßt haben, den einleuchtenden Zusammenhang mit dem Verlaufe des Furchungsprozesses selbst entweder übersehen oder wenigstens stillschweigend übergehen. Wäre die Entstehung und Ausdehnung der Furchungshöhle nur der Ausdruck einer Fluctuation im Ausscheiden und Entleeren der Secrete, so wären wir angesichts der oben erwähnten Arten zu dem Schlusse gedrängt, daß bei ihnen die nutritiven und excretorischen Funktionen entweder in ganz andrer Weise vor sich gehen (wie dies KoFoID annimmt) oder im Vergleich zu andern Blutsverwandten auf ein Minimum reduziert werden. Es handelt sich aber gerade um solche Formen, deren Ei sich durch eine große Dottermenge auszeichnet, bei denen man also einen regen Stoffumsatz und eine entsprechend gesteigerte Energie der Ausscheidung voraussetzen sollte. Nun hat neulich Hoffmans ('02) nach eingehenden Untersuchungen an Nassa mutabilis den Beweis erbracht, daß der Dotter besonders in den ersten Stadien sehr eifrig verarbeitet wird. Wir duirften also erwarten, daß bei einem intensiven Stoffwechsel sich auch ein weiter Excretraum ausbildet, was jedoch keineswegs der Fall ist. Im Gegenteil ist die primäre Furchungshöhle bei der genannten Form sehr klein und gleicht sich bald aus. KOFOrD möchte diese Erscheinung dem Einflusse äußerer Faktoren zuschreiben, welcher, wie wir oben gesehen haben, zum mindesten sehr problematisch ist.

Der Mangel bzw. die Reduktion der Furchungshöhle entspricht in diesem Falle, unsrer Meinung nach, keineswegs den physiologischen Prozessen, sondern durfte sich einfach aus durch den Dotterreichtum eingeengten Raumverhältnissen und den hierdurch verursachten Furchungsmodalitäten als eine architektonische Notwendigkeit ergeben. 
Die Beziehung zur Furchung ist also eine numittelbare und nachweisliche. Daß sich in den inneren Hohlräumen, wie sie sich aus der Konfiguration und den gegenseitigen Größenverhältnissen der Blastomeren ergeben und Hand in Hand mit der Entwicklungstätigkeit derselben rerändern, je nachdem sich die Zellen dureh Fortsätze zu verbinden oder behufs der Teilung abzurunden haben, stets anch Excretstoffe ansammeln, ist für uns ebenfalls selbstverständlich.

Die Bedeutung der Furchungshöhle, wie sie aus den Differenzierungs- und Gestaltungsprozessen des Embryo resultiert, wüde unsres Erachtens im besonderen darin liegen, daß durch ihre Ausbildung ein freier und allseitiger Kontakt zwischen den einzelnen Blastomeren ermöglicht und ihre Verschiebbarkeit wesentlich erleichtert wird. Für diese Auffassung bietet der Furchungsprozels bei Plyysa recht viele Belege. Wir wollen beispielsweise nur einige derselben herausgreifen. Wir erinnern, daß zwischen den urspringlichen zwei Blastomeren ein auffallend weiter Hohlraum gebildet wird, der alsbald bei gleichzeitiger Ausstoßung der Fliissigkeit zum Schwinden geloracht wird. Ist dieser Raum lediglich eine Excrethöhle im Sinne Kufords? Kann man schon in dieser P'hase eineu so regen Stoffwechsel voraussetzen, der eine derart ausgiebige Excretion zur Folge hätte? Wir glauben es kaum. Weun man aber bedenkt, daß an diesem so wie besouders in den nächstfolgenden Stadien bereits über die Achsenrerhältnisse, über die Richtung der Spirale, uiber die Lage der Mesodermelemente usw. entschieden wird, so diirfte der Grund der Ausbildung von enormen Hohlräumen in deu Anfangsstadien eher in der Notwendigkeit von Vorbereitungsstadien zu suchen sein, in denen die Differenzierung der Furchungszellen die Hauptanfgabe bildet.

Ein weiteres Beispiel bietet uns das 24 zellige Stadium. Wir haben einen handgreiflichen Differenzierungsprozeß an den vier Makromeren kennen gelernt, welcher sich in der Ausanumlung rou färbbaren Körnchengruppen am regetativen Pole, in ihrer Wanderung gegen das Centrum des Keimes und ihrem schließlichen Verschwinden äußert und erinnern uns, daß dabei alle 24 Zellen mit ihren centripetalen Fortsätzen in der Mitte des Keimes zusammentreffen. Es gelangt ferner der centripetal gerichtete Fortsatz der Makromere $3 D$ in einen innigen Kontakt mit eben solchen Fortsätzen der ibrigen Blastomeren, vorziiglich aber denjenigen der Ectodermzellen, wird nachher unmittelbar vor der Teilung eingezogen. wobei sich die Makromere abrundet und an die Oberfliche des 
Keimes steigt. Nach der Abtrennung der Urmesodermzelle $4 d$ bleibt diese Makromere bis zur Gastrulation an der Oberfläche ohne sich zu teilen, während die letztere vor ihren nächsten Teilungen periodisch in die Furchungshöhle einsinkt, sich mit andern Blastomeren in Verbindung setzt und während der Teilnng wieder an die Oberfläche steigt.

Beispiele ähnlichen periodischen, teilweisen Einsinkens und Auftauchens, des Ausschickens und Einziehens von Fortsätzen wiederholen sich fast bei allen sich furchenden Blastomeren mit dem Unterschiede, daß die centralwärts gerichteten Fortsätze bald feiner bald massiver sind. Stets wird dadurch ein Hohlraum gebildet, dessen Weite der Zahl und Größe der sich gleichzeitig furchenden Zellen entspricht. Ob sich derselbe jedesmal mit einer Excretionsflüssigkeit fiillt und ob dieselbe ausgestoßen wird, daruiber fehlen uns zurersichtliche Beobachtungen. Wir glauben jedoch annehmen zu dürfen, daß die erwähnten Erscheinungen des periodischen Ausschickens und Einziehens von Fortsätzen nicht ausschlieBlich im Dienste der Ernährung und Excretion stattfindet, sondern vorwiegend zum Zwecke eines wechselseitigen Stoffaustausches zwischen den Zellen, dessen Natur und Bedeutung uns freilich nicht näher bekannt ist.

Sollte tatsächlich die Hauptbedentung der periodisch wiederkehrenden Furchungshöhle lediglich in nutritiven Prozessen zu suchen sein, wie dies mehrere Forscher annehmen, alsdann müßte der ursprïngliche Dottervorrat sehr bald erschöpft sein, da ja schon vom zweizelligen Stadium an mächtige Excrethöhlen entstehen und unausgesetzt wiedergebildet werden, die nach dieser Auffassung als Ausdruck eines energischen Stoffwechsels zu betrachten sind. Indessen ist dies bei Physa keinesweg's der Fall, vielmehr findet man noch kurz vor der Gastrulation und während derselben deutlich erkenntliche Dotterelemente nicht nur in den zahlreichen Entodermzellen, sondern auch in den Makromeren des primären Mesoderms. Wenn wir ferner erwägen, daß bei dotterarmen Eiern während der Furchung oft sehr mächtige, dagegen bei dotterreichen sehr unansehnliche Hohlräume gebildet werden, so sind wir zur Annahme gedrängt, daß es nicht rein physiologische Kriterien sind, welche die Ausbildung und Ausdehnung der Furchungshöhle bedingen, soudern daß hier ebensowohl morphologische Momente eingreifen und daß wir nur unter gleichzeitiger Beriicksichtigung dieser beiden Seiten der Embryogenie Aussicht haben können einen tieferen Einblick in die eigentliche Rolle der Furchungshöhle zu gewinnen. 


\section{Vergleichende Betrachtungen.}

\section{Spiralfurchung.}

Das Problem dieser in der Ontogenie weit verbreiteten Erscheinung vereinigt in sich eine Reihe von Einzelfragen, deren Lösung nicht nur für das Verständnis morphogenetischer Vorgänge bei Formen, wo sie typisch vorkommt - wie bei zahlreichen Mollusken, Anneliden, und Turbellarien (Discocoelis) - sondern für das Verständnis der gesamten Furchungsmechanik von eminenter Bedeutung sein wïrde ${ }^{1}$.

Man sollte zunächst die Hauptfrage entscheiden: worin besteht denn das Wesen dieser Furchungsform?; ferner die Fragen: in wie weit kann dieselbe eine phylogenetische Bedeutung, sowohl fur die betreffenden Tierarten, als für ganze Tiergruppen haben? in welcher Beziehung steht die Spiralfurchung des Eies zur morphogenetischen Differenzierung und zur Asymmetrie des fertigen Gasteropoden? wovon hängt die Richtung einzelner spiraler Zellteilungen ab? waun mag sich die Konstanz spiraler Teilungsrichtungen bei den betreffenden Formen gefestigt haben? u. dgl. mehr.

Was zunächst die Hauptfrage nach dem Wesen der Spiralfurchung betrifft, so wurde ihre Lösung in ganz zutreffender Weise in der Erforschung der Gründe gesucht, welche jene ursprïnglich verursacht und zu einem weit verbreiteten Furchungstypus gemacht haben. Hier gehen aber die Ansichten der Autoren sehr auseinander und lassen sich auf die gesamte Auffassung der Entwicklungsvorgänge des Einzelnen zurïckführen, wie dies aus den weiter unten auseinaudergesetzten Ansichten einiger Autoren hervorgeht.

Nach Coxkun ('97) wird die Furchung in der Konstanz ihrer Richtungen durch die spezifische Struktur des Keimplasmas (the intrinsic structur of the gerninal protoplasm \&) causal bedingt. Unmittelbares Eingreifen mechanischer Faktoren wäre bei der Differenzierung ausgeschlossen, sie geht vielmehr durch Plasmabewegungen vor sich und nur in gewissen Punkten wäre es durch den Verlauf der im Ei bestimmten Entwicklung gewissermaßen vorgetäuscht (»exact simulation«). Es müßte demnach die qualitative Sonderung der Organanlagen stets schon durch die ersten Teilungen eingeleitet

1 Nach Mead "97, ist die Spiralfurchung bei 16 Anneliden, neun Mollusken und einer Turbellarie bekannt. Seit 1897 hat sich die Zahl der spiralfurchenden Formen wenigstens um sechs vermehrt. 
werden, so daß zwischen der Furchungsform und der Morphogenese innige Beziehungen beständen. Der Furchung wäre folglich eine phylogenetische Bedeutung nicht abzusprechen; die Spiralfurchungen von Mollusken, Anneliden und Polycladen würden sich nach ConkLIN in dieser Hinsicht ähnlich wie das Gastrula-, das Larven- und das Reifenstadium bei Metazoen überhaupt verhalten.

Anders ChILD ('00), der auf dem organistischen Standpunkte Whitmanns steht. Das verschiedene Verhalten der Blastomeren unter normalen und anormalen Furchungsbedingungen hängt nach ihm von ihrer Beziehung zum Ganzen ab. Nur der causale Einfluß des Gesamtorganismus auf die Bestandteile macht es erklärlich, daß bei verwandten Formen dieselben Zellen verschiedenes Schicksal haben können. Die rein quantitative Furchung wird anfänglich durch mechanische Faktoren, wie den gegenseitigen Druck, die Adhäsion, die Oberflächenspannung $u$. dgl. bestimmt, welche ihr die für die Organisation und eine früheitige Sonderung der Organe guinstigste Form sichern. Das Zusammenspiel äußerer Faktoren sorgt aber nur dafür, daß jede Zelle mit möglichst vielen und stets denselben Zellen in Kontakt komme, und da eine derartige Gruppierung am ehesten bei der Spiralfurchung erreicht wird, so wird dieser Furchungstypus von der Selection beguinstigt und ist infolgedessen allgemein verbreitet. Einen Angriffspunkt biete der Selection die Beschaffenheit der Eizelle, welche wenigstens die Richtung der ersten Furche irgendwie vorausbestimmt ${ }^{1}$. Der Spiraltypus erscheint also in dieser Fassung als ein Resultat der Selection. Die Spiralfurchung hätte als solche keine phylogenetische Bedeutung; diese darf erst der bilateralen Furchung, welche fruher oder später in die Entwicklung: einsetzt, zugeschrieben werden. Es würde sich also daraus ergeben, daß die Furchung selbst Änderungen erfahren kann, welche nicht notwendig auf die späteren Stadien, die Larve und das fertige Tier zuríckzuwirken und übertragen zu werden brauchen.

Nach WrLson rührt die Spiralform der Furchung von dem frühzeitigen Erscheinen der Alternation in den Zellteilungen her, die wieder ein Resultat mechanischer Faktoren, in erster Linie des Gegendruckes der Zellen darstellt. Der Einfluß jener Faktoren kann jedoch nur im Wege der Vererbnng in die Entwicklung als gestaltende Komponente eingreifen. Phyletisch leitet WILson in Über-

1 Ähnliches findet sich in der DrIEschschen Theorie der sepigenetischen Evolution« der Organismen. 
einstimmung mit CoxkLry die Spiralfurchung von der radialen, beziehungsweise orthoradialen ${ }^{1} \mathrm{ab}$ und will ihr selbst eine phylogenetische Bedeutung nur insofern zuschreiben, als sie mit der fortschreitenden Abkürzung und Kondensierung der Entwicklungsprozesse entsprechende Modifikationen erfahren hatte. - HoLMes hat sich ebenfalls fitr eine phylogenetische Bedeutung der Furchung ausgesprochen, indem er einen ursächlichen Zusammenhang zwischen der Furchung und der Asymmetrie des fertigen Tieres annimmt.

Auf demselben Standpunkte wie Coxklin und HoLmes steht auch RoBert ('03), der ebenfalls zwischen dem Furchungsmodus und der definitiven Gestalt innige Beziehungen annimmt. Bei Trochus kommt nämlich die erste Andeutung der Asymmetrie fast grenau an demselben Stadium (von etwa 145 Zellen) wie bei ('repidulu zum Ausdruck und wird durch den Teilungsmodus einer einzelnen Zelle $(4 c)^{2}$ verursacht, deren läntrope Teilung das Übergewicht der rechten Seite des Embryos über die linke bedingt. Die Auffassung RoBER's ist aus folgender Äußerung zu ersehen son peut admettre que le sens de lasymétrie des Gasteropodes est prédéterminé dans l'oeuf, qu'il se manifeste dès les premiers stades de la segmentation, et que cette asymétrie même a sa source dans la segmentation * p. 229.

Wir schließen uns der Auffassung CHiLDs, daß der Spiraltypus ein Resultat der Selection ist, vollkommen an. Denn wir huldigen der Überzeugung, daß in der tierischen Ontogenie das allgemeine Prinzip der Natur: das Passende und Ausgiebigste unter möglichster Schonung des Kraftrorrates zu leisten, bewahrt wird, daß also dieselbe nicht nur passende Organisationen, sondern auch ontogenetische Entwicklungsweisen züchtet. Somit baben wir, wie CHLL richtig folgert, auch in der Spiralfurchung zweifellos eine Konfignration vor uns, welche einer jeden Blastomere das Optimum des Stoffaustausches und der Wechselbeziehungen zu den uibrigen sichert und auf diese Weise zn einer möglichst raschen Differenzierung derselben beiträgt. So erklärt es sich, daß die Furchung in der

1 Conk Liss Bezeichnung für radiale Furchung wo meridionale und äquatorielle Teilungsfurchen miteinander alternieren;, während bei der spiralfurchung die Lage der Furchen in der Diagonale alterniert.

2 Es mag an dieser Stelle bemerkt werden, daß bei Physa der Peginn der Asymmetrie sich ebensowenig aut eine einzelne Zelle zuriickverfolgen lißßt, wie lei Planorbis, da die entsprechende Zelle des vierten Quartetts zu klein ist, ım auf die Wachstumsvorgänge des ganzen Embryos einen entscheidenden Einflußs ausitiben zu künnen. 
Verteilung der Blastomeren sich nach den Verhältnissen des Raumes zu richten scheint. Beim Alternieren der Zellteilungen finden nämlich die neu entstehenden Zellen den freiesten Raum zur Entwicklung und stehen auch mit möglichst vielen benachbarten Zellen im Kontakt; hierin liegt auch der Grund, warum sich der spiralige Typus, welcher den Zellen die günstigsten Raumverhältnisse bietet, uiberhaupt ausgebildet hat und bei verschiedensten Tiergruppen vorkommt.

Das Ei braucht höchst wahrscheinlich keine spezifischen Stoffe zu besitzen, von denen die Richtung der Spiralfurchung abhängen wiirde ${ }^{1}$.

Die Richtung der Naturauslese allein entscheidet dariber, ob sich dieser oder ein andrer Furchungstypus bei einer Tierform herauszubilden hat.

Wir wollen zum Schluß die Aufmerksamkeit darauf lenken, daß spirale Drehungen in der ganzen organischen Natur zu den gewöhnlichsten Erscheinungen gehören. Schon bei Protozoen sind dieselben allgemein verbreitet. Die spiralgewundenen Schalen der Foraminiferen, die trichterförmige Spirale des Peristomiums bei peritrichen Infusorien brauchen nicht erst erwähnt zu werden. In höheren Tierkreisen sind aufgerollte Antennen, Hinterleiber oder Schwänze ${ }^{2}$ allenthalben zu finden. Wer wäre indessen imstande anzugeben, warum eine Vorticella oder Trichodina eine dextrale und eine Spirostoma eine sinistrale Windung anlegt ${ }^{3}$. Zumal für die Lebensinteressen des Tieres die Windungsrichtung gleichgültig ist!

Die betreffende Drehungsfähigkeit mag schon in der Beschaffenheit der Ahnenzelle vorbanden gewesen sein, da bei diesen Unicellulaten von Wechselwirkungen, Adhäsion, Gegendruck und andern Momenten, auf welche man die Spiralbildungen der Metazoen zurückzuführen versucht, keine Rede sein kann.

Wie es nun müßig wäre, die Natur jener ursprïnglichen Fähigkeit erschließen zu wollen, ebenso verhält es sich mit den Erklärungsversuchen in betreff des Ursprungs und der Richtung der Spiral-

1 Wir haben versucht die Eikeime von Physa sowie sonstiger Tiere, in deren Bau Spiralasymmetrie in markanter Weise zum Ausdruck kommt, wie z. B. die Vorticellen, in polarisiertem Licht zu betrachten, ohne irgend einen positiven Anhaltspunkt darïber erlangen zu künnen, ob sie einen spezifischen Stoff enthalten, welcher die Polarisationsebene nach entgegengesetzter Richtung drehen würde.

2 Der stets nach links gekrimmte Schwanz des Haushundes.

3 Vgl. Delage, Zoologie Concréte. I. p. 454-456. 
furchung und der Schalendrehung bei Gasteropoden. Dies schien aber nicht einem jeden Autor eingeleuchtet zu haben.

Bei der Spiralnutation der Pflanzen umschreiben die Botaniker einfach diese Erscheinung, indem sie dieselbe aus einer Anlage zur kreisrunden Bewegung, verbunden mit Geotropismus und andern »inneren Ursachen * erklären, sämtlich Erklärungen, die nach Bürschl in die Kategorie der Umschreibungshypothesen hingehören. Wenn wir dagegen die spiralige Blattstellung an einem Pflanzentriebe betrachten, so wird uns auch hier die für das Wachstum und Assimilation günstigste Ausnntzung des Raumes deutlich entgegetreten, also dasselbe Prinzip, welches wir für die Schiefstellung der Kernspindeln bei der Spiralfurchung geltend gemacht haben. Hiermit ist unser Erklärnngsvermögen aber auch zu Ende.

Desgleichen wäre es müßig, die Frage zu erörtern, wie und wann sich die Spiralfurchung aus der radialen oder bilateralen Furchung entwickelt haben mag. Um dariiber zu sprechen, müßte zuvörderst die Ursprünglichkeit jener andern Furchungstypen nachgewiesen werden, wozu uns leider jedwede Anhalte feblen.

Im Zusammenhang damit steht auch die Frage zur Erörterung, ob es zwischen der Spiralfurchung und der Gestalt des fertigen Tieres Wechselbeziige gibt oder nicht? Kann die Richtung der Zellteilungen die Richtung der Schalendrehung beeinflussen? Von großer Bedeutung ist in dieser Hinsicht der Umstand, daf bei Anneliden aus einer spiralen Furchung ein streng bilateraler Organismus resultiert. Damit erscheint die Rolle der Spiralfurchung auf ihr eigentliches Grültigkeitsgebiet eingeschränkt. Bei den meisten Gasteropoden tritt der spiralige Furchungstypus, trotz der Asymmetrie der fertigen Schnecke, im Lanfe der Entwicklung zugunsten der Bilateralität immer stärker zuriick, um schließlich völlig verwischt zu werden. Die Gasteropodenlarven sind eben im frühen Trochophorastadium streng bilateralsymmetrische Organismen, die erst später mit der Ausbildung der Schalenanlage asymmetrisch werden.

Holmes meint, daß ein Abhängigkeitsverhältnis zwischen der Spiralfurchung und der Schalendrehung auch dann besteheu könne, wenn es zu subtil wäre, um in den zwischenliegenden Stadien direkt nachgewiesen $\mathrm{zu}$ werden, wir möchten uus aber trotzdem gegen die Annahme einer causalen Beziehung aus folgenden Rticksichten erklären.

Die Furchungsperiode ist in der Entwicklung eines Tieres ebensogut eine Lebensphase wie die Zeit der Reife und wie uns die er- 
worbene Metamorphose der Tiere lehrt, werden für jede Phase, je nach den Bedingungen, unter welchen sie verlaufen, besondere morphologische Eigenschaften herangezüchtet; dies muß folglich auch für die Furchungsform gelten. Es ist zweitens zu beachten, was den Autoren entgangen sein mag, daß zwischen den Drehungen der Zellteilungsebenen und der Gehäuse auch promorphologisch gar kein Zusammenhang existiert: ist ja die Spiralfurchung der Ausdruck eines streng symmetrischen Baues, welcher mit Asymmetrie gar nichts zu tun hat. Außerdem darf man nicht vergessen, daß die erste Spirale stets in entgegengesetzter Richtung angelegt wird, als die Schale gewunden ist, so daß z. B. dextral gewundene Schnecken ihre Furchung stets in laeotroper Richtung einleiten.

Die Art und Weise, wie die Schalenwindung bei Schnecken entstanden sein mag, können wir an dieser Stelle unberiicksichtigt lassen, wenn diese Darstellung mit einer Erörterung, die auf eine ausgedehnte, widerspruchsvolle Literatur Bezug zu nehmen hätte nicht verquickt werden soll. Doch möchten wir das eine betonen, daß die Faktoren, die die Schalenwindung veranlaßt haben, welcher Art sie auch seien, nur die ausgeschliipfte, freilebende Schnecke betreffen können und folglich auf den Verlauf der Furchung nur in einer höchst indirekten Weise rückwirken würden.

Es gibt unter dextralen Schnecken Arten, bei denen einzelne Individuen gelegentlich linksgewunden sind, dann solche, wo sinistrale Exemplare häufiger werden; ferner gibt es ausschließlich simistrale Formen. Für einige solche sinistralen Formen wurde nun auch in der Spiralfurchung eine dem normalen Typus der dextralen Arten entgegengesetzte Richtung der Teilungsspindeln nachgewiesen und als "reversed cleavage " bezeichnet. Diese Erscheinung, die auf ein Abhängigkeitsverhältnis hinzudeuten scheint und verschiedene Auslegung erfahren hat, erklärt sich nach der Ansicht ConkLins, RoBerts, CASTEELs sehr einfach aus der Inversität im Bau der betreffenden Eizellen. Für den Grund der Inversität selbst fehlt uns ebenso wie für den Ursprung der individuellen Variabilität überhaupt, jede Erklärung. Phylogenetisch werden wir wohl richtig annehmen, daß es ursprünglich irrelevant war, ob die Eier normal oder invers wareu und dextrale oder sinistrale Exemplare lieferten. Je nach der Art wurde bei der Naturauslese diese oder jene Richtung mehr begiinstigt, so daß z. B. bei der Weinbergschnecke gegenwärtig die atavistische Inversität sich nur ausnahmsweise einstellt. In beiden Fällen bleibt die ontogenetische Prospektivität dieselbe, nur ist sie umgekehrt, so 
daß sich auch sämtliche Entwicklungsstadien im entgegengesetzten Sinne ausbilden miissen. Ob zwischen der Furchung und dem Bau des Reifestadiums ein direkter oder gar kein Zusammenhang besteht, wäre sodann vollends gleichgtiltig.

Daß die Erklärung des Untersehiedes der Drehungsrichtungen durch Inversität plausibel ist, erhellt schließlich aus deu zahlreichen Fällen, wo bei höheren Tieren z. B. bei Säugetieren oder beim Menschen Individuen mit strenger anatomischer Inversität vorkommen. SchlieBlich erimnern wir an jene PHanzenarten, wie Hibertia dentata oder Solanum dulcamarn, bei denen die Nutationsrichtung wechseln kann. Auch bei ihnen kann die entgegengesetzte Disposition in anatomischen Bau nur auf inversen Bau der Keimzelle zurückgefuihrt werden, zumal es auch sonst Pflanzenarten gibt, bei denen die Windung nach links vor sich geht und solche, welche konstant wach rechts winden.

\section{Allgemeine Betrachtungen über das sekundäre Mesoderm}

larraler Mesoblast, Ectomesoblast, primäres Mesoderm (EIsIG)].

In meiner vorläufigen Mitteilung ('97) habe ich diejenige Partie des Mesoderms ron Physa fontinalis ${ }^{1}$, deren Ableitung vom dritten Quartett oben geschildert wurde, »sekundäres « Mesoderm genannt im Gegensatz zum "primären oder Urmesoderm. Obwohl diese Bezeichnung aus theoretischen Riicksichten vermieden werden sollte, da man wohl noch nicht dariiber einig ist, welche ron den beiden Mesodermanlagen als sekundär anzusehen ist, so habe ich sie dennoch in dieser Arbeit beibehalten, weil sie sich bereits in der betreffenden Literatur ziemlich eingeburgert hat. Mit Bezug auf die Abstammung duirfte die ron englischen Autoren gebrauchte Bezeichnung $»$ Ectomesoblast * wohl am passendsten scin, wenngleich dieselbe auch nicht ganz korrekt ist.

Das bereits bei mehreren Mollusken und Anneliden nachgewiesene sekundäre Mesoderm entsteht ausschließlich aus der sogenannten Ectodermgeneration und liefert entweder nur larvale Organe (daher larvaler Mesoblast) oder aber anch definitive.

Die bisherigen Angaben iiber dessen Genese, Differenzierung und Endschicksale sind meistenteils noch sehr schwankend, so daß sich der Vergleich nur in engen Grenzen bewegen kann. Wir wollen

${ }_{1}$ Bei Physa hypnorum wird das sekundäre Mesoderm nach meinen Beobachtungen genau in derselben Treise gebildet. wie bei Plyysa fontinalis, unsre Ausfithrungen beziehen sich somit auf beide Arten. 
denselben mit einer Form beginnen, die in entwicklungsgeschichtlicher Beziehnng Physa am nächsten steht, nämlich mit Planorbis (HoLines). Es wurde schon oben darauf hingewiesen, daß es dieselben Mutterzellen sind, welche bei diesen Formen den Ausgangspunkt der Entwicklung des sekundären Mesoderms bilden, ferner daß ihre erste und zweite Teilung ebenfalls in ganz übereinstimmender Weise verläuft und erst bei den weiteren Teilungen sich ein scheinbar wesentlicher Unterschied einstellt. Wir müssen, bevor wir diesen klarlegen, den Leser darauf anfmerksam machen, daß HoLsies die vorderen Quadranten mit $b$ und $c$ anstatt wie wir mit $a$ und $b$ bezeichnet hat, was bereits bei der Darstellung der zweiten Furchung eingehend erörtert wurde. Daselbst S. 523-527 ist auch die irrtümliche Bezeichnung dieser beiden Quartette in meiner vorläufigen Mitteilung berichtigt worden.

Die Differenzen zwischen Physa und Planorbis bestehen einzig. und allein darin, daß bei der ersteren die parigen Stammzellen $3 a^{21}$, $3 b^{21}$ und $3 a^{22}, 3 b^{22}$ vor ihrer definitiven Umwandlung in reine Mesoblasten je zwei Mikromeren abgeben, die an der Bildung des Mesoderms gar nicht teilnehmen, soudern sich der Entodermplatte zugesellen, während dieselben vier Zellen bei Planorbis (von HoLmes mit $3 b^{21}, 3 b^{22}$ und $3 c^{21}, 3 c^{22}$ bezeichnet) nur je eine Mikromere abschnüren, worauf sie sogleich in die Furchungshöhle einsinken und sich dort in acht äquale Mesodermzellen teilen. Wenn man diese letzteren in der Fig. 50, Taf. XXI, bei HoluEs und in unsrer Fig. 50 vergleicht, so kann man angesichts ihrer vollkommen identischen Lage und Gruppierung gar nicht in Zweifel sein, daB es ganz homologe Zellen sind. Hownes macht jedoch ihre Homologie davon abhängig, ob unser zweites Mikromerenpaar, über dessen Endschicksal meine vorläufige Mitteilung keine Angabe enthält, sich auch an der Bildung des sekundären Mesoderms beteiligt. Diese Voraussetzung ist aber absolut ausgeschlossen ${ }^{1}$. Dessenungeachtet halten wir an der Homologie des sekundären Mesoderms bei den beiden Formen fest, denn wir stïtzen dieselbe lediglich auf die Identität der Mutterzellen und erachten den Umstand, daß sie behufs ihrer Sonderung in dem einen Falle eine zweimalige (Physa), in dem andern eine einmalige (Planorbis), inäquale Teilung durchmachen, als ganz nebensächlich. Übrigens hat uns die Vergleichung der betreffenden Figuren in HoLmes' Arbeit

1 Sie verbleiben an der Oberfläche und werden bei der Gastrulation mit der Entodermplatte eingestiilpt. Über ihre Endschicksale wird im Kapitel Enddarme gehandelt. 
wegen ihrer mangelhaften, zum Teil auch unrichtigen Bezeicbnung keine ganz sicheren Anbaltspunkte zum strengen Vergleich gewährt, vielmehr die Vermutung nahe gelegt, daß dieser Autor möglicherweise die Abgabe des für I'hysa charakteristischen zweiten Mikromerenpaares tiberseben haben mochte. Sollte dieselbe begrïndet sein, alsdann wïrde auch die weitere Differenzierung der Ectomesoblasten beider Formen ebenso tiberrasehend ähnlich sein, wie in den Anfangsphasen, wenn nicht ganz identisch!

Ob bei Planorlis (RABL/) ebenfalls ein sekundäres Mesoderm ansgebildet wird, kann man aus dem Texte nicht erfahren, wir halten es jedoch bei der sonstigen Übereinstimmung, welche diese Form mit Pluysa und Planorbis (HoLmes) zeigt, für höchst wahrscheinlich, zumal wir dafür in RaBLs Fig. $22 B, 23 B$ und 27, in denen vor der Nierenzelle ein reich entwickeltes Mesoderm eingezeichnet ist /welches von den Mesodermzellen nicht herstammen kann), eine kräftige Stlitze finden.

Außer den besprochenen Formen gibt es unter den Mollusken keine andern, bei denen das sekundäre Mesoderm aus dem dritten ( inartett abgeleitet wäre, dafür aber unter den Würmern. Bei Podarlie (Treadwell, '01) und Thalassema (Torrey, '03) geht es sogar aus drei Quadranten dieses Quartetts hervor, namentlich bei der ersteren Form aus $3 a^{222}, 3 c^{212}, 3 d^{222}$, bei der zweiten aus $3 a^{222}$, $3 c^{2121}, 3 d^{2221}$. Merkwürdigerweise ist die Anlage in der vorderen Keimhälfte unpaar. Sie differenziert sich bei beiden Formen nach demselben Typus, wie die entsprechende Mutterzelle bei Physı, jedoch ist sie der letzteren nicht homolog, sondern einer winzigen Mikromere, die sich an der Bildung des Mesoderms gar nicht beteiligt, sondern ihre Nutterzelle $3 a^{221}$. Aus der Darstellung Torreys ist es schwer zu entnehmen, welche Schicksale die einzelnen Descendenten von $3 a^{222}$ haben, ob sie nämlich auch zum Teil im Ectoderm verbleiben.

Die beiden hinteren Stammzellen durften sich, nach ToRREYs Fig. 21-24 zu schließen, nicht ganz harmonisch differenzieren, denn die Progenitur run $3 d$ scheint viel stärker als diejenige von $3 c \mathrm{zu}$

1 Nachdem dieser Absatz abgefaßt worden ist, erschien die Arbeit CAsteels "(04 iiber Fiona marina 'Nudibranchier, bei der die Entwicklung des sekundären Mesoderms vollkommen identisch mit Physu verliuft. Indem Castefl diese Identitiit hervorhebt. zeigt er auch an einem Schema. daß die Verhältnisse bei Planorbis HoLmes, bis auf den oben auseinandergesetzten Lnterschied bei diesen beiden Formen übereinstimmend sind. 
sein. Wie sich eigentlich die Sache verbält, läßt sich aus den nicht ganz klaren Figuren und der kurzen Darstellung jenes Autors nicht entnehmen und es erheben sich auch einige Zweifel über die Richtigkeit seiner Signifizierung.

Nach vollendeter Differenzierung sinken die nunmehr reinen Ectomesoblasten in die Furchungshöhle ein, schließen sich unmittelbar den beiden Mesodermzellen an, teilen sich alsbald teloblastisch, wobei die kleinen Tochterzellen in der Richtung gegen die letzteren zu abgeschnürt werden. Sie verhalten sich also in jeder Beziehung wie die äußeren Makromeren des Urmesoderms bei Physı und müßten ohne weiteres mit denselben identifiziert werden, wenn uns TORREY nicht versichern würde, daß ihre Descendenz mit aller Sorgfalt ermittelt worden ist.

Dasselbe Verhalten wie bei Thalassema sollen nach Torrey die beiden hinteren Ectomesoblasten bei Podarke (TREadwell) zeigen, was um so mehr auffällt, als diese andern Mutterzellen entstammen. Überhaupt ist mit Rücksicht auf den letzteren Umstand schwer zu verstehen, inwiefern die Differenzierung des Mesoderms bei den genannten Arten ibereinstimmen kann, was aber doch nach TorReY der Fall sein soll.

Die Abkömmlinge der beiden hinteren Ectomesoblasten liefern bei Thalassema fast das ganze Mesenchym der posttrochalen Region, während sie selbst einen Teil der Magen- und Oesophagusmuskulatur bilden.

Die Befunde Treadwells und Torreys, nach denen das sekundäre Mesoderm auch den hinteren Quadranten des dritten Quartetts entstammt, werfen einiges Licht auf die Verbältnisse bei Physa, bei der, wie an entsprechender Stelle hervorgehoben wurde, die beiden hinteren Quadranten dieses Quartetts sich in ihrer Sonderung den beiden vorderen auffallend ähnlich verhalten, trotzdem sie kein sekundäres Mesoderm liefern. Wir möchten darin einen Hinweis auf ihre phylogenetische Rolle erblicken, da offenbar bei den Anneliden die ursprünglicheren Verhältnisse erhalten blieben.

In bezug auf den Ursprung des sekundären Mesoderms beansprucht Thalassema aus dem Grunde eine Sonderstellung unter den Anneliden und Mollusken, weil sich bei ihr außer den drei Quadranten des dritten Quartetts noch das erste Quartett einen bedeutenden Teil desselben liefert. Namentlich sinken gar sieben Zellen dieses Quartetts in die Furchungshöhle ein und werden zu Mesenchymzellen. Da das Einsinken erst auf sehr vorgertickten Furchungs- 
stadien erfolgt, so kounte ihre Descendenz nicht exakt verfolgt werden, so daß Torrey nur die Gegend und die Quadrante anzugeben imstande ist, ron denen die betreffenden Zellen herstammen. Es sind namentlich die Zellen $a$ und $c$ in der sintergirdle region *, welche unmittelbar oherhalb des P'rototrochs liegen, ferner zwei in den Kreuzarmen $b$ und $c$ und eine in der Front der Apicalplatte: uber den Rest finden wir keine näheren Angaben.

Angesichts des L'mstandes, daß außer den genannten sieben Zellen noch 16 andre in die Furchungshöhle gelangen, welche aber ron den Entodermzellen aufgezehrt werden, muß das Verhalten des Ectoderms bei Thalassema als eine höchst sonderbare Eigentimlichkeit angesehen werden, da derzeit ein solches bei keiner andern Form beobachtet wurde.

Um seine Befunde nicht ganz unvermittelt erscheinen zu lassev, zieht Torrer einige ältere Beobachtungen zum Vergleiche heran; namentlich diejenigen Kleinenbergs ('86. und Meyers, nach denen die neuro-muskularen Elemente von Lepadorhynctus aus der Prätrochalregion ihren Ursprung nehmen, ferner diejenigen Sсникешттsсн (93), welcher einen Teil des Mesenchyms bei Dinophilus durch Immigration der Ectodermzellen aus der vorderen Partie des Embryos entstehen läßt. Mit diesen ziemlich unbestimmt lantenden Angaben über die Genese dieser Zellen, so wie uber ihre Endschicksale sind die Yerhältnisse bei Thalassema bei weitem nicht aufgeklärt.

Den oben besprochenen Formen, bei denen das sekundäre Mesoderm entweder bloß aus zwei oder ans drei Quadranten des dritten Quartetts hervorgeht, schließen sich zwei Molluskenspecies an, bei denen es aus dem zweiten Quartett abgeleitet wird, namentlich Lnio (Lillie, '95) und Crepidula (Coxklix, '97). Bei der ersteren Form entstammt es einer einzigen Zelle $2 a^{2}$ i $2 a$ nach LiLLIE;, deren Abkömmlinge die larvale Muskulatur des Glochidiums bilden, bei der zweiten drei Zellen $2 a, 2 b, 2 c$, deren Differenzierung jedoch nicht näher ermittelt werden kounte. Coxklix betrachtet diesen Teil des Mesoderms als einen slarvalen Mesoblast «.

Hiermit wäre nun die Zahl derjenigen Formen erschöpft, hei denen man den Ursprung des sekundären Mesoderms bis auf einzelne Stammzellen zurïckverfolgen konnte. $\mathrm{Zu}$ diesen kämen noch mehrere Arten hinzu, bei denen zwar die Beteiligung der Ectodermgeneration an der Bildung des Mesoderms mit einiger Sicherheit nachgewiesen wurde, ohne daß es dabei gelungen wäre, die betreffenden Vorgänge im einzelnen zu rerfolgen. In diese Kategorie gehören nach der 
Zusammenstellung ToRkers und andrer Autoren folgende Formen: Aricia (Wrlson, '89), Dreissensia 'Meisexhener, '00), Cyclas (ZiegLer '85), Pisidium (Lankester, '75), Pholas (Sigerfoos, '95), Patella (Patrex, '86), Paludina (Erlanger, '91). Schließlich dürfte ein Teil des Mesenchyms auch bei folgenden Formen einen ectodermalen Ursprung haben: bei Teredo (Goette), Anodonta (Schierholz;, Astraen (Horst), Eupommatus (HatscheK) und nach unsrer Meinung anch bei Planortis (RABL, '79). Zum obigen Verzeichnis miissen wir bemerken, daß es sich zum großen Teil bloß auf Vermutungen stützt. Wenn wir aber auch von allen zweifelhaften Fällen ganz absehen, so ist die Zahl der bisher sicher nachgewiesenen vollkommen ausreichend, um die Überzeugung aussprechen zu können, daß der doppelte Ursprung des MIesoderms eine unter den Anneliden und Mollusken weit verbreitete Erscheinung ist.

Es erübrigt uns noch einiger extremen Fälle zu gedenken. Zu diesen gehört Limax, bei dem nach Koford und Mersenhener gar kein sekundäres Mesoderm gebildet wird, desgleichen Trochus, bei welchem Robert ${ }^{1}$ bis zum Stadium von 228 Zellen keine Einwanderung ron Ectodermzellen in die Furchungshöhle feststellen konnte, ferner Siphonaria und Aplysia, bei denen Fcrtra ('04) ebenfalls kein sekundäres Mesoderm finden konnte. Außerdem grehört in diese Kategorie eine ganze Reihe von Formen, deren Entwicklung in einer Zeit studiert wurde, in der die Existenz eines sekundären Mesoderms nicht einmal geahnt wurde.

Im direkten G'egensatze zu den erwähnten Formen, bei denen das ganze Mesoderm sich aus $4 d$ aushildet, steht Paludina, bei der nach Töxxiges nur ein sekundäres Mesoderm zur Ausbildung gelangt. Es entsteht durch Auswanderung von Ectodermzellen längs des Verschlußrandes des Blastoporus. Die Angaben dieses Beobachters sind ron CARızzi und andern Autoren einer scharfen Kritik unterzogen worden, die berechtigt zu sein scheint. Denn es ist sehr unwahrscheinlich, daß bei Paludina die Entwicklung des Mesoderms aus $4 d$ gänzlich unterbleiben sollte. Diese Form scheint in bezug auf die Mesodermbildung recht interessant zu sein, sobald ERLanger i'91) zu

1 In einer soeljen publizierten Nachuntersuchung ('01) ïber das Mesoderm von Trochus nimint RoBerT seine obige Angabe zuriick und liehauptet, daß doch am genannten Stadiun ein sekundiares Mesoderm, wallscheinlich aus $3 c$ und $3 d$ gebildet wird. Leider sind die betreftenden Beolsachtungen noch immer sehr mangelhaft und sehwankend. 
ganz widersprechenden Resultaten gelangte. Wie bei Paludinu fehlt das Urmesoderm auch bei Bythinia (P. SARASIN).

Viel schwieriger sind die Pädoblasten Ersıgs ('98) bei Capitellı zu deuten, wenngleich sie bereits vielfach verglichen und gedeutet wurden. Nach unsrer Ansicht läßt sich zurzeit ein strenger Vergleich gar nicht durehführen, bis die Angaben Eisigs durch erneute Beobachtungen bekräftigt werden.

Die Ergebnisse der bisherigen spärlichen Beobachtungen über das sekundäre Mesoderm können im folgenden kurz zusammengefalit werden.

1) Es entwickelt sich ganz unabhängig vom primären Mesoderm stets aus der sogenannten „Ectodermgeneration * und zwar bei den Mollusken und Anneliden ausnahmslos aus der zweiten oder dritten, bei den Gephyreen (Thalassema, TORREY) auch aus der ersten Generation.

2) Die Stammzellen des sekundären Mesoderms können beliebigen Quadranten entstammen, jedoch nehmen sie, Thalassema ausgenommen, stets von einem einzigen Quartett ihren Ursprung.

3) Thre Differenzierung erfolgt öfters unter Abgabe von kleinen, chromatinreichen Zellen, welche sich unmittelbar an die Entodermplatte anschließen (Plyysa fontinalis et Iypnonum), Fiona (CAsTEEL), Planorbis (Holmes), Thalassema (TORREY).

4) Das sekundäre Mesoderm wird entweder ausschließlich zum Aufbau von larvalen Organen verwendet oder es entstehen aus ihm auch zum Teil definitive Organe, oder ausschließlich die letzteren.

5) Es entwickelt sich in einigen Fällen viel später als das primäre Mesoderm, z. B. bei Trochus, in andern mit demselben im gleichen Tempo: Thysa, Fiona, Planorbis (HoLmes).

Für die Beurteilung der Beziehung zwisehen dem primären und sekundären Mesoderm geben die Befunde bei Plnysa sehr wichtige Anhaltspunkte. Es stellt sich nämlich aus denselben heraus, daß ein unzweifelhaft larvales Organ, die Urniere, nicht dem sekundären, sondern dem primären Mesoderm entstammt. Ferner liefert das erstere ausschließlich definitives Muskel- und Bindegewebe und spielt beim Aufbau des Embryos eine bedentend wichtigere Rolle als das letztere, aus dem neben der Urniere noch die definitive Niere und wahrscheinlich auch das Herz und die Gonaden ihren Ursprung nehmen.

Mit Riicksicht auf diese Befunde, sowie auf den Umstand, daß 
das sekundäre Mesoderm bei andern Formen sowohl larvale als auch definitive Muskulatur liefert, läßt sich ein Gegensatz zwischen einem larvalen und definitiven Mesoderm nicht länger aufrecht halten.

\section{Vergleichende Betrachtungen über das primäre Mesoderm.}

Das sog. "primäre Mesoderm" der Mollusken, Anneliden und Polycladen ist in der neueren Literatur bereits so oft und eingehend vergleichend besprochen worden, daß wir es kaum nötig haben das ganze Tatsachenmaterial bis ins kleinste Detail nochmals vorzufithren. Dies wäre schon aus dem Grunde ganz überflüssig, da neulich RoBER'T ('03) in seiner Trochus-Arbeit die Furchungstabellen von 18 Mollusken, fünf Anneliden und einer Turbellarie zusammengestellt hat, welchen die das Mesoderm betreffenden Daten entnommen werden können. Angesichts dieser sehr dankenswerten Zusammenstellung halten wir es ebenfalls für überflüssig unsre vergleichenden Furchungstabellen beizufügen.

Die bereits von früheren Autoren betonte Übereinstimmung in der Ausbildung des Mesoderms bei den Mollusken und Anneliden wird durch die von Tag zu Tag sich mehrenden neuen Arbeiten im vollen Maße bestätigt. Es stellt sich zunächst heraus, daß das primäre Mesoderm stets aus einer und derselben Zelle, d. i. aus der hinteren linken, ausnahmsweise rechten (bei der »reversal cleavage «) Makromere $3 D$ entspringt, daß diese Zelle öfters schon am Stadium von vier Blastomeren sich durch ihre Größe und öfters durch ihr Verhalten von den drei iibrigen unterscheidet ${ }^{1}$.

Diese Stammzelle des Mesoderms differenziert sich ferner ganz allgemein in einen entodermalen Descendenten $4 D$, welcher ohne Riickșicht auf seine Größe als Makromere bezeichnet wird und in einen mesodermalen $4 d(M)$, welcher gewöhnlich Urmesoderm genannt wird. Es treten bei dieser Teilung zwei Modifikationen auf: entweder ist $4 d>4 D$, was bei der Mehrzahl der bisher untersuchten Formen der Fall ist, oder $4 d<4 D$, wie bei Fulgur, Bythinia, Neritina, Ilyanassa, Crepidula, Siphonaria und Aplysia (Fustra '04) unter den Mollusken, und bei Nereis limbata, Capitella capitata, Podarke obscurc und Thalassema unter den Anneliden. Ob der Größenunterschied zwischen den beiden Teilprodukten ausschließlich von der Quantität des Dotters abhängig ist, läßt sich vorläutig nicht ent-

1 Der Zeitpunkt, an dem die Differenzierung des primüren Mesoderms beginnt, ist recht verschieden, er schwankt zwischen 28 und 50 Zellen, ausnahmsweise beginnt dieselbe bei 89 Zellen (Trochus) oder bei 113 (Ischnochiton). 
scheiden, da z. B. bei [imbrellu, Aplysin usw. $4 d>4 I$, trotzdem das Ei dieser Formen dotterreich ist. Es mügen hier also doch außer dem Dotter noch andre Faktoren den Teilungsmodus beeiuflussen.

Nach ihrer Abtrenung macht die Urmesodermzelle ganz allgemein eine äquale Bilateralteilung durch; die Schwesterzellen $\left(\boldsymbol{M}_{1}\right)$ $4 d^{1}$ und $\left(\mathrm{II}_{2}\right) 4 d^{2}$ fuihren in den meisten Fällen noch fremde Bestandteile, welche sei es schon bei der nächsten, sei es erst bei den folgenden Teilungen gänzlich abgesondert werden. Mit liücksicht auf diesen Umstand pflegt die Bezeichunng des paarigen Urmesoderms, sowie seiner späteren Derivate eine sehr verschiedene $z u$ sein ${ }^{1}$.

Auf die Bilateralteilung, die in einzelnen Fällen einen spiraligen Charakter haben kann, Trochus (RoBerT, Crepidula (Coxkits), folgt fast allgemein eine inäquale, ausuahmsweise eiue subäi,uale Teilung (Clymenclla, Crepidula). Die Abgabe der Tochterzellen $4 d^{11}$ und $4 d^{21}$ $\left(m_{1}, e_{1}, E\right)$ erfolgt entweder in der liichtung nach rorn und oben, gegen das Centrum des Keimes oder nach vorn und unten oder aher nach hinten und unten gegen die Blastoporuslippen zu, welcher Gegensatz in der Teilungsrichtung nach der Ansicht einiger Autoren von der Lage der in Teilung begriffenen Zellen abhängen soll. Die kleinen, beziehungsweise gleich großen Tochterzellen sollen nümlich damn nach vorn ahgegeben werden, wenn die Teilung in der Furchungshühle stattfindet, sonst nach hinten und unten, beziehungsweise nach vorn und unten, wie es bei Physa der Fall ist.

Auch diese inäquale Teilung erfolgt ausnahmsweise nach dem Spiraltrpus (Dreissensir!. Bei I'lyys könnte man sie der Lage der Teilspindeln nach gleichfalls als spiralig auffassen, wir beurteilen aber den Teilungsmodus nicht nach der Lage der Spindel, sondern nach der definitiven Lage der Teilprodukte.

Es mag schon an dieser Stelle hervorgehoben werden, daß die ersten Teilprodukte des paarigen Nesoderms, ihrer verschiedenen Größe, Lage und Prospektivität halber zu verschiedenen Kontroversen Anlaß gegehen haben, worauf schon ihre verschiedene Signifizierung hinweist.

Der weitere Sonderungsprozeß des Urmesoderms verläuft nicht mehr in derselben typischen Weise, wie in den Anfangsphasen, es

1 Es werden nämlich die beiden Crmesodermzellen selbst bald mit $M$, bald nit $Y_{1}, M_{2}$, bald mit $M E$, und ihre erstes kleinen Tochterzellen mit $c, r n, E$ oder $m, m_{1}$ nsw. bezeichnet, je nachilem die letzteren zur Ausbildung der entodermalen oder mesenchymatischen Organe beitragen. 
lassen sich somit nur in beschränkten Formenkreisen noch einige gemeinschaftliche Züg'e aufweisen. Für mehrerë Gasteropoden können wir noch eine äquale oder subäquale Teilung des Urmesoderms als Regel betrachten. Es treten aber auch in dieser Gruppe öfters schon bei den nächsten Teilungen bedeutende Differenzen auf, deren Beurteilung der Umstand erschwert, daß die weitere Descendenz nur in seltenen Fällen mit gewïnschter Sorgfalt beobachtet wurde, und meistenteils über die Endschicksale einzelner Elemente der Keimstreifen nur unzulängliche oder keine Angaben vorliegen, so daß eine bis ins einzelne gehende Homologisierung sich vorwiegend anf Vermutungen stiitzen kann. Wir wollen dessenungeachtet einige Beispiele zum Vergleiche herausgreifen, um an denselben zu zeigen, inwieweit sich sichere Homologieschliusse ziehen lassen.

Den Verbältnissen bei Physa, welche wir unserm Vergleich zugrunde legen, stehen wohl am nächsten diejenigen, bei Planorbis (RABL, '79). Wenn auch die diesbezuiglichen Beobachtungen Rabls nicht ganz vollständig sind, so können wir doch sowohl aus seinen im allgemeinen trefflichen Figuren, als auch aus seinen Angaben uber das Endschicksal einzelner Teile der Mesodermstreifen, insbesondere aber aus der Konfiguration der letzteren schließen, daß die Entwicklung des Urmesoderms bei beiden Formen vollkommen iibereinstimmend verläuft. Die Unterschiede in der Ausbildung der Mesodermstreifen betreffen in erster Linie die Mikromeren, deren RABL bloß drei Paare erwähnt und alle drei von den medianen Makromeren ableitet. Es ergibt sich aber aus dessen Figuren $18 \mathrm{~A}$ und $18 B$, daß die mit $m_{1}$ und $m_{2}$ bezeichneten Mikromeren nicht den medianen, sondern den seitlichen (vorderen) Makromeren angehüren, ferner daß er das erste, unserm $m_{1}$ entsprechende Paar ubersehen bat. Daß letzteres bei Planorbis ebenfalls gebildet wird, folgt ans einer Arbeit Rabls: „Über den pedicle of invagination « usw. ('80), in welcher, wie dies beim Darmkanal näher erörtert wird, ein solider Strang in unmittelbarer Nähe der medianen Makromeren beschrieben wird, der zweifellos aus den Descendenten von $m_{1} m_{1}$ (e und $E$ andrer Autoren) entsteht.

Die Makromeren des primären Mesoderms sind bei Physa und Plcnorbis sowohl ihrer Zabl und Lage als anch ihrer Prospektivitait nach ganz sicher homolog. Es werden nämlich die vier vorderen bei beiden Formen zum Aufbau der Urnieren verwendet, während die zwei hinteren zum Auflyau der bleibenden Nieren, des Herzens und des Pericards verwendet werden. 
Bedeutend schwieriger gestaltet sich der Vergleich mit I'lomorlis: trivolis (Howras, 'O0, wenngleich die Zelldescendenz bei dieser Form eingehender studiert wurde. Die Anfangsstadien sind zweifellos mit denjenigen hei Phy,sa identisch, es treten aber später Differenzen auf, ülıer welche wir kein begründetes Urteil ahgehen kïnnen, da Hotues' Darstellung sich bloß auf zwei Figuren (49 und 50) stutzt, in denen die fraglichen Punkte gerade unberücksichtigt reblicben sind. Ua ferner über die Endschicksale einzelner Bestandteile des Mesoderms von $P l$. trirolvis gar keine Angaben vorliegren, so fehlen eigentlich für die Homologisierung die Hauptgrundlagen. Wir künnen nur, gestutzt auf die Äulierung HoLMes; daß die Eutwicklung des Mesoderms bei den beiden Planorlis-Arten, d. i. trirolvis (Hownes) und marginatus $|\mathrm{RABL}\rangle$, in derselhen Weise vor sich geht, sowie anf die Ühereinstimmung des ganzen Furchungsprozesses bei Planorlis tricolic und Plysa, wohl mit einigem liecht folgern, daß die Entwicklung des Lrmesoderms bei allen drei Formen in ganz übereinstimmender Weise verläuft und daß allem Anscheine nach die fertigen Mesodermstreifen rollkommen homolog sind.

Bei weitem festere Anhaltspunkte für einen eingehenden Vergleich finden wir in der $T$ mlmolla-Arbeit Hermoxs ('93). Die fertigen Mesodermstreifen bieten bei Lmbrella ein ganz analoges Bild mit demjenigen bei Ploysa. Ihre Ausbildung verläuft aber in etwas verschiedener Weise. Zunächst wird das erste Mikromerenpaar $m$ bei Cmlsella nach vorn und oben gregren die Furchungshïhle zu abgeschnürt, dagegen bei Pliysa nach vorn und unten. Dieser Unterschied ist aber nebensächlich, da er sich bei Plyysa anf späteren Stadien durch Lmlagrerung ausgleicht. Wichtiger wäre der Lmstand, daß die dritte Teilung (in Makromeren) eine entgegengesetzte ist; da aber bei I mbrella die rorderen Makromeren später nach rückwärts und die hinteren seitwärts zu liegen kommen, so wird damit die völlige C̈bereinstimmung mit Physa hergestellt. In der Abschuiirung der nächsten zwei Mikromerenpare herrscht wieder bis auf die Größe und die entgrgengesetzte Teilungrsichtung eine volle Ü̉bereinstimmung. Die Teilung von $I_{1} . M_{1}$, welche derjenigen unserer äuBeren Makromeren entspricht, ist hei heiden Furmen inäqual und haben die kleineren Schwesterzellen genau dieselbe Lage, so daß wir die Zellen $m^{11}, m^{11}$ den Zellen $m_{3}$ bei Physa gleichsetzen künnen. Ähnliche analoge Erscheinungen finden wir auch in der weiteren Sonderung des Mesoderms bei beiden Formen. Die Aufeinanderfolge und die Richtung der Teilungen bietet zwar einige auffallende 
Differenzen, welche wir aber aus dem Grunde für nebensächlich halten, weil wir es aus eigner Erfahrung wissen und Heymons ebenfalls gesteht, daß eine strikte Bestimmung der Aufeinanderfolge der Teilungen an vorgerückten Stadien ungemein erschwert ist, so daß Verwechslungen sehr leicht unterlaufen können.

Die Hauptmomente, auf welche sich unsre Homologieschlïsse stiutzen, beruhen auf der Vergleichung der fertigen Keimstreifen, deren Gliederung bei beiden Formen auffallende Übereinstimmung zeigt, ferner auf dem Umstande, daß die Differenzierung des Mesoderms derselben unter Abgabe von vielen Mikromeren vor sich geht, die in Überzahl den mittleren Makromeren angehören, schließlich auf dem Verhalten des ersten Paares derselben $m\left(m_{1}\right)$, welches bei beiden Formen zwischen die auseinanderweichenden medianen Makromeren zu liegen kommt und allem Anscheine nach bei Umbrella in derselben Beziehung zum Enddarm steht, wie bei Physa.

Wir kommen auf den letzteren Punkt bei Besprechung der Entwicklung des Enddarmes eingehend zuriick, hier mag nur bemerkt werden, daß das Mesoderm von Umbrella allem Anscheine nach ebenfalls entodermale Elemente enthält und somit auch in dieser Beziehung demjenigen von Physa homolog ist.

Nachdem wir die Entwicklung des Mesoderms bei drei Pulmonaten und einem Opisthobranchier vergleichend betrachtet und die unsichere Grundlage für Homologieschliusse kennen gelernt haben, wenden wir uns zu andern Gruppen.

Unter den Prosobranchiern ist neulich die Zelldescendenz bei zwei Repräsentanten eingehend untersucht worden: bei Trochus von Robert und bei Crepidula von ConkLin. Über die Befunde bei der ersteren Form können wir uns ganz kurz fassen, da RoBert nur die ersten Entwicklungsphasen mit der gewünschten Sorgfalt verfolgt hat, uiber die späteren aber nur mutmaßliche Angaben macht, welche um so weniger zum Vergleich herangezogen werden können, als jegliche Beobachtungen uber das Endschicksal einzelner Elemente fehlen. Gestiitzt auf die von RовеRT sichergestellten Tatsachen, können wir wohl annehmen, daß die Anfangsphasen der Entwicklung des Mesoderms hei Trochus nach der allgemein guiltigen Norm verlaufen. Über die Mikromeren gibt weder der Text noch die Abbildungen einen näheren Aufschluß, wir erfahren nur, daß im ganzen zehn derselben gebildet werden, welche, aus der Textfigur 21 zu schließen, den medianen Makromeren entstammen möchten, wiewohl der Verfasser selbst ein Paar derselben von den ¿̈ußeren Makromeren ableitet. 
Sollte die Termutung Roberts, daß sich die äußeren, bzw. oberen Makromeren äqual teilen, begründet sein, alsdann würde in der späteren Entwicklung der Mesodermstreifen noch ein gemeinschaftlicher Zug vorkommen.

Nach dessen Dafürhalten düfte die Ausbildung des Mesoderms bei Trochus noch am ehesten mit derjenigen bei Cmbrclla in Parallele gebracht werden können. Angesichts der oben angedenteten Mängel in seinen Beobachtungen läßt sich wohl kaum etwas für oder dagegen rorbringen. Die Schwierigkeiten, welche sich der Homologisierung entgegenstellen, hat ROBERT selbst eingesehen, sie betreffen die entgegengesetzte Lage der kleineren Derivate von $4 d^{12}$ und $4 d^{22}$ bei Cmbrella, jedoch sind gerade diese Differenzen nach unsern obigen Ausfuhrungen nebensächlich.

Angenommen, daß sonst die Beziehungen zwischen dem Mesoderm von Trochus und ron Umbrella sehr nahe sind, wie dies RoBERT velmutet, dürften dieselben auch zwischen dem Mesoderm von Physa und Trochus bestehen, was wir fur sehr wahrscheinlich erachten zu können glauben, nachdem es sich aus unserm Vergleich ergeben hat, daß sie zwischen der ersteren Art und Umbrella tatsächlich bestehen ${ }^{1}$.

Die Sonderung des Mesoderms bei Crepidula, dem zweiten Repräsentanten der Prosobranchier, wurde bekanntlich von Coxkurs in einer so vorziiglichen Weise beobachtet und so klar in Wort und Bild dargestellt, daß jedwede Zweifel an der Richtigkeit seiner Beobachtungen ausgeschlossen sind.

Wir entuehmen der Darstellung dieses Forschers das wichtige Zngeständnis, daß die Differenzierung des Mesoderms bei Crcpidula so sehr von der allgemein guiltigen Norm abweicht, daß man sie als ein Unicum im Molluskenkreise betrachten möchte. Die auffallendsten Eigentiumlichkeiten beständen im folgenden: zunächst ist die Teilung der regelrecht gebildeten Urmesodermzellen $4 d^{1}$ und $4 d^{2}$ iqual, statt inäqual; die nach binten abgeschnürten Tochterzellen $E^{1}$ und $E^{2}$ sind die «primären Euteroblasten « CoxkLIxs. Die darauf folgende in¿qquale Teilung der Mutterzellen führt zur Sonderung der sprimären

1 In seiner Nachuntersuchung ('04', gibt RoßERT eine mehr erschüpfende Übersicht der Entwicklung von $4 d$, welche unsre Vermutungen zum Teil hestiitigt. Der Differenzierungsprozeß verliiuft bei Trochus im allgemeinen in derselben Weise wie bei Physa. Die äußeren Makromeren erzeugen aber bei dem ersteren vor ihrer :iqualen Teilung nur ein Mikromerenpaar (e) statt zwei; das letztere entspricht unserm $m_{3}$. 
Mesoblasten " $\left(m_{1} m_{2}\right)$, es folgt nun eine abermals äquale Teilung, bei welcher das ziveite Paar von Enteroblasten $e^{1}$ und $e^{2}$ die ssekundären Enteroblasten " abgesondert werden, deren Mutterzellen nunmehr reine Teloblasten des Mesoderms bilden. Das Ungewöhnliche in diesem Differenzierungsmodus liegt eigentlich hauptsächlich darin, daß die primären Enteroblasten eine bedeutende Größe haben, ferner, daß die sekundären Enteroblasten erst nach der Ausbildung der primären Yesoblasten abgesondert werden, kurz gefaßt, es erfolgt die Sonderung fremder Bestandteile nicht gleich bei der zweiten Teilung, sondern erst bei der vierten, welcher Befund zwar sehr iiberraschend ist, jedoch nicht isoliert dasteht, da die späte Sonderung fremder Bestandteile auch bei andern Formen vorkommt.

CoNkLIN sucht die Verhältnisse bei Crepidula mit denen bei Timbrella (HExnoxs) in Einklang zu bringen, wobei er sich geezwungen sieht anzunehmen, daß bei der letzteren Form die Teilungsordnung: umgekehrt ist, indem zunächst zwei Mikromeren nach vorn abgegehen werden und erst darauf eine ärquale Teilung der Mutterzellen folgt, während bei Crepidula gerade das Gegenteil stattfindet.

Gegen diese Auffassung Conklins erklärt sich Rober' ('03), indem er annimmt, daß die primären Enteroblasten ron Creppidula, trotz ihrer ungewöhnlichen Größe und rïckwärtigen Lage, dennoch dem ersten Nikromerenpaare bei Trochus und allen denjenigen Formen entsprechen diurften, bei denen die analogen Teilprodukte ebenfalls nach hinten abgeschnürt werden. Die Größe der Enteroblasten dürfte an und fiir sich ihrer Homologisierung mit den Zellen $m$ andrer Formen keine Schwierigkeiten bereiten, da dieselbe bekanntlich sehr verschieden sein kann, die Lage ist dabei insofern nicht maßgebend, als sie an späteren Stadien sich ändern kann. Wir sind somit hesonders nach unsern Beobachtungen an Physa mit RoBER'T daritber einig, daß die Enteroblasten von Crepidula dem ersten Mikromerenpaare ' $m$ ) von Physc, Trochus usw. homolog' sein duirften. Ob aber die primairen Hesoblasten derselben Form, d. i. $m_{1}$ und $m_{2}$ den Zellen $4 d^{121}$ und $4 d^{221}$, desgleichen die sekundiiren Enteroblasten $c_{1}$ und $e_{2}$ den Zellen $4 d^{2221}$ und $t d^{1221}$ andrer Gasteropoden homolog sind, wie es RoBERT anuimmt, dies ist nicht olne weiteres einlenchtend, denn es werden für diese Vermutung keine Gründe angeftihrt. ConkLrx vergleicht eine Gruppe von 4-6 Zellen, welche bei Lmbrella zwischen den Teloblasten des Mesoderms liegen und wahrscheinlich das Mesoderm des Enddarmes liefern, mit seinen Enteroblasten. Es würden den letzteren auch ähnlich gelegene Zellen zwischen den Teloblasten 
des Mesoderm bei Neritina, Nercis und Unio, und nach unserm Daftirhalten auch diejenigen bei Pliysa entsprechen. Die Rolle dieser Zellen scheint nach den vorliegenden Angaben recht verschieden zu sein, da sie eimmal das Epithel des Enddarmes, ein andres Mal dessen mesodermale Lmhïllung liefern sollen. Allenfalls scheint die Zahl derjenigen Fälle, wo das Mesoderm entodermale Elemente absondert, bedeutend größier zu sein, als man nach den bisherigen Beobachtungen erwarten möchte. Cirpidult beansprucht insofern eine Sonderstellung, als bei ihr mehr als die Hälfte der ganzen Mesodermanlage zur Bildung des Enddarmes rerwendet wird. Außer bei Crepidula und Plyysa (fontincalis et liyjmorum) wurden enteroblastische Elemente noch bei Aplysia (CAliazzi, 'OO) sicher nachøewiesen ${ }^{1}$. Es sind dies die Derirate der Teloblasten $4 d^{121}$ und $4 d^{222}$, welche nach hinten abgeschnuirt werden und dem dritten Mikromerenpalar bei Pliysa entsprechen. Caliazzi bezeichnet sie mit $e, f$ und bomologisiert sie mit den von ganz andern Mutterzellen erzengten Mikromeren $m^{1}, m^{2}$ bei Umbrella (Heymons).

Aus unsern vergleichenden Betrachtungen iiber das Mesoderm bei den Repräsentanten der Hauptgruppen der Gasteropoden ergibt sich, dab zurzeit für eine strenge Homologisierung öfters die wichtigsten Anhaltspunkte fehlen, weshalb sie sich nur auf einer schwankenden Basis bewegen und anf eine schr geringe Zahl ron Species beschränken muß.

Indem wir jetzt zu den Lamellibrauchiaten iibergehen, lassen wir die älteren Angalıen uber die Mesodermentwicklung bei dieser Gruppe unberieksichtigt und beschrïnken uns bloß anf zwei Formen, namentlich Unio (Liblie, '95) und Dreissensic Mersmenemer, '01'. Bei beiden werden ron den bilateral geteilten Urmesodermzellen zunächst kleine Elemente nach hinten, gegen den Blastoporus zu, abgegeben, welche wohl den Zellen $m\left(4 d^{11}\right.$ und $\left.4 d^{21}\right)$ bei den Gasteropoden entsprechen. Auf diese inäruale Teilung folgt bei Thio abermals eine inäquale, es wird ein zweites Mikromerenpaar gebildet, während bei Dreissensia mehrere » Bilateralteilungen s statt-

1 Nachdem dieser Aufsatz abgefaßt worden war, erhielt ich die Arbeit Casteels '04 ïber Fiona, aus der ich entnchme. daß die Sonderung des Mesoderms bei dieser Form in ïberraschend iibereinstimmender Weise mit Plyysu verliuft, wobei elenfalls Enterohlasteu $E^{2}$. $E_{2}^{2}$, gebildet werden. Hiese l'atsache ist um so mehr bedeutungrsoll, als Fiona ein Opisthobranchier und I'hysa ein I'ulmonat ist. Bezüglich der IIomologie des Mesorlerms bei C'rrpirhela. Ümbrella, Trochus, bzw. Physa und Fiona stimmen die Auseinandersetzungen Casteels mit den unsrigen der Hauptsache nach überein. 
finden, durch welche das nunmehr reine Mesoderm in gleiche Komponenten zerlegt wird. Das Schicksal der Zellen $m$ ist bei beiden Formen ganz verschieden, denn während sie bei Unio mesenchymatische Elemente liefern, schieben sie sich bei Dreissensia mitten zwischen die Entodermzellen und gehen in denselben auf. MersexHEIMER scheint sie auf Grund der analogen Verhältnisse bei Cyclas (STALFfacher) als entodermal zu betrachten, sie müßten aber eigentlich als rudimentär betrachtet werden.

Nach dem obigen finden wir somit bei den Lamellibranchiaten dasselbe Verhalten, wie bei vielen Gasteropoden, daß nämlich die Urmesodermzelle ursprünglich fremde Elemente enthält, welche durch eine inäquale Teilung frühzeitig abgesondert werden. Das Vergleichsmaterial ist aber für weitgehende Vergleiche noch sehr unzulänglich.

Bei den Anneliden kommt die bilaterale Teilung ron $4 d$ und eine unmittelbar anf dieselbe folgende Erzeugung von Mikromeren fast allgemein vor. Denn nur bei Polymnia soll das erste Mikromerenpaar gar nicht zur Ausbildung gelangen und bei Capitella, т0 bekanntlich die Sonderung des Mesoderms in höchst eigentiumlicher Weise vor sich geht, werden die entsprechenden Zellen zu sog. »Pädoblasten «.

Im allgemeinen weist der Bildungsmodus und das Verhalten der ersten Abkömmlinge des paarigen Urmesoderms bei den Anneliden starke Variationen auf. Einmal sind sie nämlich so groß, wie die Mutterzellen (Clymenella), ein andres Mal rudimentär (Aricia, Spio, Amphitrite), bald weisen sie einen mesenchymatischen, bald entodermalen Charakter auf.

Entodermale Bestandteile des Urmesoderm werden bei den Anneliden ebenso wie bei den Mollusken entweder unmittelbar nach der ersten Bilateralteilung abgeschnuirt (Thalassema [TORREY]), oder erst bedeutend später (Podarke, Nereis). Leider beschränkt sich die Zahl der bisher genauer beobachteten Fälle, in denen sog. "Enteroblasten erzeugt werden, auf die soeben angefulhrten drei Species. Überhaupt läßt die Erforschung der Descendenz des Mesoderms bei den Auneliden woch viel zu wünschen iibrig, und deshalb ist nicht zu verwundern, wenn über die Homologie einzelner Derivate des Lrmesoderms, sowie über ihre Beziehung zu analogen Zellen bei den Mollusken widersprechende Ansichten geäußert werden.

Wir halten die Diskussion iiber diese Punkte so lange fur unfruchtbar, bis iiber die Descendenz des Mesoderms bei Anneliden, 
sowie iiber die Endschicksale seiner einzelnen Derirate erschöpfenile und zuverlåssige Daten gewonnen werden.

Auf Grund der vorliegenden Tatsacheu läßt sich nur so viel mit Sicherheit feststellen, daß die Entwicklung des primären Mesoderms bei Anneliden und Mollusken nur in den Anfangsphasen vollkommen iibereinstimmend verläuft.

Unter den Derivaten des Urmesoderms beanspruchen das meiste Interesse die sog. "Enteroblasten", weshalb wir densellen noch einige Bemerkungen widmen wollen.

Nach den bisherigen Beohachtungen sind "Enteroblasten" bei folgenden Formen sicher nachgewiesen worden: bei tTereis, Podrrlie, Thalassema unter den Anneliden, bei Crepidula (CoxkLIN), Fione (Casteel), Physa fontinalis und I'h. hypnorum (Wrerzesskir), Aplysia (CARaZZI) unter den Mollusken. Zu diesen fünf Formen dürften unseru obigen Auseinandersetzungen entsprechend auch zwei Planorlis-Arten sowie Umbrella hinzugezählt werden.

Zweifelhaft wäre das Vorkommen von Enteroblasten bei Cyyclas, Patella, Serpulorbis und Aricia. Bei Dreissensia ist, wie bereits oben bemerkt wurde, nach den Angaben Mersenienuers schwer zn entscheiden, ob die den Enteroblasten andrer Mollusken analogen Elemente entodermal oder aber rudimentiir sind. Sie sollen schließlich in Mesoderm von Amphitrite, Arenicola, Lnio, Limax gäinzlich fehlen. Aus dieser Zusammenstellung ist zu entuehmen, daß die Mesodermanlage, besonders bei den Gasteropoden, recht häufig entodermale Elemente enthält. Bezuiglich derjenigen Formen, bei denen weder Enteroblasten noch analoge Derivate des Iesoderms beobachtet wurden, wäre eine Nachuntersuchung sehr wünschenswert.

Bekanntlich faßt Wilsox (98; die Enteroblasten und ihre Homologa in phylogenetischem Sinne als Derivate des Archenterons auf, welches seiner Ansicht nach bei der Ahnenform die ausschließliche Bildungsstätte des Mesoderms gewesen war, während das vierte (Quartett rein entoblastisches Material lieferte. Dementsprechend nimut ferner dieser Forscher an, daß erst in einer späteren phylogenetischen Entwicklungsphase allmählich die Bildungsstiitte des Mesoderms in die hintere Makromere I) verlegt wurde. Sie multe somit urspringlich gemischte Elemente enthalten, deren sie sich erst im Laufe der Zeiten nach und nach zu enticdigen und in cine reine Mesodermanlage zu rerwandeln bestrebt ist. Diese Tendenz offenbart sich nach WiLsox darin, daß wir bei den heutigen Anneliden und Mollusken eine stufen- 
weise Eliminierung des entoblastischen Materials aus $4 d$ feststèllen können, indem z. B. bei Crepidula noch mehr als die Hälfte der ganzen Mesodermanlage entoblastisch ist, während bei Aricia und Spio nur noch unbedentende Rudimente der Enteroblasten sich erhalten haben, dagegen bei Unio, Limax usw. $4 d$ schon rein mesoblastisch geworden ist.

Wir bätten demnach nach WiLsoN in dem gegenwärtigen Entwicklungsmodus des Mesoderms nicht nur $»$ the persistence of vestigial processes in the formation of the germ layers «, sondern auch "the persistence of vestigial cells " (scil. rudimentäre Enteroblasten) zu erblicken.

Die Hypothese WILsons ist seit ihrer Veröffentlichung bereits öfters besprochen worden und hat beiläufig ebensoviele Anhänger wie Gegner gewonnen. $\mathrm{Zu}$ den letzteren gehören ChrLd ('00), Mead ('97) und Torex ('03).

Der erstere sieht in der Tatsache, daß die rein entodermale Blastomere $D$ sich bei den Polycladen gelegentlich bilateral teilt und daß dieselbe bei einigen Mollusken und Anneliden entodermale Elemente mitführt, keine hinreichende Stiitze für die Annahme WILsons, daß das Urmesoderm bei diesen beiden Gruppen dem Archenteron entstammt. Denn die verschiedene Verwendung der kleinen Descendenten der paarigen Mesoblasten hängt seiner Auffassung nach lediglich von dem Umstande $a b$, ob sie an der Keimoberfläche oder aber in der Furchungshöhle abgeschnürt werden. Wir hätten hier somit eher mit einer cänogenetischen Erscheinung zu tun, welche neben vielem audern den Beweis liefert, daß anscheinend homologe Zellen zu verschiedenen Zwecken verwendet werden können, je nachdem es die Bedürfnisse des Ganzen erheischen.

Mead weist darauf hin, daß die bilaterale Teilung von $D$ bei Discocoelis (L.NG) allem Anscheine nach ebenso zur Ausbildung der paarigen Mesodermanlage führt, wie im Mollusken- und Annelidenkreise; es wäre somit erwlunscht vorerst genauere Beobachtungen über diesen Punkt anzustellen bevor man die Bilateralteilung dieser hinteren Makromere als eine Stütze für phylogenetische Spekulationen ausnutzt.

Betreffend die kleinen Descendenten von $4 d$, welche eine so variable Größe und Verwendung zeigen, läßt sich nach diesem Autor nur so viel vermuten, daß sie die Anlagen gewisser variabler oder rudimentärer Bildungen sind. Im ïbrigen können wir den 
besonderen Teilungsmodus des parigen L'rmesoderms so lange nicht verstehen bis uns die Endschicksale der kleinen Teilprodukte genauer bekannt sein werden.

Auf diesen Punkt legt auch Torrex ein großes Gerricht, indem er hervorhebt, daß wir eigentlich einzelne Derivate des Urmesoderms lediglich mit Ruicksicht auf ihre Lage mesodermal nennen, ohne ihre eigentliche Rolle zu kennen. Seiner Ansicht nach müssen wir uns vorläufig vor jedem Lirteil üler ihre Bedeutung enthalten sobald wir nicht wissen ron was fur Faktoren die Differenzierung abhängig ist. Es soll dazu bemerkt werden, daß derselbe Autor an einer andern Stelle in der Deutung der kleinen Zellen ganz auf dem Standpunkte WiLSONS steht.

Schließlich muß noch hervorgehoben werden, daß GarBowski ('03) in einer erschöpfenden, kritischen Besprechung der neneren Mesodermtheorien die Hypothese Wrisoxs einfach als overwirrend zuriickweist.

Die Unzulänglichkeit der Beweisgriunde WiLsoxs äußert sich nicht so sehr im Mangel ganz zurerlïssiger Angaben über das Endschicksal der den Enterohlasten analogen Zellen, sondern vielmehr im Mangel genauer Beobachtungen iiber das Verhalten der Entomere $D$ bei den Polycladen, welches den Ausgangspunkt der Hypothese bildet. Denn sollte es sich herausstellen, daß diese rein entodermale Makromere ebenfalls mesodermale Elemente liefert, wie dies MEAD für wahrscheinlich hält, alsdann wäre der Archenteron-IIypothese völlig der Boden entzogen.

Die zweite Hauptstitze derselben, d. i. die zuweilen vorkonmende Verwendung der ersten Derivate des paarigen Lrmesoderms zum Aufbau der hinteren Archenteronwand, hat auch eine schwache Seite. Denn es gibt Formen (Physaa, Fiona, vielleicht Planorlis und Cmbrella, bei denen die Enteroblasten den Enddarm koustituieren, welcher nicht mehr als ein rein entodermales Organ gelten kann, sobald er z. B. nach Meisexhemer bei Limax und Ireissensia aus dem Ectoderm entspringt. Wenn es also erwiesen wäre, dal das Verhalten bei diesen Formen ein ursprünglicheres ist, so müßten wir die an der Bildung des Enddarmes sich beteiligenden Derivate des Mesoderms ihren Endschicksalen entsprechend als ectodermal bezeichnen und künnten den Ursprung des Mesoderms mit gleichem Rechte ins Ectoderm verlegen.

$\mathrm{Zu}$ ähnlichen Schluissen konnten anch die Schicksale der kleinen Derivate des sekundüren Mesoderms Anlaß geben, welche bei I'hy:s 
in die Zusammensetzung des ectodermalen Vorderdarmes eingehen. Für Autoren, welche unser sekundäres Mesoderm als das phyletisch ältere betrachten, würden die Endschicksale seiner kleinen Derivate, den Beweis liefern, daß die ursprüngliche Bildungsstätte des Mesoderms im Ectoderm zu suchen ist.

Wir ersehen aus diesen zwei Beispielen, daß die Endschicksale der Derivate beider Mesoblastanlagen uns bei Ableitung des Mesoderms aus den beiden primären Keimblättern zu keiner einheitlichen Auffassung führen können. Angesichts dessen, daß die Prospektivität der Blastomeren wechseln kann, daß sie also als etwas Zufälliges betrachtet werden muß, können wir dieselbe als Stuitze für unsre phylogenetischen Spekulationen nicht ausnützen.

Hiermit schließen wir die Diskussion über die Hypothese WiLsons $a b$ und behalten uns die Entwicklung unsrer Ansicht über die Bedeutung der kleinen Derivate der beiden Mesodermanlagen für den nächstfolgenden Abschnitt vor.

Es eriibrigt uns noch einige Worte den Bezeichnungen "primäres « und "sekundäres " Mesoderm zu widmen, deren wir uns bei unsrer Darstellung fortwährend bedient haben. Es wurde bereits bei Besprechung des sekundären Mesoderms hervorgehoben, daß wir diese Bezeichnungen nicht etwa im phyletischen Sinne gebrauchen, sondern um die beiden Anlagen irgendwie auseinander halten zu können.

Die Erforschung der Endschicksale der fertigen Mesodermstreifen hat uns nämlich die Überzeugung anfgedrungen, daß zwischen denselben trotz ihres verschiedenen Ursprungs und ihrer ganz unabhängigen Entwicklung kein Gegensatz besteht, denn es wurde bereits bei Besprechung des sekundären Mesoderms gezeigt, daß aus beiden in gleicher Weise sowohl larvale als auch definitive Organe hervorgehen können. Beide beginnen ihre Sonderung beinahe gleichzeitig bereits am Stadium von 28 Zellen, vollziehen dieselbe in auffallend ähnlicher Weise, beide entwickeln sich nebeneinander, durchdringen sich gegenseitig und gehen beim Aufbau der Organe vielfach ineinander über.

Wir können also auf Grund unsrer Erfahrungen bei Physa die Ansicht Treadwells', daß »no hard and fast distinction can be mad between the two forms of Mesoblast«, im vollen Maße bestätigen.

Diese Ansicht wurde auch von GaRBowski ('O3) bei dessen Ausführungen über die Beziehung zwischen dem Mesenchym und dem epithelialen Mesoderm (für welche ebenfalls die Bezcichnung primär und sekundär eingeführt wurde) in eingehender Weise begründet. 
Der L'mstand, daß das sekundäre Mesoderm aus der Ectodermgeneration, wogegen das primäre aus dem Entoderm seinen Lrsprung nimmt, fällt hier gar nicht in die Wagschale, nachdem es sich aus mehreren organogenetischen Befunden herausgestellt hat, daß die erstere potentialiter alle Keimblätter in sich enthält.

Schließlich wollen wir nicht unerwähnt lassen, daß RonBerT nach seinen erneuerten Untersuchungen des sekundären Mesoderms bei Trochus $\langle 05\rangle$ die verhältnismäß $\{i g$ sehr späte Entwicklung desselben als einen Beweis fur seine sekundaire Natur anfiihrt. Dem gegenüber sind die oben erwähnten Befunde bei IM!ys zu betonen, welche beweisen, daß beide Anlagen fast gleichzeitig zur Sonderung gelangen.

Auch der radiale Lrsprung des Ectomesoblasten kann nur so lange als Beweis seiner primiticen Natur gelten, so lauge wir daran festhalten, daß bei den Polycladen das ganze Mesoderm ausschließlich aus dem Ectoderm seinen Ursprung nimmt. Wird es sich aber herausstellen, daß hei diesen Würmern ein Teil des Mesoderms aus dem Entoderm (aus $3 D_{j}$ seinen Ursprung nehmen kann, alsdaun fällt die Hauptstutze der Theorie weg.

Von unserm Standpunkte aus halten wir auch die Diskussion iiber die phyletische Beziehung zwischen den beiden Mesodermanlagen zum mindesten so lange für unfruchtbar, bis wir iber das Terhältnis derselben zu den Organen ganz zurerlässige Aufschliusse gewonnen haben werden und so lange wir nicht über den Begriff des mittleren Keimblattes zu einer eimheitlicheren Auffassung gelangt sind.

In der neueren Litteratur fehlt es nicht an Bemiilıungen einerseits die Unhaltbarkeit dieses Begriffes zu beweisen (G.ıRвowski, Morph. Stud.), anderseits densellen auf einfache Organanlagen zu-

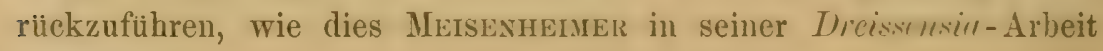
versucht.

Dieser Autor weist nämlich auf die iiberraschende Übereinstimmung in der Entwicklung der beiden Somatollasten ( $X^{1}$ u. $4 d, . M$ ) hin und leitet aus derselben folgenden Schluß ab: "Die Sonderung des zweiten Somatoblasten, d. h. also der ,Urmesodermzellen', steht demnach in ihrer Eigenart durchaus nicht ohne Parallele in andern Zellkomplexen da, nichts berechtigt dazu sie als ein besonderes Keimblatt den übrigen Furchungszellen entgegen zu setzen. Beide

2 Ans diesem gehen die Schalendrise und der Fuß hervor. 
Somatoblasten sind Organanlagen, beide bergen in sich nach ihrer völligen Sonderung ganz bestimmte Organkomplexe, die sie nun zur Entfaltung bringen " usw. (S. 33) und weiter heißt es (S. 119): "An Stelle der Keimblätter haben wir also eine Reihe von Organanlagen gesetzt, Primitivanlagen, wie man sie auch genannt hat $\ldots . . .$. »Beide Begriffe können morphologisch und physiologisch hier und da mit dem zusammenfallen, was man bis jetzt als das eine oder das andre Keimblatt bezeichnet, brauchen es aber nicht zu tun. "

Dieser Standpunkt ist gewiß ganz richtig und seine Konsequenzen dürften für das Verständnis der Entwicklungsvorgänge viel fruchtbringender sein, als das gewaltsame Einzwängen der Organanlagen in die Kategorien der Keimblätter.

\section{Rudimentäre Zellen.}

Unter dieser Bezeichnung werden in der Embryologie der Anneliden und Mollusken gewisse Produkte stark inäqualer Furchungen angeführt, welche sich im allgemeinen durch eine sehr geringe Größe und den Chromatinreichtum ihrer Kerne auszeichnen und sich entweder während der ganzen Furchungsperiode ganz passiv verhalten oder aber schon fruihzeitig spurlos zugrunde gehen. Leider wurden ihre Endschicksale nur in den allerseltensten Fällen exakt verfolgt, während die meisten Angaben vorwiegend auf Vermutungen beruhen.

Wilson ('98) war der erste, der den rudimentären Charakter der kleinen Derivate der Mesodermzellen nachzuweisen versuchte. Er betrachtet sie bekanntlich als Rudimente der Enteroblasten und bezeichnet sie als » vestigial cells, " worïber bereits oben beim Mesoderm ausführlicher berichtet wurde.

Seit dieser Zeit hat man das Vorkommen ähnlicher Gebilde bei verschiedenen Formen der Anneliden, Gephyreen, Mollusken, ja sogar Rotatorien und Crustaceen festgestellt. Es mögen nun im folgenden einige Fälle angeführt werden.

Conklin ('97) hat bei Crepidula plana die Beobachtung gemacht, daß die sehr kleinen »Tipcells " des vorderen Kreuzarmes schließlich aus dem Verbande der Ectodermzellen weggedrängt werden und allem Anscheine nach außerhalb des Keimes zugrunde gehen. Desgleichen beobachtete Miß LANGEnbeck ('98) bei Microdeutopus (Amphipod) zwei vom Blastoderm herstammende Zellen, welche ins Blastocöl gelangen und daselbst einer vollständigen Degeneration anheimfallen. Über ihre Descendenz ist leider nichts Näheres bekannt.

Die auffallendste und zugleich wertvollste Beobachtung machte Zeitschrift f, wissensch, Zoologie. LXXXII. Bd. 
neulich TorRey ('03) bei Thulassema (Gephyrea). Hier werden wiihrend des Furchungsprozesses nach der Schätzung dieses Autors wenigstens sechzehn ganz kleine Zellen im ersten und zweiten Quartette erzeugt, welche kurz nach ihrer Abschnirung sichtlich an Größe abnehmen, wobei ibre Kerne dicht reticuliert erscheinen. Diese Zellen beginnen alsbald in die Tiefe zwischen den Ectomeren einzusinken, gelangen in die Furchungshöhle, dringen sodann zwischen und in die Entomeren ein und werden schließlich von denselbeu gänzlich resorbiert. Nach Ablauf von 14 Stunden, vom Beginn der Furchung, ist von ihnen keine Spur mehr vorhanden. Der ganze Vorgang wurde von Torkex Schritt fur Schritt verfolgt und in den Textfiguren S. 232 bildlich dargestellt, so daß an der Richtigkeit seiner Beobachtungen kaum gezweifelt werden darf.

Es ist wohl der erste sicher nachgewiesene Fall einer massenhaften Vernichtung der Furchungsprodukte durch eine Art Phagocytose. Recht interessant ist dabei der Umstand, daß einigen von den fur den Untergang bestimmten Zellen bei andern Würmern funktionierende Zellen entsprechen, so z. B. den Zellen $1 d^{1 \cdot 1 \cdot 2 \cdot 2 \cdot 1}$ und $1 c^{1 \cdot 1 \cdot 2 \cdot 2 \cdot 1}$ von Thalassema die Nephroblasten bei Noreis und Drüsen bei Amplitrite und Capitella, während dieselben Zellen bei Podrorke von Treadwell ('01) ebenfalls für rudimentär gehalten werden. Noch mehr auffällig ist der Befund TonReys, daß diese typisch rudimentären Zellen bei der sogenannten radialen Varietät der Embryonen von Therlassema groß und offenbar funktionsfähig sind, ferner daß die Zellen $1 d^{1 \cdot 1 \cdot 2 \cdot 1 \cdot 2}$ bei derselben Species bald funktionierend bald rudimentär erscheinen - ein Beweis, daß gleichnamige Zellen sehr verschiedene Prospektivität haben können - TokReY vergleicht das Verhalten der rudimentären Zellen bei Thalassema mit den ${ }_{\text {Pädo- }}$ blasten* Ersigs bei Capitellu, welch letztere durch die entodermalen Massen hindurchdringen, um als funktionierende Mesenchymzellen emporzutauchen; dieser Vergleich erscheint jedoch mit Riicksicht auf den letzteren Umstand nicht ganz zutreffend.

Außer den oben besprochenen werden noch in die Kategorie der rudimentären Zellen solehe kleine und anscheinend bedeutnngslose Furchungsprodukte eingereiht, deren Endschicksale nicht genau bekannt sind. Vor allem die kleinen Descendenten der Polzellen bei Aricic und Spio, in denen WiLson ('98) das Rudiment der Enteroblasten erblickt. Vom Standpunkte seiner Hypothese düften auch die analogen Derivate bei Amphitrite (MEAD, 97), Podarlie (Treadwell, 97), Arenicolc (Child, '00); ferner bei Planorbis (Holmes), 
Crepidula (Conklin), Limbrella (Hemmons), Physa (WIErzeJski) hierher eingereiht werden, die sei es funktionierende Enteroblasten oder deren Rudimente repräsentieren dürften.

Schließlich dürften auch die von Jennings ('96) bei Asplanchna beobachteten winzigen Derivate der Entomeren, welche während der Gastrulation abgeschnuirt werden, in die Reihe der rudimentären Zellen gestellt werden.

Die allgemeine Verbreitung und die öfters ansehnliche Anzahl der bei einzelnen Formen erzeugten sogenannten rudimentären Zellen weist darauf hin, daß sie irgend welche physiologische oder morphologische Bedeutung haben müssen oder beide zugleich.

Faßt man sie mit WILson als Rudimente auf, welche ibre ursprüngliche Funktion aufgegeben haben und sich bloß als ein Überbleibsel eines altertiumlichen Furchungstypus als "vestigial cells « erhalten haben, so müßte in jedem Falle darüber entschieden werden, welche Rolle sie bei der Ahnenform gespielt haben mochten.

Wir haben beim Mesoderm gesehen, daß die Hypothese WiLsons, insofern sie die Existenz palingenetischer Prozesse in der Differenzierung des mittleren Keimblattes wahrscheinlich zu machen sucht, nicht aufrecht erhalten werden kann. TorRey faßt aber das Wesen der rudimentären Zellen bei Thalassema vollkommen im Sinne der Hypothese WiLsons auf, denn er meint »that the radially arranged rudimentary cells may be reminiscent of the foundations of certain radial organs «. Im speziellen mögen es einstens Mesenchymzellen gewesen sein, wofür einerseits der radiäre Ursprung der letzteren bei den Polycladen, anderseits das Vorkommen von Ectomesoblasten bei den Anneliden und Mollusken, insbesondere aber diese Tatsache spricht, daß die Zelle $2 a^{21}$ bei Unio den ganzen Ectomesoblast liefert, während sie bei Amphitrite schon sehr klein und bei Thalassema ganz rudimentär geworden ist. Wir hätten hier also denselben stufenweise fortschreitenden Reduktionsprozeß der ehemaligen Funktion und dieselbe Übertragung der letzteren an andre Blastomeren zu erblicken, wie sie die Hypothese WiLsors für das primäre Mesoderm annimmt.

Es muß aber in Erinnerung gebracht werden, daß bei Thalassema gegenwärtig drei Blastomeren des dritten und sogar sieben des ersten Quartetts an der Bildung des Ectomesoblastes beteiligt sind, somit im ganzen zehn Zellen! Außerdem sind Rudimente des mesenchymatischen Materials, nach der Schätzung TorRers, auf mindestens 16 Eetomeren verteilt, so daß der Keim eine ge- 
radezu erstaunliche Menge des Mesenchyms mitfuhrt, von dem die größere Hälfte schließlich von Entoderm resorbiert wird. Bedenkt man weiter, daß bei der Differenzierung der Polzellen bei dieser Form ebenfalls palingenetisches Material abgesondert wird und, daß es allem Anscheine nach auch bei der Differenzierung der drei vom dritten Quartett herstammenden Ectomesoblasten in Gestalt von kleinen Zellen abgeschieden wird, so gewinnt man beiläufig die Vorstellung, wie viel Zeit und Energie der Keim von Thalassema auf verschiedene palingenetische Prozesse verschwenden muß, beror er die Befähigung erlangt, den künftigen Organismus modern aufzubauen. Würde bei irgend einer verwandten Form außerdem noch etwa das Entoderm Rudimente erzeugen, wie es bei z. B. Asplanchna tatsächlich der Fall ist, alsdann müßte man in einzelnen Ontogenien auf Schritt und Tritt auf "vestigial cells \& stoßen.

Unsrer Erfahrung nach kommen auch bei Physa masseuhaft kleine Zellen vor, die auf :ihnliche Weise wie die rudimentären Zellen von Thaldssema und andern Formen (d. i. durch stark inäquale Teilung) gebildet werden und sich während des Furchungsprozesses sehr lange ganz passiv verhalten, sie gehen aber unsres Wissens nicht zugrunde.

Vor allem werden solche Zellen von denjenigen Blastomeren in größerer Anzahl erzeugt, welche eine wichtige Rolle im Keime zu übernehmen haben. In erster Linie sind es die Protoblasten der beiden Mesodermanlagen.

Wir haben bei der Darstellung des Differenzierungsprozesses der letzteren bei dieser Form nachdrücklich hervorgehoben, daß der Teilungsmodus in beiden auffallend tibereinstimmt. Beide schnüren nämlich zunächst eine größere Tochterzelle ab und zwar schnürt sie die Stammzelle des Urmesoderms gegen den vegetativen, diejenige des sekuidären gegen den animalen Pol zu, dann folgt die äıuale Bilateralteilung und auf diese eine stark inäquale, deren Produkte beim sekundären Mesoderm kleiner sind als diejenigen beim primären. Die Stammzellen des ersteren teilen sich darauf subäqual. da ihre neuen Tochterzellen verhältnismäßig bedeutend kleiner sind als die entsprechenden Derivate des Urmesoderms. Die beiden Makromeren des letzteren repräsentieren von nun an Organanlagei, desgleichen enthalten die Stammzellen des sekundüren Mesoderms von: nun an reines Mesoderm. Ihre weiteren Teilungen führen direkt zur Ausbildung der vorderen Mesodermstreifen, wobei der soeben dargestellte abwechselnd äquale und inäquale Teilungsmodus noch später zum Ausdruck gelangt. 
Von den vier Makromeren des Urmesoderms enthalten die vorderen die Anlage der Urnieren. Ihre Differenzierung äußert sich wieder in der Abgabe von zwei bedeutend kleineren Tochterzellen (ganz nach dem Muster der Urmesodermzellen), die wir bei der Darstellung des Furchungsprozesses als Mikromeren $\left(m_{3}, m_{5}\right)$ bezeichneten, sodann teilen sie sich äqual und es gestaltet sich die hintere Tochterzelle direkt zur Riesenzelle der Urniere, während die vordere noch eine winzige Tochterzelle abgibt, bevor sie ihre endgültige Differenzierung erreicht. Es werden also von den beiderseitigen Anlagen der Urniere kleine, chromatinreiche Zellen abgeschnürt, die an dem Aufbau des fertigen Organs keinen Anteil nehmen und deshalb als Rudimente angesehen werden könnten.

Wir finden ferner auch bei den Antipoden des sekundären Mesoderms $3 c^{1}, 3 d^{1}$ ganz denselben Sonderungsmodus, mit dem Unterschiede, daß anstatt je zwei Paare bloß je ein Paar von Mikromeren abgeschnuirt wird. Die Mutterzellen liefern später wichtige Teile der unteren Leibeswand, während ihre kleinen, an das Entoderm angefügten Tochterzellen bis zur Gastrulation und auch noch viel später ungeteilt verbleiben. Ihr Verhalten gibt also über die ehemalige Rolle der Mutterzellen gar keinen Aufschluß und wenn wir an entsprechender Stelle die Vermutung ausgesprochen haben, daß sie einst ebenfalls als Ectomesoblasten fungiert haben mochten, so geschah dies nur auf Grund ihres konformen Differenzierungsmodus und ihres analogen Verhaltens mit den gleichnamigen Zellen bei Thalassema und Podarke.

Wir finden sonst auch im Ectoderm von Physa mehrere Beispiele ähnlicher Differenzierungsteilungen, bei denen je ein oder je zwei kleinere Teilungsprodukte gebildet werden, welche eine nur sehr untergeordnete Rolle im Keime spielen, während ihre Mutterzellen die Anlagen wichtiger Organe bilden. Dies ist z. B. im ersten Quartette $(1 a-1 d)$ der Fall, aus dessen ersten Teilprodukten $\left(1 a^{2}-1 d^{2}\right)$ sich die Trochoblasten entwickeln. Diese teilen sich nur einmal und schließlich gehen die hinteren von denselben in der Zusammensetzung der Kopfblase auf, während die vorderen in derjenigen des Velums anfgehen. Thre zweite nach den Polen zu abgeschnuirte Generation $1 a^{11}-1 d^{11}$ bildet schließlich die centrale Partie der Kreuztigur, deren Rolle untergeordnet ist, während die Mutterzellen die sehr wichtigen Kreuzarme liefern. Sie machen noch eine stark inäquale Teilung durch, deren Resultat wieder bedentungslose Tochterzellen sind. In den seitlichen Armen sind es die äuBeren Medianzellen, welche wahrhaft rudimentär sind, denn sie teilen sich gar nicht und 
gehen sehließlich in der Bildung der Kopfblase, als eine ganz unbedeutende basale Ergänzung derselben auf. Aus dem Material der drei vorderen Mutterzellen $a-c$ gehen sehr wichtige Organe hervor, d. i. die Cerebralganglien, die Mundtentakeln und die Augen. Hier sehen wir also wieder Zellen, die eine wichtige Rolle im Aufbau des Keimes zu spielen haben, bei ilırer Differenzierung kleine passive Tochterzellen erzeugen, die zu ganz andern Zwecken als ihre Mutterzellen verwendet werden, namentlich zur Bildung von embryonalen Körperteilen.

Im zweiten Quartett kommen ähnliche stark inäquale Teilungen vor. So werden von den Blastomeren $2 a^{1}-2 d^{1}$ am Übergange von $24-28$ Zellen die sog. "Tipcells « des Kreuzes $2 a^{11}$ $-2 d^{11}$ erzeugt, ron denen bei $P / h y s a$ nur die rordere ansnahmsweise einer Teilung unterliegt, während die drei ibrigen sich gar nicht teilen. Sie könnten also ebenfalls als Rudimente betrachtet werden, zumal sie bei andern Formen bald eine einmalige (Trochus, Ischnochiton), bald sogar eine zweimalige (Crepidula) Teilung durchmachen und die sog. sekundären Trochoblasten liefern. Bei marinen Formen, deren freischwimmende Larven ein starkes Velum ausbilden, beteiligen sich noch drei ${ }^{1}$ Tipcells an der Zusammensetzung desselben, bei Süßwasserformen nur noch die vordere, schließlich haben sie alle vier bei den Landformen ihre Funktion eingebiiß3t. Bei I'hysa und Planortis (Howmes) gehen die drei übrigen Tipcells a, c; d) sowie die hinteren Trochoblasten in der Bildung der Kopfblase auf. Wir hätten hier also ein klassisches Beispiel des Funktionswechsels der Zellen im Zusammenhange mit der Riickbildung oder maximalen Entwicklung eines Organs.

Wenn wir ferner der unteren Etage des zweiten Quartetts $2 \iota^{2}-2 d^{2}$ unsre Aufmerksamkeit zuwenden. so fiuden wir, daß diese Zellen bereits am Stadium von 32 Blastomeren ganz kleine Tochterzellen $\left(2 a^{22}-2 d^{22}\right)$ gegen den regetativen Pol abschniren, von denen zwei $2 a^{22}$ und $2 c^{22}$ bis zur Gastrulation ungeteilt bleiben und erst während derselben einer äqualen Teilung unterliegen, um dann sofort mit dem Entoderm eingestulpt zu werden.

Würde es sich nun herausstellen, daß sie zum Aufbau des Archenteron beitragen, so muißten sie als entodermale Elemente aufgefaßt werden und ihre Mutterzellen als Ectoentoblasten.

1 Merkwïrdigerweise gehen bei der marinen Crepidula die vorderen Tipzellen zugrunde. 
Die Descendenten der vorderen Tochterzellen $2 b^{22}$ liefern die Stomatoblasten (bei Thalassema spielen dieselben eine wichtige Rolle als Oesophagoblasten), die hintere $2 d^{22}$ teilt sich erst am Stadium von etwa 134 Zellen, ihr unteres Derivat $2 d^{222}$ verhält sich noch während der Gastrulation passiv und wird vielleicht beim Verschluß des Blastoporus eingestiilpt, während das obere $2 d^{221}$, welches ebenfalls ungeteilt bleibt, eine untergeordnete Rolle in der Konstituierung der Leibeswand zu spielen scheint.

Wir haben also in den obigen Angaben den Beweis geliefert, daß bei Physa in jedem der drei Ectomerenquartette und in jedem Quadrant derselben durch stark inäquale Teilungen Zellen erzeugt werden, die sich durch ihr längeres passives Verhalten während des Furchungsprozesses, durch ihre untergeordnete Rolle im Ausbau des Keimes, manchmal durch ihren offenkundigen Funktionswechsel auszeichnen, oder aber solche, die vielleicht schließlich zugrunde gehen. Die Zahl derartiger Derivate ist aber um so größer, je wichtiger die Rolle ihrer Mutterzellen im Keime ist, wie wir dies für die Protoblasten des primären und sekundären Mesoderms gezeigt haben.

Es werden aber nicht nur bei der Differenzierung von Keimblättern, sondern auch bei derjenigen von Organanlagen ähnliche Zellen gebildet, so z. B. bei Physa bei der Differenzierung der Nephroblasten, bei Dreissensia bei Differenzierung des ersten Somatoblasten, aus dem die Schalendrüse hervorgeht und dessen Differenzierung nach Mersenheimer in ganz genau derselben Weise verläuft, wie diejenige des ersten Somatoblasten, aus dem sich das Mesoderm entwickelt, wobei ebenfalls rudimentäre Zellen $\left(X^{3}\right)$ erzeugt werden, die allem Anscheine nach zugrunde gehen.

Aus allen oben vorgefuihrten Tatsachen folgt, daß bei Physa und, wie es scheint, ganz allgemein bei den Mollusken und Würmern in allen Quartetten und allen Quadranten derselben ursprünglich ein gewisses Quantum von iberflusssigem Material enthalten ist, welches einzelne Blastomeren, die eine wichtige Rolle als Organanlagen zu spielen haben, nicht brauchen können, sobald sie dasselbe in Gestalt von kleinen Zellen entfernen. $\mathrm{Ob}$ diese Zellen auch qualitativ von ihren Mutterzellen verschieden sind, darüber können wir in Ermangelung jeglicher Anhaltspunkte nicht urteilen und deshalb ist das Wesen des Vorganges selbst so schwer zu erfassen.

Wenn wir einstweilen von der Erklürung desselben ganz absehen und nur den Teilungsmodus selbst näher ins Ange fassen, so fällt vor allem seine fast schablonenmäßige Einförmigkeit auf. Wir sehen 
iberall die Reifungsteilungen der Eizelle und ihre nachherige Furchung in mehr oder weniger genauer Weise kopiert. Sogar die drei Ectomerenquartette werden nach demselben Muster gebildet, denn es erzeugen die vier ursprïnglichen Blastomeren zunächst ganz kleine, fast knospenförmige Tochterzellen (das erste Quartett), darauf etwas größere (das zweite Quartett) und schließlich teilen sie sich subäqual und liefern das dritte Quartett.

Mit Rücksicht auf den Bildungsmodus bringt bekanntlich V. HÄCKer ${ }^{1}$ sowohl die Erzeugung von den sog. rudimentären Zellen bei den Anneliden, Mollusken und Rotatorien, als auch von Richtungskörperchen, samt ähnlichen Gebilden in der Pflanzenwelt in die Kategorie der »vorbereitenden « und »iiberzähligen " Teilungen, denen er eine hochwichtige biologische Rolle bei der Differenzierung der tierischen und pflanzlichen Gewebe zuschreibt.

Es würde sich demnach bei diesen Teilungen offenbar um Prozesse handeln, durch welche sowohl die Eizelle selbst, als auch ihre spätere Nachkommenschaft die Befähigung erlangt, die bevorstehende Aufgabe in der Entwicklung des Keimes erfüllen zu können.

R. Hertwig ('98) betont in seiner Arbeit über Actinosphaerium Eichhorni, daß der Vorgang der Vierteilung, die Bildung der Richtungskörperchen und ähnliche Vorgänge sich unabhängig aus gleichen physiologischen Ursachen entwickelt haben möchten und daß wir auf eime einheitliche phylogenetische Erklärung derselben verzichten miissen. Dies ist auch unsre Meinung.

Der hartnäckige Fortbestand der sog. rudimentären Bildungen im Furchungsprozess ganzer Tiergruppen, die ansehnliche Zahl von Blastomeren, welche in einzelnen Ontogenien mit der Bildung von Rudimenten betraut sind, weist darauf hin, daß es sich dabei eher um physiologische als um morphologische Momente handelt. Das ultimäre Verhalten dieser Rudimente kann ebensowenig über die Ursache ihrer Erzeugung einen sicheren Aufsehluß geben wie dasjenige der Richtungskörperchen, mit denen sie öfters verglichen worden sind. Wie verschieden ist die Dauer und das Verhalten der letzteren! Sie lösen sich bald gleich von der Eizelle los und gehen zugrunde oder aber verharren sehr lange am animalen Pole des Keimes, sogar bis zur Ausbildung der Larve (Mollusken, Anneliden). Im letzteren Fall können sie versehiedenen Wandlungen unterliegen,

1 Vgl. V. HÄсker, Theorie und Praxis der Zell- und Befruchtungslehre. Jena 1899. 
z. B. Flüssigkeitsräume ausbilden, gerade wie die Blastomeren (Limax, Kofoid, Meisenheimer), oder aber es zieht sich ihr Plasma in längere und kürzere Fortsätze aus (Cerebratulus, ANDrews), sie können ferner zusammenfließen und rom Ooplasma aufgenommen werden (Canthocamptus, Cyclops, Ascaris) oder auch mit einzelnen Furchungszellen verschmelzen, wie dies bei einigen Anneliden als: Lepidonotus (MEAD), Podarke (Treadwell), Arenicola (ChILd) der Fall ist u. dgl. mebr.

$\mathrm{Zu}$ welch verschiedener Deutung ihrer phylogenetischen Rolle könnte dieses so verschiedene Verhalten der Richtungskörperchen führen? Sie sollen aber schon ohnehin ihrem ursprünglichen Wesen nach abortive Eier repräsentieren. Was für Rudimente müßten sie denn sonst repräsentieren, wenn ihre verschiedenen Endschicksale als Maßstab ihrer phylogenetischen Rolle dienen möchten?

Es erscheint somit für die Beantwortung der uns beschäftigenden Frage viel wichtiger, anstatt den wechselnden Endschicksalen der rudimentären Bildungen, ihren Mutterzellen eine größere Aufmerksamkeit zuzuwenden als es bisher geschehen ist.

Wir haben bei unsern Untersuchungen an Physa die Überzeugung gewonnen, daß die letzteren um so mehr stark inäquale Teilungen durchmachen, je wichtiger ihre Rolle im Keime ist. Es ergibt sich also aus denselben der Schluß, daß es sich bei diesen Teilungen hauptsächlich, wenn nicht ausschließlich, um physiologische Momente handelt.

Der charakteristische Teilungsmodus ist gewiß uralt, dagegen diurfte das Verhalten der Teilprodukte in den meisten Fällen ganz recent sein. Wir zweifeln deshalb, daß in den kleinen bedeutungslosen Zellen so wichtige Rudimente enthalten sind, für welche sie von WrLson und seinen Anhängern angesehen und den rudimentären Kiemenspalten und Kiemenbögen oder dem embryonalen Zahne der Walfischembryonen an die Seite gestellt werden. Die Tatsache, daß ihre Prospektivität bei nahe stehenden Formen wechseln kann, spricht ganz deutlich gegen diese Auffassung.

\section{Gastrulation.}

Die erste Einsenkung des Entodermzellenfeldes macht sich an Stadien bemerkbar, bei denen die Entodermplatte aus 33-35, das Kreuz aus 34-38, das sekundäre Mesoderm aus 10_16, das primäre aus 4 Makromeren und etwa 10 Mikromeren besteht, während dabei die Gesamtzahl der Zellen im Keime 200 oder etwas darüber beträgt. 
Die Entodermplatte ist bei Beginn der Einsenkung aus lauter kleinen Zellen zusammengesetzt und hat eine fast kreisrunde Form; sie zählt ganz konstant 24 Zellen des vierten Quartetts, welche sehr regelmäßig in zwei konzentrische äußere nach vorn kouvergierende Reihen geordnet sind, welche die übrigen 8-10 Komponenten, d. i. die vier Makromeren, das fünfte bzw. auch das sechste Quartett zwischen sich fassen (Fig. 67). Die ectodermale Umrahmung der Entodermplatte bilden dazumal folgende Zellen: rorn $2 b^{2222}$, hinten $3 c^{222}$ und $3 d^{211}$, an den Seiten $2 a^{222}, 2 c^{222}$, in den vorderen Ecken $3 a^{212}, 3 a^{222}$ und $3 b^{212}, 3 b^{222}$, in den hinteren $3 d^{22}, 3 d^{212}$ und $3 c^{21}$, $3 c^{221}$, im ganzen also 13 Zellen, von denen zehn dem dritten Quartett angehörev. Vom zweiten wird die Zelle $2 d^{222}$, welche an fruheren Stadien unmittelbar mit dem Eutoderm in Berihiung war, kurz vor der Gastrulation von dessen Lmgrenzung definitiv ausgeschlossen (Fig. 67).

Der Umstand, daß man an Keimen gleichen Alters bald 13 bald nur 11 Zellen im unmittelbaren Kontakt mit der Entodermplatte findet, erklärt sich dadurch, daß die Teilung ron $3 c^{22}$ und $3 d^{21}$ bald friuher bald später zu erfolgen pflegt.

Der ganze Keim hat unmittelbar vor der Gastrulation eine stark abgeflachte Gestalt und ist vom animalen $\mathrm{Pol}$ aus tief invaginiert, namentlich sind es die Polzellen und die Basis des hinteren Kreuzarmes, welche tief einsinken, so daß dadurch eine von diesem $\mathrm{Pol}_{0}$ ausgehende Gastralinvagination vorgetäuscht wird.

Über diese apicale Einsenkung des Ectoderms wurde bereits in einem besonderen Abschnitte berichtet (S. 562), hier mag nur hinzugefügt werden, daß sie noch während der Einstullpung des Entoderms einige Zeit forthesteht, infolgedessen es eine kurze Phase gibt, in der die abgeflachte Keimscheibe zugleich doppelt inraginiert erscheint.

Entsprechend der bei Gasteropoden und Anneliden sehr verbreiteten Lorm, sinken zunächst die Makromeren und das fünfte, beziehungsweise sechste ${ }^{1}$ Quartett ein, worauf erst die Einsenkung des vierten Quartetts erfolgt. Aus den zuerst eingestiulpten Zellen entsteht alsbald ein ziemlich tiefes Divertikel, dessen rundliche ̈̈flnung von den Zellen des vierten und vorn von denjenigen des dritten Quartetts umgrenzt wird Fig. 69). Dieser "primäre" Blastoporus ist

${ }^{1}$ Das sechste Quartett wird bald vor der Einstiilpung, bald erst wiihrend derselben gebildet. 
anfänglich recht weit, in dem Maße aber als die Einstülpung fortschreitet zieht er sich zusammen und wird zugleich immer mehr nach vorn verschoben. Dies ist die Folge der gleichzeitigen Einsenkung: des vierten Quartetts, dessen Komponenten schon lange vorher sich in der Richtung der ersten Einsenkung stark verlängert haben. Sie scheinen sich jetzt gegen die letztere zu drängen und übereinander zu schieben, so daß die innere Reihe von der äußeren dachziegelartig überdeckt wird. Offenbar folgen sie dabei zum Teil dem seitens des Ectodermwalles ausgeiibten Drucke, vorwiegend aber verhalten sie sich ganz aktiv.

Während die Einsenkung fortschreitet bemerkt man unter den Zellen des vierten Quartetts einzelne Mitosen, deren Spindelachsen in verschiedenen, für die Teilung oft sehr ungünstigen Richtungen liegen. Die Entodermplatte wächst also und vertieft sich zugleich, so daß der sich ausbildende Entodermsack in gleichem Maße an Tiefe und Weite gewinnt.

Der Blastoporus bleibt dabei rund, ziemlich weit und liegt fast central. Von den 13 Zellen, welche die einsinkende Entodermplatte umrandeten, haben sich einige geteilt, andre sind tiefer eingesunken. Wir sehen (Fig. 70) das innere Paar der Mikromeren des sekundären Mesoderms geteilt und zugleich tiefer eingesunken, desgleichen ist das jederseitige äußere Paar von den Zellen $3 a^{112}, 3 a^{122}$ und $3 b^{112}$, $3 b^{122}$ überdeckt; auch die seitlichen Grenzzellen $2 a^{222}$ und $2 c^{222}$ sowie die hinteren $3 c^{22}, 3 d^{21}$ pflegen oft um diese Zeit geteilt zu sein, so daß die Zahl der die Entodermscheibe umrandenden Zellen in dieser Phase eventuell von 13 auf 16 steigen kann.

Während das Entoderm immer tiefer einsinkt und die Zahl seiner Komponenten stetig wächst, finden auch im Ecto- und Mesoderm rege Teilungen und durch dieselben veranlaßten Verschiebungen statt.

Man bemerkt in der Kreuzfigur einen Zuwachs um etwa 5-6 Zellen und zugleich ihre weitere Verschiebung nach vorn, ferner finden sehr rege Teilungen in den Quadranten $a, c$ und $d$ des zweiten Quartetts, in $c$ und $d$ des dritten Quartetts statt. Am ausgiebigsten sind wohl die Teilungen in den beiden seitlichen Quadranten, deren ventral gerichtete Descendenten bereits jederseits mächtige Buckel gebildet haben. Auch in den vorderen Quadranten des zweiten Quartetts bemerkt man einige Teilungen, welche zur Erzengung der definitiven Velarzellen führen. Am animalen Pol erheben sich die hinteren Trochoblasten blasenartig 
uber das Niveau des Keimes, ihnen folgt der bisher eingesunkene hintere Kreuzarm, es ist der erste Schritt zur Differenzierung der Kopfblase. Die vordere Kreuzpartie fallt jetzt sehr abschüssig nach vorn ab, so daß der Keim in der Seitenansicht die Gestalt eines stumpfen Kegels gewinnt. Auch das primäre Mesoderm ist während der ersten Phase der Gastrulation in weiterer Entwicklung begriffen, denn es werden nicht nur stets neue Mikromeren seitens der medianen Makromeren erzeugt, sondern es entstehen durch Teilung der äußeren Makromeren die Nepbroblasten. Im noch rascheren Tempo schreitet die Entwicklung des sekundären Mesoderms fort, das bereits weit nach hinten reichende Streifen ausbildete und noch immer rege Teilungen aufweist.

Durch diese fortschreitende Entwicklung der beiden Mesodermanlagen, sowie durch den Einstilpungsprozeß des Entoderms wird

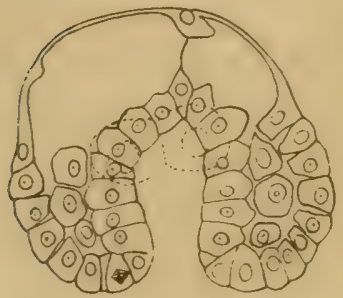

Textfig. 9.

Erontalschnitt einer Gastrula mit weit offenem Blastoporns. die Furchnngshöhle fast ganz zum Schwunde gebracht und ihre Stelle nimmt jetzt die sich ausbildende Kopfhöhle ein.

Indem wir nun zu den Erscheinungen der Gastrulation selbst zurickkehren, wenden wir zunächst die Aufmerksamkeit auf das recht auffällige Verhalten der am vorderen Rande des Blastoporus befindlichen Zellen $2 b^{2221}$ und $2 b^{2222}$. Sie lagen nåmlich nach ibrem Entstehen und noch beim Beginn der Gastrulation genau hintereinander, während der letzteren erfahren sie zunächst eine leichte Drehung nach links, werden sodann gegeneiuander verschoben und gelangen schlieBlich in eine bilaterale, mediane Lage, in der sie bis zur völligen Ausbildung des Stomodäums rerharren (Fig. 71). Selbstrerständlich steht ihre Lageänderung im innigen Zusammenhange mit dem asymmetrischen Wachstum des Keimes, welches sowohl in der stärkeren Entwicklung der rechten Seite als insbesondere in der Verzerrung der Kreuzfignr zum Ausdruck kommt.

An der Textfig. 9, welche den Frontalschnitt eines Gastrulastadiums mit weit klaffendem Blastoporus darstellt, sieht man ganz deutlich die asymmetrische Entwicklung der beiderseitigen Körperhälften, von denen die rechte viel stärker ausgebildet erscheint als die linke. Die unmittelbare Ursache dieser Asymmetrie, sowie der Zeitpunkt ihrer ersten Erscheinung ließ sich nicht mit Sicherheit feststellen. Es wurde bereits beim Entoderm hervorgehoben, daß sich der 
Beginn derselben bei Physa nicht auf eine einzelne Entodermzelle zurückführen läßt, wie dies ConkLin bei Crepidula und CASTEEL bei Fiona ('04) gelungen ist. Sie mag vielmehr durch eine ungleichmäßige Entwicklung des Mesoderms und der Quadranten $c$ und $d$ bedingt und bereits auf viel frïheren Entwicklungsstadien vorbereitet sein.

Kehren wir aber zum Blastoporus zurück. In Fig. 70 hatte er eine rundliche Form, sie geht aber schon an den allernächsten Stadien in eine langgezogene schlitzförmige über und, indem sich der Schlitz nach vorn verbreitert, wird die bekannte weitklaffende Form des Blastoporus gewonnen, wie sie aus unsrer Fig. 71 zu ersehen ist. Sie resultiert einerseits aus der raschen Verbreiterung der vorderen Partie des Embryos, anderseits aus dem gleichzeitigen üppigen Wachstum der beiden Quadranten des zweiten Quartetts $a$ und $c$, infolgedessen der Schlitz nach hinten in einen scharfen Winkel ausgezogen erscheint, schließlich aus dem seitens der Descendenten der Quadranten $c$ und $d$ von hinten ausgeủbten Drucke.

Nach übereinstimmender Ansicht mehrerer Autoren bewirkt der letztere von den drei Faktoren das Vorwärtsschieben und im Verein mit dem zweiten den endgültigen Verschluß des Blastoporus, wobei der vordere Rand desselben, also in erster Linie die Zellen $2 b^{2221}$ und $2 b^{2222}$ als relativer Fixpunkt angenommen werden. Der ganze Vorgang des Verschlusses oder, wie wir es nennen wollen, der Zusammenschniirung des Blastoporus, beruht also auf dem Zusammenwirken mehrerer Faktoren, welches sich im einzelnen nicht analysieren läßt. Thre Wirkung wird gewiß durch die gleichzeitige Ausbildung der Kopfblase und des Archenteronsackes in bedeutendem Maße unterstiitzt. Die Folge dieses Zusammenwirkens ist einerseits die verhältnismäßig rasche Verengung des Blastoporusschlitzes, anderseits die Verkürzung desselben, welche öfters als Verwachsung seiner Lippen in der Richtung von hinten nach vorn aufgefaßt wird. Man gewinnt wohl aus manchen Bildern den Eindruck als wenn die Verkürzung der Blastoporuslippen in der Tat nur durch die Concrescenz zustande kommen müßte, indessen liefert eine schärfere Beobachtung den Beweis, daß letztere höchstens nur auf einer ganz kurzen Strecke stattfindet. Denn man bemerkt, daß sich die hinteren Zellen $3 c^{222}$ und $3 d^{211}$ keilförmig stark nach vorn verlängern und zwischen die beiden seitlichen Ectodermwiilste gleichsam hineingetrieben werden, daß ferner, in der letzten Phase, vor denselben nur noch ein Paar schmale Zellen in der Medianlinie (? $3 c^{21}$ und $3 d^{22}$ ) liegen, welche aber schon unmittelbar an die Blastoporusöffnung 
grenzen, welch letztere schließlich von nicht mehr als im ganzen zehn Zellen umrandet wird. Es kann also von einer Verwachsung der Blastoporuslippen auf einer längeren Strecke keine Rede sein, vielmehr von einer Zusammenschntirung derselben, wie dies SoвotTA ${ }^{1}$ u. a. auch für Amplioxus annehmen. Um den Mechanismus dieser Zusammenschniirung zu verstehen, muß man sich die in den beiden Hauptebenen liegenden Zellengruppen als elastische Federn denken, von denen die hintere am stärksten wirkt.

Es erübrigt uns noch der Schicksale der oben aufgezählten Randzellen des Blastoporus mit einigen Worten za gedenken. Von den vorderen werden die acht Mikromeren des sekundären Mesoderms und ihre Descendenten ganz bestimmt eingestillpt, ferner ein Teil ron den unmittelbar hinter ihnen liegenden acht Zellen $3 a^{112}+122+\ldots$, $3 b^{112}+122+\ldots$, während die übrigen an der Oberfläche verbleiben und später die vordere Umrandung der beiden, rom zweiten Quartett ( $a$ und $c$ ) herstammenden, Ectodermwuilste bilden. Die vier seitlichen Randzellen $2 a^{22}, 2 c^{22}$ werden nach ihrer Teilung insgesamt eingestiilpt, von den hinteren verbleiben die medianen Makromeren $3 d^{211}+\ldots, 3 c^{222}+\ldots$ an der Keimoberfläche und werden, wie bereits erwähnt, ganz nach vorn verschoben. Von den in den Ecken betindlichen Mikromeren werden nur zwei bis drei innere jeder Seite eingestiulpt, während die äußeren, namentlich die den Mutterzellen $3 c^{11}$, $3 c^{12}, 3 d^{11}, 3 d^{12}$ entstammenden, an der Oberfläche verbleiben, um später die hintere Umrandung der oben erwähnten Eetodermwtilste zu bilden.

Man ersieht, daß das Verhalten dieser, oft als "Stomatoblasten * bezeichneten Zellen, versehieden ist und, daß sie nicht alle in dieselbe Kategorie einbegriffen werden können. Wie wir dies beim Darmkanal näher ausfübren werden, werden sie gar nicht zur Bildung des Stomodïums, sondern vielmehr zu derjenigen des primären Schlundes verwendet.

Der Vergleich dieser Randzellen mit solchen bei andern Formen zeigt im allgemeinen eine große Übereinstimmung (namentlich besteht dieselbe im hohen (trade zwischen I'lysa und Fiona), er läßt sich aber sonst in Ermangelung sicherer Angaben uber die Endschicksale derselben nicht weit ziehen und wirde sogar in den allgemeinsten Zügen auf lauter Vermutungen stoßen, wie dies aus den

1 Vgl. S. SовоттA, Beob. über d. Gastrulationsvorg. beim Amphioxus. Verh. Wiirzb. Medic. Ges. 1897. 
diesbezüglichen Ausführungen RoBents ('03) S. 167-170 zu ersehen ist.

Der Blastoporus schließt sich bei Physa nie gänzlich und wenn man auch öfters an Totalpräparaten seinen gänzlichen Verschluß zu finden glaubt, so überzeugt man sich dennoch an Schnitten, daß es nur eine Täuschung war.

Bei Planorbis (HoLyes) soll sich der Blastoporus schließen, während er bei Planorbis (RABL) offen bleibt. Solcher Widersprüche gibt es mehrere, sowohl im Annehiden- als auch im Molluskenkreise, und sie liefern nur den Beweis, daß die diesbezüglichen Beobachtungen ungenau sind, denn es ist kaum anzunehmen, daß im Bereich eines und desselben Genus solche fundamentale Gegensätze bestehen können.

Wir konnten uns bei Physa an Schnittserien überzengen, daß der primäre Schlund gleich am Eingange zeitweilig durch den Druck der umgebenden Mesoderm- und Eiweißzellen verschlossen wird. Es mag sein, daß auch der Blastoporus für eine ganz kurze Zeit so stark verengt wird, daß er augenblicklich als verschlossen erscheinen könnte.

Wenn wir uns noch zum Schluß die Frage aufwerfen, welchem Typus die Gastrula von Physa angehört, so können wir sie vom Standpunkte des Schemas weder dem rein embolischen noch dem rein epibolischen anreihen, denn für den ersteren fehlt als Ausgangsform das charakteristische Blastulastadium, gegen den letzteren spricht die successive Einstülpung des Entoderms. Wir können also diesen Gastrulatypus als eine Zwischenform betrachten, wie sie anch bei Planorbis (RABL et Holmes) u. a. zu finden ist.

Was den Vorgang der Gastrulation selbst betrifft, so können wir denselben selbstverständlich keineswegs auf die Tätigkeit rein mechanischer Faktoren zuriekführen. Ein Blick auf die Fig. 81, wo die spontan von den Ecto- und Entodermzellen ausgeschickten Fortsätze geradezu einen Wald bilden, liefert uns wohl die beste Überzeugung von der Aktivität der Blastomeren während des Gastrulationsprozesses.

Schließlich mag noch nachdriicklich hervorgehoben werden, daß das entodermale Material von dem ectodermalen bereits vom 36-zelligen Stadium an histologisch streng geschieden erscheint, so daß wir beim Beginn der Einstülpung eine ganz scharf ausgeprägte Grenze zwischen den beiden Keimblättern nachweisen können. Dieses Verhalten weist auf eine sehr frühzeitige Differenzierung des Entoderms hin, welche wir bereits bei Erörterung der Frage nach der Zahl der Ectomerenquartette S. 577 in den Vordergrund gestellt haben. 


\section{Entwicklung der Organe.}

\section{Larvale Organe.}

Wir beabsichtigen in der nachfolgenden Darstellung der Organogenese kein vollständiges Bild der Entwicklung der Larve von Physa zu geben, sondern nur unsre Beobachtungen iiber die Bildung einzelner Organe, welche uns ein größeres Interesse zu bieten schien, zu verzeichnen. Beziiglich der stufenweisen Entwicklung der äußeren Form der Larve, welche zum Verstïndnis der Organentwicklung unumgänglich notwendig ist, miissen wir auf die fast ganz identisehen Vorgänge bei Planorlis (Rabl und Holmes) hinweisen, welche vou den genannten Autoren, namentlich rom ersteren, eingehend berücksichtigt und in Wort und Bild dargestellt werden.

Wir beginnen mit den larvalen Organen.

\section{a. Das Velum.}

An der Zusammensetzung des Velums von Plyysa beteiligen sich ausschließlich die Zellen des ersten und zweiten Quartetts, namentlich die vier vorderen Trochoblasten $1 a^{21}, 1 a^{22}$ und $1 b^{21}, 1 b^{22}$, sowie die Descendenten der Zellen des zweiten Quartetts $2 b^{121}, 2 b^{122}$ und $2 b^{211}, 2 b^{212}$, zu welchen noch die rordere Tipzelle $2 b^{11}$ hinzutritt, die, wie bereits bekannt, entweder ganz ungeteilt bleilst oder aber sich äqual und bilateral teilt. Demnach setzt sich die erste Aulage des Velums bald aus 9, bald aus 10 Zellen zusammen.

Die vier Trochoblasten bleiben bei der weiteren Differenzierung des Velums ungeteilt, sie rücken während der Umbildung der vorderen Partie der Kreuzfigur immer weiter nach außen und nehmen schließlich ihre definitive Lage ganz an der Außenseite der Scheitelplatten ein (Fig. 79, 80). Die dem zweiten Quartett angehörigen Komponenten teilen sich in acht Zellen schon während oder kurz nach der Gastrulation, so daß das Velum auf der nächsten Stufe seiner Ausbildung aus 13 bzw. 14 (falls $2 b^{11}$ geteilt wird) Zellen besteht. Diese liegen anfangs alternierend, später bilden diejenigen des zweiten Quartetts eine einfache Reihe, welche über dem Munde und seitwärts um die beiden Scheitelplatten zieht und jederseits an der Basis der Kopfblase endigt. Über den heiden Enden dieser Zellreihe liegren je zwei inzwischen enorm entwickelte Trochoblasten, weshalb hier das Velum zweireihig, während der ganze übrige Teil nur einreihir ist (Fig. 79, 80). 
Die Zusammensetzung und Form des ausgebildeten Velums tritt am klarsten an gelungenen Silbernitrat-Präparaten hervor (Fig. 79, 80), an denen es als ein heller Streifen mit scharf markierten Zellgrenzen sich von den dunkler gefärbten Partien andrer Organe scharf abhebt. An solchen Präparaten kann man auch die Überzeugung gewinnen, daß außer den Zellen des zweiten Quartetts im Quadranten $B$ sonst keine andern accessorischen Komponenten an der Bildung des Velums teilnehmen.

An Stadien mit vollkommen ausgebildeter Kopfblase, mit Anlage der Schalendriise, des Fußes und des Stomodäums, konnten im Velum etwa 21-23 Zellen unterschieden werden, von denen nur vier den primären Trochoblasten, die übrigen dem zweiten Quartett $b$ angehören. Es ist nicht ausgeschlossen, daß an späteren Stadien durch Teilung der Descendenten dieses Quartetts noch ein kleiner Zuwachs entsteht, wiewohl dies nach unsern Beobachtungen wenig wahrscheinlich ist. Aber auch ohnehin duirfte das Velum von Physa als ein wohlentwickeltes larvales Organ angesehen werden, da das Velum der Anneliden und der primitiven Molluskenformen in der Regel nicht mehr als 25-30 Zellen enthält. Bei Planorbis (RABL) scheint das Velum noch stärker ausgebildet zu sein, da es hier zweireihig sein soll. Merkwürdigerweise ist es bei dem amerikanischen Planorbis tricolvis nach HoLMEs nur aus 11 Zellen zusammengesetzt, also verhältnismäßig ganz rudimentär. Diese auffallenden Unterschiede dürften aber nur darauf beruhen, daß es auf späteren Stadien schwierig ist, die eimzelnen Komponenten genau zu unterscheiden und zu zählen.

Unter den Velarzellen erreichen die primären Trochoblasten die stärkste Ausbildung, sie bilden mächtige Vacuolen aus und erheben sich infolgedessen bedeutend über das Niveau der Keimoberfläche, so daß sie von vorn oder hinten betrachtet zwei an den Seiten des Körpers angebrachten Henkeln ähnlich sehen. Bei Physa sieht man, wenigstens zeitweise, an diesen größten Velarzellen Flimmern, welche bei Planorbis (RABL) nicht ausgebildet werden. Ihr Plasma enthält zahlreiche gelbliche Körnchen, vielleicht Excretkörnchen? Diese vier Zellen zeigen schon am Gastrulastadium eine ganz eigentiimliche Gestalt, indem sie mehrere Pseudopodien in die Furchungshöhle ausschicken - ein Beweis ihrer wichtigen, physiologischen Iiolle.

Vergleichende Betrachtung'en über das Velum der Mollusken und Anneliden sind bereits so oft und so eingehend durchgefiilurt worden, daß es uiberflussig ist, einzelne Tatsachen nochmals vorzufuihren. Fast alle Autoren sind dariiber einig, daß unter den das Velum der Mol- 
lusken und Amneliden zusammensetzenden Zellen bloß die primären Trochoblasten und ihre Abkömmlinge ganz homolog sind, während die übrigen teils dem ersten, teils dem zweiten oder sogar dritten Quartett entstammenden Komponenten, deren Zahl und Art der Verwendung beim Aufbau des Velums recht verschicden sein kamn, nicht mehr streng homologisiert werden dürfen. Somit kann das Velun als Ganzes eben seiner wechselnden Zusammensetzung halber nur in ganz speziellen Fällen als ein absolut homologes (iebilde angesehen werden. Schon unter den Anneliden gibt es Formen wie: Amplitrite, Arenicola, Podarle, Thalassema, bei denen \%war die Zusammensetzung: des Velums aus den Derivaten der primairen Trochoblasten vollkommen identisch zu sein pflegt, withrend aber bei einigen derselben zu diesem Grundstock des Velums noch einige ron den intergirdle Zellen und Derivaten des zweiten Quartetts aus den Quadranten $A$, $B, C$ hinzukommen, beschränkt sich seine '/usammensetzung bei deu andern entweder ausschlieBlich anf die Trochohlasten oder auf diese und einen ganz geringen Anteil von accessoriselien Bestandteilen, oder aber es wird nicht einmal die volle Zahl der Trochoblasteu (d. i. 16) zum Aufbau des Velums verwendet. Mit Riticksicht auf diese Unterschiede hat sich CHILd ('99j gegen eine spezielle Ilomologisierung dieses Organs selbst im Annelidenkreise erkliirt, wiihrend MEAD ('98) nicht nur eine vollkommene Homologie des Annelidenrelums anerkennt, sonderu auch des letzteren und des MolluskenVelums. Zwischen den Komponenten des Prototrochs verschiedener Typen bestände nach ihm dieselbe genetische Beziehung, wie zwischen den einzelnen Skelettteilen der Extremititen der Vertelsraten. Diese Ansicht teilt auch Torrey '03) auf Grund seiner Befunde bei Thalassema, deren Velum aus seuau denselben Descendeten der sog. primären Prototrochzellen gebildet wird, wie dasjenige vom Amphitrite, Arenicola, I'odarlie u. m. a. Der L'mstand, dall die 16 P'rotstrochzellen bald vollzählig, bald nur zum grußen Teile in die Bildung des Velums eingehen, sowie daß die accessorischen Bestandteile verschieden sein künnen, bildet nach der Ansicht der genamnten Autoren ebensuwenig eine Einschrinkung der Homologie des gauzen Organs wie die wechselnde Zusammensetzung der Extremitaten in einzelnen Vertebratenklassen.

Am meisten nähert sich dem trpischen Prototroch der Anneliden das Velum von Ischnochiton (HEatri, '99. und Trochus (RonkikT, '03), da der centrale Teil desselbeu aus 16, den Prototrochzellen der Anneliden homologen Zellen besteht. Freilich findet man bei der 
Mehrzahl der marinen und Süßwasser-Gasteropoden diese Zahl stark reduziert, aber der Rest, welcher bei den meisten der untersuchten Formen vier Zellen beträgt, entspricht vollkommen den primären Prototrochzellen der Anneliden.

Was die accessorischen Bestandteile des Velums der Gasteropoden betrifft, ist nach unsrer Ansicht zurzeit ein tiefgehender Vergleich kaum zwischen zwei bis drei Formen möglich, sonst lauten die Angaben so unbestimmt ${ }^{1}$ und sind so unzulänglich, daß es sich wohl nicht lohnt, dieselben miteinander zu vergleichen. Im allgemeinen geht aus den bisherigen Angaben über die Zusammensetzung des Velums der Gasteropoden nur so viel sicher hervor, daß die hinteren primären Trochoblasten nur ausnahmsweise als Velarzellen fungieren, dagegen kommt diese Eigenschaft den vorderen durchgehends zu. Als accessorische Bestandteile des Velums erscheinen fast allgemein die Zellen des zweiten Quartetts und zwar entweder nur im Quadranten $B$ oder auch in $A$ und $C$.

Mit der Ausbildung des Velums tritt die Larve in das charakteristische Trochophorastadium ein, welches vielfach als eine Grundform aller Molluskenlarven aufgefaßt wird. Thre phyletische Beziehung zur Trochophora der Anneliden wurde gar oft als erwiesen dargestellt, neuerdings äußert Meisenhemer (Dreissensia '01) die Überzeugung, „daß der enge Zusammenhang von Anneliden nnd Mollusken durch das Bindeglied der Trochophoralarve als eine durchaus bewiesene Tatsache der vergleichenden Entwicklungsgeschichte betrachtet werden muß

Ohne uns auf diese Frage näher einlassen zu wollen, möchten wir nur bemerken, daß wir diesen vermeintlichen Beweis bloß als eine subjektive Ansicht betrachten, welche ebensowenig die Verwandtschaftsverhältnisse der Mollusken und Anneliden aufzuklären vermag wie die auffallende Übereinstimmung in den Furchungsprozessen beider Typen.

\section{b. Urniere.}

Über den Bau und die Entwicklung dieses larvalen Organs bei den P'ulmonaten lagen bis auf die neneste Zeit nur vereinzelte, meist unsichere und sich widersprechende Angaben vor. Erst im Jahre 1899 hat J. Meiseximemen eine größere Zahl von Arten suwohl ans der Gruppe der Basommatophoren, als anch der Stylom-

1 Casteel ('04) hebt in seiner Arbeit über Fiona hervor, daß es ihm trotz vieler Miihe nicht geluugen ist die Zusammensetzung des Velums genau kennen zu lernen, was auch seine diesbezitglich unklaren Figuren bestätigen. 
matophoren einer eingehenden rergleichenden Lntersuchung unterzogen, aus der sich folgende, für die richtige Auffassung der Morphologie der Urniere wichtige Sätze ergeben haben:

1 Die Lrniere der Basommat ophoren besteht ganz konstant aus rier Zellen, d. i. zwei Excretionszellen, einer Wimperzelle und einer ausfihrenden Zelle, dagegen stellt diejenige der Stylommatophoren ein typisehes Epithelrohr dar.

2) Das innere Ende der Urniere ist in beiden Gruppen gegen die Leibeshühle rollkommeu alggeschlossen und zwar in der ersteren durch eine eimzige, in der letzteren mindestens durch zwei, in der Regel aber durch mehrere Wimperzellen.

3) Bei Limax maximus ist die Urniere nach Mersexhemer ('98; ein $\rightarrow$ rein ectodermales Gebilde, zu dem das Mesoderm auch nicht den geringsten Beitrag geliefert hate (S. 584, bei den Basommatophoren entsteht sie vermutlich ebenfalls aus dem Ectoderm.

4) Im Bau der Urnieren beider Gruppen besteht kein prinzipieller Gegensatz, sie lassen sich vielmehr unter einen einheitlichen Gesichtspunkt bringen.

Über Stylommatophoren fehlen mir eigne Beobachtungen, dagegen bin ich in der Lage, nach sorgffiltigen und erschöpfenden Untersuchungen an Physa, einem Repräsentanten der Basommatophoren, die Angaben Meisexhemens, betreffend die Nierenstruktur dieser Form, in vollem Umfange zu bestätigen. Da es feruer für mich keinem Zweifel unterliegt, daß die Beobachtungen, welche derselbe außer an Plyysa, noch an drei andern Arten jener Gruppe, d. i. an Planorbis corneus, Limnaea stagnalis und Ancylus fluriatilis gemacht hat, ebenso genau und zurerlässig sein werden, so halte ich die wichtige Frage nach dem Bau der Larreuniere der genannten Gruppe für endgültig gelöst. Infolgedessen erachte ich es für ganz uiberfliissig: mich an dieser Stelle über anders lautende Angaben sonstiger Autoren auszulassen, zumal bereits Mersexnemen die betreffende Literatur genügend beriicksichtigt hat.

Ergänzend müehte ich nur herrorheben, daß Hownes in einer später erschienenen Arbeit ('00) über Plnorlis trirolvis bezüglich der Morphologie der Urniere noch auf dem Standpunkte älterer Autoren, namentlich RabLs, steht, indem er deu inneren Arm dieses Organs ans einer Reihe ron durchbohrten Zellen zusammengesetzt und gegren die Leibeshöhle often sein lälst: ,The inner arm is directed toward the head, it is formed of a row of perforated cells, and the lumen is ciliated and prorided with a ciliated opening near the end. 
(p. 422). Diese Angabe muß ich entschieden für unrichtig halten, denn es ist kaum anzunehmen, daß bei zwei Arten derselben Gattung, d. i. Planorbis corneus und Planorbis trivolvis, in der Struktur ein und desselben Organs ein so prinzipieller Unterschied obwalten könnte. HoLxes mochte sich durch den Umstand täuschen lassen, daß in vorgeriuckten Stadien außer den vier typischen Zellen noch mehrere andre mesodermale Elemente an dem Aufbau der Urniere sich zu beteiligen scheinen. Indessen sind es Zellen, welche zwar allerdings sich an die echten Urnierenzellen mehr oder minder eng anschließen, jedoch bloß die Befestigung und wahrscheinlich auch die Ernährung derselben zu besorgen haben, während die Aufgabe der Excretion und Ausfuhrung der Excretstoffe ausschließlich den vier typischen Konstituenten zufällt. Ebenso halte ich die Angabe HoLmes', daß das Lumen des inneren Armes bewimpert ist, für unrichtig.

Schließlich mag noch erwähnt werden, daß die von RABL für Planorbis comeus beschriebenen Verhältnisse ebenfalls auf eine Ungenauigkeit der Beobachtung zuriickzuführen sind. Es sollen nämlich nach diesem Autor die beiden Urnierenschenkel gegen die Leibeshöhle offen sein, ferner soll die Uniere als »hereditives Urorgan" erhalten sein, welches nicht mehr funktioniert und ein kleiner, durchbohrter Fortsatz der Riesenzelle soll das Rudiment eines obliterierten ursprïnglichen Ausführungskanals repräsentieren. Wie sich nun aus meinen eignen und fremden Untersuchungen an mehreren Basommatophoren ergibt, ist die Urniere ein regelrecht funktionierendes, proximal mit einer großen seitlich komprimierten Wimperzelle anhebendes, mit einer kolossalen Excretionszelle, der sog. "Riesenzelle« versehenes und mit einer einzigen Miindungszelle nach außen sich öffnendes Excretionsorgan.

Über das Verhältnis der Urniere zu den Keimblättern gehen die Ansichten der Autoren sehr weit auseinander. Nach FoL (1880) soll sich das ganze Organ aus einer Einstiilpung des Ectoderms entwickeln, während nach Erlanger bei Bythinia ('91), Planorbis und Limnaeus ('95) wenigstens der Ausführungskanal aus diesem Keimblatte hervorgehen soll. Nach Wolfsor (1880) entsteht bei Limnaeus strgnalis die Urniere aus einer großen Ectodermzelle, die sich unter das Velum hineinschiebt. Nur Rabl leitet die Urniere bei Planorlis (1879) in ihrem ganzen Umfange von den Mesodermstreifen ab; ihm schließt sich Hownes auf Grund seiner Studien an der amerikanischen Art Pl. trinolvis an, ohne jedoch direkte Beweise fuir die 
Richtigkeit seiner Meinung vorzubringen. Bezitglich des Ausfuhırungsganges bleibt er allerdings im Zweifel, ob dieser rom Mesoderm oder aber den Befunden ErLaNGers gemäß vom Eetoderm abzuleiten sei; ferner äußert er auch iiber die Eutstehungsweise des Exeretionskanals bloß Vermutungen. Überhaupt stiitzen sich die Ausführungen dieses Autors lediglich auf fragmentarische Beobachtungen, welchen bloß eine einzige Figur (Taf. XXI, Fig. 52 zugrunde liegt. Schlicßlich gelangt Meisexhener i. c.j auf Grund seiner bloß gelegentlichen (nach eignem Geständnis) Beobachtungen und, wie es scheint, hauptsächlich unter dem Eindrucke seiner an Limux maximus ('99, erzielten Resultate zu der Überzeugung, daß die Lrniere im Gegensatz zu liabls Ansicht weher direkt rom Ectoderm als vom Mesoderm abzuleiten ist $\%$.

Angesichts dieses Widerstreites der Meinungen und in Anbetracht der Wichtigkeit des (regenstandes schien es nun dringend geboten, die Sachlage durch eigne Untersuchungen festzustellen, zumal dieselben ron keinem meiner Vorgänger hinlänglich geuau durchgefuhrt worden sind.

Nachdem ich nun die Differenzierung dieses Organs bei Physa Schritt fuir Schritt rerfolgt habe, hin ich in der Lage, dieselbe bis anf die Lrmesodermzelle $t d$ zuriickzufihren und den tatsäichlichen Berreis zu erbringen, daß die Lruiere bei dieser BasommatophorenGattung in ihrem ganzen Lmfange dem Mesoderm entstammt.

Wie sich die Sache bei den Stylommatophoreu verhailt, ob nämlich deren Lrniere durchgehends ectodermaler Abkunft ist, oder aber ob sich vielleicht auch mesodermale Elemente an ihrem Aufbau beteiligen, bleibt für mich nach wie vor unentschieden.

Auf das Verhältnis der beiden oben charakterisierten Bantypen zueinander wollen wir erst am Schlusse unsrer Darstellung zuriickkommen.

Indem wir jetzt zur Schilderung der Entwicklung der Urniere bei Physa iibergehen, müssen wir des Zusammenhanges halber die wichtigsten Tatsachen aus den Kapiteln iiber den Furchungsprozeß und das primäre Mesoderm in Erinnerung bringen.

Wir haben dort ein Stadium kemnen gelernt, wo die Urmesodermzelle $4 d$ sich in zwei äquale Descendenten $4 d^{1}, 4 d^{2}\left(M^{1}, M^{2}\right)$ bilateral geteilt hat, ferner ein solches, wo die letzteren nach Abschuiirung

1 Bei Dreissensia leitet Meisenhemer ('01) die Urniere aus dem Ectoderm $\mathrm{ab}$, wïhrend sie Hatschek bei Terelo aus dem Mesoderm und StacfFacher bei Cyclas teils ans dem Ectoderm teils Mesoderm ableitet. 
von zwei Mikromeren $\left(m^{1}, m^{1}\right.$ bzw. $\left.4 d^{11}, 4 d^{21}\right)$ sich abermals äqual, jedoch diesmal in horizontaler Richtung geteilt haben, nämlich am Stadium von 97 Zellen (Taf. XX, Fig. 48b). Nach dieser letzteren Teilung scheint die endgtiltige Sonderung des mesoblastischen Materials vom nephroblastischen vollzogen zu sein, denn von nun an verfolgt jedes von den neu entstandenen Zellpaaren seine eignen Wege. Das mittlere erzeugt nämlich noch eine Reihe von Mikromeren und teilt sich schließlich auf dem Veliger-Stadium melirere Male bald vollkommen äqual, bald subäqual, um die hinteren Mesodermstreifen zu bilden, das äußere dagegen schnürt bloß zwei Paare von Mikromeren ab, worauf es sich vollkommen äqual teilt und die beiden Hauptzellen liefert, aus denen sicb die Urniere herausbildet und die wir somit als Nephroblasten $(N)$ bezeichnen können. Die Abgabe des ersten verhältnismäßig großen Mikromerenpaares erfolgt am Stadium von 125-135 Blastomeren und zwar in der Richtung nach hinten und unten. Diese Descendenten $\left(m_{3}\right)$ lehnen sich an die medianen Makromeren derart an, daß sie dieselben zum Teil von oben überdecken (Fig. 66).

Nach einer längeren Ruhepause erfolgt bei etwa 160-180 Zellen die nächste, abermals auffallend inäquale Teilung der Nephroblasten $\left(M_{11}\right.$ und $M_{21}$ ), bei welcher winzige Tochterzellen $m_{5}$ zwischen die Mutterzellen und die medianen Nachbarzellen $M_{12}$ und $M_{22}$ förmlich eingezwängt werden (Fig. 66, 826). Der Teilungsakt selbst ist in der Prophase dem nächstfolgenden ïhnlich und könnte leicht mit demselben in bezug auf die Zeitfolge verwechselt werden oder ganz der Beobachtung entgehen; derselbe muß somit an einer ununterbrochenen Reihe von Entwicklungsstadien festgestellt werden, was bei Physa geschehen ist.

Die soeben dargestellte zweimalige und jedesmal im verschiedenen Grade inäquale Teilung der vorderen (äußeren) Makromeren, unsrer Nephroblasten, fuhrt zu ihrer endgültigen Differenzierung. Da wir auf diese Differenzierungsteilungen bereits bei Besprechung des primären Mesoderms hinweisen, so gehen wir hier gleich zur Darstellung der weiteren Entwicklung der Nephroblasten uiber. Ihre nächste Teilung ist vollkommen äqual (Taf. XXIV Fig. 82) und findet erst beim Beginn des Einsinkens der Entodermplatte, zuweilen etwas früher oder später statt.

Unmittelbar nach der vollzogenen Teilung liegen die beiden vollkommen gleichen Tochterzelłen in derselben Ebene mit den medianen Mesodermzellen und verbleiben in derselben, solange sie noch der 
Zwischenkörper verbindet 'Taf. XXIV, Fig. $\left.82, \Lambda_{1}, \Lambda_{2}\right)$. Ist aber die Trennung erfolgt, alsdann werden aus dieser Lage die vorderen nach oben verschoben, während die hinteren tiefer gregen die Baucliseite rücken. Vor der Trennung und kur" nach dersellen beurkunden alle vier Nephroblasten den genetischen Zusammenhang mit dem medianen Mesoderm durch den identischen histiologischen Charakter, namentlich durch den allen Mesodermmakromeren eigentumlichen, gelblichen, von feinen Dotterkürnchen herrührenden Farbenton; welcher sie von den nächstliegenden Zellen des sekundären Mesoderms, sowie ron den Ectodermzellen sehr leicht unterscheiden lernt.

Das hintere Paar strebt von nun an auf dem kürzesten Weure seinem Endschicksale zn; ohne sich zu teilen wächst es nämlich sehr rasch und iberholt binmen kurzem alle ubrigen Mesodermzellen an Größe, wobei auch die Kerne in gleichem Maße wachsen und zu kolossalen Bläschen mit einem reich verästelten Chromatinnetze und einem großen Nucleolus anschwellen. Während dieser Lmbildung lassen sich diese Zellen schon als die kiuftigen » Riesenzellen * der Lrniere unzweifelhaft erkennen, welche, wie eingangs erwähnt wurde, den Kern dieses Organs bilden. Zu ihrer vollendeten Ausbildung fehlt nur noch der intracellulare Excretionsgang, welcher sich erst später ausbildet.

Das vordere Nephroblastenpaar $\Lambda_{2}^{\top}$ (Fig. 85a) macht zunächst eine stark inäquale Teilung durch, wobei die Teilungsspindeln bald harmonisch nach einer Richtung sich einstellen, bald eine divergente Lage zeigen. Die kleinen chromatinreichen Tochterzellen werden aber immer nach inmen gegen die Archenteronwand, bzw. nach oben gregen die spätere Kopfblase abgeschnürt und lehnen sich den entsprechenden Riesenzellen an (Taf. XXIV, Fig. $85 a, b j$. Die in:iquale Teilung des zweiten Nephroblasteupaares ist gleichsam eine Wiederholung der zweiten Differenzierungsteilung ihrer Mutterzellen ./21 und $M^{11}$.

Die Riesenzelle ist zu dieser Zeit bereits von mehreren Mikromeren umgeben, von denen zwei, an ihrem oberen Rande gelegenen, dem primären Mesoderm entstammen, während die dritte, welche an ihrem vorderen und unteren Rande sich befindet, zwar denselben Charakter wie die zwei oberen zeigt, zweifellos von keinem der beiden Nephroblastenpaare, sondern allem Anscheine nach ron einer Zelle des sekundären Mesoderms erzengt wird.

Ähnliche Mikromeren erscheinen auch am vorderen Ende der beiden vorderen Nephroblasten und mögen gleichfalls vom sekundüren 
Mesoderm herstammen, wofur die im letzteren mehrfach beobachteten stark inäqualen Teilungen sprechen (Fig. 82).

Die soeben beschriebene inäquale Teilung der beiden vorderen Nephroblasten wurde wenigstens an acht Keimen beobachtet, unterliegt somit keinem Zweifel. Sie findet bei bereits weit fortgeschrittener Einstiilpung des Entoderms statt und ist deshalb schwierig zu verfolgen.

Bis zu dieser Phase konnte man über den Entwicklungsgang der Urnierenanlagen die vollste Klarheit gewinnen, mit dem nächsten Schritt begianen sich Schwierigkeiten zu häufen und kommen recht verschiedene Bilder zur Beobachtung, welche der sicheren Deutung des wahren Sachverhaltes im Wege stehen. Dazu tragen mehrere Umstände bei, vor allem die rasch fortschreitende Entwicklung and Umbildung der Archęteronzellen, welche große Vacuolen ausbilden und die Mesodermzellen an die Ectodermwand pressen, ferner die ungemein starke Wucherung sämtlicher Mesodermzellen, insbesondere derjenigen des sekundären Mesoderms, welch letztere die $\mathrm{Ur}^{-}-$ nierenanlage allseitig umgeben und mit ihr auf verschiedene Weise in Verbindung treten, schließlich das energische Wachstum des Ectoderms und die mit demselben Hand in Hand gehende Umbildung der allgemeinen Gestalt des Embryos. Durch alle diese Umstände wird die genaue Beobachtung der im Innern des Keimes vor sich gehenden Veränderungen an einzelnen Zellen im hohen Grade erschwert, so daß gerade die interessantesten Vorgänge in der definitiven Ausbildung der Urniere sich der unmittelbaren Beobachtung entziehen. Sie muissen vielmehr aus einzelnen Bildern erschlossen werden.

Wir erinnern, daß die fertige Urniere aus drei Zellen besteht, zu denen roch eine ausführende hinzukommt. Die drei Hauptzellen derselben waren nun bereits nach der letzten Teilung der vorderen Nephroblasten vorhanden, d. i. die Riesenzelle, vor ihr die Mikromere, an welche sich ihre Mutterzelle unmittelbar anschließt (Fig. 90). Nichts erscheint also wahrscheinlicher, als daß sich diese drei Zellen zu definitiven Urnierenzellen in der Weise differenzieren, daß das vordere Glied sich an die sog. Scheitelplatte anheftet und in die Wimperzelle, das nächstfolgende in die Excretionszelle umwandelt, während die Riesenzelle sich mit einer Ectodermzelle verbindet und auf diese Weise die Kommunikation des späteren Nierenkanals mit der Außenwelt hergestellt wird. In der Tat kommen an Stadien, wo die Kopfblase bereits stark ausgebildet ist und der Embryo rotierende Bewegungen ausfuhrt, Bilder zu Gesicht, welche diese Deutung sehr wahrscheinlich machen. 
Man bemerkt z. B. in Fig. 90 vier Zellen, welchè wir der Reihe nach mit $n \therefore I, n_{i} I I, n: I I I$ und $n: I V$ bezeichnen, von denen die erste die Ansfiihrungszelle, die zweite die Riesenzelle, die dritte die zweite Excretionszelle und die vierte die Wimperzelle der fertigen Umiere repräsentiert. Ein gan\% ähnliches Bild gibt Meisexneimer ('99, für die Entwicklung der Lrniere von Ancylus fluriatilis (Fig. 2) und deutet es in der oben bezeichneten Weise.

Indessen lehrt eine sorgfultige L'ntersuchung der Entwicklung dieser Nierenanlage an einer ununterbrochenen Reile von Entwicklungsstadien, daß der spätere innere Arm derselben nicht atus zwei, sondern aus drei oder gar aus vier Zellen und somit die ganze Anlage aus fünf bzw. sechs anstatt aus vier Zellen zusammengesetzt ist Fig. 89 (ij. Dieses Bild wiederholt sich so oft, mąmentlich an Stadien, wo bereits die Schalendriise ziemlich tief eingestilpt ist, dali man es keineswegs als eine zufällige Erscheinung betrachteu kamn. Da aber der innere Arm typisch aus zwei Zellen besteht. so wirft sich die Frage auf, woher diese drei Zellen stammen und welche ron ihnen bei der definitiven Koustituierung dieses Armes eliminiert wird? Allem Anscheine nach teilt sich der vordere Nephroblast wach Abschniirung der Mikromere ärual, wofiir der histiologische Charakter der an die Riesenzelle proximal sich anreihenden drei Zellen sprechen wirde. Es ist aher nicht ausgeschlossen, daß zu deu urspriinglichen drei Deriraten der Nephroblasten Elemeute des sekundïren Mesoderms hinzutreten, welche die Aufgabe haben, das proximale Ende des inneren Uruierenarmes mit der inneren Wand der Kopfplatte zu verlöten.

Dieser zweifelhafte P'unkt konnte durch unmittelhare Beobachtung nicht entschieden werden. An einigen Präparaten wurde zwar cine größere Zelle in ummittelbarer Nähe der liesenzelle in mitotischem Zustande beobachtet, ob dies aljer der zweite Nephroblast ist, war nicht zu entscheiden. Alle Bilder, die an Dutzenden von Präparaten beohachtet wurden, sprechen dafiir, daß der innere Arm der Crmiere sich aus dem hinteren Yephroblasten allein ausbildet und die mit seinen Derivaten in Verbindung tretenden Zellen des sekundiren Mesoderms nur zur Anheftmog der Wimperzelle dienen. Wie schwierigr die Entscheidung dieser Frage ist, lehrt ein Blick auf die Fig. 87, ans der klar zu ersehen ist, welch eine groke Menge rou gleichgestalteten Zellen die Nierenanlage umgibt.

Maßgebend für die lieurteilung der Genese des ganzen Organs ist die Tatsache, daß schon auf deu allemichsten Stadien der innere Arm wieder aus zwei Zellen besteht, ron denen die unmittelbar an die 
Riesenzelle angereihte bereits die Fortsetzung des inzwischen in der letzteren ausgebildeten Excretionskanals enthält.

Der äußere Unnierenarm besteht aus einer einzigen Zelle, welche sehr frühzeitig mit der Riesenzelle mit breiter Fläche verlötet erscheint. Es ist dies die künftige Ausführungszelle. Die Erforschung ihrer Abkunft bietet die größten Schwierigkeiten. Ist es eine ectodermale oder aber eine mesodermale Zelle und im letzteren Falle stammt sie rom primären oder sekundären Mesoderm ab? Auf die Entscheidung dieser Alternative wurde die größte Sorgfalt verwendet, trotzdem aber Dutzende von Präparaten, sowohl Schnittbilder als auch Totalansichten, verglichen wurden, konnte die Einwanderung einer Epithelzelle nicht nachgewiesen werden. Diese müßte aber unbedingt stattfinden, sobald man bereits an Stadien, wo die Riesenzelle noch keine Spur von einem Kanal zeigt, die spätere Ausführungszelle mit ihr verbunden und in die Furchungshöhle so weit eingesunken findet, daß nur der distale Teil ihres Körpers an das Hautepithel angedrückt erscheint und an Schnittpräparaten von den Ectodermzellen eingefaßt erscheint, wie dies aus den Fig. $89 a, b$ und 90 klar zu ersehen ist. Diese und ähnliche Bilder berechtigen wohl zur Annahme, daß die A usfuhrung'szelle keine Epithelzelle, sondern eine mesodermale Zelle ist, welche an das Epithel gepreßt wird und dessen Zellen auseinander drängt, um mit ihrem distalen Ende an die Oberfläche zu gelangen. Für diese Annahme spricht einerseits der Umstand, daß diese Zelle schon sehr friihzeitig tief in der Furchungshöhle liegt, anderseits, daß die Riesenzelle von dem Ectoderm durch eine mesodermale Schicht geschieden ist, daß die Ausführungszelle unmittelbar nach ihrer Verlötung mit der Riesenzelle den Charakter der angrenzenden Mesodermzellen zeigt, schließlich, daß sie nach Ausbildung des Ausfuhrungskanals nicht mitten zwischen den Ectodermzellen liegt, sondern an dieselben nur angelehnt erseheint (Fig 89 ausz).

Trotzdem also das Verhalten bei andern Basommatophoren und bei Stylommatophoren fur die ectodermale Abkunft der ausfiuhrenden Zelle spricht, konnten wir für dieselbe in den Befunden bei Physa keine überzeugenden Gründe gewinnen.

Im Gegenteil unsre Beobachtungen an dieser Form habeu uns die Überzeugung aufgedrängt, daß das ganze Organ ein Derivat des Urmesoderms ist, wie es auch RABL fur Planorbis annimmt.

Nachdem wir die Frage nach der Beziehung der vier Urnieren-

1 R. S. Bergar (Excretionsorgane der Würmer, 185) leitet den TrichterSchlingen- und Endabschnitt der Anneliden-Nephridieu aus dem Mesoderm ab. 
zellen zu den Keimblättern erörtert haben, gehen wir zur Darstellung der weiteren Differenzierung des ganzen Organs tiber.

Es wurde oben hervorgehoben, daß die Hauptzelle, d. i. die sugr. Riesenzelle, sich sehr zeitlich durch ihre ungewöhnliche Größe, den kolossalen, bläschenfürmigen, mit reichem Chromatinnet\% und großem Nucleolus rersehenen Kern kennzeichuet. Da sich in dieser Zelle, wie Mersenenerner richtig angibt, die excretorische Funktion hauptsächlich konzentriert, so ist es ganz natiirlich, daß in ibr der Exeretionskanal zunächst zur Ausbildung gelangt. Man bemerkt die erste Andeutung desselben - einen hellen Spaltraum nahe an der Verbindungsstelle mit der Excretionszelle - gleichsam eine intercelluläre Vacuole, welche sich bald in das Zellplasma um den Keru herum an der Außenseite der Riesenzelle bogenfürmig fortsetzt.

Von seiner Bildungsstätte aus dringt der Kanal nach entgegengesetzten Richtungen vor: proximalwärts in die zweite Excretionszelle und distalwärts in die Ausfiibrungszelle. Es ist nicht ausgeschlossen, daß derselbe in der ersten unabhängig von demjenigen der Riesenzelle entstehen mag, in der letzteren aber bildet er sich ganz bestimmt unter ihrem Einfluß aus. Man sieht ihn anfänglich nur von der Kontaktfläche eine kleine Strecke weit ins Cytoplasma hineinragen, dann immer weiter nach auswärts vorriicken, his er fast das auswärtige Ende der Zelle erreicht hat. Alsbald dehnt er sich gewaltig aus, so daß die ganze Zelle zu einer, eine riesige Vacuole enthaltenden Blase mit wandständigem Kerne sich umwandelt (Fig. 896). An diesem Präiparate bemerkt man zugleich, daß die riesig vergrößerte Ausführungszelle fast ganz in der Furchungshöhle liegt. Laige sie mitten unter den Ectodermzellen, so wïren letztere sehr weit seitlich abgedrängt, was hier nicht der Fall ist.

Die Ansammlung ron Flissigkeit in der Ausfuhrungszelle deutet darauf hin, daß die Excretion bereits im Flusse ist, bevor noch eine Ausmindungsöffung gebildet wurde. Die letztere ist eben das Werk der Vacuole, dureh welche das distale Ende der Zelle ausgedehnt und schließlich durchlöchert wird. Wir haben vor Jahren bei Spongilliden die Vacuolèn als ein Mittel zur Bildung von Hautporen kennen gelernt, weshalb uns die soeben geschilderte Erscheinung bei Physa sofort klar wurde.

Der ausgebildete Excretionskanal hat eine charakteristische Gestalt, welche am besten aus Fig. 88, 99 zu ersehen ist. Seine Wände färben sich stark mit Fuchsin, desgleichen erhalten sie nach Behandlung mit Silbernitrat das Kolorit der Intercellularsubstanz. 
Was schließlich die beiden Komponenten des inneren Armes, d. i. die zweite Excretzelle und die Wimperzelle, betrifft, so ist uber die erstere nur so viel zu bemerken, daß sie sich auf späteren Stadien sehr stark in die Länge ausdehnt; die letztere höhlt sich in der Richtung des Armes nach Art einer Kragenzelle aus und erzeugt die langen Flagellen, welche in den Ausführungskanal der nächstliegenden Excretionszelle weit hineinreichen. Sie nimmt dabei eine seitlich komprimierte fächerförmige Gestalt an, bildet in ihrem Inneren einen mächtigen Flüssigkeitsraum aus, so daß ihr Plasma bloß auf eine napfartige Grenzschicht zwischen der Vacuole und den aus ihm ausstrahlenden Flagellen bildet. An dem vacuolenhaltigen Teile der Wimperzelle sitzen mehrere mesodermale Zellen kappenartig auf und verschmelzen mit der Wimperzelle so innig, daß man sie bei Herauspräparieren der Urniere nicht mehr trennen kann (Fig. 88). Es möchte somit scheinen, daß das proximale Armende der Urniere ein aus mehreren Excretzellen zusammengesetzter Excretionsapparat sei; dem ist aber entschieden nicht so, denn die mit der Wimperzelle eng verbundenen kleinen Zellen haben nur ihre Anheftung an die innere Leibeswand zu besorgen. Es gehören demnach zum Aufbau der fertigen Urniere nicht mehr als vier für alle Basommatophoren ganz typischen Zellen, wie sie zuerst von Meisenheimer klar aufgefaßt wurden.

$\mathrm{Zu}$ den oben hervorgehobenen morphologisehen und physiologischen Eigenschaften dieser vier Hauptzellen möchte ich noch eine speziell für die Flimmerzelle charakteristische Eigenschaft hinzufügen, welche meines Wissens bisher noch nicht beobachtet wurde. Ich finde nämlich an ihrer äußeren Oberfläche auffallend lange und dabei sehr feine, geißelartige Fäden, welche in dem sie umgebenden freien Leibesraum zu flottieren scheinen. Sie setzen sich sogar auf den Wimperkanal fort. Als ich diese Geißeln an Sublimatpräparaten zum erstenmal beobachtete, glaubte ich sicher ein Kunstprodukt vor mir zu haben, etwa die Verschiebung der langen Flagellen der Wimperzelle durch das Messer. Da aber an mehreren Serien stets dasselbe Bild wiederkehrte, überzeugte ich mich, daß eine Täuschung ausgeschlossen ist und daß diese geißelartigen Fäden tatsächlich von der äußeren Wand der Wimperzelle ausgehen. Leider besitze ich augenblicklich weder ein entsprechend konserviertes, noch frisches Material, um mir die absolute Sicherheit über deren Natur zu verschaffen und das histologische Detail näher kennen zu lernen.

Die Existenz von Cilien bzw. Geißeln an der äußeren Wand der 
Wimprerzelle, die schon ohnehin einen mächtigen Schopf äußerst lanwer Flagellen ${ }^{1}$ ausbildet, ist allenfalls eine sehr therraschende Erscheinung, welche eine nähere lieachtung rerdient. In physiolocischer Beziehung wäre die flimmernde Oberfläche der Wimperzelle leicht zu verstehen. es wiirde sich nämlich um eine Erneverung der die Wimperzelle umspülenden Fliissigkeit handelı — und die ganze Vorrichtung durfte den mehrzelligen Wimperapparat der Stylommatophoren ersetzen. Es mag noch hinzugefügt werden, daß einzelne Mesodermzellen feine Pscudopodien in die Umgebung der Wimperzelle ausschicken, welche wohl dieselbe physiologische Bedeutung haben kïmnten wie die Cilien, insofern sie einer pendelartigen Bewegrung fähig wären.

Ijetreft's der sonstiren, an spiiteren Stadien besonders mit der Obertliche der Riesenzelle mehr oder wenirer innir verbundenen Zellen muf nachdrücklich hervorgeholsen werden, dall sie nicht zu den funktionierenden Zellen der Lmiere gehören, sondern daß es mesenchymatische Elemente sind, welche nur zu ihrer lefestigung, vielleicht anch zu ihrer Ernährung beitragen.

Die mesodermalen Elemente treten schon an sehr friihen Eutwicklunerstadien mit den Tephroblasten in nähere Verbindung, sie umhüllen nämlich dieselben allseitig̨, jedoch verbleilst später nur ein Teil derselben mit dern auscelifileten Orean danernd verbunden.

Wir schließen die Darstellung der Entwicklung der Crniere mit einiren Bemerkungen üher ihre Endschicksale als. Die Funktionsperiode beginnt etra am Stadium Fig. 99, an dem bereits das Velum. der Fuß, die Tiadula, der Marendarm und die Schalendriise anssebildet ist und die Anlite des Enddarmes deutlich hervortritt. Yit dem Wachstum der Larre in der Lünrsachse geht alueh das Waclistum der Lruiere Hand in Hand, man bemerkt an den $̈$ C̈berfancsstarlien ron der Larve zur fertiren schnecke, daf der innere Arm eine enorme Länge erreicht hat, die Ausfihrumescelle gewinnt ebcufall: cine gestreckte, zylindrische fiestalt, während das Plasma der Riesenzelle inmer mehr vaculenhaltigr erscheint, his es ganz schwammig wird und das ranze Organ nach und nath dem litickbildungsprozesse anheimfältt. Es wird immer blasser und undeutlicher, versehwindet aber nicht, sundem ist sourar in den letzten Degenerationsstadien leci der auscebildeten Schnecke in seinen Hauptkonturen nachweisbar

1 Diese Flagellen tingieren sich in In minsusisscher Lijsung schwarz, während die von der Oberfläche ausgehenden ungefürrbt bleiben. 
(Fig. 111). Nach Fol erbält sich die Urniere auch bei andern Pulmonaten noch lange nach der Anlage der bleibenden Niere, welcher Befund ron RABL ganz richtig als ein Beweis dafür angesehen wird, daß zwischen den beiden Organen keine genetische Beziehung besteht. Genau wie bei Plyssa fontinalis entrickelt sich die Urniere bei der zweiten Physt-Art, d. i. hypnorum; bei beiden Formen ist sie ein rein mesodermales Gebilde. Da das fertige Organ, wie eingangs hervorgehoben wurde, bei allen Bas ommatophoren denselben typischen Aufbau zeigt, so glauben wir schließen zu künnen, daß ein morphologisch so einheitliches Gebilde sich auch in entwicklung'sgeschichtlicher Beziehung als ein solches erweisen wird, d. i., daß es sich aus derselben mesodermalen Anlage entwickelt. Fiir diese Ansicht finden wir in der mehrmals zitierten Arbeit Mersexhenenes eine feste Stiitze, denn, wenu auch dieser Antor sich für die ectodermale Abkunft der Urniere erklärt, so sprechen doch alle Figuren in seiner Arbeit, welche die späteren Entwicklungsstadien rexanschaulichen, deutlich dafuir, daß sie sich aus demselben Keimblatt und in derselben Weise wie bei Physa entwickelt.

In Erwägung des Umstandes, daß Rabl die Urniere der Tellerschnecke in analoger Weise rom Mesoderm ableitet nud HoLxes dessen Befunde der Hauptsache nach bei Planorlis tricolv is bestätigt, glauben wir für unsre obige Verallgemeinerung genügende Anhaltspunkte zu haben.

Wir hätten also, falls unsre Ableitung der Lrniere furr die ganze Basommatophorengruppe guilitg ist, in der Pulmonatengruppe zwei embryologisch grundrerschiedene Nierentypen zu unterscheiden, nämlich den mesodermalen Typus der Basommatophoren und den ectodermalen der Stylommatophoren. Der morphologische Gegensatz ist ebenfalls schwer auszugleichen, da, mie eingangs hervorgehoben wurde, die Urniere der letzteren Gruppe ein typisches Epithelrohr darstellt, während diejenige der ersteren aus einer einzelnen Reihe ron durchbohrten Zellen zusammengesetzt ist. MersexIELMER ist indessen der Ansicht, daß die Kluft zwischen den beiden Bautypen sich doch iiberbriicken läßt. Für ihn bestght zwischen denselben insofern kein prinzipieller Unterschied, als die aus durchbohrten Zelleu gebildete Lrniere ebenfalls als ein Epithelrohr aufgefaßt werden kamn, dessen Zellen weit anseinander gerickt sind, so daf schließlich eine einzige Zelle rings das Lumen des Ganges umschließt, welcher somit stets intracellular hleilte. Zur Stiitze dieser Auffassung zieht Mersexnemer die Ausfihrungen S̈chäffers iiber 
iuter- und intracelluläre Tracheenbildung heran, sowie die öfters geiul kein prinzipieller Gegensatz zu bestehen brancht.

Man kann gegen diese Ausführungen an und für sich nichts einwenden. Im Gegenteil, wir können dieselben durch anderweitige, belangrolle Beispiele bestätigen. In rerschiedenen Tierkreisen findet man Belegee dafuir, daß ein und dasselbe Organ - seien es Nephridien oder einfach Hautdruisen - jene beiden Typen der histologischen Tektonik in sich vereinigt. So sind z. B. bei den C'estoden die größeren Stämme des Excretionsapparates mit einem wohl ausgelbildeten Epithel versehen, während das Netzwerk von feineren Kanälen sich nur aus durchbohrten Zellen zusammensetzt. Dem geçeuub)er wird bei Turbellarien und Trematoden das gesamte Nierensystem intracellulär, bei den Nemertinen aber ist sowohl an den Hauptstämmen, wie an den Zweigen ein dentliches Epithel vorhanden. Es mügen hier ferner die rielzelligen Fußdrisen vieler Malacostraken erwähnt werden, die in ihrer Struktur ebenfalls die beiden Bauprinzipien aufweisen. Dieses Zugeständnis wollen wir aber nicht zugunsten MeIseshemers ausuitzen, wenn es sich um einen Beweis der morphologischen Gleichwertigkeit der Niere ron Basommatophoren and Stylommatophoren handelt.

Wir miissen uns vor allem die Frage aufwerfen, ob diese Gleichwertigkeit so zu verstehen sei, daß sich aus der primitiven, intracellulären Lrniere jener die komplizierten, epithelialen Nephridien dieser entwickelt haben, oder daß sich die beiden Nierentypen unabhängig voneinander ausgebildet haben?

Diese Frage ist durch entwicklungrsgeschichtliche Lntersuchungen ihrer Lösung keineswegs näher gebracht worden. Nachdem es sich nämlich herausgestellt hat, daß die beiden Typen sich aus verschiedenen Keimblättern aufbauen, ist die Wahrscheinlichkeit einer Einheitlichkeit der Nierenanlage in genetischer Beziehung noch geringer geworden. Denn obgleich es aus gewissen Angaben der Autoren, wie Fols, Wolesoxs, Erlaxgers u. a. hervorzugehen scheint, daß die Urniere mehrerer Basommatophoren bald im ganzen Lmfange, hald nur teilweise aus dem Ectoderm ihren Ursprung nimmt, so künnen wir diese älteren Befunde auf Grund unsrer eignen Erfahrung nicht für maßgehend halten und als Berreise jener genetischen Einheitlichkeit gelten lassen, wie dies Mersinhemen rersuchte. Wir finden ferner auch in der Embryologie andrer Molluskengruppen, wie z. B. derjenigen von Proso- und Opisthobranchiern keine 
festere Grundlage für die einheitliche Auffassung der beiden Nierentypen.

Im Gegenteil stoßen wir beim Vergleich ihrer Genese auf dieselben Gegensätze wie in der Pulmonatengruppe. So werden bei den Opisthobranchiern die sog. Nephrocysten, welche gewiß von einem Teile der Beobachter mit der Anlage der definitiven Niere verwechselt wurden, bald aus dem Ectoderm (Heymons, Umbrella), bald aus dem Mesoderm (Trinchese, Doto, Ercolania usw.), bald aus beiden zugleich (v. ERLanger, '94) abgeleitet. Insofern die betreffenden Beobachtungen sich auf das sog. "Analorgan" beziehen, welches nach den umfassenden Untersuchungen Mazzarellis ('95) nichts andres als die Anlage der bleibenden Niere ist, gehören sie nicht hierher. Es ist aber in einzelnen Fällen sehr schwer zu entscheiden ob sich die Angaben der Autoren auf ein larvales oder ein definitives Excretionsorgan beziehen, wie dies aus den Kontroversen zwischen v. Erlanger und Mazzarelli einerseits und Heymons anderseits hervorgeht.

Ganz dieselbe Verwirrung herrscht in bezug auf die Ableitung der Larvalniere der Prosobranchier. So wird sie z. B. von ConkLin bei Crepidula aus dem zweiten Quartett abgeleitet, während sie v. Erlanger bei Bythinia teils aus dem Ectoderm, teils aus dem Mesoderm herleitet. Schließlich herrscht auch bezuiglich der Ableitung der larvalen Nieren der Lamellibranchier keine einheitliche Auffassung. Denn während HatscheK ('80) bei Teredo und StaufFACHer ('97) bei Cyclas dieses Organ aus dem Ecto- und Mesoderm. ableiten, leitet es Meisenheimer ('01) bei Dreissensia polymorpha ausschließlich aus dem Ectoderm ab.

Aus dieser kurzen Andentung des heutigen Standes der Frage nach der Ableitung der Larvalniere in einzelnen Molluskengruppen geht klar hervor, daß die Homologisierung der typischen Urniere der Pulmonaten mit ähnlichen Gebilden der Proso- und Opisthobranchier ${ }^{1}$ noch nicht bald wird streng durchgeführt werden können, was bereits von andern Autoren (Meisenhermer, Casteel, '04) hervorgehoben wurde. Bei der mangelhaften Kenntnis ihres Ursprunges, ihrer Funktion und ihrer Endschicksale, können selbstverstïndlich alle Versuche, die gegenseitigen Beziehungen aufzuklären, nur einen hypothetischen Wert haben.

1 MAZZarelli vermutet, daß die aus einer einzigen Zelle bestehende Urniere der Opisthobranchier-Larven mit der Riesenzelle in den Urnieren der Basommatophoren verglichen werden kann. Refer. Zool. Centralbl. 1905. Nr. 67. 
Wie schwankend noch derzeit die Basis fur eine strenge Homologisierung ist, beweist unter anderm der Umstand, daß CAsteel ('04) neulich die Vermutung ausspricht, daß die sog. Nephrocysten der Opisthobranchier, welche einen ganz andern Bau zeigen, als die Urnieren andrer Gruppen, als rudimentäre Gebilde aufuufassen seien, mofiir die frühzeitige Funktionierung der Anlagen der definitiven Nieren spricht. Er folgert darans weiter, daß sie gegenwärtig bloß die Verstärkung der Anlagen der definitiven Niere zu bilden haben und daß somit eine echte Larvalniere den Opisthobranchiern völlig mangelt.

Betreffend die Phylogenie darf nicht unerwähnt bleiben, daß Meisexhermer die Uniere der Mollnsken mit den Endzellen des WassergefäBsystems der Plathelminthen vergleicht und in der ganz

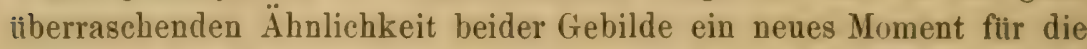
Ableitung der Molluskeu ron turbellarienähnlichen Vorfahren erblickt.

Solange wir indessen das Verlältnis der Molluskenurniere zur Kopfniere der Chätopodenlarven nicht kennen, solange wir nicht einmal wissen, ob zwischen dem Excretionsapparat der Anneliden und der Plathelminthen irgend welcher Zusammenhang besteht, halten wir derartige Spekulationen für unfruchtbar.

Bezüglich der sog. „Nuchalzellen^, welche wir nach den Befunden bei Physa als ein larvales Excretionsorgan ansprechen, verweisen wir auf das nachfolgende Kapitel.

\section{c) Bemerkungea uber die sogenannten "Nuchalzellen*.}

Bei mehreren Süßwasser-Gastropoden (Lymnaeus, Planorbis, Paludinu, Bythinia, Ancylus) wurde eine scharf umschriebene Zellengruppe in der Nackengegend der Larre beobachtet, uber deren morphologische und physiologische Bedentung man noch immer völlig im unklaren ist, trotzdem sie bereits im J. 1862 ron LEREBOLLI.ET entdeckt und im Laufe der Zeit von mehreren Forschern (LANKEsTER, Wolfsox, Fol, Rabl, Sarasix, v. ErLanger) näher untersucht wurde. Die Bezeichnung "Nuchalzellene rührt von FoL ('83, her, der diese rätselhafte Zellengruppe bei drei Formen (Planorlis, Ancylus, Lymmaeus, genauer studierte und mit Riicksicht auf ihre Lage in der Nackengegend als , Cellules nucales bezeichnete. Derselhe leitet sie zwar aus dem Eetoderm ab, scheint sie aber doch als mesodermale Elemente aufzufassen, denn in der Tafelerklärung werden sie einfach als »ein Haufen mesodermaler Zellen « angeführt. Über ilıre Endschicksale fehlen überhaupt zurerlässige Angaben. Nach 
FoL dürften die Nuchalzellen keinem speziellen Organe den Ursprung geben, sondern sich wahrscheinlich mit mesodermalen Elementen mischen und wie diese zu verschiedenen $Z$ wecken verwendet werden. Im übrigen vermutet er in denselben ein rudimentäres Organ.

Bei Paludina sind es nach v. Erlanger rundliche oder unregelmäßig polygonale mit einem oder mehreren Kernen und einem sehr deutlichen Nucleolus versehene Zellen, welche alle übrigen Zellen des Embryos an Größe übertreffen. In der Nähe ihrer Kerne kondensiert sich eine stark färbbare plasmatische Substanz. Sie sollen sich schließlich in der Leibeshöhle zwischen einzelnen Organen ausbreiten und schließlich denjenigen Bindegewebszellen entsprechen, welche Brock als "Plasmazellen " beschrieben hat. Als ectodermale Elemente unterscheiden sie sich sodann ganz scharf von den gewöhnlichen mesodermalen Bindegewebszellen. Es wären also Mesenchymzellen, die aber sonderbarerweise vom Ectoderm, namentlich vom hinteren Rande des Velums, entspringen sollen.

Weil sie vom Velum aus und gerade zu einer Zeit entstehen, wo die Resorption desselben beginnt, glaubt sie v. ERLANGER mit dem letzteren in einen causalen Zusammenhang bringen $\mathrm{zu}$ sollen. Wie er sich aber diesen Zusammenhang vorstellt, ist wirklich schwer zu enträtseln.

Bei Physa kommen ebenfalls ganz äbnliche Nuchalzellen vor, wie bei den oben erwähnten Formen. Sie erscheinen bereits auf einer sehr frühen Entwicklungsstufe der Larve, zu einer Zeit, wo die Radula erst kaum angedeutet und die Einstïlpung der Schalendriise noch ziemlich flach ist. Man bemerkt dazumal unmittelbar an den dorsalen Rändern der beiden Scheitelplatten größere Zellen in Längsreihen nach vorn und gegen die Medianebene ziehen. Von den angrenzenden Mesodermzellen unterscheiden sie sich schon jetzt sowohl durch ihre bedeutendere Größe, als auch durch ihre mächtig entwickelten, körnchenreichen Nuclei, sowie durch ihr dichtes, helles Plasma. Sie beginnen bald sich stark zu vermehren und erreichen am Stadium Fig. 120 die maximale Zahl und Größe. In Fig. 113 sehen wir sie in einem Halbkreise über dem Schlunde verteilt und von dem inneren Arm der einen Urniere bis zu demjenigen der andern ausgebreitet. Am Stadium, dem diese Figur entnommen wurde, ist aber diese Gruppe verhältnismäßig noch schwach ausgebildet, denn die Zahl und Größe der Nuchalzellen steht im geraden Verhältnisse zum Alter der Larve. An Stadien, wo die Torsion begonnen hat, scheinen dieselben die stärkste Entwicklung zu erreichen und von 
den hinteren Rändern des Velums auszugehen, weshalb sie v. ERLANGER direkt aus dem letzteren ableitet. Indessen breiten sie sich noch weit unter den Scheitelplatten seitwärts und nach vorn aus. Sie rerbleiben in der Nackengegend bis zur Ausbildung der Schnecke und fallen dem Beobachter schon an den unmittelbar vorhergehenden Stadien, an denen sie bereits in dichten Reiben auftreten, sofort auf, Fig. 106, während sie bei ganz jungen Larven leicht ubersehen werden können. Diesem Umstande ist zuzuschreiben, daß man nach ihrem Trsprung erst an solchen Stadien geforscht hat, wo sie bereits stark entwickelt und sogar zum Teil in Riickbildung begriffen sind.

Bei Physa sind mir zwar ihre Mutterzellen unbekannt geblieben, aber es unterliegt keinem Zweifel, daß sie dem sekundären Mesoderm entstammen, aus dessen Derivaten sie sich sehr zeitlich zu differenzieren beginnen. Ihre Anlage ist paarig, erst bei der späteren Entwicklung treffen die beiderseitigen Gruppen in der Medianlinie zusammen, um eine einzige Zellplatte zu bilden, Fig. 119, 120. Eine genetische Beziehung der Nuchalzellen zum Velum und zum Ectoderm der Scheitelplatten ist absolut ausgeschlossen.

Wie schon Fol für andre Formen richtig voraussetzt, bilden sie auch bei Physa keine Organanlage. Über ihre Funktion während des Larvenlebens lassen sich aber leider nur Vermutungen aufstellen. Ihre Lage in der Nackengegend in unmittelbarer Nachbarschaft der inneren Nierenarme, wo eine große Quantität der Leibesflissigkeit angesammelt ist, führt auf den Gedanken hin, daß sie vielleicht, neben den Urnieren, mit der Excretion betraut sind. Dafür würde sonst der Lmstand sprechen, daß man in denselben oft große Vacuolen und glänzende Körnchen findet und daß ihre stärkste Vermehrung in einer Phase stattfindet, wo die Lrnieren zu atrophieren beginnen.

Was ihre Endschicksale betrifft, kann ich mich den Vermutungen v. Erlaxgers und Fols nicht anschließen, nach welchen die Nuchalzellen sich schließlich zerstreuen und die Rolle von Mesodermelementen übernehmen. Für eine solche Annabme fehlen bei Plyysa jedwede Anhaltspunkte. Denn es wurden diese Zellgruppen an ihrer urspringlichen Stätte, in der Nackengegend, bis zum Ausschlupfen der Schnecke beobachtet. Einige wenige rücken etwas tiefer oder gelangen in den Hohlraum zwischen den beiden Nantelblaittern. Je älter aber die Larre ist, desto auffallender wird die Metamorphose, welche die Nuchalzellen binnen einer verhältnismäßig kurzen Zeit erleiden. Sie erreichen nämlich infolge der Ausbildung von Vacuolen eine wahrhaft riesige Größe, wobei ihr Plasma zu einem weiten streifigen 
Mantel ausgedehnt und der Kern ganz an die Oberfläche weggedrängt wird. Einige sehen schließlich stark aufgebläht aus, andre geschrumpft oder zum Teil aufgelöst, von andern sind nur noch die Kerne mit einem Überrest von Plasma erhalten. Wir haben hier offenbar das Bild eines Rückbildungsprozesses vor uns, dessen Anfangsstadien uns Fig. $117 b$ und die Endstadien Fig. $117 a$ veranschaulicht. Man bemerkt, da $B$ in der letzteren drei Zellen zusammengeballt und von mehreren ganz kleinen Bindegewebszellen umgeben sind; je weiter die Degeneration fortschreitet desto zahlreicher sieht man diese kleinen Zellen um die Trümmer der Nuchalzellen geschart. Es hat den Anschein als wenn hier eine Phagocytose im Spiele wäre.

Nach den bisherigen eignen Beobachtungen kann ich nicht entscheiden ob diese metamorphotischen Elemente sich noch erholen oder aber ganz zugrunde gehen. Die letztere Alternative erscheint jedoch wahrscheinlicher, weil man diese charakteristische Gruppe von Zellen bei ausgeschlüpften Schnecken nicht mehr nachweisen kann.

Sehr bezeichnend für das ultimäre Verhalten der Nuchalzellen ist der Umstand, daß ihre Metamorphose mit der Rückbildnng der Urnieren gleichen Schritt hält. Man kann aber aus dem Zusammentreffen dieser Erscheinungen keinen Schluß über die wechelseitigen Beziehungen der beiden larvalen Organe ableiten.

Nach den Befunden bei Physa unterliegt es wohl keinem Zweifel, daß die Nuchalzellen keine Organanlagen, sondern vorïbergehende Bildungen sind, entweder larvale Organe oder Rudimente irgend welcher definitiver Organe. Für die Entscheidung dieser Alternative fehlen uns zurzeit spezielle Beobachtungen, insbesondere aber über ihre Funktion. Sind es Exkretionsorgane oder aber Zellen, welche gewisse Reservestoffe in sich aufspeichern, um sie in einer bestimmten Phase an andre Zellen oder an Organe abzugeben? Wir haben zwar oben auf die Lage der Nuchalzellen in unmittelbarer Nachbarschaft der Wimperzellen der beiden Urnieren hingewiesen, ferner auf die Ausbildung von Vacuolen und glänzenden Körnchen, alle diese Befunde sind aber kaum ausreichend, um ihre excretorische Funktion nachzuweisen. Desgleichen läßt sich ohne Analyse des Inhaltes ihrer Vacuolen über ihre nutritive Tätigkeit eine, nur einigermaßen begriundete Vermutung aussprechen.

Mit den Urnieren stehen die Nuchalzellen in keiner genetischen Beziehung; sie entstehen nach unsrer Beobachtung aus dem sekundären Mesoderm, während die ersteren aus dem primären ihren Ursprung nehmen. 
Lnsres Wissens sind die Nuchalzellen bei den Landpulmonaten gar nicht beobachtet worden, bei den Süßwasser-Gasteropoden verteilen sie sich auf zwei Gruppen: auf die Pulmonaten (Lymnacus, Planorbis, Physa) und auf die Prosobranchier (Paludina, Bythinia). Wenn wir uns bei den marinen Prosobranchiern nach ähnlichen Gebilden umsehen, so können wir wohl uur in den äußeren Nieren der letzteren analoge Organe erblicken, welche fast dieselbe Lage haben.

Mit Ruicksicht auf ihren mesodermalen Ursprung bei Physa und auf ihre Lage innerhalb der Leibeshöhle, könnte man vielleicht die Nuchalzellen eher mit den sog. "Nephrocysten * (Trichense) der Opisthobranchier in Parallele bringen. Leider aber sind diese Organe auch noch zu wenig bekannt, um sich aus dem Vergleich mit denselben irgend welches Urteil uiber die Natur unsrer Nuchalzellen ausbilden zn können.

Wo wir also bei den Gasteropoden den Vergleich versuchen, stoßen wir uiberall auf den Mangel sicherer Beobachtungen über die Herkunft, Funktion und Endschicksale der als larvale Excretionsurgane angesprochenen Gebilde. Er kann uns also zur Lösung unsrer Frage wenig verhelfen.

Die Nuchalzellen wurden bisher bald bei den Sinnesorganen (v. ErLanger), bald beim Mesoderm (Fol) behandelt. Sie gehören weder in das eine noch in das andre Kapitel, deshalb haben wir sie in einem besonderen Abschnitte behandelt. Allenfalls sind es (wenigstens bei Illysa, nur vorübergehende Bildungen, deren Rolle im Larvenleben nicht ganz unwichtig zu sein scheint, wofür ihr frühzeitiges Erscheinen, ihre starke Entwicklung und ihre schließliche Metamorphose spricht, deren Bedeutung uns freilich bisher verborgen geblieben ist.

Es stellt sich aus dem Obigen heraus, daß die Nuchalzellen in jeder Beziehung eine viel größere Aufmerksamkeit verdienen, als man ihnen bisher gewidmet hat, trotzdem For $\left({ }^{8} 80\right)$ versichert, schon seit langer Zeit ihren Ursprung und ihre Rolle aufgeklïrt zu haben. Er betrachtet sie nämlich als Rudimente eines Organs, welches ehemals eine wichtige Rolle gespielt haben mochte. In welche Kategorie von Organen diese Rudimente gehören könnten, daruber gibt er uns leider keinen Aufschluß, und, wie eingangs hervorgehoben wurde, hat keiner der bisherigen Beobachter über ihre Endschicksale direkte Beobachtungen angestellt. 


\section{Definitive Organe.}

\section{a) Das Nervensystem.}

Alle Beobachter, die sich mit der Entwicklung des Nervensystems und der Sinnesorgane bei den Mollusken speziell befaßt haben, wie z. B. T. Schuidt ('91), A. P. Henchman ('90), v. Erlanger ('91) ı. a., sowie diejenigen, die über dieselbe nur gelegentliche Beobachtungen gemacht haben, sind dariiber einig, daß das centrale Nervensystem der Mollusken seinen Ursprung dem Ectoderm verdankt. Es wird im allgemeinen angenommen, daß die Cerebralganglien aus den beiden Scheitelplatten, sei es durch Verdickung und Wucherung oder durch Einstülpung des Epithels entstehen. In ähnlicher Weise sollen sich die Anlagen der Pedal- und Visceralganglien als Wucherungen des Epithels des Fußes frïhzeitig loslösen.

Die ältere Angabe Bobretzkys ('76) über den Ursprung des Nervensystems von Fusus aus dem Mesoderm wurde bereits von RABL ('79) entschieden zurückgewiesen und v. ERLANger ('91) suchte dieselbe durch direkte Beobachtungen zu widerlegen. Trotzdem die Ableitung Bовкетzку den neuesten Untersuchungen gegenüber ganz verkehrt erscheint und trotzdem sie nicht auf unumstößlichen Beweisen beruht, dürfte sie doch vielleicht nicht ganz unberechtigt sein, denn wir finden weder in den Ausfiihrungen RabLs noch in den Beobachtungen v. ErLangers ganz überzeugende Gründe für ihre absolute Unrichtigkeit. Namentlich geht aus Fig. 10, Taf XXXII v. ErLANGERS nicht zweifellos hervor, daß es ectodermale Zellen sind, die sich senkrecht zur Oberfläche des Epithels teilen und dessen Wucherung beweisen sollen.

An meinen Präparaten bemerke ich oft sehr zahlreiche Mitosen im Epithel der Scheitelplatten, schließe aber aus der Richtung der Teilspindeln, daß es sich bei dieser Teilung nur um Vergrößerung der Oberfläche der Scheitelplatten, nicht aber um eine Verdickung derselben handelt. Ich sehe überhaupt an Stadien, wo die letztere nach Angabe der Autoren vorkommen soll, daß die Zellen der Scheitelplatte zwar höher sind, daß aber ihre Dicke durch dicht angelagertes sekundäres Mesoderm verursacht wird.

Die Feststellung dieser Tatsache sowohl an Totalpräparaten als auch an Schnitten erweckt gewisse $\mathrm{Z}$ weifel gegen die Genauigkeit derjenigen Beobachtungen, nach denen das centrale Nervensystem ausschließlich aus dem Ectoderm seinen Ursprung nehmen soll; denn sie stitzen sich zum großen Teile nur auf die Fest- 
stellung der Verdickung der Scheitelplatten, ohne fur die Art und Weise, wie dieselbe zustande kommt, positive Beweise zu erbringen.

Nach unsern Beobachtungen könnten wir die Beteiligung des Mesoderms an der Bildung der Ganglien nicht absolut ausschließen, halten somit die Frage nach ihrer Herkunft noch immer fur offen. Für diese Beteiligung erklärt sich außer BoвREтzky und Bürschli ('77, Paludina) auch Fou ('80). Letzterer hält die Diskussion tiber Ursprung des Centralnervensystems fur tuberfliissig, sobald es sich heraustellt, daß ectodermale Zellen in die Furchungshöhle auswandern. Sie wäre auch bei solchen Formen als gegenstandlos zu betrachten, bei denen sich ein Ectomesoblast ausbildet, weil des:en Vorkommen schon an und für sich gegen den prinzipiellen Gegensatz zwischen dem Ecto- und Mesoblast spricht.

Wir hegen die Überzengung, daß es sich bei genauer Untersuchung herausstellen wird, daß diese älteren Angaben wenigstens teilweise berechtigt sind. In derselben bekräftigt uns eine neuere Angabe der A. Hexchuas, nach der die Ganglienzellen bei Limax maximus an frithen Entwicklungsstadien von Mesodermzellen kaum zu unterscheiden sind, was uns auch bei Physa oft aufgefallen ist.

Was die Scheitelplatten selbst betrifft, aus deren Material die Cerebralganglien, die Mundtentakel und Augen sich aussehließlich entrickeln sollen, so unterliegt es keinem Zweifel, daß sie sich wesentlich aus dem Vorderarme und den Seitenarmen des Kreuzes aufbauen und $\mathrm{da} B$ außer den Intermedialzellen sonst keine andern Elemente an ihrer Bildung teilnehmen. Die Einstiilpung der Scheitelplatten, genau iiber den großen Velarzellen, haben wir auch bemerkt und ihren Zusammenhang mit großen Mesodermzellen festgestellt, es konnte aber nicht ermittelt werden, in welcher Beziehung sie zu den Cerebralganglien stehen.

Über die Entwicklung der Sinnesorgane bätte ich zu den Beobachtungen meiner Vorgänger nichts Wesentliches beizufuigen. Die Augen- und Otolithenblase erscheinen bei Physa fast gleichzeitig. Die Einstilpung der ersteren konnte an Schnitten (Fig. 114) ganz sicher in ihren einzelnen Phasen verfolgt werden. Nachdem sie sich zu einem Bläschen umgebildet hat, bemerkt man in dem reduzierten Lumen derselben eine stark färbbare Substanz, die kein Eiweiß zu sein schien. Über die Einstullpung der Otolithenblase konnte ich ebensowenig wie meine Vorgänger eine Sicherheit erlangen. Nach A. Henchman und Meisenheimer entsteht sie bei Limax durch Einwucherung, wenngleich der letztere die Stelle, von 
der aus das Epithel einwuchert, nicht anzugeben vermag. Die Tentakel und Mundlappen entstehen ganz bestimmt aus den Scheitelplatten als einfache Auswüchse derselben.

\section{b) Darmkanal.}

Die Entwicklung des Darmkanals bei den Gasteropoden wurde bereits von so vielen und zum Teil tüchtigen Forschern eingehend untersucht, daß eine erneuerte Behandlung dieses Themas bei einer einzelnen Form nur durch besondere Umstände veranlaßt werden kann. Für mich bildeten die nächste Veranlassung die Befunde Meisenhenmers ('98, '03) bei Limax und Dreissensia, nach denen der ganze Darm vom After bis zur Einmündung in den Magen aus einer Einstiilpung des Ectoderms entsteht. Eine weitere Veranlassung hat die Feststellung der Tatsache geboten, daß trotzdem die Entwicklung des ganzen Darmkanals von Physa in auffallend übereinstimmender Weise mit Planorbis (RABL) vor sich zu gehen schien, dennoch an keinem meiner Präparate eine derartige Ausstuilpung der hinteren Mitteldarmwand nachgewiesen werden konnte, wie sie RABLs Figuren $24 A-26 A$ zeigen. Es war also im vorhinein zu erwarten, daß diesbezüglich die Verhältnisse bei Physa anders liegen müssen. Mein Hauptaugenmerk richtete sich also in erster Linie auf die Genese des Enddarmes. Da aber bei der Verfolgung derselben selbstverständlich auch andre Vorgänge sowohl am Darmkanal selbst, als auch am ganzen Keime mit berücksichtigt werden mußten, so wurden meine Untersuchungen auf den ganzen Darmkanal ausgedehnt.

Indem wir nun zur Darstellung unsrer Beobachtungen schreiten, wollen wir uns zunächst über die erste Anlage der Hauptbestandteile des Darmtractus an dem in Fig. 92a abgebildeten Stadium im allgemeinen orientieren. Dasselbe ist bereits mit wohl entwickelter Kopfblase $(K b)$, stark vortretenden Scheitelplatten $(S p)$, einem noch schwach entwickelten Velum $(V)$, einer kaum angedeuteten Schalendrüse $\langle s d\rangle$, einem deutlich vorgewölbten Fußhöcker $(p)$ und mit einem bis auf eine feine Öffnung reảuzierten Blastoporus versehen. Die inneren Organisationsverhältnisse eines solchen Stadiums veranschaulicht am besten ein medianer Längsschnitt (Fig. 92b).

Das Entoderm bildet bereits einen mächtigen Sack, welcher fast die ganze Furchungshöhle ausfullt und dessen rundliches Lumen durch einen feinen, kurzen Kanal mit der Außenwelt kommuniziert. Die Wandungen dieses Sackes bestehen aus den wohlbekannten Eiweißzellen. Die Reste des Dotters sind nur noch in 
ihren peripheren Teilen enthalten, von denen plasmatische Fortsätze gegen das Ectoderm ausgezogen sind, die läugsten derselben sind zwischen den flachen Zellen der Kopfblase und der oberen Wand des Entodermsackes ausgespannt, die kurzesten an derjenigen Stelle, wo die beiden Urmesodermzellen samt ihren Mikromeren liegen (vgl. Fig. 81). Daselbst ist auch die hintere Partie der Archenteronwandungen anders beschaffen, nämlich aus gewöhnlichen Cylinderzellen zusammengesetzt, in denen wohl kleine Tropfen Eiweiß aber nie größere Vacuolen vorkommen.

Wir bezeichnen diese Partie mit RABL als , Darmplatte oder kleinzellige Darmwand" und heben gleich hervor, daß sie fur die spätere Differeuzierung des Darmkanals von hoher Wichtigkeit ist. Sie hat an unserm Stadium einen noch sehr geringen Umfang, im Längsschnitt ist sie etwa zwei bis fünf Zellen breit.

Nach RABL entsteht die Darmplatte aus den Abkömmlingen der Makromeren, welche ihre ursprüngliche, körnige Beschaffenheit bewahren; nach unsern Beobachtungen ist dies nicht ganz richtig, denn ein Teil dieser Abkömmlinge verbindet sich mit dem hinteren Kreuzarme $D$, so daß nur einige derselben in die Zusammensetzung der Platte eingehen, welche somit, wie weiter unten gezeigt werdeu soll, einen Zuwachs seitens des vierten Quartetts erhält.

Zwischen der Darmplatte und dem Ectoderm liegen median die beiden hinteren Makromeren des Mesoderms und iber denselben gegen die Basis der Kopfblase zu ein aus ungleich großen Zellen gebildeter Strang, welcher gleichsam die Fortsetzung der Platte gegen das Ectoderm zu bilden scheint $(e d)$. Es ist dies die erste Anlage des Enddarmes. Bei Planorbis liegt genau an derselben Stelle eine von RABL ${ }^{1}$ als solider Strang oder Darmplattte * bezeichnete Zellgruppe (Fig. 5), nur sind hier die Makromeren des Mesoderms iber statt unter derselben eingezeichnet.

Wenu wir jetzt dem Blastoporus und Schlund unsre Aufmerksamkeit zuwenden, so bemerken wir, daß der erstere an diesen Stadium zu einer feinen Öffunng reduziert, der letztere kurz und aus kleinen Zellen zusammengesetzt ist, welche sich von den Eiweißzellen scharf abheben. Aus dieser allgemeinsten Orientierung in den Organisationsverbältnissen des soeben besprochenen Stadiums folgt, daß dessen Darmkanal bereits seine drei typischen Bestandteile mehr

1 Vgl.: Über den spedicle of invagination und das Ende der Furchung von Planorbis. Wien 1880. 
oder minder deutlich erkennen läßt. Am weitesten ist die Differenzierung des Mitteldarmes vorgeschritten, der bereits in voller Funktion begriffen ist und dessen Höhlung mit Eiweiß vollgefüllt ist. Der Vorderdarm wird erst durch ein kurzes Rohr repräsentiert, an dessen Eingang bereits eine Flimmerung zu bemerken ist. Der Hinterdarm ist aber nur durch eine kleine Zellgruppe $(e d)$ angedeutet, deren Bestimmung jetzt noch gar nicht klar ist, da sie sich erst viel später zu einem deutlichen Rohre differenziert.

Wir wollen nun die Darstellung der weiteren Differenzierung mit dem Vorderdarme und zwar zunächst mit dem Stomodäum beginnen. Letzteres entsteht genau an der Stelle des Blastoporus, der sich nie gänzlich schließt und in derjenigen Phase, wo die Ausbildung des bleibenden Mundes beginnt, unmittelbar hinter dem Velum liegt, von welchem es nur durch eine einzige Reihe kleiner, von $2 b^{221}$ herstammender Zellen ${ }^{1}$ abgegrenzt wird. An diese schlieBen sich seitwärts die Zellen des dritten Quartetts an. Die vordere Wandung des Blastoporus bilden die Zellen $2 b^{2221}, 2 b^{2222}$, die einzigen unter den sogenannten Stomatoblasten, welche ibre urspriungliche Lage unverändert bewahrt haben. Da sie auch fernerhin bis zur Ausbildung der Larve in derselben verbleiben und dabei nicht nur eine charakteristische histologische Beschaffenheit gewinnen, sondern auch Flimmern ausbilden, so dienen sie als vorzügliche Anhaltspunkte beim Studium der weiteren Differenzierung des Stomodäums und des Oesophagus. Die seitlich an dieselben anstoßenden Zellen gehören dem dritten Quartett an, es läßt sich aber ihre Descendenz nicht mehr genau feststellen. Nach hinten wird der Blastoporus von schmalen, wahrscheinlich ebenfalls dem dritten Quartett angehörenden Zellen begrenzt. $\mathrm{Zu}$ beiden Seiten desselben erheben sich hiigelartige, ectodermale Wiulste, die zum größten Teil aus den Descendenten von $2 a^{2211}, 2 a^{2212}$ und $2 c^{2211}, 2 c^{2212}$ und ihren nïchsten Nachbarn im zweiten Quartett bestehen. Sie werden vorn und hinten von kleinen, dem dritten Quartett entstammenden Zellen streifenartig umsäumt und in der Medianebene durch eine tiefe, ebenfalls aus schmalen Zellen des dritten Quartetts gebildete Furche voneinander getrennt (Fig. 75). Indem sie an den allernächsten Stadien rasch an Größe zunehmen, fließen sie schließlich in einen einzigen Ectodermwulst zusammen, welcher von dem Fußhöcker

1 Unter den Descendenten dieser Zellen spielt bei Thalassema (TORREY) $2 b^{2212}$ eine sehr wichtige Rolle als Oesophagoblast, bei Physa gehen sie gar nicht in die Bildung des Vorderdarmes ein. 
durch eine Furche deutlich abgegrenzt erscheint und den gemeinschaftlichen Ausgangspunkt fur die Bildung des Stomodäums, des Oesophagus und der Radulatasche bildet.

Bevor wir die Differenzierung dieser drei Bestandteile des Vorderdarmes näher ins Auge fassen, wollen wir vorerst einen Blick auf den primären Schlund werfen. Bei der Darstellung des Gastrulationsprozesses wurde iber die Endschicksale aller derjenigen kleinen Zellen, welche die Entodermplatte umsäumen, speziell berichtet und hervorgehoben, daß eine bedeutende Anzahl derselben mit ihr eingestuilpt und schließlich bei der Zusammenschniurung der Blastoporuslippen nach vorn und in die Tiefe verschoben wird. Man überzeugt sich nun an Schnitten durch entsprechende Stadien, daß diese Zellen mitsamt den nachrückenden Descendenten der vorderen Quadranten des dritten Quartetts " und b) hauptsächlich den primären Scblund konstituieren. Die meisten derselben lassen noch jetzt ihre Herkunft an ihren chromatinreichen Kernen erkennen, es ist aber unmöglich ihre Descendenz im einzelnen zu verfolgen. Dies wäre auch ganz zwecklos, nachdem es sich herausgestellt hat, daß ihre Endschicksale dieselben sind. Wir haben nämlich nach genauen Beobachtungen an einer ganzen Reihe von Schnittserien die feste Überzeugung gewonnen, daß keine von den Zellen, welche die Entodermplatte während ibrer Einstilpung umrahmen, an der Bildung des primären Entodermsackes wesentlich beteiligt ist. Denn es läßt sich einerseits zwischen denselben und den charakteristischen großen Eiweißzellen stets eine ganz scharfe Grenze ziehen Fig. 91, anderseits wurde niemals ihre direkte Lmwandlung in die letzteren beobachtet.

An bedeutend späteren Stadien, wann sich die kleinzellige Darmplatte rentralwärts bis zur Einmuindungsstelle des Oesophagus ausgedehnt hat, gehen ihre Elemente ohne deutliche Grenze in diejenigen des Oesuphagus üher, wie dies aus dem schnitte Fig. 95 $a, b$ leicht $\mathbf{z u}$ ersehen ist.

Es ist also leicht erklürlich, wenn Autoren, welche nur diese älteren Stadien beriicksichtigen, keine deutliche Grenze zwischen dem ectodermalen Oesophagrus und dem entodermalen Mitteldarm sehen ${ }^{1}$. Sie läßt sich tatsächlich, namentlich an der Ventralseite,

1 RabL "79 läßt es unentschieden. ob das Epithel des Oesophagus dem Ectoderm oder aber dem Entoderm entstamme. Nach MeIsexherMer ist bei Limax die dorsale Wand des (Jesophagus rein ectodermal. die ventrale nur zum Teil ectodermal und an den Seiten gehen die beiden Keimblätter ineinander über. 
histologisch kaum scharf ziehen, dürfte aber doch in physiologischer Hinsicht bestehen.

Wir haben auf die Erforschung der Endschicksale der kleinen Derivate des zweiten und dritten Quartetts deshalb ein großes Gewicht legen zu müssen geglaubt, weil jene nach der allgemein guiltigen Auffassung über ihre Beziehung zu den Keimblättern entscheiden.

Aus unsern Beobachtungen hat sich nun ergeben, daß sie in der Bildung des Oesophagus aufgehen, welchen wir als eine rein ectodermale Bildung betrachten; aus diesem Grunde wären sie somit als ectodermale Elemente aufzufassen. $\mathrm{Da}$ es sich aber aus den Angaben andrer Autoren ergibt, daß ein Teil des Oesophagus entodermale Elemente enthalten dürfte, so könnte man dieselben Elemente bei andern Formen auch als entodermale ansehen. Man könnte sie sogar bei Physa als solche betrachten, weil sie sich schließlich an der Einmündungsstelle des Oesophagus in den Entodermsack ansammeln und weil von dieser Stelle aus später eine Proliferation von Zellen stattfindet, die zur Vergrößerung des Mitteldarmes beitragen, welcher als eine rein entodermale Bildung gilt. Es stellt sich also heraus, daß die Endschicksale einzelner Blastomeren über ihre Beziehung zu den Keimblättern keinen sicheren Aufschluß zu geben vermögen, so lange über den Ursprung der einzelnen Organe widersprechende Ansichten herrschen.

Nach diesem Exkurs kehren wir zu den Ectodermwülsten zuriick, welche den Blastoporus von hinten und von den Seiten umgeben und von denen, wie bereits erwähnt, die Differenzierung des Oesophagus, des Stomodäums und der Radulatasche ansgeht. Man bemerkt unter denselben schon sehr frühzeitig eine starke Lage von Mesodermzellen, welche sich auch auf den primären Schlund bis zur Einmiundungsstelle desselben in den Eiweißsack erstreckt. Diese Zellen gehören ausschließlich dem sekundären Mesoderm an, welches die ganze Muskulatur des Vorderdarmes liefert. Der ganze Vorgang: der Differenzierung des letzteren wird gewöhnlich auf eine einfache Einstuilpung des Ectoderms zurückgeführt. Nach unsern Beobachtungen an Physa läßt sich weder der Ringwall des Stomodäums noch die Anlage der Radulatasche und die Bildung des Oesophagus durch einfache Einstülpungsvorgänge erklären. Es sind vielmehr ganz geregelte, lokale Wucherungsprozesse in der Umgebung des Blastoporus, welche zur Ausbildung des Stomodäums und des Oesophagus fuibren. Man findet nämlich bereits an Stadien mit be- 
ginnender Bildung des Mundtrichters in seinem ganzen Umkreis sehr zahlreiche Mitosen, deren Teilungsspindeln jeder Zeit die Richtung zeigen, in der die Wncherung des Ectoderms stattfindet.

Am raschesten wächst der Mundwall, sodann die ventrale und die seitlichen Wände des Schlundes, während die dorsale ganz stationär zu bleiben scheint. Hier erkennt man am Eingange die uns wohlbekannten Zellen $2 l^{2221}, 2 l^{2222}$, welche ihre ursprüngliche Lage nur insofern rerändern, als sich zwischen dieselben und das Velum neue Reihen von Ectodermzellen einschieben, durch welche sie immer tiefer herabgedrängt werden. Es konnte nicht sicher ermittelt werden ob jene charakteristischen Zellen sich an späteren Stadien teilen, soviel ist aber sicher, daß mit denselben die dorsale Reihe der Flimmerzellen' beginnt, welche später durch die ganze dorsale Seite des Desophagus zieht und deren Tätigkeit in der Einführung von Eiweiß in den Mitteldarm besteht. Das Stomodäum ist anfangs dreieckig, dann rundlich, an späteren Stadien quer oval.

Was die Radulatasche betrifft, so wird ihre erste Anlage von einzelnen Beobachtern verschieden dargestellt. Nach RABL wird sie bei Planorbis durch einen von der unteren Wand des Vorderdarmes aussehenden »kurzen, hohlen blind endigenden Fortsatz dargestellt, der sich nach unten und hinten richtet«. Bei Limar (Meisexhermer) besteht die erste Andeutung der Radulatasche in einer beträchtlichen Verdickung der hinteren Wand des Stomodäums, welche sich bald zu einer Einstïlpung verdickt, die unter Verengung ihres Lumens bedeutend nach innen wächst .

Auch Schnabel faßt die Radula (in einer speziellen Arbeit ${ }^{2}$ über dieselbe) als eine *anfangs weite Ausstulpung des ectodermalen Vorderdarmes* auf; bei den Pulmonaten sollen sich dann die Ränder von der Miindung allmählich aneinanderlegen, so daß das Lumen vollständig schwindet.

Aus diesen nur beispielsweise angefuhrten Angaben tuber den Ursprung der Radula geht hervor, daß sie allgemein als eine Ausstülpung der hinteren Wand des Stomodäums, bzw. des Vorderdarmes aufgefaßt wird. Mit dieser Darstellungsweise stimmen nun die Beobachtungen an Physa nicht ganz uiberein, bei welcher die erste Anlage der Radulatasche ganz unabhängig vom Stomodäum gebildet

1 Diese Reihe von Flimmerzellen entspricht dem ösophagealen Wimperwulste der Stylommatophoren.

2 Über die Embryonalentw. der Radula bei den Mollusken. II. Die Entw. der Radula bei den Gasteropoden. Diese Zeitschrift. LXXVIII. Bd. 1903. 
wird. Es erscheinen nämlich in dem oben beschriebenen Epithelwulst hinter der Mundöffnung zwei kreisförmige, scharf umschriebene, bilateral liegende Zellmassen, in denen sich mehrere mitotische Zellen befinden, die durch einen median verlaufenden, ebenfalls fast aus lauter mitotischen Zellen bestehenden Zellstreifen voneinander getrennt sind (Fig. 98b). Die ganze Anlage wird von einem besonderen Epithelwall umgeben, welcher mit demjenigen des Stomodäums eine Achterfigur bildet (Fig. 98b). Von den beiden kreisförmigen Zellmassen aus wird die Einstülpung bilateral eingeleitet und, wie wir glauben, tubernehmen dabei die unter denselben liegenden Mesodermzellen die leitende Rolle. Indem die beiderseitige Einstülpung fortschreitet, entstehen zwei nach außen divergierende Blindsäcke, welche durch eine mediane Leiste voneinander getrennt werden. Gleichzeitig mit dem Wachstum dieser Säcke vertieft sich die ganze Anlage, die Leiste wird in dem Maße, als sich der die ganze Anlage umgebende Wall höher erhebt, niedriger und es entsteht hinter dem Stomodäum eine zweite napffürmige Vertiefung, in deren Grunde zwei rundliche Öffnungen sich befinden. Diese Verhältnisse sind am besten aus Fig. 98a zu ersehen. Die Vereinigung dieser beiden, hintereinander liegenden saugnapfähnlichen Vertiefungen in eine einzige erfolgt erst an späteren Stadien, nachdem die Anlage der Radulatasche bedeutend nach unten und hinten ausgewachsen ist. Wie aus der Vergleichung einer kontinuierlichen Reihe von naheliegenden Stadien entnommen werden konnte, erfolgt die völlige Einstilpung der Radulaanlage in die Mundbucht erst an einem Stadium, an dem bereits die Larve stark im Längsdurchmesser gewachsen ist, wobei sich das ursprüngliche Stomodäum ganz bedeutend erweitert. Die Ausmündung der Radulatasche, die inzwischen sehr breit und flach geworden ist, kommt erst jetzt in die untere Wand des Stomodäums zu liegen. Demnach wäre der definitive Mund eine verhältnismäßig späte Bildung.

Die weitere Differenzierung der Radulaanlage wurde nicht speziell verfolgt, weil dieses Organ bereits von mehreren Autoren entwicklungsgesschichtlich untersucht und neulich von SchNabeL (l. c.) vergleichend behandelt wurde.

Die Anlage der Speicheldrüsen fällt bei Physa in eine sehr späte Periode nach Ausbildung der Schneckengestalt, und wurde deshalb nicht verfolgt.

Nachdem wir nun die Differenzierung des ectodermalen Vorderdarmes kennen gelernt haben, wenden wir uns zum Mitteldarme, der nach unsrer Auffassung rein entodermal ist. Die Differenzierung der 
Entodermzellen in die Eiweißzellen beginnt, wie bereits oben erwähnt wurde, unmittelbar nach ihrer Einstullpung; es wurde anch daselbst hervorgehoben, dal der Entodermsack mittels langer, plasmatischer Fortsätze mit dem Ectoderm verbunden ist (Fig. 81) und daß dessen hintere Wand aus kleineren Zellen besteht, welche die sog. Darmplatte bilden. Die weitere Umbildung des primären Entodermsackes beruht in einer sehr raschen Größenzunahme der Eiweißzellen und insbesondere in dem Wachstum der kleinzelligen hinteren Wand.

Der histologische Unterschied zwischen den Komponenten der Wandungen dieses Teiles des Darmkanals tritt erst auf späteren Stadien deutlicher hervor, wir wollen ihn aber weiter unten im $\mathrm{Zu}$ sammenhange mit der Differenzierung des Enddarmes näher betrachten, zu deren Darstellung wir jetzt übergehen.

Die Anlage des Enddarmes läßt sich erst an solchen Stadien ganz deutlich als solche erkennen, bei denen bereits der Mitteldarm bedeutende Dimensionen erreicht hat und die Schalendruise ziemlich tief eingestülpt ist. In Fig. 95a, 96, welche zwei sagittale Schnitte von einem solchen Stadium wiedergeben, bemerkt man einen aus dicht gedrängten größeren und kleineren chromatinreichen Zellen zusammengesetzten soliden Strang $e d$, welcher von der unteren Wand des Mitteldarmes ausgeht und schräg nach hinten und unten, dicht an der Schalendrüse gegen das Ectoderm zieht und sich mit demselbeu in der Medianlinie verbindet. Sowohl an Schnitten als auch an Totalpräparaten überzengt man sich, daß das distale Ende dieses Stranges mit zwei großen, stark vacuolisierten Zellen verlötet ist (Fig. 93a, an), welche sich durch alle nachfolgenden Stadien bis zur vollkommen ausgebildeten Schneckengestalt an derselben Stelle nachweisen lassen. An Sublimatpräparaten färbt sich ihr Plasma und insbesondere der Inhalt ihrer Vacuolen mit Fuchsin ebenso rot, wie das Eiweiß in den Eiweißzellen. Sie unterscheiden sich also schon in tinktioneller Beziehung von angrenzenden Epithelzellen ganz deutlich, aber außerdem auch durch ihre bedeutende Größe. Es unterliegt keinem Zweifel, daß diese zwei Zellen den bei mehreren andern Gasteropoden beobachteten *Analzellen * homolog sind, weshalb wir fur dieselben diese Bezeichnung anwenden. Sie lassen sich schon sehr frühzeitig, bevor noch der Darmstrang deutlich hervortritt, an dessen distalen Ende erkennen ${ }^{1}$ (Fig. $101 \mathrm{ed}$ ).

${ }_{1}$ RABL macht bei Planorbis keine Erwähnung von derartigen Zellen, desgleichen Metrenhemer bei Limax. Fou hat sie auch bei keiner Form. beobachtet. Dafür beschreibt CaSTeEr bei Fiona zwei Zellen von demselben Habitus (Fig. 87) und vergleicht sie mit den Analzellen andrer Mollusken. 
Betrachtet man die oben beschriebene Darmanlage an einem unversehrten Keim gleichen Alters von der Banchseite, so bemerkt man, daß ihr distales, mit dem Ectoderm fest verlötetes Ende genau in der Medianlinie liegt und rechts und links von demselben sieht man die beiden Mesodermplatten (Fig. 101), welche aus der Teilung: von $M_{1} M_{2}$ hervorgegangen sind. Unmittelbar mit dem Darmende verbinden sich mehrere Mesodermzellen, die insgesamt dem sekundären Mesoderm anzugehören scheinen 1 .

Das proximale Ende der Darmanlage steckt zapfenartig tief zwischen den blasigen Eiweißzellen und wird von denselben ganz verdeckt, so daß es nur in ganz tadellosen Präparaten und in schiefer Lage von der Bauchseite aus gesehen werden kann. Diejenige Stelle des Mitteldarmes, an die sich der Enddarm ansetzt, besteht aus niedrigen Entodermzellen, welche denjenigen sehr ähnlich sind, aus denen der letztere zusammengesetzt ist.

An Stadien, denen unsre Figuren 93-97 entnommen sind, läßt sich weder an Schnitten noch an Totalpräparaten die Beziehung des Enddarmes zum Mitteldarme ermitteln. Um also seine Genese richtig erfassen zu können, müssen wir auf ein Übergangsstadium von der Gastrula zur sog. Trochophora zuriickgehen. Uns interessiert an einem solchen Stadium vor allem diejenige Gegend, welche von den beiden Urmesodermzellen und den von ihnen erzeugten Mikromeren eingenommen ist. Dieselbe ist zwar unmittelbar nach Ausbildung der Kopfblase etwas abgeflacht, aber von der Schalendrüse ist noch gar keine Spur vorhanden. Die beiden Urmesodermzellen, welche noch kurz vorher in der Medianlinie dicht nebeneinander lagen, sind jetzt weit seitwärts auseinander gewichen. Eine derselben befindet sich gerade in Mitose (Fig. 84); es wird nämlich jetzt eine Teilung eingeleitet, welche zur Erzeugung der beiden hinteren Mesodermstreifen führt.

Von den beiden medianen Mikromeren, welche seit ihrem Entstehen bis zu dieser Phase sich ganz passiv verhalten haben, findet man an dem einen oder dem andern Präparate bald nur eine, bald beide in Teilung begriffen (Fig. 84, 87). Die Achse ihrer Teilspindeln ist mit der Medianebene parallel, ihre Teilprodukte kommen zwischen die Kuppe des Entoderms und das Ectoderm zu liegen. Aus den zitierten Figuren, welche uns diese Lage am besten veranschaulichen,

1 Bei Planorbis (Rabl) soll sich ein Afterhöcker ausbilden, bei Physa ist das Ectoderm an Stelle des künftigen Anus gar nicht erhoben.

Zeitschrift $\mathrm{f}$, wissensch. Zoologie. LXXXII, Bd. 
ist zugleich zu ersehen, daß eine von den Tochterzellen sich zwischen die Entodermzellen gleichsam einzuzwängen strebt. Zu diesen Descendenten von $m_{1} m_{1}$ gesellen sich sogleich die nächstliegenden Mikromeren des Mesoderms und bilden zusammen eine Zellgruppe, welche sich zwischen der hinteren Entodermwand und dem Ectoderm ausspannt (Fig. 91, 92). Verfolgt man nun die weiteren Schicksale dieser Gruppe an einer ununterbrochenen Reihe von Stadien bis zu demjenigen, an welchem die Anlage des Darmes bereits ganz deutlich hervortritt (Fig. 96), so überzeugt man sich, daß sie sich direkt in die letztere umbildet. Sie ist an dem nächstjüngeren Stadium bereits aus etwa 12-15 Zellen zusammengesetzt (Fig. 92c) und mit dem schmäleren Ende zwischen die Entodermzellen eingelassen, während das breitere sich an das Ectoderm ansetzt (Fig. 92c, 94c). Man erkennt zwischen den Komponenten dieser Gruppe ganz deutlich die seitlichen Mikromeren an ihren chromatinreichen Kernen und ihrer geringen Größe; sie liegen mehr nach auswärts von den Descendenten des ersten Mikromerenpaares, welche den Hauptbestandteil der Gruppe bilden. Die Grenzen ihrer einzelnen Komponenten sind ganz verwischt, da sie noch sehr leicht verschiebljar zu sein scheinen (Fig. 92c).

Diejenige Stelle des Entoderms, mit der das schmälere Ende der erwähnten Gruppe zusammenhängt, besteht aus niedrigen Zellen, welche die uns bereits bekannte kleinzellige "Darmplatte bilden (Fig. 96).

Die nächste Differenzierung findet in derjenigen Phase statt, wo das Schalendrüsenfeld einzusinken beginnt. Die einzelnen Elemente der Gruppe ordnen sich jetzt in Längsreihen und bilden einen soliden Zellstrang, welcher bereits dieselbe Beschaffenheit zeigt, wie der oben beschriebene (Fig. 96).

An gelungenen Präparaten unterscheiden sich die ihn zusammensetzenden Elemente nach Hämatoxylinfärbung ganz deutlich von den gelblichen Entodermzellen durch ihren graublauen Ton und das dunkel gefärbte Chromatin ihrer Kerne. Das distale Ende der Darmanlage verbindet sich an diesem Stadium mit den hinteren Mesodermstreifen, welche nach rechts und links in zwei Reihen gegen das vordere Ende des Embryos hinauslaufen (Fig. $94 b-d$ ).

Nachdem wir nun die Genese dieses Stranges, welcher sich später zum ganzen Darm differenziert, kennen gelernt haben, dürften wohl über seine Herkunft von den Descendenten des primären Mesoderms, insbesondere vom ersten Mikromerenpaare $m_{1} m_{1}$, keine Zweifel 
obwalten. Die letzteren repräsentieren dieselben Elemente, welche bei andern Gasteropoden seit ConkLIN als »Enteroblasten « bezeichnet zu werden pflegen. Es gesellen sich aber bei Physa zu denselben noch einige von den nächstliegenden Schwesterzellen, deren Zahl sich nicht genan bestimmen läßt, welche also ebenfalls als Enteroblasten anzusprechen wären. Bei der weiteren Differenzierung dieser Anlage handelt es sich nunmehr um Wachstumsvorgänge und um Ausbildung eines Lumens, welche aber erst bedeutend später erfolgt.

Einen ähnlichen Strang beschreibt RABL bei Planorbis, faßt ihn aber als eine direkte Ausstiulpung der hinteren Archenteronwand auf und seine Fig. $23 A-26 A$ scheinen sehr deutlich dafür $\mathrm{zu}$ sprechen, weil in allen das Lumen des Mitteldarmes durch einen weiten Kanal direkt in den ausgestiulpten Strang übergeht. Bei Physa sind, wie bereits eingangs hervorgehoben wurde, derartige Bilder an Stadien gleichen Alters durchaus nicht zu finden, so daß wir hier eine reguläre Ausstiilpung der hinteren Archenteronwand a priori unbedingt ausgeschlossen haben, im Gegenteil ist der Strang von seinem ersten Erscheinen an, in seiner ganzen Ausdehnung solid und steht sogar nach Ausbildung des Lumens mit der Höhlung des Mitteldarmes in keiner Verbindung. Wollte man ihn aber trotzdem von der Archenteronwand direkt ableiten, so müßte man ihn eher als einen soliden Auswuchs derselben betrachten, wofür einige Bilder bei älteren Larven zu sprechen scheinen, bei denen man an der unteren Mitteldarmwand rechts einen kurzen, blindsackartigen Auswuchs findet, der direkt in die Enddarmanlage überzugehen scheint. Dieses Bild ist aber sehr verfuhrerisch und hat wahrscheinlich RABL dazu verleitet, den Enddarm in seiner ersten Anlage als eine einfache Ausstiilpung des Entodermsackes aufzufassen. Diese blinde Aussackung des Mitteldarmes hat jedoch mit der Bildung des Enddarmes nichts zu tun, da sie erst später entsteht, nachdem der Strang bereits deutlich ausgebildet ist. Er könnte somit nur von einer lokalen Wucherung des Entoderms seinen Ursprung nehmen, welche sich aber an keinem meiner Präparate unzweifelhaft feststellen ließ. Es wurden zwar an der Verlötungsstelle des Enddarmes mit der Wand des Mitteldarmes öfters Mitosen gesehen, man konnte jedoch bei näherer Prüfung sowohl der Lage der Teilspindeln als auch der Teilprodukte feststellen, daß die Teilung im Entoderm bloß die Vergrößerung des Umfanges der hinteren Mitteldarmwandung zum Zweeke hat. Übrigens treten diese Teilungren erst dann in größerer Anzahl auf, wenn die strangförmige Anlage des Darmes bereits merklich groß geworden ist. 
Es mag zum Schluß noch die Möglichkeit der Ableitung des Enddarmes bei Physa vom Ectoderm in Erwägung gezogen werden, da auch für eine solche einige unsrer Präparate $z u$ sprechen schienen. Man bemerkt nämlich bei ganz jungen Larven an der späteren Verbindungsstelle des Enddarmes mit dem Ectoderm eine leichte Einsenkung (Fig. 92c), von welcher einzelne Ectodermzellen ins Innere des Keimes vordringen. Das Bild macht den Lindruck, als wenn es sich um eine leichte Einstiilpung, verbunden mit der Einwucherung des Ectoderms, handeln würde. Es ist aber weder das eine noch das andre der Fall. Die einzeln in die Furchungshöhle vordringenden Zellen verbinden sich nämlich nur zeitweise mit dem Entoderm, dagegen bleiben bloß die "Analzellen mit der Anlage des Darmes dauernd verbunden.

Eine Einstülpung mit nachheriger Abtrennung des Ectodermsackes, wie sie nach MeIsenhener bei Limax und Ireissensia stattfindet, kommt bei Physa bestimmt nicht vor.

Aus den obigen Erörterungen ist zu ersehen, daß wir beim Studium der Genese des Enddarmes alle Möglichkeiten der Ableitung desselben erwogen haben. Es blieb aber nur eine, durch direkte Beobachtung begründete, d. i. die Ableitung ron den Mikromeren des Mesoderms, iibrig. Unentschieden dürfte nur der Umstand bleiben, ob zu der mesodermalen Anlage nicht etwa einzelne Elemente durch Auswanderung aus dem Entodermsacke hinzukommen. Die Entscheidung dieser Frage ist fast unmöglich, denn die Anlage des Enddarmes verbindet sich so innig mit der Entodermwand, daß es kaum möglich wäre, die Auswanderung einzelner Zellen aus der letzteren in die Anlage des Enddarmes durch direkte Beobachtung festzustellen. An Stadien mit maximal ausgebildeter Schalendriise findet man den Enddarm mit der sog. kleinzelligen Partie des Mitteldarmes bereits so innig verlötet, daß eine Grenze zwischen beiden sich absolut nicht ziehen läßt.

Die drei Hauptbestandteile des Darmkanals, deren erste Sonderung wir im Vorhergehenden bereits kennen gelernt haben, erfahren nun bei ihrer Weiterentwicklung mehr oder minder tiefgreifende Umwandlungen, bis sie ihre definitive Ausgestaltung erhalten.

Verhältnismäßig sind die Lmwandlungen am Vorderda rme selır unbedeutend, denn derselbe zeigt nach Ausbildung der Aulage der Radulatasche und ibrer Einstillpung in die Nundhöhle nur geringe Abweichung von derjenigen Form, die er schon an jungen Larvenstadien gewomnen hat und die uns die Figuren $107 a-c$ in drei ver- 
schiedenen Ansichten veranschaulichen. $\mathrm{Da}$ sie auch an bedentend fortgeschrittenen Larvenstadien im Grunde dieselbe bleibt, ist aus der Fig. 110 ersichtlich. Es ändert sich nur der Querdurchmesser und die Dicke der Wandungen der Mundhöhle, so daß sie sich an ganz späten Stadien zu einem weiten, dickwandigen Trichter umgestaltet.

Der Oesophagus behält ziemlich lange seine kurz gedrungene Gestalt, erst bei ausschlüpfenden Tieren wächst er in einen langen Schlauch aus (Fig. 111). Seine $\bullet$ Beziehung zum Mitteldarm läßt sich nur im Zusammenhange mit der Entwicklung des letateren verstehen, weshalb wir diesbezüglich auf den nächstfolgenden Abschnitt verweisen müssen.

In histologischer Beziehung bemerkt man erhebliche Differenzen zwischen den Zellen, welche die Wandungen des Oesophagus zusammensetzen. Im allgemeinen sind dieselben im dorsalen Teile höher und dunkler, als im ventralen, wo sie niedriger nnd teilweise vacuolisiert sind. Im ersteren trägt eine mittlere Reihe lange Flimmern, die besonders am Eingange auffallend stark sind, kürzere Flimmerhaare sind auch an andern Zellen im ganzen Umkreis zu bemerken, aber erst an späteren Stadien.

Die auffallendste Umgestaltung erleidet der primäre Mitteldarm, aus dem sich im Laufe der Entwicklung der Magen, die Leber und ein Teil des Darmes herausdifferenziert, die also rein entodermal sind. Die Ausbildung dieser Organe erfolgt nicht nur in steter Abhängigkeit voneinander, sondern wird auch einerseits von dem immer tiefer eindringenden Oesophagus, anderseits von der in entgegengesetzter Richtung auswachsenden Schalendrüse wesentlich modifiziert.

Die ersten Stufen der Ausbildung des Mitteldarmes haben wir bereits kennen gelernt, sie können an den Figuren 91, $92 a, b$ in Erinnerung gebracht werden; man bemerkt, daß.die Wandungen des Entodermsackes am Stadium Fig. 92 hauptsächlich aus den charakteristischen Eiweißzellen zusammengesetzt sind, mit Ausnahme der hinteren Partie, welche aus zylindrischem oder kubischem Epithel besteht und die oben erwähnte kleinzellige Darmplatte bildet, mit der die Anlage des Enddarmes innig zusammenhängt. Wir künnen uns über ihren Umfang und ihr Verhältnis zum ganzen Entodermsacke aus den Figuren $92 c, 93 c, 94 b$, wo man sie von der Flïche und aus Fig. 96, wo man sie im Sagittalschnitt sieht, leicht orientieren. Man kann sie als den eigentlichen Bildungsherd für sämtliche aus dem Entodermsacke hervorgehenden Organe ansehen, denu sein übriger, aus den Eiweißzellen bestehender Teil verhält sich fast passiv, 
indem die letzteren sich zwar mächtig auszudehnen rermïgen, aber nach ibjereinstimmenden Beobachtungen aller Autoren von einer bestimmten Phase an nicht mehr teilungsfühig sind.

Man bemerkt an der Darmplatte die ersten Wachstumsrorgänge von dem Augenblicke an, als die Anlage des Enddarmes mit ihr zu verscbmelzen beginnt. Eine fast rapide Vergrößerung ihrer Dimensionen wird aber erst ron dem Zeitpunkte an bemerklbar, wo das Schalendrüsenfeld sich einzustulpen byeginnt. Diese Vergrößerung ist aber keineswegs das ausschließliche Resultat der Teilung der wenigen Zellen, aus denen die Darmplatte ursprïnglich bestand, sondern es werden auch, nach unsrer Beobachtung, die nächstliegenden Eiweißzellen und die kleineren, dorsalen Komponenten des Entoderms einbezogen, die unter dem Einflusse des einsinkenden Ectoderms ihre Vacuolen einbüßen und sich schließlich teilen, möglich, daß sie vorber ihre Nährstoffe an die Anlage der Scbalendriise abgeben, in der gleichzeitig ehenfalls sehr lebhafte Teilungen stattfinden. Ohne Feststellung dieses Verhaltens der Eiweißzellen könnte man nicht verstehen, auf welche Art die kleinzellige Partie so rasch an Umfang zunimmt, denn man bemerkt in ihr nur seltene Mitosen.

Die ersten Wachstumsvorgänge in dieser Partie sind bereits ron RABL bei Planortis beobachtet rorden. Derselbe unterscheidet an ihr an einem Stadium, das etwa unserm in Fig. 99 dargestellten entsprechen dürfte, einen dorsalen, ventralen und hinteren Abschnitt. In diesen drei Richtungen erfolgt auch bei Physa ihr Wachstum; wir bemerken an einem viel jüngeren Stadium Fig. 95 $a, b$ die dorsale und ventrale Ausdehnung in sagittalen Längssschnitten und überzeugen uns deutlich, daß der ventrale Teil offenbar rascher wächst, sobald er bereits die Einmündung des Oesophagus erreicht hat, wäbrend zwischen der letzteren und dem dorsalen Streifen nuch eine Liicke besteht, die ron Eiweißzellen ausgefültt ist. An entsprechend gefuihrten Querschnitten uilserzeugt man sich, daß der ventrale Streifen zugleich breiter ist.

Infolge der gleichzeitig rasch fortschreitenden Einstulpung des Schalendrüsenfeldes ändert sich bald die urspringlich ovale Gestalt des Eiweißsackes, indem er einerseits immer tiefer in der Richtung der Längsachse eingedrückt, anderseits zugleich auch im Meridian eingeschnürt wird. Daraus resultiert die Teilung der Darmböhle in eine rechte und linke Hälfte, welche, wie der Querschnitt Fig. $93(a)$ eines jungen Stadiums zeigt, schon fribizeitig deutlich ausqeprägt erscheint und zwar sogar an der Eimmindungsstelle des Oesophagus, zu der die kleinzellige Partie noch nicht vorgedrungen ist. 
Wir entnehmen sowohl aus der zitierten Figur, wie aus Fig. 97, daß dabei der ganze Entodermsack eine leichte Drehung um seine Längsachse, nach links in der Figur und in der Wirklichkeit nach rechts, erfahren hat.

Die Ursache dieser Drehung liegt in den Wachstumsbedingungen des Keimes, die allem Anscheine nach bereits in der Eizelle gegeben sind. Sie wird unmittelbar durch die asymmetrische Entwicklung der beiden Körperhälften veranlaßt, auf welche wir bereits bei der Gastrulation hingewiesen haben. Als weitere Folge dieser Wachstumsbedingungen ist ferner die stärkere Entwicklung der rechten Seite der Darmplatte anzusehen, welche bereits am ganz jungen Trochophorastadium sich bemerkbar macht. Man überzeugt sich davon am besten an einem parallel zur Darmplatte gefuhrten Schnitte Fig. 93b, an dem rechts ein Streifeu kleiner Zellen zu sehen ist, während ein solcher links weder an diesem noch an den nächsten Schnitten vorkommt.

Als ein weiterer Beweis der ungleichmäßigen Entwicklung der Mitteldarmwandungen ist ferner die Tatsache zu betrachten, daß der rechte Rand des dorsalen und ventralen Abschnittes der kleinzelligen Platte zuerst verschmilzt, während der linke zu gleicher Zeit durch eine breite Bricke von Eiweißzellen voneinander abgetrennt wird.

Diese ungleichmäßige Entwicklung hat RABL in derselben Weise bei Planorbis beobachtet und an Querschnitten auf Tafel XXXVI und XXXVII erläutert, weshalb wir es nicht für nötig halten, unsre diesbeziiglichen Abbildungen beizufügen.

Es mag aber ergänzend hervorgehoben werden, daß eben an der rechten Seite, nach erfolgter Verschmelzung der Ränder, eine lokale Zellwucherung, genau oberhalb der Kuppe der Schalendrüse stattfindet, welche schließlich zur Ausbildung einer leichten Ausbuchtung der rechtsseitigen Wandung (Fig. 100), sodann zur Ausbildung eines ziemlich tiefen Divertikels (Fig. 103) führt, der nachher ventralwärts auswächst. Da nun mit diesem Divertikel der Darmstrang seitlich innig zusammenhängt, so ist es leicht verständlich, daß RABL, durch dieses Bild getäuscht, den Enddarm aus einer unmittelbaren Ausstiilpung der hinteren Mitteldarmwand hervorgehen läßt. Wir haben aber oben gesehen, daß bei Physa der solide Strang, welcher die erste Anlage des Darmes bildet, bereits an einem solchen Stadium ganz deutlich ausgebildet ist, an dem die Darmplatte noch einen ganz geringen Umfang hat (Fig. $93 b$ und 97). Dies ist, wie weiter 
unten gezeigt werden soll, höchst wahrscheinlich auch bei Planorlis der Fall.

Das Lumen des Divertikels ist, wie Fig. 103 zeigt, ziemlich weit, es verengt sich etwas nach links gegen die Ansatzfläche des Enddarmes, geht aber in denselben nicht tiber, weil sein Lumen sich erst spüiter und zwar zuerst am distalen Ende ausbildet. Die Kommunikation zwischen dem Mittel- und Enddarm läßt sich auch dann nicht feststellen, wenn sich das Lumen des letzteren auf seine ganze Länge erstreckt.

Während der Ausbildung des rechten Divertikels wächst auch der dorsale und ventrale Streifen in die Breite und Länge, der ganze Mitteldarm gestaltet sich zu einem geräumigen Sack, uber dessen wechselnde Konfigurationen uns die Figuren $107 a, b, c, 108$ und 109 den besten Aufschluß geben. Man ersieht zugleich aus denselben, daß der kleinzellige Teil der Mitteldarmwandungen sich sehr rasch auf Kosten der Eiweißzellen ausgebreitet hat, welche nur noch die Seitenteile der Darmhöhle unmittelbar begreuzen. Die letztere hat inzwischen einen sehr bedeutenden L'mfang gewonnen und man findet sie in der Regel ganz mit Eiweiß erfillt, welches nach Fixierung der Larve einen ganz getreuen $A b$ gu $B$ aller Teile der Mitteldarmhöhlungen liefert. An diesem Modell gewinnt man wohl am besten die Überzeugung, daß der erwähnte Dirertikel blind geschlossen ist und daß der Enddarm nur seitlich mit demselben rerwächst, ferner daß der Mitteldarm im Laufe der weiteren Entwicklung noch auffallendere Drehungen erfahren hat, als dies anfangs, bei der Teilung seiner Höblung in eine rechte und linke Hälfte, der Fall war.

Wir wollen gleich hervorheben, daß die beiden bloß ron Eiweißzellen begrenzten Höhlungen die Anlage der Leber bilden, während der rechtsseitige kleinzellige Dirertikel diejenige des Magens repräsentiert. Mit diesem Divertikel steht das Lumen des Oesophagus in direkter Verbindung, dessen rechtsseitige Wandung ebenfalls direkt in die Magenanlage übergeht.

Die weitere Umbildung der parigien Anlage der Leber konnte nur bis zur Ausbildung der Schnecke verfolgt werden, wo die Ausmuindungsstelle wie bei andern Gasteropoden, noch immer doppelt ist (Fig. 111.

Über die ultimäre L'mwandlung der Eiweifzellen in Leberzellen herrscht noch eine große Meinungsverschiedenheit. Sie erfolgt erst nach dem Ausschlüpfen der Schnecke und wurde nicht speziell rerfolgt. Wir konnten aber doch an Schnitten durch ein reifes Staldium die Überzengung gewinnen, daß die Eiweißzellen doch nach gewissen Lmbildungen in die Zusammensetzung der fertigen Leber 
eingehen. Aber man bemerkt an ihren Basen recht kleine Zellen, die allem Anschein nach nicht aus der Teilung ihrer eignen Kerne hervorgegangen sind, sondern von der kleinzelligen Partie der Mitteldarmwand herrühren, die schon an mittleren Stadien sich unter die Eiweißzellen schiebt und wahrscheinlich auch die Leberkanäle austapeziert.

Was nun die weiteren Umbildungen des Darmkanals betrifft, so bestehen sie hauptsiichlich in dem Wachstum der erwähnten Anlagen und ihrer Lageänderung, welche durch die Torsion der Larve und Ausbildung der Atemhöhle verursacht wird.

Über die Differenzierung des Enddarmes ist nicht viel zu sagen. Er verbindet sich schon frühzeitig, wahrscheinlich durch Vermittlung des sekundären Mesoderms mit breiter Basis mit dem ventralen Teile des Mitteldarmes und wächst unabhängig rom letzteren zu einem langen Rohre aus, welches von seiner ursprünglichen medianen Lage zunächst nach rechts rückt, wobei es sich nach vorn bogig krümmt und sein blindes Ende nach links wendet.

Am Stadium, wo die Schalendriise sich ganz abgeflacht hat, entsteht an der Basis des Enddarmes eine kleine birnförmige Anschwellung, die wir als Anlage des Dünndarmes betrachten. Der Enddarm hat inzwischen bedeutend an Lage zugenommen und beschreibt jetzt einen Bogen: ron rechts kommend wendet er sich nach rorn und links und verläuft längs des aufgewulsteten Randes der Schalendrüse. Diese Richtung wird auch später beibehalten und wir sehen in Figur 120, daß der Enddarm von der Riickenseite und rechts sich nach links wendet, parallel mit den Körperwänden verläuft, um in der Atemhöhle auszumünden.

Die Schlingenbildung erfolgt erst nach dem Ausschlüpfen der Larve und wurde nicht näher beobachtet. In histologischer Beziehung: gehen am Enddarm seit seiner ersten Anlage nur sehr unbedeutende Veränderungen vor. Er besteht anfänglich aus Cylinderzellen, die sich an späteren Stadien sehr stark vermehren und ein Wachsen des Darmes in der Längsachse bewirken. Ein Lumen bildet sich, wie bereits erwähnt, erst ziemlich spät, und zwar zunächst am distalen Ende aus. Bis zur Ausbildung der Schnecke kommt der After nicht zum Durchbruch, sondern es bleibt das Lumen des Enddarmes durch die stark vacuolisierten Analzellen nach außen abgeschlossen.

Nachdem wir nun die Entwicklung des Darmtractus kennen gelernt haben, möchten wir noch unsre Bcobachtungen über die $\mathrm{Ab}$ leitung des Enddarmes mit einigen fremden Angaben vergleichen. 
Was zunächst Planorbis (RABL) betrifft, bei dem der Enddarm direkt aus einer Ausstiilpung der hinteren Archenteronwand hervorgehen soll, haben wir bereits oben betont, daß seine erste Anlage auffallend mit derjenigen bei Physa ubereinstimmt. Man muß aber zum Vergleich nicht die Figuren der Hauptarbeit RABLs, sondern diejenigen seiner oben (S. 666) zitierten Abhandlung: "Über den pedicle" usw. zum Vergleich heranziehen, namentlich die Figuren 9 und 10. In denselben wird ein solider Strang (i) abgebildet, der aus körnchenreichen Zellen besteht und von der Archenteronwand ausgeht, um sich an die Ectodermwand anzuheften. Der Verfasser betont nachdrücklich, daß dieser Strang nicht etwa durch Einstilpung des Ectoderms entsteht, sondern eigentlich die Fortset\%ung der hinteren Archenteronwand bildet. Von dieser soll später ein kurzes Divertikel in den soliden Strang eindringen, ohne daß es die Haut erreicht und es soll dasselbe nach RABL die eigentlicue Anlage des Enddarmes bilden. Wir erfahren freilich nicht, auf welche Weise das Divertikel in den soliden Strang eindringt und welche Rolle der letztere bei der Bildung des Enddarmes spielt. Nichtsdestoweniger gibt uns RaBL. iiber die Genese des soliden Stranges selbst einen näheren Aufschluß. Es scheint aber keinem Zweifel zu unterliegen, daß der letztere noch vor der Bildung des Divertikels entsteht und in :ihnlicher Weise von den Mikromeren des Mesoderms gebildet wird wie bei Phy.sa. Fitr diese Ansicht spricht einerseits der Umstand, daß die Entwicklung des ganzen Darmkanals bei beiden Formen auffallend ähnlich verläuft, anderseits die Differenzierung des Enddarmes bei Planorbis, welche, wie wir insbesondere aus den Figuren 4-7 Taf. XXXVI und Fig. 14 Taf. XXXVII entnehmen, ganz genau mit derjenigen bei Physa ubereinzustimmen scheint.

Was ferner den spedicle of invagination bei Limnaeus betrifft. welchen RAY LANKESTER als eine Ectodermeinstulpung betrachtet, und Rabl mit dem soliden Strang oder Platte bei Planorbis homologisiert. so diirfte derselbe der Anlage des Enddarmes bei Plyysa entsprechen 1.

Ähnliche Bilder wie bei Plyysa und Planortis finden wir an früheren Entwicklungsstadien des Darmkanals bei Lmbrella /HEYMoss). Man bemerkt nämlich in Fig. 29 und 30 bei Hexsoss genan in der Medianlinie und am Hinterende der Schalendrise vier bis sechs kleine Mesodermzellen zwischen den auseinandergewichenen Makronieren des Mesoderms, welche nach Coxkuix den Enteroblasten

1 Nach Vergleichung entsprechender Starlien ron Limnacus finde ich diese Annahme sehr wahrscheinlich. 
bei Crepidula entsprechen. In dieser Zellengruppe sind nach HeYMoNs die zuerst entstandenen Mikromeren $(\mathrm{mm})$ enthalten, sie setzt sich ebenso an das Ectoderm und zwar an zwei Analzellen an, wie bei Physa. Es sollen sich aber ihre Komponenten später auflösen, um das Mesenchym des Enddarmes zu bilden, während er selbst von den Derivaten von $C^{\prime \prime}$ und $D^{\prime \prime}$ den Ursprung nehmen soll. Die erstere Angabe stützt sich aber mehr auf Vermutung als auf direkte Beobachtung, kann somit keinen Gegenbeweis gegen unsre Annahme bieten, daß die besagte Zellgruppe die Anlage des Enddarmes vorstellt.

Wenn die Beteiligung des primären Mesoderms an der Bildung des Enddarmes bei den soeben besprochenen Formen nur als höchst wahrscheinlich angenommen werden darf, ist sie bei mehreren andern Formen als sicher nachgewiesen zu betrachten. Zu diesen gehören unter den Mollusken: Crepidula (Conklin), Aplysia (Carazzi), Fiona (CASTEEL), Physa fontinalis et hypnorum (WIERze ISki); unter den Würmern: Nereis (Wilson), Podarke (Treadwell), Thalassema (Torrey). Bei Crepidula beteiligen sich vier Derivate des Mesoderms, »die Enteroblasten "ConkLins, an der Bildung der Archenteronwand selbst, aus welcher sich später durch eine röhrenförmige Ausstiilpung der Enddarm differenziert. ConkLin ist aber geneigt, anzunehmen, daß aus den vier zwischen den Teloblasten des Mesoderms liegenden Zellen nicht bloß das Mesoderm des Enddarmes, sondern teilweise auch dessen distales Ende hervorgeht.

Eine auffallende Übereinstimmung mit Physa zeigt die Anlage des Enddarmes bei der systematisch weit entfernten Form Fiona marina (CASTEEL), wie dies aus der Vergleichung unsrer Fig. 96 mit Casteel's Fig. 87 sofort zu ersehen ist. Auch die Genese des Stranges ist bei beiden fast ganz identisch, denn er wird bei Fiona aus den Zellen $E^{1} E^{2}$ und $e^{1} e^{2}$ gebildet, welche unsern $m_{1} m_{1}$ und $m_{2} m_{2}$ entsprechen und ebenso beteiligen sich auch andre chromatinreiche Derivate des Mesoderms an seiner Zusammensetzung. Trotz dieser täuschenden Ähnlichkeit der Anlage herrschen doch wichtige Unterschiede, indem die Enteroblasten $E^{1} E^{2}, e^{1} e^{2}$ bei Fiona direkt an der Begrenzung der Entodermhöhle teilnehmen, was bei Physa nicht der Fall ist. Es verbindet sich ferner bei der ersteren der Darmstrang durch Vermittlung der Zellen $z^{1} \gamma^{2}$ mit dem Ectoderm, welche nnserm dritten Mikromerenpaar entsprechen, das sich aber an der Zusammensetzung des Enddarmes gar nicht beteiligt. Der letztgenannte Unterschied diurfte aber nur auf einer ungenamen Beobachtung 
Casteels beruhen, da diese Zellen auch bei Fiona von der Anlage des Enddarmes ebenso weit entfernt sind wie bei Physa.

Angesichts dessen, daß die oben besprochenen drei Formen drei verschiedene Gasteropodengruppen repriisentieren (die Proso-Opisthobranchier und die Pulmonaten) dürfte die Verwendung eines Teils des Urmesoderms zum Aufbau des Darmkanals als eine bei den Gasteropodeu weit verbreitete Erscheinung betrachtet werden. Da sie, nach den bisherigen Angaben zu schließen, auch bei den Anneliden ebenso weit verbreitet sein dürfte, so erscheint es höchst wahrscheinlich, daß wir es hier mit einem alten Bildungsmodus zu tun haben. Wir haben bereits beim Mesoderm die betreffende Hypothese WiLsoxs, welcher in diesem Bildungsmodus den Beweis für die Herkunft des Mesoderms vom Archenteron erblickt, ausführlich besprochen.

Im sehroffen Gegensatze zu den meisten bisherigen Angaben uber die Entwicklung des Darmes stehen die Beobachtungen Mersexhemens an Limax ('98) und Dreissensia ('01), bei denen sder ganze Darm vom After bis zur Einmiindung in den Magen als ectodermales Gebilde aufzufassen ist .

Diese Angabe stitzt sich auf eine sehr sorgfältige Untersuchung an Schnitten und unterliegt, nach der Versicherung des Verfassers, keinem Zweifel. Um so mehr ist sie überraschend und steht derzeit noch ganz unvermittelt da. Es stellt sich aus ihr herans, daß sogar in der engen Molluskengruppe nicht einmal der Darmkanal in seiner ganzen Ausdehnung als ein homologes Gebilde gelten darf.

Da die ron Mersenhenen untersuchten Formen zwei verschiedenen Gruppen: den Pulmonaten und Lamellibranchiern angehören, so ist kaum anzunehmen, daß der ectodermale Ursprung ihres Darmes nur eine ganz seltene Ausnahme bildet, vielmehr sollte man erwarten, daß er auf eine größere Anzahl von Molluskentypen ausgedehnt ist. Mersenhener weist diesbeziiglich auf die Befunde andrer Forscher hin, nach denen der Darm vom Ectoderm entspringen soll, er hält sie aber selbst mit Ausnahme deren von LANKester bei Limnaeus und Henchuas bei Limax für nicht ganz zuverlässig. Üher die Beobachtungen LANKesters haben wir bereits oben unsre Ansicht geäußert. Es wurde daselbst ebenfalls betont, daß weder bei Physa noch bei Planorbis stichhaltige Beweise für die Beteiligung des Ectoderms an der Bildung des Enddarmes erbracht werden konnten, weun atch bei beiden in der Gegend, wo der solide Strang entsteht, eine leichte Einstiulpung des Ectoderms sich bemerkbar macht, ja bei 
Physa sogar ein teilweises Vordringen von Ectodermzellen in die Furchungshöhle beobachtet wurde.

Sollen nun diese Befunde als die erste Stufe des bei Limax und Dreissensia bereits vollendeten Bildungsmodus betrachtet werden oder als die letzte Spur desselben? Diese Frage läßt sich rom Standpunkt der bisherigen Beobachtungen noch nicht fruchtbar diskutieren.

Wir möchten noch zum Schluß auf einen Punkt in der Entwicklung von Limax und Dreissensia die Aufmerksamkeit lenken. Es ist die hochwichtige Rolle, welche bei denselben das Ectoderm im Aufbau der Organe spielt, denn es liefert nicht nur den bei weitem größeren Teil des Darmkanals (den ganzen Vorderdarm, Mitteldarm und Enddarm und die Speicheldrüsen), sondern auch die Urniere, die bleibende Niere, das Herz und Pericard, ja sogar die Geschlechtsdrüsen. Da sonst aus demselben Keimblatte auch das Nervensystem samt den Sinnesorganen, die Hautdrüsen, die Schale, überhaupt das ganze Integument hervorgeht, so ist selbstverständlich den beiden andern Keimblättern nur eine sehr untergeordnete Rolle zugewiesen - ein Verhalten, das so lange als ein sehr frappanter Ausnahmsfall betrachtet werden muß, bis es gelingt, bei andern Formen eine kräftigere Stütze für die Auffassung Mersenhemers zu finden, als es bisher gelungen ist.

\section{c. Definitive Niere.}

Meine Beobachtungen über die Differenzierung dieses Organs bei Physa erstrecken sich nur bis zu derjenigen Phase, wo es die Gestalt eines langgestreckten, an seinem proximalen Ende schlingenförmig umbiegenden Schlauches gewinnt (Fig. 120n). Sie haben ergeben, daß die hierbei sich abspielenden Vorgänge wesentlich dieselben sind, wie bei Planorbis (RABL) und daß die Niere von Physa ebenso wie bei dieser Form ihren Ursprung dem primären Mesoderm verdankt.

Mit Rücksicht darauf, daß die Befunde RABLs, betreffend die mesodermale Ableitung der Niere, neulich von Meisenheimer ('98) als nicht maßgebend angesehen werden, ist eine strenge Begründung. dieser Befunde um so mehr erwünscht, als der letztere dieses Organ bei Limax, Dreissensia und Cyclas vom Ectoderm ableitet und seine Auffassung auf positive Beweise stiitzt.

Die Beweisfuhrung RabLs ist insofern nicht ganz einwandsfrei als sie hauptsächlich auf der Beobachtung beruht, daß die erste Anlage der Niere an entsprechenden Stadien mit dem Ectoderm in keinem Zusammenhang steht, sondern daß letzteres "kontinuierlich 
in einfacher Schicht über dieselbe hinwegstreicht . Daraus folgert dieser Autor, »daß weder von einer Verdickung noch von einer Einstullpung des Ectoderms die Rede sein kann". Dies durfte ganz richtig sein, es bleibt aber fraglich, ob die Anlage nicht etwa schon anf viel friheren Stadien durch Auswanderung von Ectodermzellen entstanden sein könnte?

Zugunsten der Auffassung Rabls müssen wir MeIsenheimer gegenüber hervorheben, daß der erstere die mesodermale Ableitung nicht einzig und allein auf den obigen Befund stlitzt, vielmehr noch andre wichtige Momente beriicksichtigt. Namentlich den Umstand, daß das Ectoderm derjenigen Seite, welche die Nierenanlage enthält, von demjenigen der Gegenseite nicht verschieden ist, ferner daß die histologische Beschaffenheit der dieselbe zusammensetzenden Zellen in jeder Beziehung den Mesodermzellen so sehr ähnlich ist, daß man über ihre Abstammung von den letzteren gar nicht im Zweifel sein kann. Diese Beobachtung ist sehr wichtig und geradezu ausschlaggebend, denn wir finden auch bei Physa eine auffallende Übereinstimmung zwischen den Hauptzellen der ersten Anlage der Niere und den Derivaten des primären Mesoderms. Namentlich tritt dieselbe am dentlichsten an Sublimatpräparaten hervor, die mit EurLichs Triacid tingiert wurden. Das Plasma zeigt denselben gelblichen oder rotgelblichen Ton, welcher den Abkömmlingen des Urmesoderms, sowie den ursprünglichen Entodermzellen eigentümlich ist und offenbar von noch nicht ganz aufgelösten Dotterkörnchen herruhrt. Durch die Feststellung der histologischen Identität der Nierenanlage mit den Mesodermelementen ist schon für den genetischen Zusammenhang beider ein sehr wichtiger Stiitzpunkt gewonnen. Zum strengen Beweis fehlt aber noch die Ermittlung der Descendenz, welche wir bei RABL vermissen.

Es soll also im folgenden diese Lücke durch diesbeztigliche Beobachtungen an Physa ausgefullt werden.

Wir haben den fraglichen Zellenhaufen, welchen RABL und andre Forscher zum Ausgangspunkt ihrer Beobachtungen ther die Entwicklung der Niere machen, genetisch verfolgt und die volle Überzeugung gewonnen, daß er aus den Derivaten der beiden medianen Lrmesoderm-Makromeren seinen Ursprung nimmt. Wenn man nämlich die Schicksale dieser letzteren an einer unterbrochenen Reihe von Stadien verfolgt, so bemerkt man zunächst, daß sie schon während der Gastrulation seitlich auseinanderweichen oder richtiger durch die eindringenden Fortsätze der Ectodermzellen auseinander gedrängt werden. 
Bevor noch die Verengung des Blastoporus ihr Maximum erreicht hat, haben sie sich bereits geteilt (Fig. $90 M$ ), so daß man an den allernächsten Stadien an ihrer Stelle bereits mehrere größere Zellen von mesodermalem Charakter findet, welche zu beiden Seiten der inzwischen ausgebildeten Anlage des Enddarmes symmetrische Reihen bilden und sich sowohl durch die Eigenschaft ihres Plasmas, als auch durch ihre Größe und ihre großen, bläschenförmigen Kerne auszeichnen (Fig. 94b, $c$, mesh). Durch weitere Teilung nehmen die beiderseitigen Reihen an Länge zu, olıne dabei ihre ursprünglichen histologischen Eigenschaften einzubüßen. Mit diesen jüngsten Descendenten der medianen Makromeren des Mesoderms treten alsbald ihre älteren, kleinen Tochterzellen in Verbindung, welche wir als Mikromeren bezeichneten, desgleichen ein Teil der den vorderen Makromeren angehörigen Mikromeren, welche in den Ecken zwischen diesen und den medianen Makromeren sich befanden (Fig. 104b). Die letzteren haben inzwischen durch Teilung bedeutend an Zahl zugenommen. Durch Aufnahme mehrerer von diesen kleinen Zellen entstehen zwei ziemlich lange Stränge aus gemischten Elementen, die als die hinteren Mesodermstreifen bezeichnet werden könnten. Es sind aber keine vollständigen hinteren Mesodermstreifen, weil die vorderen Makromeren sich bereits zu den Urnieren differenziert haben und ein Teil der Mikromeren die Anlage des Enddarmes gebildet hat, während ein andrer sich in der Leibeshöhle zerstreute. Diese Stränge ziehen von der Medianlinie an der Bauchseite nach den Seiten gegen die Urnieren $\mathrm{zu}$ und setzen sich mit den letzteren durch eine Kette von kleineren Zellen in Verbindung. Fig. 94a-c, mesh zeigt uns die Konfiguration derselben an einem Stadium, bei dem die Einstiulpung der Schalendriise kaum begonnen hat. Wir sehen in denselben neben den großen, grobkörnigen Komponenten, den jüngsten Derivaten der beiden medianen Makromeren, einige kleine chromatinreiche Zellen, welche anfangs besonders an den distalen Enden der Streifen angehängt sind. An einem der nächstfolgenden Schnitte derselben Serie sieht man aber ebenfalls ganze Reihen von Mesodermzellen, die vom Enddarme ausgehend die Anlage der Schalendrise umziehen (Fig. 94d). An Präparaten erkennt man aber sofort, daß diese Zellreihen einer andern Quelle entstammen, als die soeben beschriebenen Mesodermstreifen, sie gehören nämlich dem sekundären Mesoderm, welches sich inzwischen bis an das Hinterende des Keimes ausgebreitet hat. Mit der Nierenbildung haben sie aber sicher nichts zu tun.

An Schnitten Fig. 97, 104a, welche nur etwas älteren Stadien 
entnommen wurden, bemerkt man, daß an Stelle von Streifen rundliche, flach ausgebreitete Zellenhaufen entstanden sind, in denen man ohne weiteres die Komponenten der ersteren wieder erkennt. Noch deutlicher zeigen uns ihre Gestalt und ihre Zusammensetzung Flächenbilder Fig. 101. Diejenige Partie des Eetoderms, welche diese mesodermalen Zellhaufen überdeckt, ist anfangs nur ganz schwach, später auffallend stark vorgewölbt und aus kleinen Zellen zusammengesetzt, unter denen man gewöhnlich mehrere in Mitose trifft. Ihre Teilspindeln liegen aber fast ausnahmslos tangentiell zur Oberfläche des Ectoderms, was auf eine Proliferation in der Fläche hindeutet.

Anfangs sind die beiderseitigen Zellenhaufen mehr oder weniger an Umfang einander gleich und die Zellen, aus denen sie zusammengesetzt sind, hängen nur lose miteinander zusammen, später bilden sie ganz dichtgedrängte Zellenmassen, in denen die Grenzen einzelner Zellen derart verwischt sind, daß das Ganze einem Syncytium ähnlich sieht (Fig. 105n). Der linke Zellenhaufen, der alsbald stärker entwickelt erscheint, bildet nun die erste Anlage der Niere, iiber deren mesodermale Herkunft wohl keine Zweifel mehr obwalten können, nachdem wir die Descendenz desselben Schritt für Schritt verfolgt haben. Die größeren Komponenten dieser Anlage behalten auch fernerhin ibren ursprünglichen mesodermalen Charakter, wenngleich sie inzwischen mehrfache Teilungen ausgeführt haben. Was die Mikromeren betrifft, deren Zahl an älteren Entwicklungsstufen sichtlich zunimmt und welche sich an der dem Entoderm zugekehrten Fläche der Anlage ansammeln, so gehört ein Teil derselben zweifellos den Urmesodermmikromeren an, der andre dürfte von den größeren Komponenten geliefert werden, welche öfters in stark inäqualer Teilung getroffen wurden, schließlich können wohl einige auch aus der Teilung der Mikromeren selbst hervorgehen.

Verfolgt man die Nierenanlage an Serien von Stadien verschiedenen Alters, so gewinnt man oft den Eindruck, daß eine Auswanderung der Ectodermzellen ${ }^{1}$ behufs Vergrößerung der soeben beschriebenen Anlage stattfindet. Man bekommt manchmal ähnliche Bilder zu Gesicht, wie sie Meisenienduen in den Figuren 82-90 Taf. XXXV als Beweis für die ectodermale Herkunft der gemeinsamen Anlage von Niere und Herz bei Limax vorfuhrt. Derartige Bilder

1 Nach Pötsch ('04) treten auch bei Planorbis corneus Bilder auf, die einen engeren Zusammenhang der Nierenanlage (deren Ursprung dem Verfasser nicht gauz klar ist) mit dem Ectoderm vermuten lassen. Zool. C'entralblatt. 1905. Nr.67. 
sind sehr verführerisch und man wäre versucht, auch bei Physa die Nierenanlage vom Ectoderm abzuleiten, wenn ihre mesodermale Herkunft durch direkte Beobachtung nicht sichergestellt wäre. Namentlich könnten Schnitte, wie der in Fig. 105 dargestellte, mit Recht als Beweise für eine ectodermale Ableitung ausgenutzt werden, da hier eine ganze Kette von Ectodermzellen soeben in die Furchungṣhöhle eingewandert zu sein scheint. Wir konnten aber trotz alledem nach Durchsicht mehrerer Dutzende von Schnittserien die Überzeugung gewinnen, daß es sich dabei tatsächlich um Auswanderung von Ectodermzellen in die Furchungshöhle handelt. Ebensowenig konnte die Beobachtung, daß einige Mesodermzellen keilförmig zwischen den Epithelzellen stecken, als ein Beweis für ihre Einwanderung in das letztere gedeutet werden. Wir fassen vielmehr diese Verschiebung der einzelnen Zellen als Ausdruck eines wechselseitigen Verkehrs zwischen dem Ectoderm und der Nierenanlage, bzw. den sie umgebenden Mesodermzellen auf. Sollte aber tatsächlich eine Auswanderung von Ectodermzellen stattfinden, so hätte sie allenfalls nicht den Zweck, die Anlage der Niere zu bilden, denn diese ist schon längst fertig.

Die weitere Differenzierung der Nierenanlage besteht anfangs fast nur in einer Vermehrung ihrer Komponenten. An Schnitten von Stadien mit wohl ausgebildeter Schalendrüse überzengt man sich, daß die Anlage eine massive Platte bildet, deren kleinzellige, chromatinreiche Bestandteile an der Oberfläche liegen und die großzelligen zum Teil mantelartig einhüllen, zum Teil zwischen dieselben eindringen. Lange Zeit hindurch bleibt sie sonst fast unverändert liegen, bis etwa zu derjenigen Phase, wo die Schalendrüse ganz flach geworden ist und ihre Verschiebung von der Medianebene beginnt. Man sieht sie dann zunächst die Gestalt eines kurzen soliden Stranges annehmen, dann streckt sie sich mehr in die Länge, höhlt sich am inneren Ende aus, während das äußere, mit der Haut verbundene noch kein Lumen zeigt. Vielmehr sind hier die Zellen stark zusammengedrängt und wie der Schnitt Fig. 118 zeigt, beginnen einzelne Ectodermzellen in den Strang einzudringen.

Auch noch jetzt erkennt ein geübtes Auge, daß die Wandungen des Stranges aus großen Zellen bestehen, welche ein andres Aussehen zeigen, als die Ectodermzellen. An der Oberflitche des Stranges liegen ziemlich dicht kleinere mesodermale Zellen, welche wahrscheinlich die bindegewebigen Elemente der Niere zu liefern haben.

Über die weitere Differenzierung dieses an beiden Enden noch 
blind endigenden Schlauches hahen wir nicht viel zu berichten, sie besteht im Längswachstum desselben und einer Umbiegnung an derjenigen Stelle, wo er mit dem Darm in Beriihrung kommt. Am Stadium Fig. 120 sehen wir die Niere in Gestalt eines langen Rohres, welches an der linken Seite der Schnecke links vom Enddarm nach außen . mündet.

Die Beziehung der Niere zum Pericard wurde leider nicht näher rerfolgt, desgleichen die Differenzierung einzelner Abschnitte, welche bereits RABL beobachtet hat. Aus einigen Beobachtungen durfte aber geschlossen werden, daß keine nennenswerten Abweichungen von der allgemein erkannten Norm vorkommen.

Es wurde oben hemerkt, daß während der Konstituierung der beiden hinteren Mesodermstreifen sich bald zwei symmetrisch zu beiden Seiten des Enddarmes liegende Zellenhaufen oder Platten bilden, ron denen die linke sich zur Anlage der definitiven Niere differenziert. Wir hätten also noch der gegenseitigen Platte zu gedenken, welche kurz nach ihrem Entstehen wenigstens so groß, wenn nicht größer als die linke ist. Sie streckt sich aber sehr bald in die Länge und ihre Komponenten zeigen das Bestreben, sich nach vorn gegen die Kopfpartie, seitwärts gegen die linke Platte und die Basis des Enddarmes auszudehmen. An späteren Stadien (Fig. 120a, b, mesh) sieht man sie noch ziemlich umfangreich und mit der Nierenanlage durch eine Zellbrücke verbunden. Über die späteren Schicksale konnten keine sicheren Beobachtungen gesammelt werden, so viel ist aber sicher, daß mehrere von den größeren Zellen bis zur Torsion der Larve in der ursprïnglichen Lage verharren, worauf sie auf die linke Seite herüberwandern. Allem Anschein nach entsteht aus diesem Material das Herz und Pericard und es ist auch nicht ausgeschlossen, daß demselben auch die Geschlechtsdriisen ihren Ursprung verdanken.

Ist unsre Vermutung gerechtfertigt, alsdann würden bei Physa und Planorbis aus dem Urmesoderm sehr wichtige Organe hervorgehen, nämlich außer den Urnieren, der bleibenden Niere und dem Enddarm, deren miesodermale Abteilung wir im vorhergehenden nachgewiesen haben, auch das Herz, Pericard und die Geschlechtsdrisen. Es bliebe somit nur ein ganz geringer Rest für das Mesenchym bzw. auch für das Cölom übrig. Las mittlere Keimblatt dieser Formen enthält also schon nach seiner ersten Differenzierung die Anlagen der genannten Organe und bringt sie in einer gewissen Zeitfolge zur Entfaltung. Zuerst differenzieren sich die Enteroblasten, darauf die Nephroblasten, dann folgen mehrere Differenzierungsteilungen der ge- 
bliebenen Mutterzellen, welche schließlich in die beiden Mesodermstreifen zerfallen, aus denen die weiteren Anlagen hervorgehen.

Die mesodermale Ableitung der bleibenden Niere wurde bei den Pulmonaten nur ausuahmsweise versucht, im allgemeinen haben sie ältere Autoren aus dem Ectoderm abgeleitet.

Bei den Prosobranchiern leitet v. ErLanger ("91, '92) die Niere von Paludina und Bythinia rom Mesoderm, den Ausführungsgang vom Ectoderm ab. Bezuiglich der Opisthobranchier hat Mazzarelli '98) auf Grund seiner eingehenden Untersuchungen an vielen Larven und in Übereinstimmung mit v. ErLaNger den Nachweis zu erbringen versucht, daß das sog. »anale Organ « derselben der definitiven Niere andrer Gastropoden entspricht, ferner daß es mit Ausnahme des ectodermalen ausführenden Porus der Hauptmasse nach aus dem Mesoderm gebildet wird. Höchst wichtig ist der Befund dieses Autors, daß es ganz allgemein einer paarigen Anlage entstamme, namentlich sind es zwei Zellen, die ursprünglich im Entoderm liegen, sich später von diesem abtrennen und in die Blastocölhöhle einwandern. Dieselben rereinigen sich später infolge der Drehung und bilden eine einzige, links rom Rectum gelegene Anlage, welche auch bei vielen Prosobranchiern an derselben Stelle liegt und die Anlage der definitiven Tiere bildet. Somit ist diese Anlage nach Mazzareldr der linken Niere der monotocarden Prosobranchier homolog. Es wäre noch zu bemerken, daß der entodermale Entwicklungsmodus nach Mazzarelli nur als ein abgekürzter zu deuten wäre, während der eigentliche Xierensack unzweifelhaft aus dem Mesoderm hervorgeht.

Mit den Befunden bei den Opisthobranchiern lassen sich diejenigen bei Physa ganz gut in Einklang bringen. Man könnte auch hier die erste Anlage als paarig ${ }^{1}$ ansehen, denn wenngleich derzeit noch ein direkter Nachweis dafür fehlt, daß die bleibende Niere von der anderseitigen Anlage einen Beitrag erhält, so halte ich dies für höchst wahrscheinlich.

Im strengen Gegensatze zu den oben erwähnten Befunden stehen diejenigen mehrerer älterer und neueren Beobachter, welche die Niere aus dem Ectoderm ableiten. Unter den letzteren verdienen die meiste Beachtung die Beobachtungen Meisenheners ('98), welcher auf Grund einer sehr sorgfältigen Untersuchung den Beweis liefert, daß bei Limax die gemeinsame Anlage von Herz und Niere aus einer Wucherung des Ectoderms entsteht. Dieser Befund wurde von demselben

1 Anch bei Cyclas (ZIEGLER) und Paludina (nach Tönniges) ist die Anlage parig, bei Dreissensia (Meisenheimer) unpaar. 
Beobachter auch fur Dreissensia und Cyclas cornea ('01) bestïtigt und näher präcisiert1. Wir hätten also wie bei der Urniere zwei Entwicklungstypen zu unterscheiden, den mesodermalen und ectodermalen. Als Stitze fuir die Auffassung Meisenhemens können die Befunde Hexmons ('93) bei Umbrella dienen, welche sich zwar nach Auffassung dieses Autors auf die larvale Niere beziehen, aber nach der Deutung Mazzarellis die bleibende Niere betreffen, ferner diejenigen Casteers ('04) bei Fiona, wo mit aller Sicherheit die Analniere aus dem Ectoderm (von $3 e^{1111}$ ) herstammen soll.

In der kritischen Übersicht der bisherigen Angaben uber die Ableitung der Niere sucht Meisenheimer (l. c.) die anders lautenden Befunde seiner Vorgänger, welche die Niere, sei es rein vom Mesoderm, sei es von diesem und dem Eetoderm ableiten, zugunsten seiner eignen Auffassung zu deuten. Wir haben oben hervorgehoben, daß man oft versucht ist, die Wucherung der Ectodermzellen dort anzunehmen, wo sie nicht stattfindet. Es ist in der Tat sehr schwer, wenn der histologische Charakter nicht zu Hilfe kommt, in einzelnen Fällen zu entscheiden, ob eine Auswanderung aus einem Keimblatte tatsächlich stattfindet, so daß eine Täuschung auch bei größter Sorgfalt und Vorsicht nicht ausgesehlossen ist. Sollten aber alle Beobachtungen über den ectodermalen Ursprung der Niere ganz richtig sein, alsdann hätten wir um einen Beweis mehr, daß die Natur sich an keine festen Regeln hält.

\section{Résumé.}

1) Die Furchung des Eies von Physa fontinalis und Ph. hypnorum verläuft nach dem umgekehrten Furchungsmodus und weist einen ausgesprochen determinierten Charakter auf.

2) Dieselbe wurde synchron nur bis zum Stadium von 123 Zellen ganz genau verfolgt, die Geschichte der einzelnen Quartette konnte dagegen bis in die spätesten Stadien verfolgt werden.

3) Die Ursache des umgekehrten Furchungsmodus liegt höchstwahrscheinlich in der inversen Eistruktur der betreffenden Formen.

Den Spiraltypus halten wir mit CHILD ('00) fur das Resultat der Selection, welche nicht nur passende Organisationen, sondern auch ontogenetische Entwicklungsweisen züchtet. Ein Abhängigkeits-

1 Im Gegensatz zu Meisenheimer leitet Ziegler ('85) die Niere von Cyclas aus dem Mesoderm ab. 
verhältnis zwischen der Spiralfurchung und der Schalendrehung läßt sich nicht streng nachweisen.

4) Das regelmäßige Alternieren der Spirale findet nur in den Anfangsstadien statt, hört bei Physa schon auf dem Stadium von 28 Zellen auf.

5) Die bilaterale Furchung beginnt mit der ersten Teilung von $4 d$ am Stadium von $44-50$ Blastomeren. Fast gleichzeitig (bei 52 Zellen) teilen sich die Zellen $3 a^{2}, 3 b^{2}, 3 c^{1}, 3 d^{1}$ bilateral.

Die bilaterale Furchung führt nicht notwendig zur Ausbildung von Organanlagen, indem z. B. $3 a^{1}$ und $3 b^{1}$ sich bilateral teilen ohne Organanlagen zu bilden.

6) Die erste und zweite Teilung ist äqual. Das Zustandekommen des für Mollusken und Anneliden charakteristischen Viererstadiums mit gekreuzten Polarfurchen läßt sich ebensowenig auf rein mechanische Faktoren zurückführen wie das der weiteren Furchungsbilder. Die Ursache desselben liegt in den Blastomeren selbst, mechanische Faktoren üben nur einen sekundär determinierenden Einfluß aus.

7) Es werden nur drei Ectomerenquartette gebildet. Diese höchst wichtige Erscheinung in der Furchung der Mollusken und Anneliden steht wohl nicht im Zusammenhang mit der definitiven Sonderung der drei Keimblätter, sondern mit der Differenzierung der vier ursprünglichen Makromeren, welche von nun an nur ento- und mesodermale Elemente führen. Die definitive Sonderung der Keimblätter findet bei Physa erst bei 107 Zellen statt.

8) Die Furchung ist mit gleichzeitiger Differenzierung der Blastomeren verbunden, ohne welche die Erreichung des Endzieles nicht denkhar ist. Als äußerer Ausdruck derselben sind die stets nach demselben Typus verlaufenden stark inäqualen Teilungen in den wichtigsten Blastomeren, ferner das periodische Erscheinen und Verschwinden von tingierbaren Körnchen, unsrer Ectosomen (Taf. XXVII) auf den Stadien von 4-24 Zellen und ihre Wanderung: nach dem Eicentrum zu betrachten.

9) Das Eiplasma spielt bei der Zellteilung eine aktive Rolle, welche sich im Aussenden und Einziehen von Fortsätzen, sowie im Einsinken und Emportauchen der Blastomeren äußert.

10) Der Embryo gewinnt am Stadium von 40 Zellen einen regelmäBigen radialen Bau. In den Hauptebenen liegt das erste, zweite und vierte, in den intermedianen das dritte Quartett.

11) Vom zweizelligen Stadium an erscheint eine geräumige. Furchungshöhle, welche an den nachfolgenden Stadien periodisch 
verschwindet und wiederkehrt. Sie steht nach unsrer Auffassung nicht nur in inniger Beziehung zum Stoffiwechsel, sondern in unmittelharer und nachweislicher Beziehung zum Furchungsprozesse (vgl. Abschn. 13).

12) Dio Geschichte des ersten Quartetts wurde bis zu 59 Zellen genau rerfolgt. Von dieser Zahl eutfallen auf das Kreuz 51, auf die Trochoblasten 8 Zellen. Die Protoblasten der Kreuzfigur differenzieren sich nach dem Vorgange andrer Protoblasten durch eine dreimalige inäquale Teilung zu den "Basalzellen", aus denen die ganze Kreuzfigur herrorgeht. Letztere tritt zuerst bei 40 Zellen deutlich auf. Das erste Quartett liefert einen Teil des Velums und der Kopfblase, ferner die Scheitelplatten, welche blok aus den seitlichen und dem vorderen Krenzarme entstehen. Erstere liefern hauptsächlich das Zellenmaterial fur die Cerebralganglien, Augen und Tentakeln.

13) Das zweite Quartett, dessen Geschichte bis 77 Zellen verfolgt wurde, beginnt seine Differenzierung mit Abschnürung ron indifferenten Zellen $2 a^{1.1}-2 d^{1.1}$. Es entwickelt sich bei Pliysa der sog. erste Somatoblast $X\left(2 d^{1}\right)$ nicht, jedoch hat diese Zelle eine eigne Geschichte und wird zum regen Wachstunscentrum. Die schwächste Entwicklung zeigt $2 b$, aus dem nur cin Teil des Stomodäums, des Velums und Schlundes entsteht. Aus 21 gelit die Schalendriise, ans $2 "$ und $2 c$ ein Teil des Stomodäums und Oesophagus, sowie die Radulatasche herror. Die kleinen veutralen, an die Eutodermplatte anstolienden Descendenten $2 r^{22}-2 c^{2 \cdot 2}$ (sog. Stomatoblasten) werden eingestülpt und tragen zur Bildung des Oesophagus bei.

15) Das dritte Quartett, dessen Geschichte bis 57 Zellen rerfolgt wurde, liefert das sekundüre Mesnderm, einen Teil des Stomodäums und Fußes. Seine zwölf ventralen Descendenten, die sich an das Entoderm anlehmen, werden zum grrößeren Teil mit derselben eingestulpt und tragen zum Verschlul des Blastoporus sowie zur Ausbildung des Oesophagus bei.

16, Das vierte Quartett und die Makromeren liefern ausschlielilich das Entoderm. Es wird vor der Einstiilpung noch ein funftes und sechstes Quartett gebildet, im Ganzen 32-35 Entorlermzellen.

17. Das primäre Mesoderm entwickelt sich aus $4 /$, dessen Descendenz bis 24 Zellen (sechs Makromeren und 18 Mikromeren) verfolgt wurde. Es liefert mehrere wichtige Organanlagen.

18; Das sekundire Mesoderm entstelit aus $3 a^{2.11 .1}, 3 a^{22.1 .1}$ und $3 b^{21.1 .1}, 3 b^{2.2 .1 .1}$, deren Progenitur bis 16 Zellen verfolgt wurde. 
Thre endgültige Differenzierung vollzieht sich erst bei 107 Zellen, sie erzeugen die vorderen Mesodermstreifen, welche die Hauptmasse des Mesoderms bilden. Ihnen entstammen die Nuchalzellen, Fig. 117, welche als voriubergehende Bildung zu betrachten sind (s. Abschn. 18c).

19) Bei Physa läßt sich kein Gegensatz zwischen dem primären und sekundären Mesoderm feststellen, beide entwickeln sich nebeneinander und gehen ineinander iiber.

20) Die bei der Sonderung der beiden Mesodermanlagen erzeugten Mikromeren (rudimentäre Zellen) sind als Differenzierungsprodukte zu betrachten, deren wechselnde Endschicksale kaum zur Aufklärung ihrer phylogenetischen Rolle dienen können.

21) Keine von den sog. rudimentären Zellen des zweiten, dritten und vierten Quartetts geht in die Zusammensetzung des primären Entodermsackes ein.

22) Die Gastrulation beginnt bei 33 Zellen im Entoderm und uiber 200 im Keime und ist ein unmittelbares Resultat der Furchungsvorgänge. Die Gastrulainvagination beginnt bei gleichzeitiger Einsenkung des animalen Poles.

23) Der Blastoporus schließt sich nie ganz und geht direkt in den primären Schlund über. Der von hinten nach vorn fortschreitende Verschluß desselben wird unter Mitwirkung der Mikromeren des dritten Quartetts bewerkstelligt.

24) Das Stomodäum entsteht aus dem zweiten und dritten Quartett.

25) Die Radulatasche erscheint zunächst als eine paarige Einstiulpung (Fig. 98a) hinter dem primären Stomodäum; sie entstammt dem zweiten Quartett.

26) Das Velum wird aus den vier vorderen Trochoblasten und den Descendenten von $2 b^{1.2}, 2 b^{2.1}$, sowie von der Tipzelle $2 b^{1.1}$ gebildet.

27) Die Urniere ist ein rein mesodermales Gebilde, welches sich aus den hinteren Makromeren des primären Mesoderms aufbaut. In ihrer vollendeten Gestalt besteht sie aus den für Basommatophoren typischen vier Zellen: einer Wimperzelle, zwei Excretionszellen und einer Ausführungszelle. Sie atrophiert sehr spät, nämlich nach Ausbildung der Schneckengestalt.

28) Die Wimperzelle erzengt bei der Larve außer der Wimperflamme noch äußere Cilien (Fig. 88).

29) Die Cerebralganglien entstehen aus den Scheitelplatten, vielleicht unter Beteiligung des sekundären Mesoderms. Im 
Zusammenhang mit denselben und aus demselben Zellmaterial entstehen durch Einstilpung die Augenblasen und dureh Ausstulpung die Tentakeln.

30) Pedalganglien bilden sich unabhängig von den C'erebralganglien, ihre Anlagen konnten nicht bis auf einzelne Blastomeren verfolgt werden. Otocysten entstehen durch einen EinstilpungsprozeB.

31) Der Enddarm entsteht als solider Strang aus den Mikromeren der hinteren, medianen Makromeren des Urmesoderms, vorwiegend aus $m_{1} m_{1}=e_{1} E$ der Autoren. An seiner Ansatzstelle an das Ectoderm erscheinen zwei große charakteristische, ectodermale Zellen, die "Analzellen", welche sich bis zur Ausbildung des Proctodäums erhalten.

32) Die definitive Niere ist mesodermal, wahrscheinlich auch das Herz, Perikard und die Geschlechtsdrise. Alle nehmen in den hinteren Platten des primären Mesoderms ihren Ursprung.

33) Der Beginn der Asymmetrie läßt sich bei Physa ebensowenig wie bei Planorbis (Ant) auf eine einzelne Entodermzelle zurickfuihren. Sie erscheint schon vor der Gastrulation und mag in ungleichmäßiger Entwicklung des Mesoderms bedingt sein.

34) Ans den Beobachtungen der Differenzierungsvorgänge und der Organogenese bei Physı kann auf eine frübzeitige Lokalisierung ron organbildenden Substanzen in einzelnen Blastomeren (im Sinne Coxkliss [-05]) nicht geschlossen werden. Es können nämlich aus Zellen desselben Ursprungs verschiedene Organe entstehen, z. B. aus den Descendenten vor 4 4 : die Larvalnieren, Muskeln und Bindegewebe, wahrscheinlich auch das Herz und die Geschlechtsdriise.

35j Für eine strenge Homologisierung der Blastomeren und Keimblätter fehlen zurzeit noch sichere Anhaltspunkte.

\section{Literaturverzeichnis,}

'82. 1. Blocmuaxa, Üłer die Entwicklung der Neritina fluviatilis Müll. Diese Zeitschrift. XXXVI.

'83. — Beiträge zur Kenntnis der Entwicklung der Gasteropoden. Diese Zeitschrift. XXXVIII.

'00. D. CAkazzi, L'embryologia dell' Aplysia limacina L. fino alla formazione delle strisce mesodermiche. Anat. Anz. XVII.

'00. - Georgevitch und die Embryologie von Aplysia. Ibid. XVII.

'04. B. D. Casteel, The Cell-Lineage and Early Development of Fiona marina, a Nudibranchiate Mollusk. Proc. Ac. Nat. Sc. Philadelphia.

100. C. M. Child, The Early Development of Arenicola and Sternaspis. Arch. f. Entwm. der Organismen. Bd. IX. Heft 4. 
91. E. G. Conkurn, Preliminary note on the Embryology of Crepidula fornicata and of Urosalpinx cinerea. J. Hopkins Univ. Cireul. Vol. X. Nr. 88.

197. — The Embryology of Crepidula. Journ. of Morph. Vol. XIII.

'98. - Cleavage and Differentiation. Biol. Lect.

'05. - Mosaic Development in Ascidian Eggs. Journ. Exp. Zool. Vol. II.

194. H. E. Crampton, Reversal of Cleavage in an Sinistral Gasteropod. Ann. N. Y. Ac. of Sc. VIII.

196. _- Experimental Studies on Gasteropod Development. Arch. f. Entwickl. III.

'94. H. Driesch, Analytische Theorie der organ. Entwicklung. Leipzig.

196. — Betrachtungen iiber die Organisation des Eies und ihre Genese. Arch. f. Entwickm. IV. 1.

'98. - Von der Beendigung morphogener Elementarprozesse. Arch. f. Entwickm. VI. 2.

'99. — Die Lokalisation morphogener Vorgänge. Ibid. VIII. 1.

199. Die Methode der Morphologie. Biol. Centralbl. XIX. 2.

191. R. Ertanger, Zur Entwicklung der Paludina vivipara. Morph. Jahrb. Bd. XVII.

191. Zur Entwicklung von Bythinia tentaculata. Zool. Anz.

'94. _ Zur Bildung des Mesoderms bei der Palud. vivipara. Morph. Jahrb. Bd. XXII.

'80. H. Fol, Developpement des Gasteropodes pulmones. Arch. Zool. Exp. Gen. Tom. VIII. 1.

04. T. Fujis, On the Formation of the Germinal Layers in Gasteropoda. Journ. College of Sci. Imp. Univ. Tokio. Vol. XX. Art. 1.

'03. T. Garbowski, Morphogenetische Studien. Jena.

'03. —Über parthenogenetische Entwicklung der Asteriden. Bull. Ac. Sc. Cracovie.

'00. P. M. Georgevitch, Zur Entwicklungsgeschichte von Aplysia depilans L. Anat. Anz. XVIII.

181. B. Hatscheк, Entwicklungsgeschichte von Teredo. Arb. Zool. Inst. Wien. Bd. III.

186. _ Entwicklung der Trochophora von Eupomatus uncinatus Phil. Arb. Zool. Inst. Wien. VI.

99. H. HEATH, The Development of Ischnochiton. Zool. Jahrb. XII.

'00. K. Heider, Das Determinationsproblem. Verh. Deutsch. Zool. Ges.

'93. R. Heymons, Zur Entwicklungsgeschichte von Umbrella mediterranea Lam. Diese Zeitschrift. LVI.

'02. R. W. Hofrmann, Über die Ernährung der Embryonen von Nassa mutabilis Lam. Diese Zeitschrift. LXXII.

199. S. Holmes, Reversal of Cleavage in Ancylus. Americ. Natur. XXXIII.

'00. The Early Development of Planorbis. Journ. of Morph. Vol, XVI.

'96. H. S. Jennings, The Early Development of Asplanchna Herrickii de Guerne. Bull. Mus. Comp. Zool. XXX. 1.

195. C. A. Koford, Early Development of Limax. Bull. Mus. Comp. Zool. Vol. XXVII. 2.

96. Kostanecki und WierzeJSkI, Über das Verhalten der sog. achromat. Substanzen im befrucht. Ei. Arch. mikr. Anat. Bd. XLII.

'95. F. R. LiLLie, Embryology of the Unionidae. Journ. of Morph. Vol. X.

'99. — Adaptation in Cleavage. Biol. Lect. 


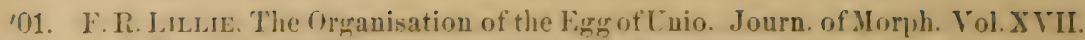

81. E. I. M.ark. Maturation. Fecondation and secmentation of limax campestris. Bull. Mus. Comp. Zool. Vol. VI.

98. G. Mazzarela. Bemerk. iiber die Inalniere der freileb. Larven der Opisthobranch. Biol. Zentralbl. Bd. XVIII.

97. A. D. MEaD. The Early Development of Marine Annelids. Journ. of Morph. Vol. XIII.

196. S. Meisexhener. Entwicklungsereschichte von Limax maximus. 1. Teil. Furch. u. Keimblätterl,ild. Diese Zeitschrift. LXII. Bd.

198. _ Organogenese einer Lungenschnecke. Ibid. LXIII. Bd.

98. — Über die Lruiere der siibwasserumbonaten. Verh. Deutsch. Zool. Ges. Heidelberg.

199. _- Zur Morpholugie der Lmiere d. Pulmonaten. Inese Zeitschrift. LAY. Bd.

99-00. — Entwicklungsgeschichte von Dreissensia polymorpha. Ibid. LXIX. Bd. - Die Entwicklung von Herz, Perikard, Niere u. Genitalzelle bei Cyclas ete. Ibid.

186. W. Pattex, The Embryology of Patella. Arb. Zool. Inst. Wien. Bd. VI.

79. C. Rabs. I"her die Entwicklung der Tellerschnecke. Morph. Jahrb. V.

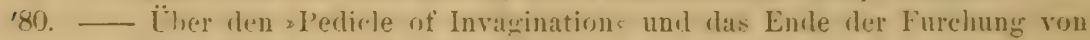
Planorbis. Morph. Jahrb. Bd. VI.

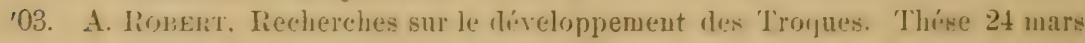
1903. Arch. Zool. expér. Serie X.

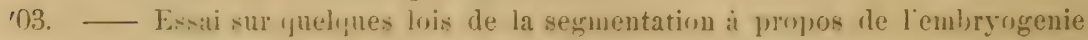
du Troque. Bull. Scient. de la Fac. des Se. Paris.

104. Le mésoderme du Troque. Mem. Soc. Zool. de France. T. XVII. Prem. partie.

96. C. Trijsurses. Die Bildung des Mesoderms bei I'aludina vivipara. Diese Zeitschrift. LXI. Bd.

'03. J. C. Tonkx: The Early Eubryology of Thalassema melita Coun. Ann. N.Y. Acad. Sc. Vol. XIV.

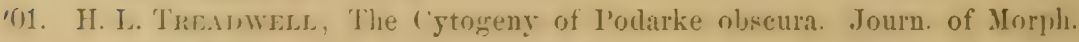
Vol. XVII.

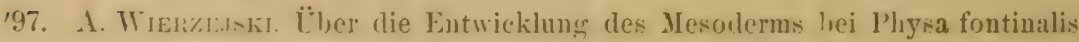
L. Biol. Centralbl. XVII.

94. E. H. Whans: The Mosair Theorice of Development. Biol. Secet. Wrods Holl.

196. — On Clearage and Mosaic Work. Arch. f. Entw.

97. Considerations on Cell Linneage and Ancestral Reminiscence. Ann. N.Y. Acad. Sc. Vol. XI.

19x. _- rell Linneage and Ancestral Reminiscence. Ann. N. Y. Acarl. S'c. Vol. XI. Nr. 1.

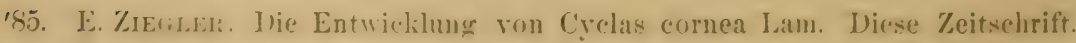
XLI. Bd.

\section{Erklärung der Abbildungen.}

Sämtliche Fignren sind. soferm nicht eine audre Vergrïberung ausdrïcklich angegeben wurle. bei Zerss (obj. I). Oc. II mit dem Zeichenprisma nach konservierten (b)jekten entworten. Das histologrsche [jetail wurde nicht eingetragen. Auf simtlichen Furehumgsbildern wurlen die Jidnente des primären Mesoderms in veilchenblaner, die Makiromeren des sekumliren Mesoderms in rosaroter, die 
ersten zwei Paare der von ihnen herstammenden Mikromeren in grïner Farbe hervorgehoben.

Erklärung der allgemein durchlaufenden Bezeichnungen.

äc, äußere Cilien der Wimperzellen;

an, Analzelle;

an\%, Anheftungszellen der Uniere;

arh, Archenteronhöhle;

art, Anlage der Radulatasche;

aug, Augenblase;

äuss.un, äußere Urnierenöffnung;

aus.z, ausfihhrende Zelle der Urniere;

at, Atemhöhle;

bl, Blastoporus;

$\mathrm{blm}$, Blindsack des Mitteldarmes;

d, Darm;

$d p$, Darmplatte;

ect, Ectoderm;

ed, Enddarm;

eda, Enddarmanlage;

eins, Einstiilpung;

ekt, Ectosomen;

en, Entoderm;

eis, Eiweiß;

eir, Eiweißzelle;

ev, Vacuole in der Endzelle der Niere;

exx, Excretionszelle;

$f, \mathrm{FuB}$;

ge, Gangl. cerebrale;

g.ped, Gangl. pedale.

g.vise, Gangl. viscerale;

$7 b$, Kopfblase;

$l$, Leber;

$l l$, linker Leberlappen; $m$, Mantel;

ma, Magen;

$m f$, mittlere Zellen des Fußes;

mesh, hintere Mesodermstreifen;

mesp, Mesodermplatte;

mi, Mikromeren;

$m l$, Mundlappen;

$n$, definitive Niere;

nu, Nuchalzellen;

oe, Oesophagus;

ot, Otocyst;

re, Radulaeinstiilpung;

$r l$, rechter Leberlappen;

$r t$, Radulatasche;

$r \approx$, Riesenzelle;

$s$, Schale;

$s d$, Schalendriise;

sec.mes, secundïres Mesoderm;

$s p$, Scheitelplatte;

St, Stomodium;

$\imath \iota$, Urnierenkanal;

un, Urniere;

$w \sim$, Urnierenzelle;

$V$, Velum;

$v k$, Vacuole;

wf, Wimperflamme;

$w \%$ Wimperzelle;

$x$, Einstillpung im Mantelrand, Riechgrube?

\section{Tafel XVIII.}

Fig. 1. Ei nach der Zweiteilung; Lage des Zwischenkörpers außerhalb der Eiachse; die hintere Blastomere soll mit $C D$ statt mit $C B$ bezeichnet sein.

Fig. 2. Teilung in vier Blastomeren vom animalen Pol gesehen. Polare Knickung der ersten Furche.

Fig. 3. Das vierzellige Stadium vom animalen Pol gesehen. Ausbildung der Polarfurchen.

Fig. 4. Dasselbe Stadium vom vegetativen $\mathrm{Pol}$ gesehen. Übergang ins Ruhestadium, Lage des Zwischenkörpers, Ectosomen, elt.

Fig. 5. Übergangsphase zum achtzelligen Stadium. Die Spiraldrehung sehr stark ausgeprägt. Ectosomen am vegetativen Pole.

Fig. 6. Achtzelliges Stadium, animaler Pol.

Fig. 7. Achtzelliges Ausnahms-Stadium, in welchem alle acht Zellen gleichzeitig in Teilung begriffen sind. Vom animalen Pol.

Fig. 8. Dasselbe, seitliche Ansicht. 
Fig. 9. 16-zelliges Stadium vom animalen Pol gesehen. (ieräumige Furchungshøhle.

Fig. 10. Dasselbe, Seitenansicht. Furchungshöhle.

Fig. 11. Bildung des 24-zelligen Stadiums; animale Hälfte.

Fig. 12. Dasselbe; vegetative Hialfte.

Fig. 13. 24-zelliges Stadium unmittelbar nach der Teilung von acht Zellen; vegetative Hälfte.

Fig. 14. 24-zelliges Ruhestadium; animale Hälfte. Erste Andeutung der Kreuzfigur.

Fig. 15. Dasselbe; vegetative II:älfte. An der Polarfurche die vier charakteristischen Kürnchengruppen „Ectosomene. Die Figur etwas zu stark nach rechts verdreht.

Fig. 16. 29-zelliges Stadium; animale Häfte. Die Zellen $2 a^{2}-2 l^{2}$ in Teilung.

Fig. 17. Dasselbe; vegetative Hälfte. Die hintere Makromere $3 \mathrm{I}$ geteilt. begriffen.

Fig. 18. 33 zelliges Stadium; animale Hälfte. Das erste Quartett in Teilung

Fig. 19. Dasselbe; regetative Hälfte. Der rechte in der Figur der linke' Protoblast des sekundären Mesoderms geteilt.

\section{Tafel XIX.}

Fig. 20. 37zelliges Stadium. Vegetative Hälfte; das dritte Qnartett in erster Teilung begriffen.

Fig. 21. 40 zelliges Stadium; animale Hälfte. Verspïtete Teilung von $1 d$.

Fig. 22. Dasselbe; vegetative Hälfte. Das dritte Quartett geteilt. An beiden Hälften tritt die radiäre Anordnung deutlich hervor.

Fig. 23. Übergang zum 44 zelligen Stadium. Vegetative H:ilfte. Bildung des vierten Quartettes.

Fig. 24. 44 zelliges Stadium; animale Hälfte. Die vorderen Trochoblasten $\left(1 a^{2}, 1 b^{2}\right)$ in Teilung begriffen.

Fig. 25. Dassellse; vegetative Hailfte. Symmetrische Anordnung der Makromeren zur Polarrosette.

Fig. 26. 49 zelliges Stadium; animale Irilfte. Teilungren von $2 a^{1.2}-2 d 1.2$.

Fig. 27. Dasselbe; vegetative Hälfte. Bilaterale Teilung cles Lrmesoderms.

Fig. 28. 52 zelliges Stadium; animale Hälfte. Teilung von $2 d^{2.1}$. und $3 d^{3}$.

Fig. 29. Dasselbe; vegretative Hälfte. Bilaterale T'eilung von $3 a^{2}, 3 l^{2}, 3 c^{1}$

Fig. 30. 57zelliges Stadium; animale Hälfte. Teilungen im ersten und zweiten Quartett.

Fig. 31. Dasselbe; vegetative Hülfte. Firste Teilung des vierten Quartetts.

Fig. 32. 6tzelliges Stadium; animale Hiilfte. Bildung der iußeren Medianzellen des Kreuzes in $1 a^{12}-1 c^{12}$.

Fig. 33. Dasselbe; vegetative Ḧ̈lfte. Das vierte Quartett bilateral geteilt.

Fig. 34. Vegetative Hailfte eines etwas älteren Stadiums. Lage der Teilungsspindeln in den beiden Urmesodermzellen vor der Erzengung des ersten Mikromerenpaares.

Fig. 35. 73zelliges Stadium; animale Hailfte. Teilung von $3 a^{1}$ und $3 b^{1}$, $3 c^{1.1}$ (Immersion). 
Fig. 36. Dasselbe; vegetative Hälfte. Inäquale Teilung der vier Zellen des sekundären Mesoderms, sowie der Zellen $3 e^{1.1}$ und $3 d^{1.2}$; Erzeugung von Mikromeren im dritten Quartett. Immersion.

\section{Tafel XX.}

Fig. 37. 78zelliges Stadium; animale Hälfte. Teilung von $1 d^{2}$ und $3 d^{1.1}$.

Fig. 38. Dasselbe; vegetative Hälfte. Das sekundäre Mesoderm in zweiter Teilung begriffen. Zweite Teilung des vierten Quartetts. figur.

Fig. 39. 82 zelliges Stadium; animale Hälfte. 16 zellige regelmäßige Kreuz-

Fig. 40. Dasselbe; vegetative Hälfte. Teilungen in den beiden hinteren Quadranten des dritten Quartetts, im vierten Quartett und von $2 b^{2.2}$ und $2 c^{1,2.2}$. Quere Lage der Spindel in $4 b^{2}$.

Fig. 41. 92 zelliges Stadium; animale Hälfte. Teilung der Basalzellen des Kreuzes $1 a^{1.2 .1}$ und $1 e^{1.2 .1}$ und von $2 d^{1.22}$.

Fig. 42. Dasselbe; vegetative Hälfte. Dritte Teilung von $4 d(\mathbf{M})$, Teilung von $2 a^{2} \cdot 2,2 c^{2.2}$, ferner frühzeitige Teilung der Makromere $4 B$.

Fig. 43. 97zelliges Stadium. Animale Hälfte. Teilung der Basalzelle 1b1.2.1, der Apicalzellen, ferner der Zellen $2 d^{\prime} \cdot 2.1,2 d 1.2 .2$ und $2 c^{2.1 .2}$.

Fig. 44. Dasselbe, regetative Hälfte. Entodermplatte 16 gliedrig, dreieckig; das Urmesoderm in dritter Teilung begriffen.

Fig. 45. 106 zelliges Stadium, animale Hälfte. Wichtige Teilungen im zweiten Quartett und in den Apicalzellen. Arm $d$ der Kreuzfigur verschoben.

Fig. 46. Dasselbe; vegetative Hälfte. Teilungen im sekundären Mesoderm. Abschnürung des fünften Quartetts soeben vollendet. Teilung von $2 d^{2.2 .}$.

Fig. 47. 116zelliges Stadium; animale Hälfte. Teilung der Apicalzelle 1 $c^{1.1}$, ferner Teilungen im zweiten und dritten Quartett der Quadranten $c$ und $d$.

Fig. $48 a$. Dasselbe; vegetative Hälfte.

Fig. 48b. Anordnung der sechs Zellen des primären Mesoderms desselben Stadiums.

Fig. 49. 123zelliges Stadium in Ruhe. Animale Hälfte. Beginnende Einsenkung am animalen Pol.

Fig. 50. Dasselbe; vegetative Hälfte. Die regelmäßige Entodermplatte schildförmig gewölbt, ihr hinterer Rand erhoben.

\section{Tafel XXI.}

Fig. 51. Optischer Querschnitt durch ein 125 zelliges Stadium, um die Lage des primären und sekundären Mesoderms zu zeigen. Die vier Makromeren des ersteren in vierter Teilung begriffen. Zwischen den Zellen des sekundären Mesoderms treten radiale Spalten auf.

Fig. 52. 134zelliges Stadium; animale Hälfte. Beginn der Längsteilung der Kreuzarme von den Basalzellen aus. Einsinken der Apicalrosette. Das Kreuz zöhlt 25 Zellen. An der Peripherie Teilungen im zweiten und dritten Quartett.

Fig. 53. Dasselbe; vegetative Hälfte. In der Entodermplatte dritte Teilung der Zellen des vierten Quartetts; Teilung der Makromeren (3 $a^{2}$.1.1.1 und 3a2.2.1.1 des sekundïren Mesoderms.

Fig. 54. Dasselbe; optischer Querschnitt, mit Teilungen in den beiden Mesodermanlagen. 
Fig. 55. Paramedianel Lüngsschnitt durch ein etwa 143zelliges Stadium. Signifizierung nur annäherungsweise. Immersion.

Fig. 56. Ungeführ 150 zelliges Stadium. Animale Hälfte. Das in der Mitte bereits merklich verbreiterte Kreuz zühlt 27 Zellen. (Immersion.)

Fig. 57. Dasselbe; vegetative Iliilfte. Die Entodermplatte \%iihlt 21 Zellen. Teilungen in den vorderen Quadranten des dritten Quartetts, die Zellen $3 e^{2}$ und $3 d^{2}$ geteilt. Teilungen in der Peripherie.

Fig. 50. Optischer Quersehnitt durch einen Keim beinahe desselben Alters. fruppierung der acht Zellen des sekundiren Mesoderms. (Vom vegetativen Pol aus gesehen.)

Fig. 59. Ungef:ihr 180 zelliges Stadium. Animale IIilfte. Das Kreuz z:ilht 31 Zellen, die apicale Einsenkung ist größer geworden. 'Teilung von 1 6 1:2.2 rollzogen. Starke Ausbildung und Vorwölbung der 'Trochoblasten (Immersion!

Fig. 60. Vegetative Hilfte eines ungefähr gleichalterigen stadiums mit 32 zelligem animalem Krenze. Wichtige Querteilungen im zweiten Quartett von $2 b^{1.2 .2}$ und $2 b^{2.1 .2}, 2 b^{2.2 .2}, 2 a^{2.2 .1}$ und $2 e^{2.2 .1}$ und von $4 D$ !

Fig. 61. Ein andres gleichalteriges Stadium. Animale Hälfte. Auffallend starke Einsenkung des 31 zelligen Kreuzes. Der Arm $D$ durch Einsenkung deformiert (Immersion).

\section{Tafel XXII.}

Fig. 62. Dasselbe Stadium wie in Fig. 61. Vegetative Hälfte. Die Entodermplatte zähilt 32 Zellen. Sekundiires Mesoderm noch nicht ganz in das Innere eingesunken. Teilung von $2 a^{2.2 .1}$ und $2 c^{2.2 .1}$. Immersion.

Fig. 63. Ungefähr 182zelliges Stadium. Animale Hälfte. Das Krenz ziihlt 34 Zellen. Teilungen in den Intermedianzellen im vorderen Kreuzarme und in den hinteren Quadranten des dritten Quartetts (Immersion).

Fig. 64. Dasselbe; vegetative Hiilfte unmittelbar vor der Finsenkung des Entoderms. Die Entodermplatte ziihlt 32 Zellen. Der Keim asymmetrisch nach rechts verschoben. Teilung von $3 d^{2.1}$ und $5 e$ (Immersion).

Fig. 65. Vegetative Hälfte eines Stadiums von ähnlichem Alter 'die Gesamtzahl der Zellen im Keime betrig't indessen nur etwa 170 Zellen, das animale Kreuz zählt 38 Zellen). Die Entodermplatte zählt 34 Zellen. Erzengung des sechsten Quartetts in $5 A$ und $5 B$. Teilungen der Randzellen im zweiten Quartett. Teile des sekundiiren Mesoderms sind noch oberflichlich sichtbar (Immersion).

Fig. 66. Die Mesndermanlagen aus einem Keime mit 31 zelligem Kreuze. Beginuende Verdoppelung der Zellenzahl des sekundïren Mesoderms von 8-16: Differenzierung der Nephroblasten (nephr) $M^{1.1}$ und $M^{2.1}$.

Fig. 67. Vegetative Hälfte; das Kreuz zählt 40 Zellen, die Entodermplatte 38, Gesamtzahl 220 Zellen. Sehr regelmäßige Figur, um die Cruppierung der Rand- und Eckzellen der einsinkenden Entodermplatte zu zeigen. Teilung der Velarzellen $2 b 2.1 .1$ und 2 $b 1.2 .1$. Immersion.

Fig. 68. Animale Hailfte eines Keimes mit 38 zelligem Kreuze. Selten beobachtete Teilung der Tipzelle 2 b.1. Weitere Aufteilung des Kreuzes. Teilung von $2 c^{1.2 .1 .1}$. Verschiebung der ganzen Kreuzfigur nach vorn (Immersion).

Fig. 69. Dasselbe; Vegetative IIiilfte. Entodermplatte zählt 34 Zellen. Teilung von $2 b 1.2 .1,2 b 1.1$, anormale dritte Teilung von $3 d^{2} .1 .1$. Teilung im zweiten Quartett. Die Entodermplatte in der Gegend der Makromeren und des fuinften Quartetts tief eingestillpt. Die Makromere $4 D$ geteilt. 


\section{Tafel XXIII.}

Fig. 70. Gastrulationsprozeß weiter vorgeschritten als in Fig. 69. Die Entodermplatte tief eingesunken, teilweise Linstiilpung der ectodermalen Blastoporuslippen (Immersion).

Fig. 71. Vegetative Hälfte eines Gastrulastadiums mit beginnendem Verschluß der Blastoporuslippen. Teilung der Mikromeren des sekundiiren Mesoderms $3 b^{2.1 .2}$ und $3 a^{1.2 .2}$.

Fig. 72. Ein versilberter Keim mit 34 zelligem Kreuze. Animale Hälfte. Starke Verbreiterung der hinteren Trochoblasten samt dem Arme D. Das Kreuz gewinnt eine ankerförmige Gestalt infolge der Verschiebung nach vorn.

Fig. 73. Ein Teil der animalen Hälfte eines Keimes mit 53 zelligem Kreuze. Weitere Aufteilung der Basalzellen in seitlichen Armen des Kreuzes. Die Basalzelle des Armes $b$ noch immer ungeteilt. Die Apicalzellen merklich vergrößert. Das Kreuz beginnt sich in zwei seitliche Zellgruppen zu zerteilen (Immersion).

Fig. 74. Animale Hälfte eines Keimes mit 71 zelligem Kreuze und weit offenem Gastrulamunde. Das Kreuz in zwei polsterartige Zellgruppen (die künftigen Scheitelplatten) aufgelöst. Der Arm $D$ und die Apicalzellen werden durchsichtig und flach. Die äußeren Medianzellen des Vorderarmes 1.b1.2.2.1 und 1 161.2.2.2 geteilt; der Vorderarm vierzeilig. Die transversalen Arme sind wegen der starken Zellvermehrung nicht mehr bestimmbar (Immersion).

Fig. 75. Vegetative Hälfte eines späten Gastrulastadiums. Der Urmund stark verengt, weit nach vorn gerückt. Die seitlichen Zellengruppen der Quadranten $a$ und $c$ treten polsterförmig hervor.

Fig. 76. Animale Hälfte eines Keimes mit 45 zelligèm Kreuze. Auffallende Verbreiterung des vorderen Armes; Teilung von 161.2.1.2.1.1 und 161.2.1.2.2.1 (Immersion).

Fig. 77. Stadium mit hoher Kopfblase, scharf abgegrenzten Scheitelplatten und sehr stark verengtem Blastoporus. Schicksale der Apicalzellen. Silberpräparat (Immersion).

Fig. 78. Ein etwas jüngeres Stadium. Kopfblase von oben gesehen, um das Verhalten der beiden seitlichen und der hinteren Tipzellen zu zeigen. Silberpräparat.

Fig. $79 \alpha$. Seitenansicht eines Embryos mit angelegter Schalendrüse und Radulatasche. Zusammensetzung des Velums.

Fig. $79 b$. Idem von der Bauchseite, um das Velum, die durchsichtige Scheidewand zwischen den Scheitelplatten, sowie die aus hellen Zellen gebildete Furche zwischen den beiderseitigen Fußhöckern zu zeigen. Beide Figuren nach einem Silberpräparate.

Fig. 80. Zusammensetzung des Velums einer älteren Larve mit begonnener Torsion. Rechte Seite.

Fig. 81. Optischer Längsschnitt dureh ein Gastrulastadium. Blastoporus stark verengt, aber noch immer offen; lange Fortsïtze der Entodermzellen gegen das Ectoderm. Teilung von $M 2.2$ und $m^{1}=e$, letztere soll mit der kleineren, geteilten Zelle verbunden werden.

\section{Tafel XXIV.}

Fig. 82. Mesoderm bei Beginn der Gastrulation. Elzengung des siebenten Mikromerenpares, das dritte $\left(m_{3}\right)$ in Teilung begriffen (Immersion).

Fig. 83. Mesoderm eines etwas jüngeren Stadiums, die medianen Makro- 
meren haben erst die Furchungsspindeln ausgebildet. Mikromere $m_{3}$ noch ungeteilt. rler ganze Embryo asymmetrisch, nach links verschoben Immersion .

Fig. 81. Jesoderm einer Gastrula mit ziemlich hoher Kopfblase. Die medianen Makromeren sind seitwïrts auseinandergewichen. Erste 'Teilung der medianen Mikromeren $m_{1}$ (Immersion).

Fig. 85 a. Mesoderm eines jüngeren Stadiums; $M_{1.2+.}$ und $M_{2.2+\ldots}$ stoßen noch in der Mittellinie zusammen; die rorderen Nephroblasten $N^{2}$ erzeugen das achte Mikromerenpaar $\left(m_{8}\right)$ (Immersion).

Fig. $85 \mathrm{l}$. Die rechte Crnierenanlage eines andern Embryos, die Mikromere $m_{\mathrm{s}}$ wird nach innen abgegeben. Das sekundïre Mesoderm umgilt den vorderen Nephroblasten (Immersion).

Fig. 86. Horizontalschnitt durch ein Gastrulastadium. Beide Mikromeren $m_{1} m_{1}$ in Teilung. Anlage des Enddarmes. Vorn die eingestülpten Mikromeren $m i$ des dritten Quartetts.

Fig. 87. Uptischer Sagittalschnitt einer G'astrula. Die Anlage der rechten Urmiere, die ron sekundïren Mesodermzellen und Mikromeren des primären Mesoderms ganz umhüllt ist, $N_{2}$ in Teilung.

Fig. 88. Lrniere in ihrer vollendeten Ausbildung. Die Wimperzelle mit äußeren Cilien. Urnierenkanal knieförmig.

Fig. $89 a$. Lrniere aus fünf Zellen zusammengesetzt: mittleres Stadium.

Fig. $89 \mathrm{~b}$. Ein Stück der Urniere eines älteren Stadiums, der Lrnierenkanal dringt in die ansführende Zelle ein.

Fig. 90. Crniere aus vier Zellen zusammengesetzt, kurz vor ihrer endgültigen Konstituierung. Schnitt aus einem Veliger-Stadium.

Fig. 91. Sagittalschnitt eines Gastrulastadiums. Beginnende Differenzierung der Entodermzellen; die Mikromeren $m_{1} m_{1}$ geteilt, Verhältnis der eingestiilpten Mikromeren mi zum Archenteron.

Fig. 92 a. Larve mit hoher Kopfblase, mit Velum, mit der Anlage der Schalendruise, des Stomodäums, des Fußes und Enddarmes.

Fig. $92 b$. Idem. Optischer Sagittalschnitt.

Fig. 92 c. Idem. Hintere Archenteronwand mit der Darmplatte und Anlage des Enddarmes. Bildung der hinteren Urmesodermstreifen aus $\mathbb{M} / 2+. ., M^{2} 2+\ldots$

\section{Tafel XXV.}

Fig. 93 \%. Embryo mit erster Anlage der Schalendriise. Querschnitt durch den Oesophagus, an dessen Einmindungstelle in den Mitteldarm.

Fig. 93 b. Vierter Schnitt derselben Serit Immersion: Darmplatte rechts stärker ausgebildet als links, ventralwärts vertieft und mit der Anlage des Enddarmes verlötet.

Fig. 93c. Der nächstfolgende Schnitt; die Anlage des soliden Darmstranges tritt noch deutlicher hervor, derselbe ist beiderseits von den Eiweißzellen umfaßt, proximalwärts mit der Darmplatte. distalwärts mit der Analzelle verbunilen.

Fig. $94 a-d$. Querschnitte durch ein jiingeres Stadium wie das vorhergehende: $a$. mittlerer, $l,-d$, drei weitere aufeinanderfolgende Schnitte durch die Ehene des Enddarmes. Die Anlage des letzteren noch sehr plump. Bildung der hinteren Mesodermstreifen.

Fig. 95 $a$ and $b$. Zwei unmittell ar aufeinanderfolgende Sagittalschnitte einer Trochophora. Einstiilpung der Schalendrise. Ablenkung des Enddarmes nach unten und hinten, die kleinzellige Partic des Mitteldarmes an der Gastralseite 
schon mit dem Oesophagus verbunden, an der Dorsalseite nähert sie sich erst demselben.

Fig. 96. Jüngeres Stadium. Rechter paramedianer Schnitt einer Sagittalserie. Die Darmplatte noch schwach ausgebildet, Enddarm wach rechts abgelenkt

Fig. 97. Querschnitt durch die Ebene des Enddarmes, die Darmböble in lorsoventraler Richtung eingedriickt und um die Horizontalachse gedreht. Fintere Mesodermstreifen bilden sich zu Platten um.

Fig. 98a. Embryo mit erster Anlage der parigen Radulatasche anßerhalb der primären Mundhöhle.

Fig. $98 b$. Frontalschnitt der Radulaanlage und des Stomodäums eines gleichalterigen Stadiums.

Fig. 99. Totalansicht einer jungen Larve mit wohl ausgebildetem Velum. Urniere, Radulatasche, Fuß und mit niedriger Kopfblase.

Fig. 100. Der ganze Darmkanal einer Larve fast desselben Alters von rechts. Der blinde Divertikel des Mitteldarmes im regen Wachstum begriffen.

Fig. 101. Ein Teil einer Larve wie in Fig. 99 von der Bauchseite gesehen, die beiden Streifen des Urmesoderms zu Platten umgebildet, die symmetrisch zu beiden Seiten des Enddarmes (ed) liegen. Die Analzellen sichtbar.

Fig. 102. Sagittalschnitt durch den Oesophagus; zeigt die Ausdehnung der kleinzelligen Darmwand.

Fig. 103. Rechter Paramedianschnitt durch ein etwas älteres Stadium, der Enddarm teilweise vom blinden Divertikel des Magens verdeckt.

Fig. 104a. Anlage der definitiven Niere. Der Schnitt geht auf die linke Hälfte des Embryos iiber.

Fig. 104b, Die Nierenanlage stärker vergrößert, um die charakteristischen Mesodermzellen zu zeigen.

Fig. 105. Sagittalschnitt durch die mesodermale Nierenanlage. Anscheinende Auswanderung der Ectodermzellen (Immers.).

\section{Tafel XXVI.}

Fig. 106. Ältere Larve vom Riicken. Einstiilpung der Scheitelplatten iiber dem Velum, Anlage der Nuchalzellen (nu); Oesophagus und Schalendrüse nach rechts abgelenkt, die diinne Riickenhant aus denselben 13 Zellen zusammengesetzt, welche rursprünglich die Kopf blase bildeten.

Fig. 107. Darmkanal einer etwas älteren Larve in drei Ansichten: $a$, vom Riicken, $b$, von der Bauchseite, $c$, von rechts.

Fig. 108. Darmkanal einer bedeutend älteren Larve im optischen Längsschnitt. Der Enddarm kommuniziert noch nicht mit der Magenhöhle.

Fig. 109. Etwas schiefer Frontalschnitt durch den Oesophagus und den Enddarm eines bedentend jiingeren Stadiums. Enddarm nach links ausgebogen.

Fig. 110. Ein ans mehrerer Schnitten kombiniertes Bild, um die Konfiguration des Darmkanals an diesem Stadium zu veranschaulichen.

Fig. 111. Erwachsener Embryo nach Abnahme der kleineren rechten Hiilfte. Uniere und Nuchalzellen in Rïckbildung; Euddarm und Niere links, Faltung der Magenwand und Leberdivertikel.

Fig. $112 a, b$. Zwei anschließende Frontalschnitte, Bauchseite. Nierenanlage durch eine Zellbriicke mit der rechten Platte des Urmesoderms verbunden.

Fig. 113. Schnitt durch den Oesophagus, Radulatasche und Fuß. Anlage der Ganglien und Sinnesorgane, Iage der Nuchalzelleu, Wimperzellen, ()rientierungssehnitt. 
Fig. 114. Einstiilpung der Augengrube.

l'ig. 115. Aus drei sagittalschnitten kombiniertes Bild. Iage ter drei Hauptganglien.

Fï. 116. Frontalschnitt. Ausgrobildetes Starlium. Schließliche Lage der Nuchalzellen. selben.

Fig. 117. Nuchalzellen, $a$ beim Beginn der Rückbildung; $b$ zu Ende der-

Fig. 118. Bildung des Ausfihhrungsganges des Nierensïckchens.

Fig. 119. Embryo beim Beginn der Ausbildung der Atemhöhle.

Fig. 120. Erwachsener Embryo von der linken Seite kurz vor dem Ausschliipren. Einsenkung $x$ entsjuricht rielleicht der Riechgrube andrer Formen FoLs s fossette olfact.e).

\section{Tafel XXVII.}

Alle Figuren beziehen sich auf die slictosomene, wolehe in tiefblaner Farbe hervorgehoben sind.

Fig. 1. Die Makromere eines l̈bergangsstadiums von 12-16 Zellen im Asterstadium. Ine letosomen außerhalb der Sphäre, an der veutralen Zellhailfte.

rig.2. Achtzelliges Stadium unnittelbar vor der T'eihng der vier Makromeren. vegetative Hälfte. Einer der Kerne bereits in Prophase. Lage der Eotowomen unmittelbar über den Kernen.

Fig. 3. Lüngsschnitt durch ein achtzellimes Stadium. alle Nakromeren haluen bereits die Teilunusspinclel ausgelbildet. Ectosomen liegen im Dotter eingebettet unmittelbar unter der ventralen Oberflïche.

Fig. 4. Ein etwas älteres achtzelliges Stadium, in dem sich bereits alle Makromeren im Asterstadium betiudeu. Tom vegretativen I'ol. Lage und fiestalt der Ectosomen. Sphïre.

Fig. 5. Hakromere eines 16 zelligen Stadiums. E.tosomen im Linkreis der

Yig. 6. Die verretative I'olarfurche eines 24 zelligen IRuhestadiums. C'harak teristische Lage und Gestalt der Eetosomen.

Fig. 7. Längsschnitt durch ein 24 zelliges Stadium. Die Ectosomen beginnen sich centralwärts längs der Hauptachse zu bewegen.

Fig. 8. Fin Teil eines Längsschnittes vom 24 \%elliren Stadium. Vegetative Eihälfte. Die Ectosomen zichen in Form von Kümchenstreifen gegren das Eicentrum.

Fig. 9. Längsschnitt durch ein 24 zelliges Stadium. Jie Kctonomen nähern sich dem Eicentrum.

Fig. 10. Idem. Die lictosomen haben bereits die spitze der kegelfïrmigen Fortsïtze der Makromeren erreicht.

Fig. 11. Idem. Im Simmelpunkte der Fortsitze aller 24 Blastomeren ein stark vacuolisierter Raum. Wir lictosomen beginnen zu verschwinden.

Fig. 12. Idem. Von den Ectosomen nur noch eine undeutliche Spur in einer Makromere. Die centralwirts grerichteten spitzen der Ectosomen nach Fuchsintärbung stark gerötet. 

Zeitschrift f.uzss. Zoologie Bd.LXXYIII.

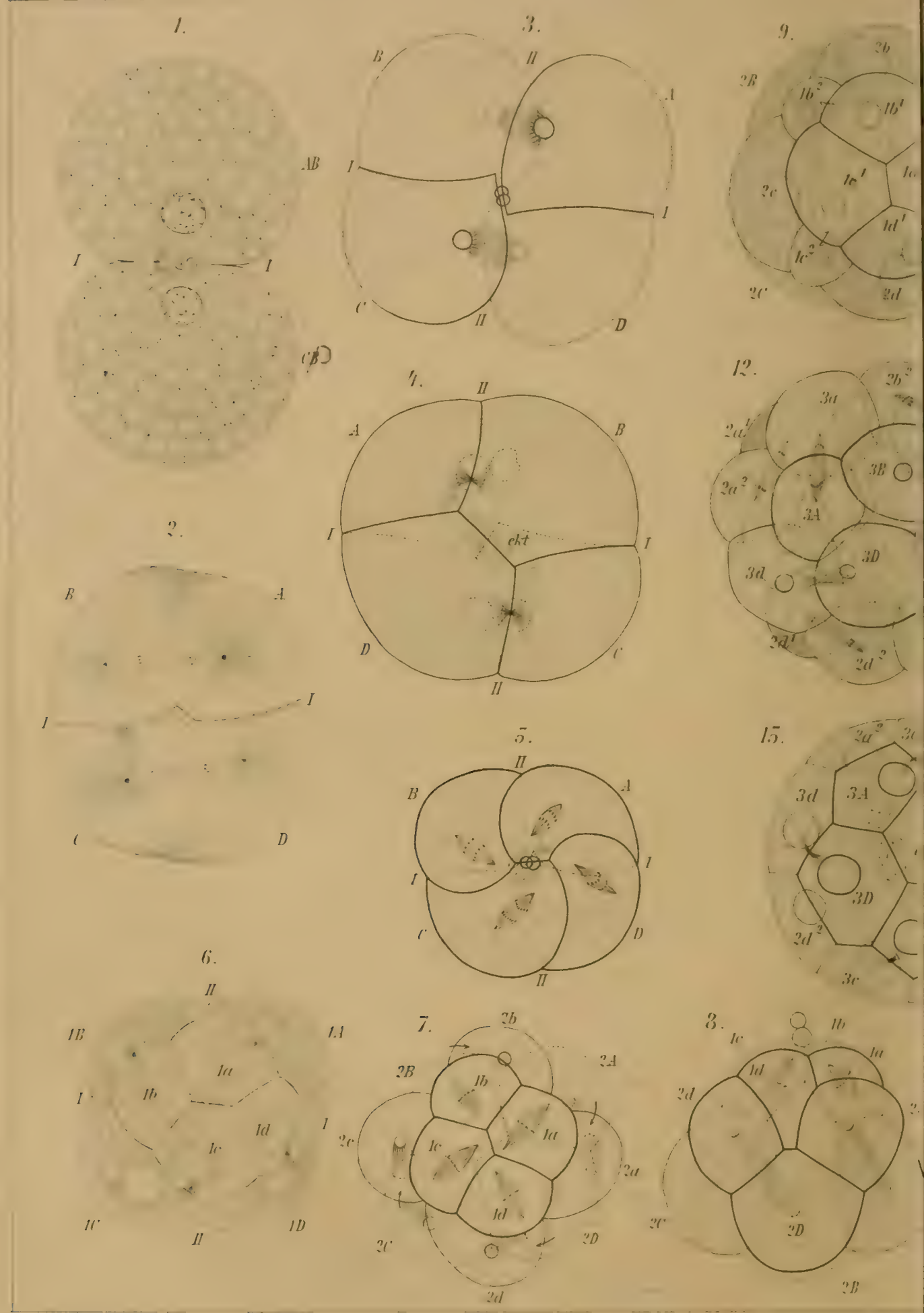




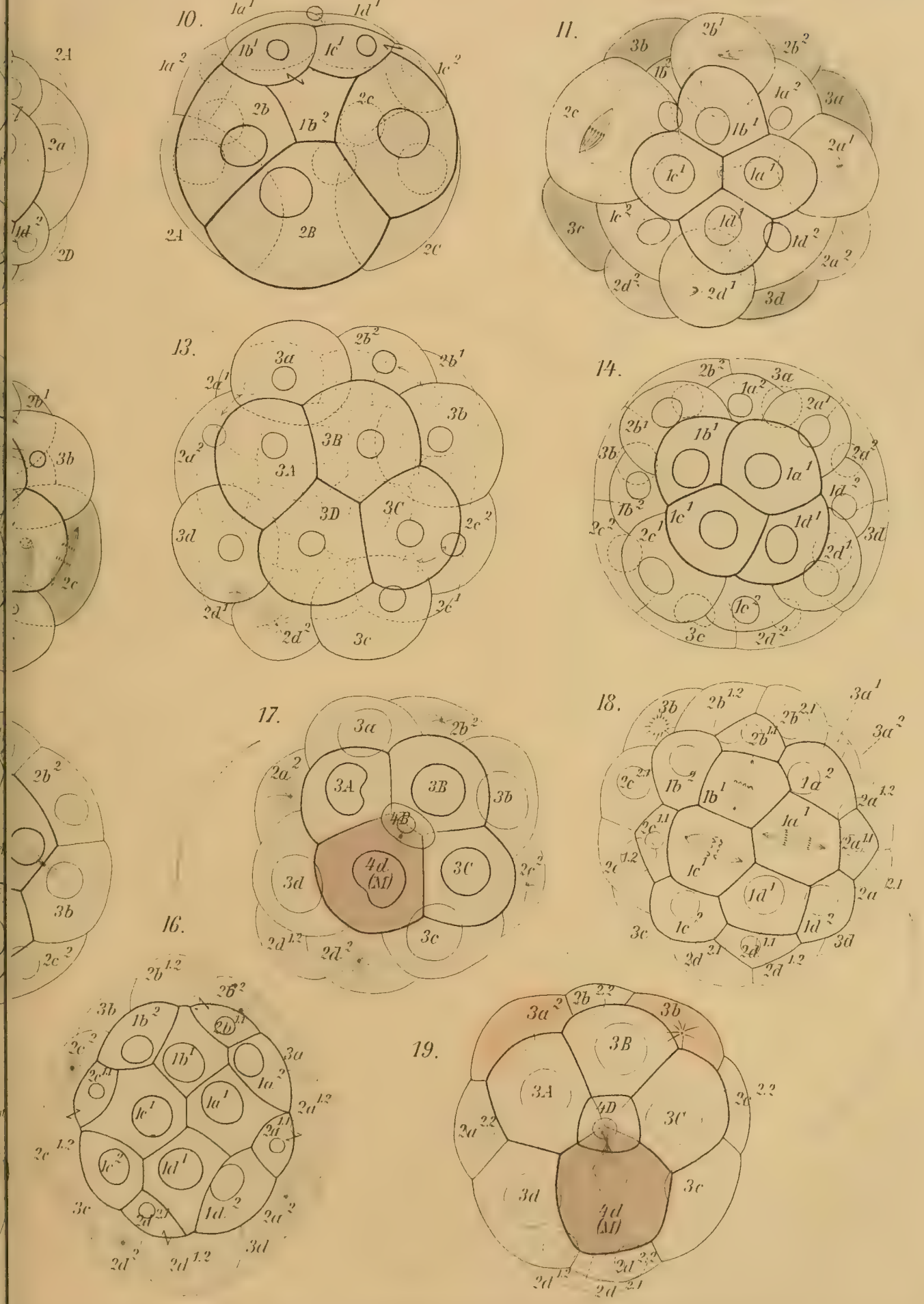




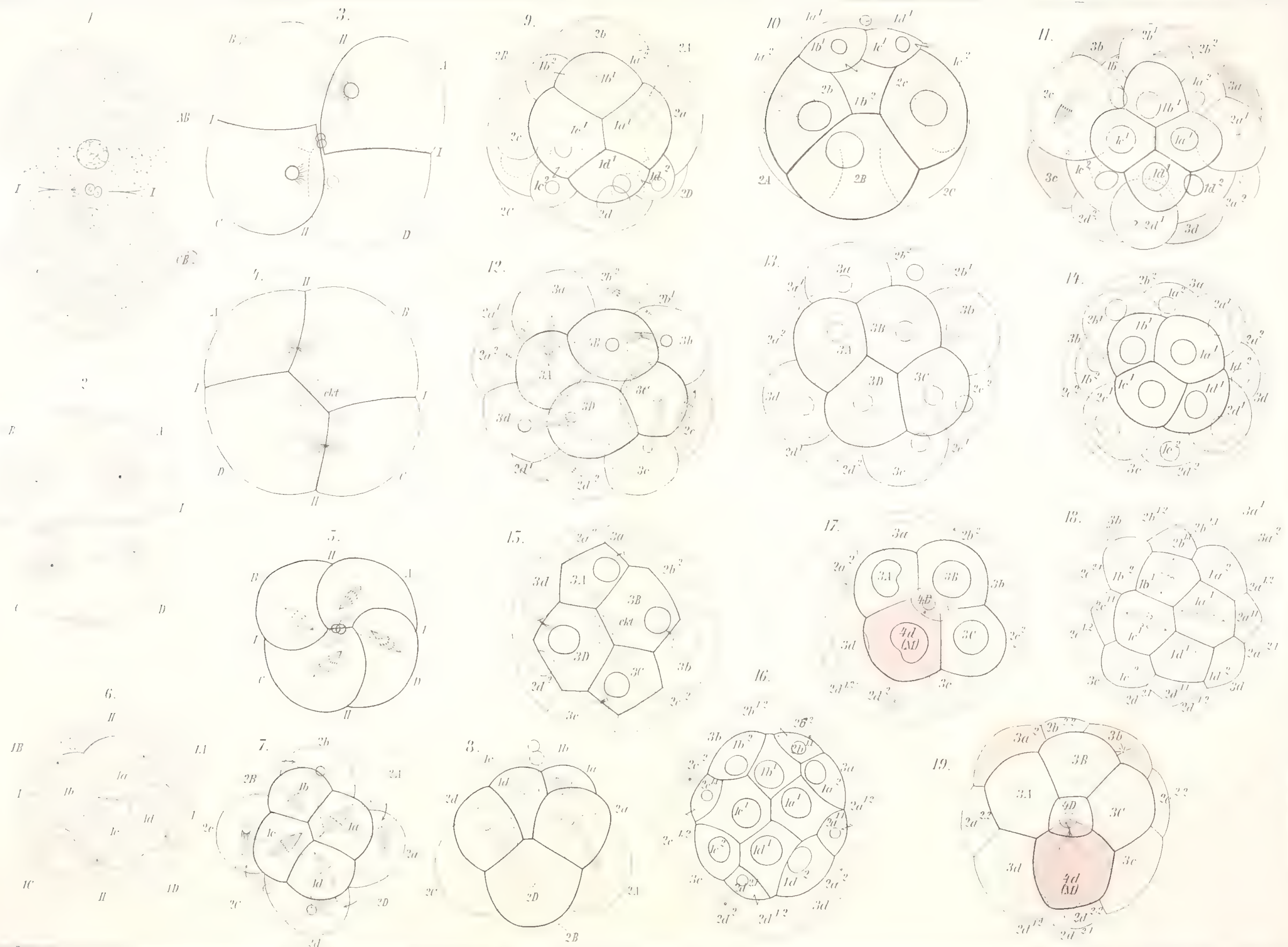




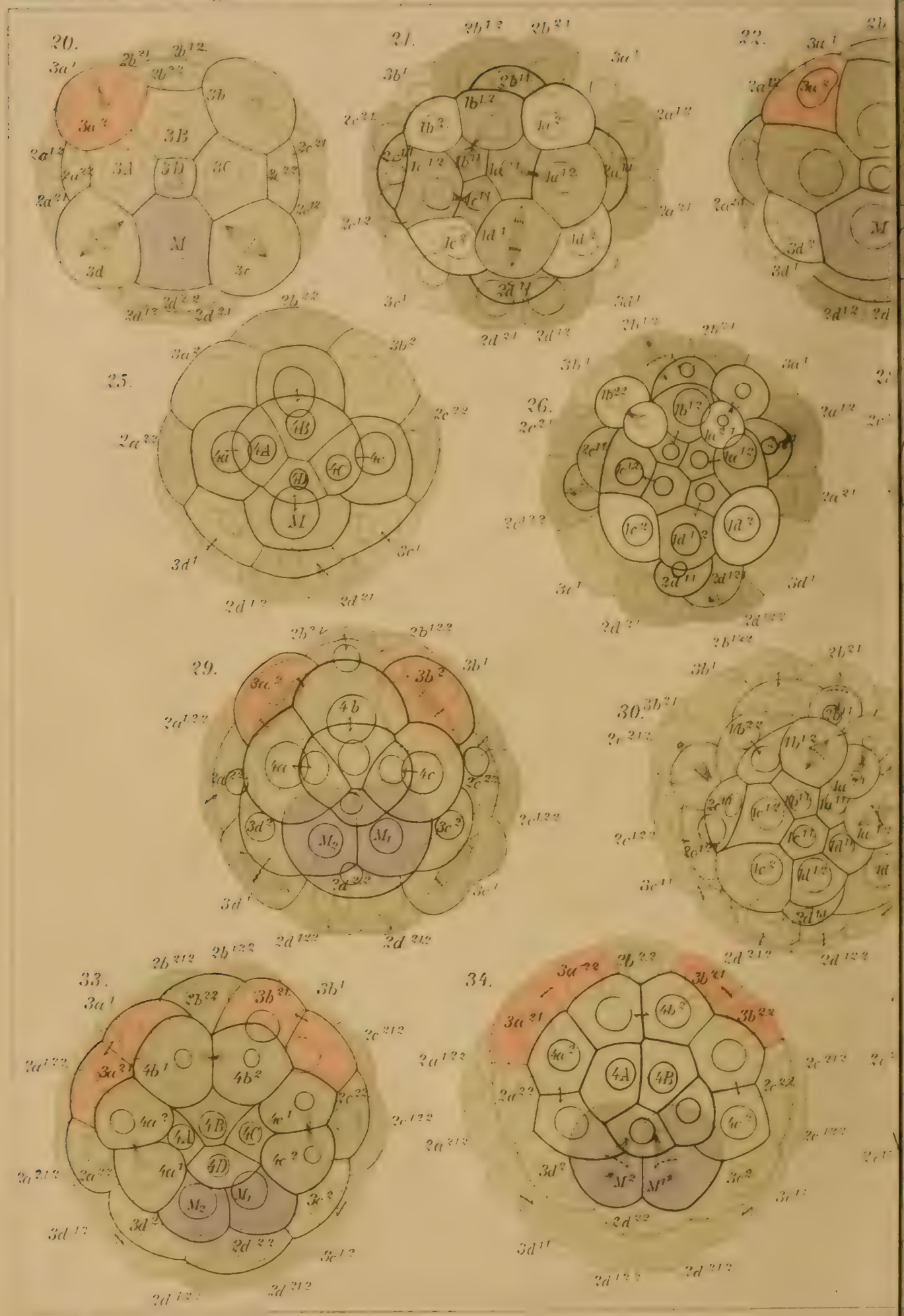




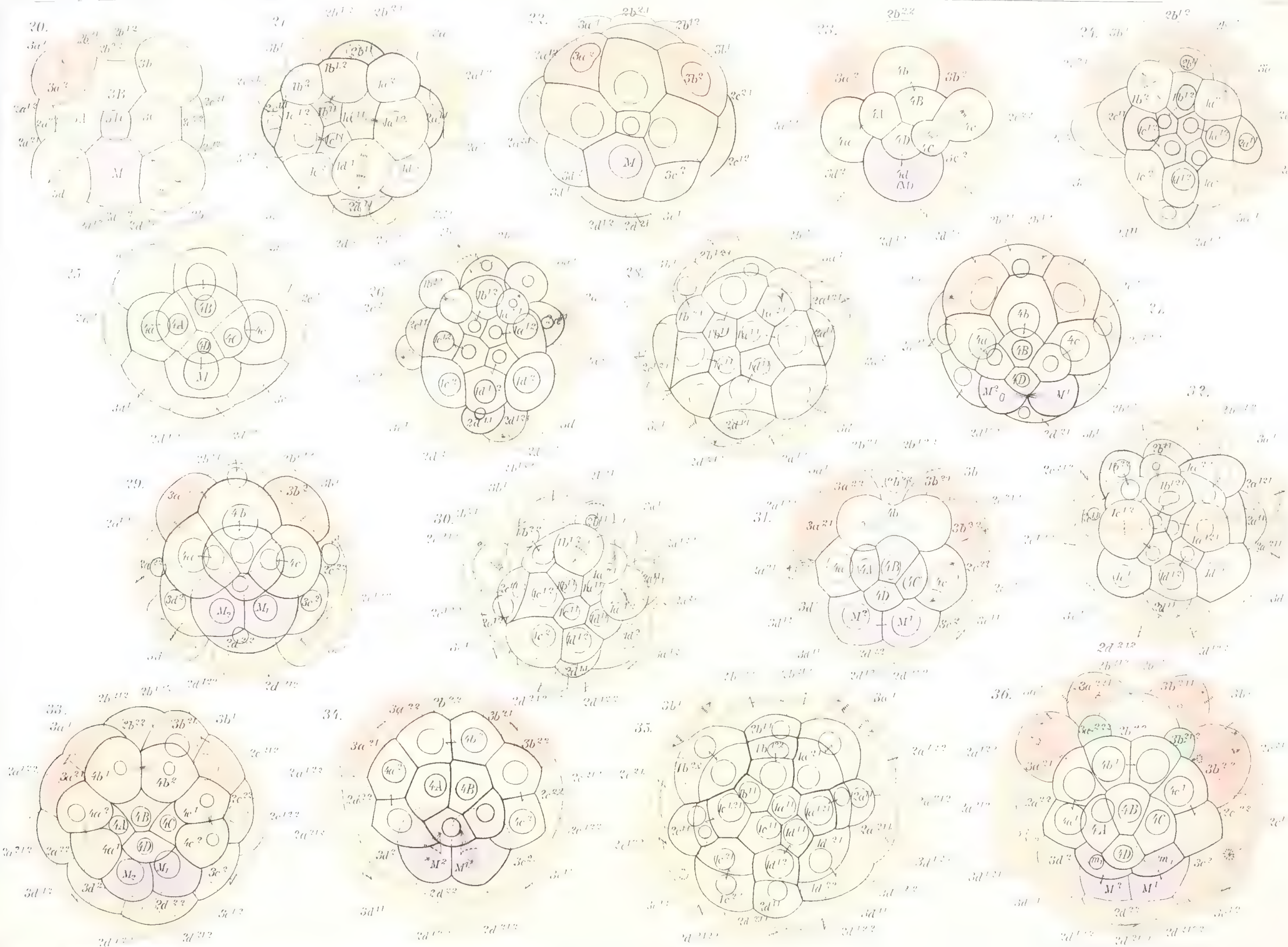



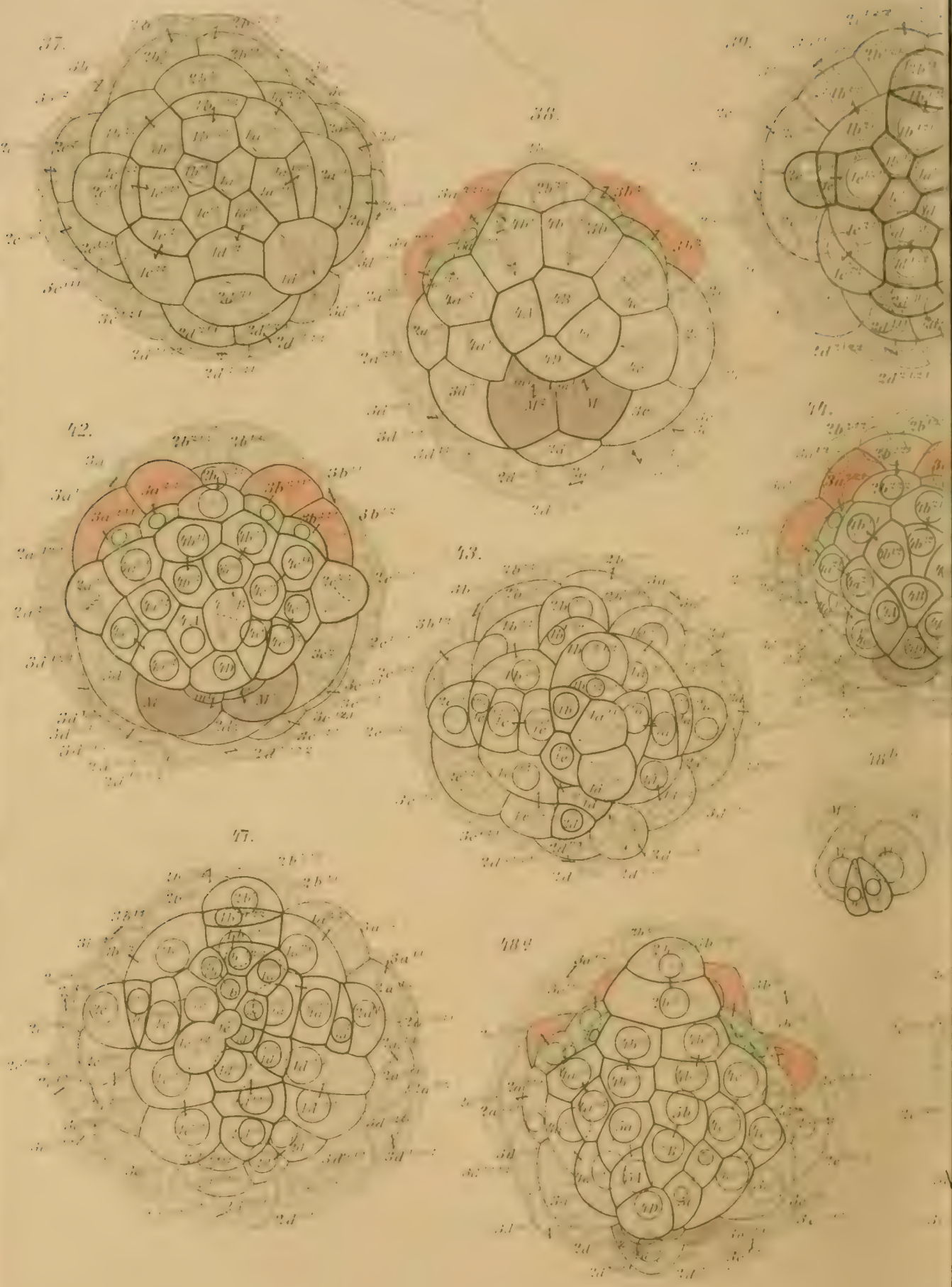

Veridy Wilhelr 


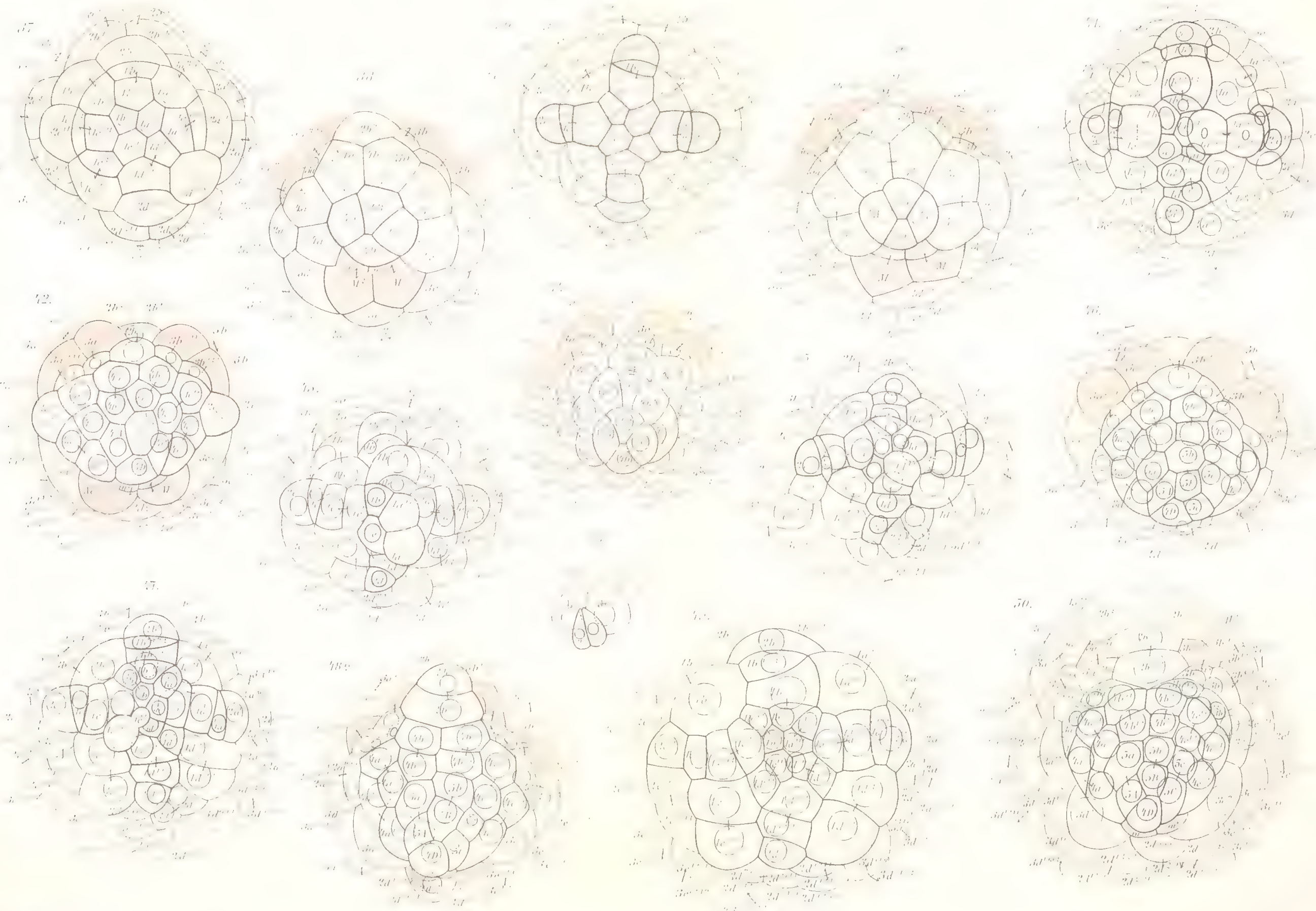



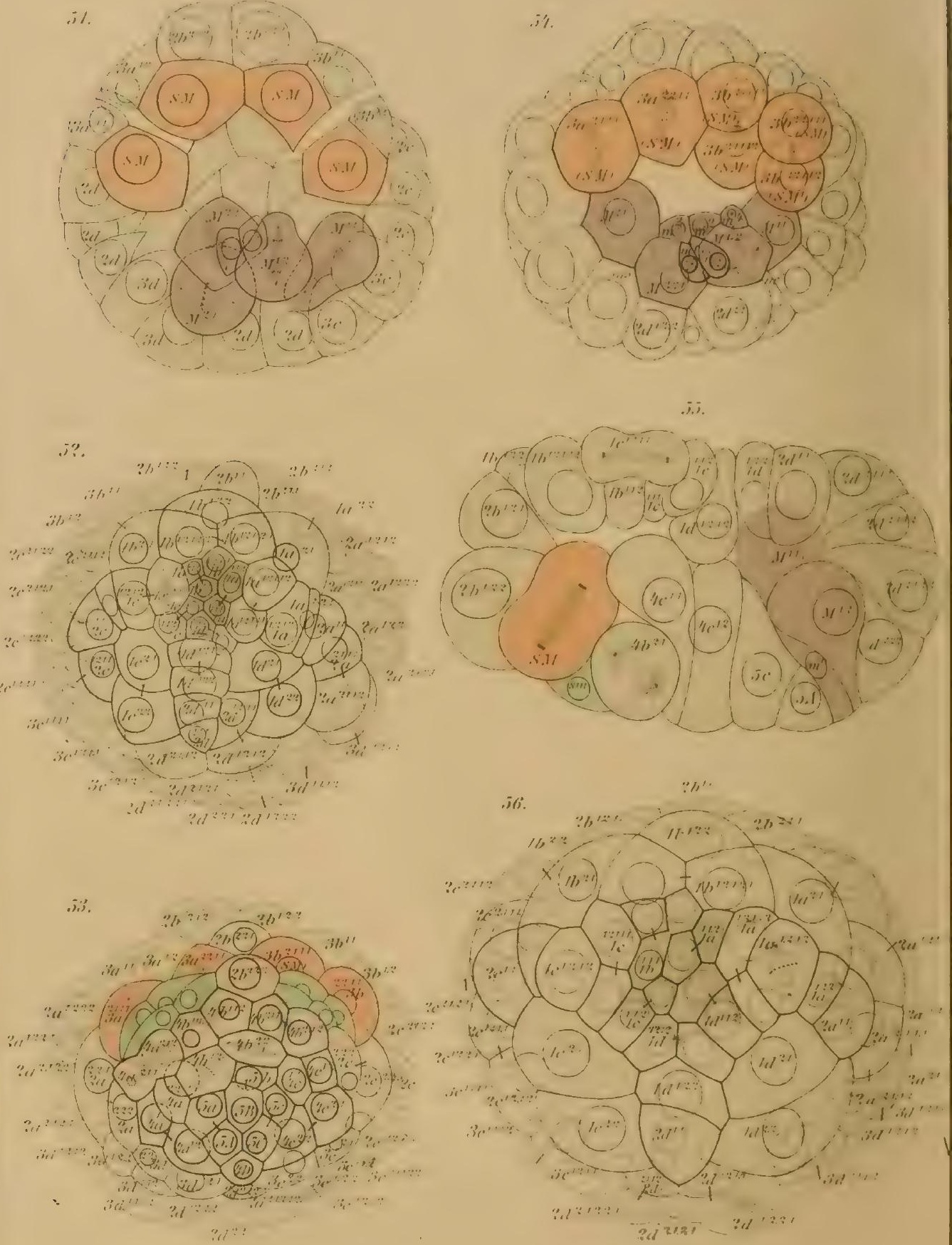
58.

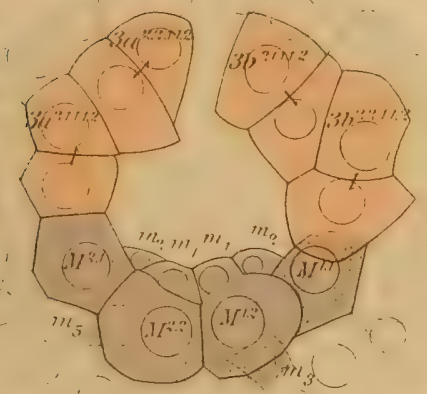

i\%
.99.

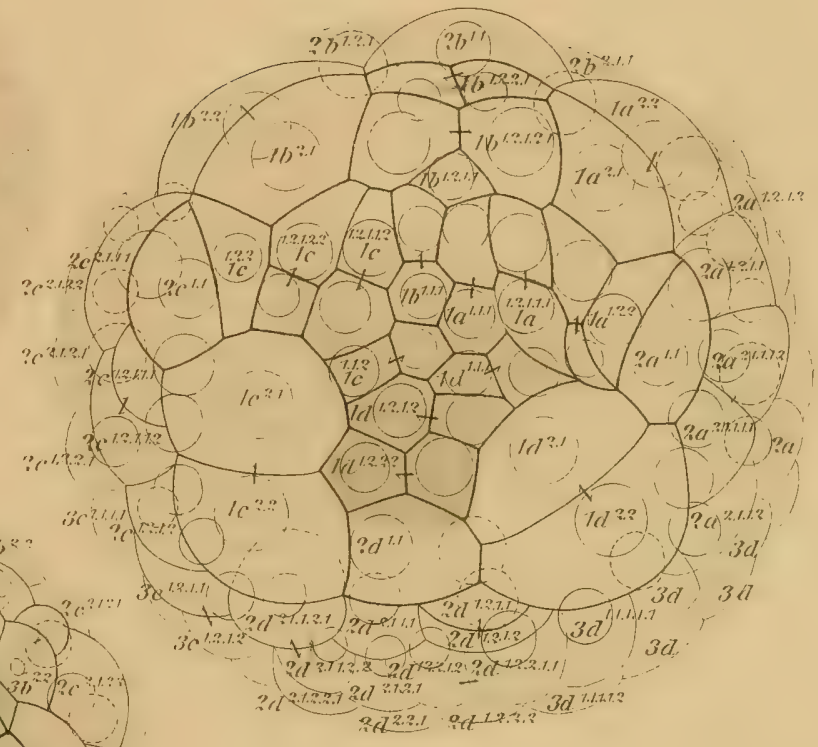

(6)

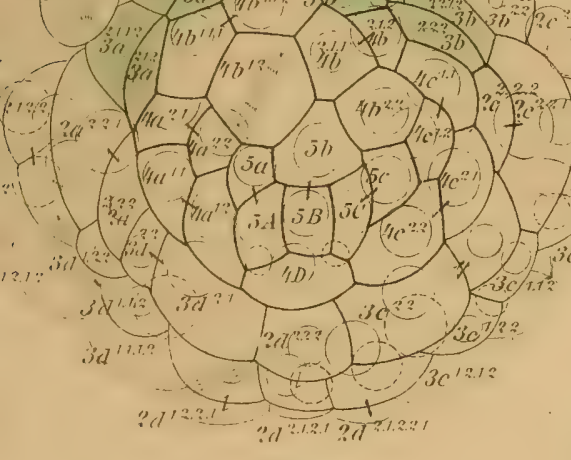

(i).
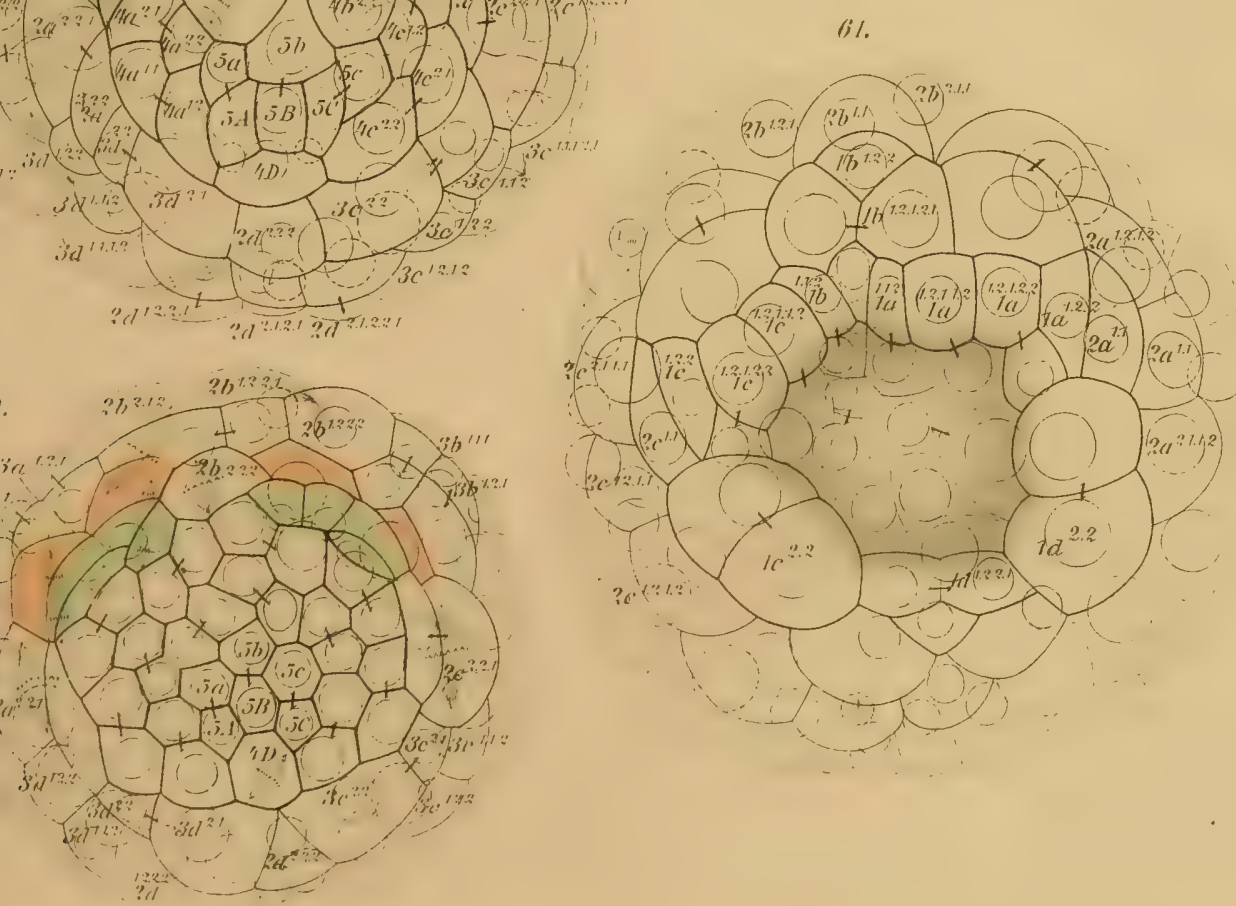



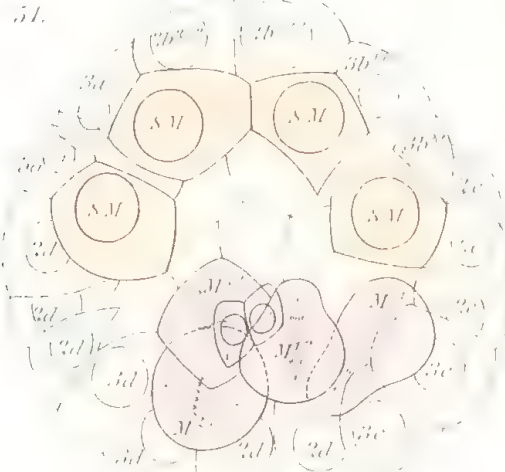

.$i \%$

ii).
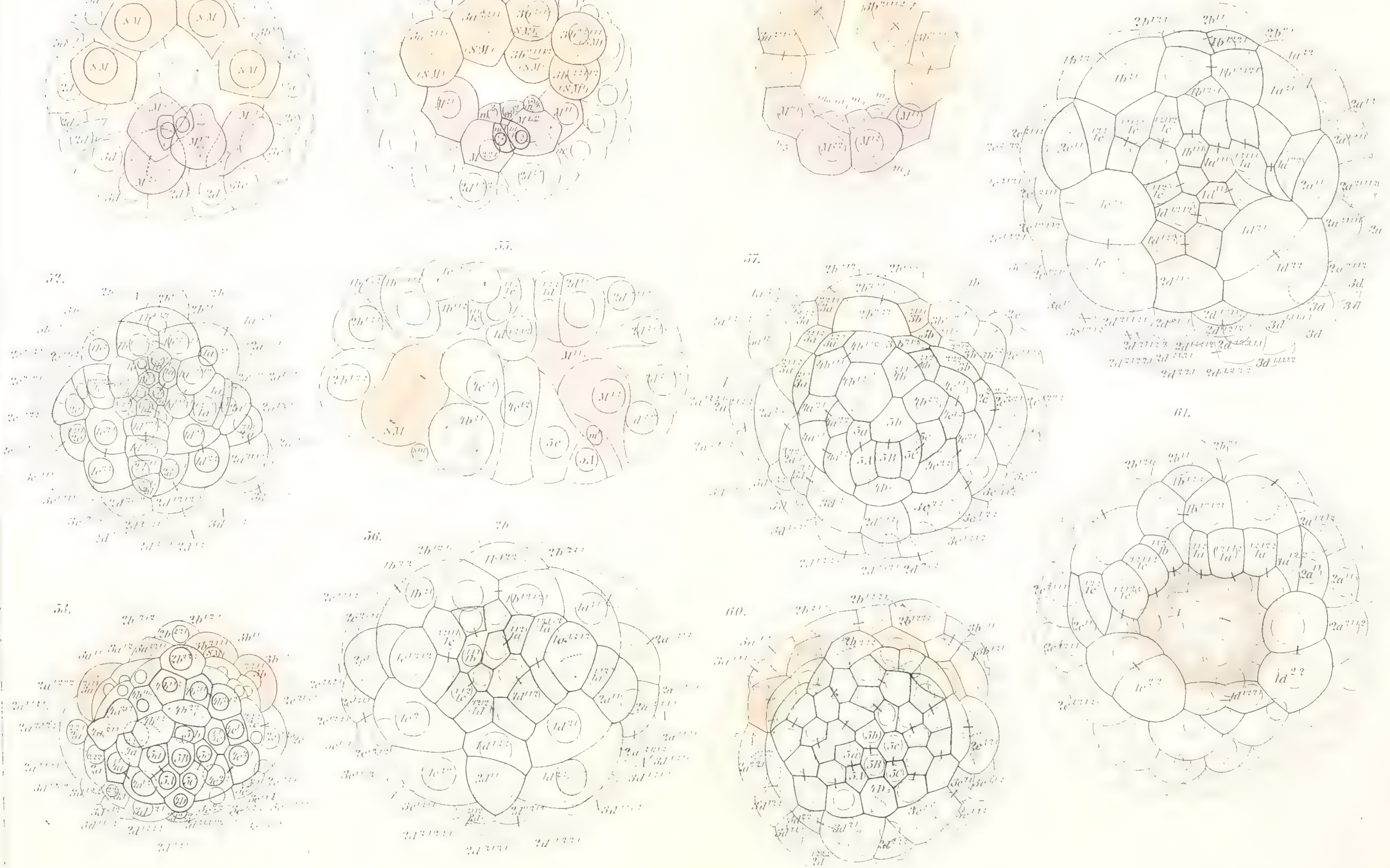




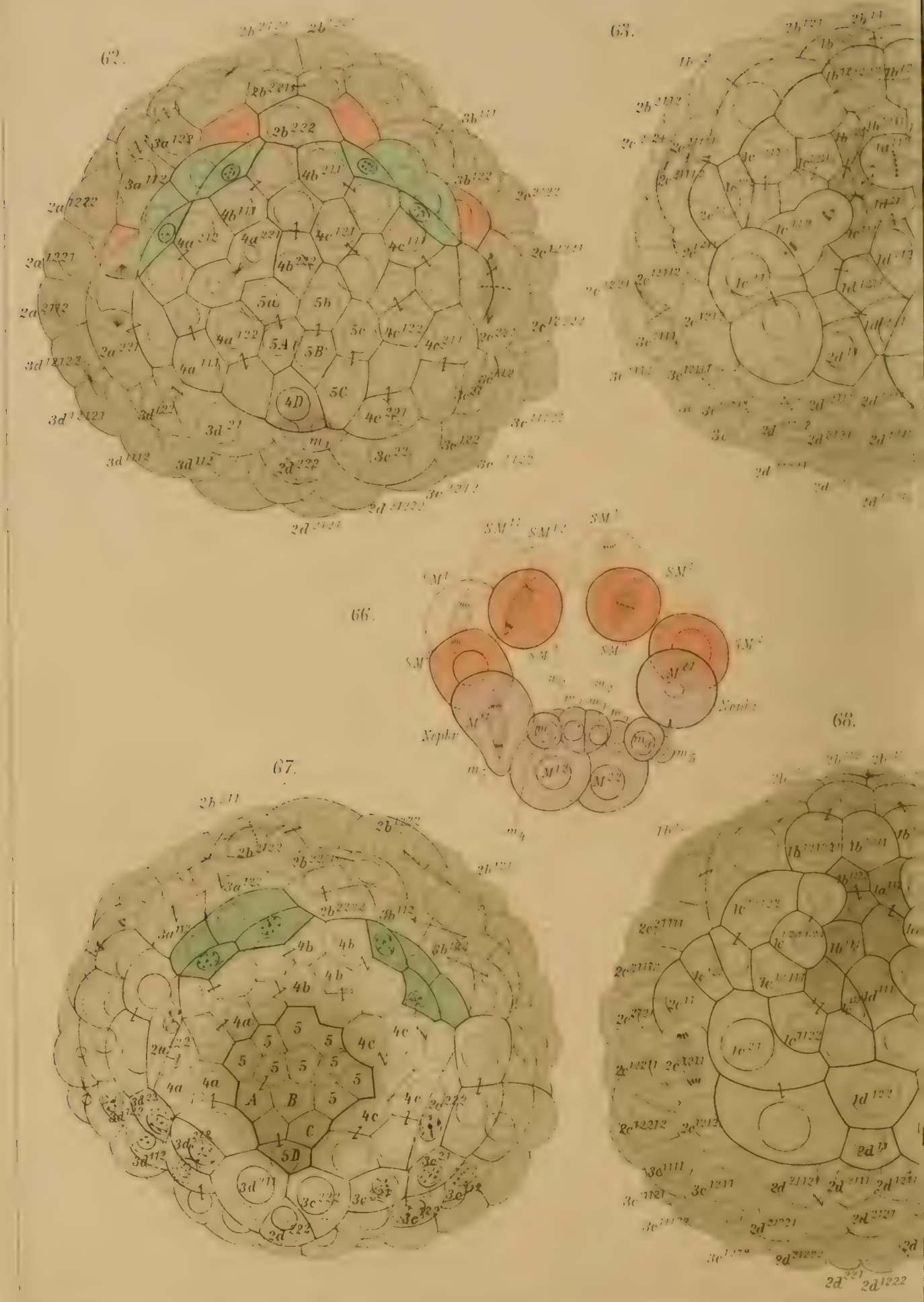





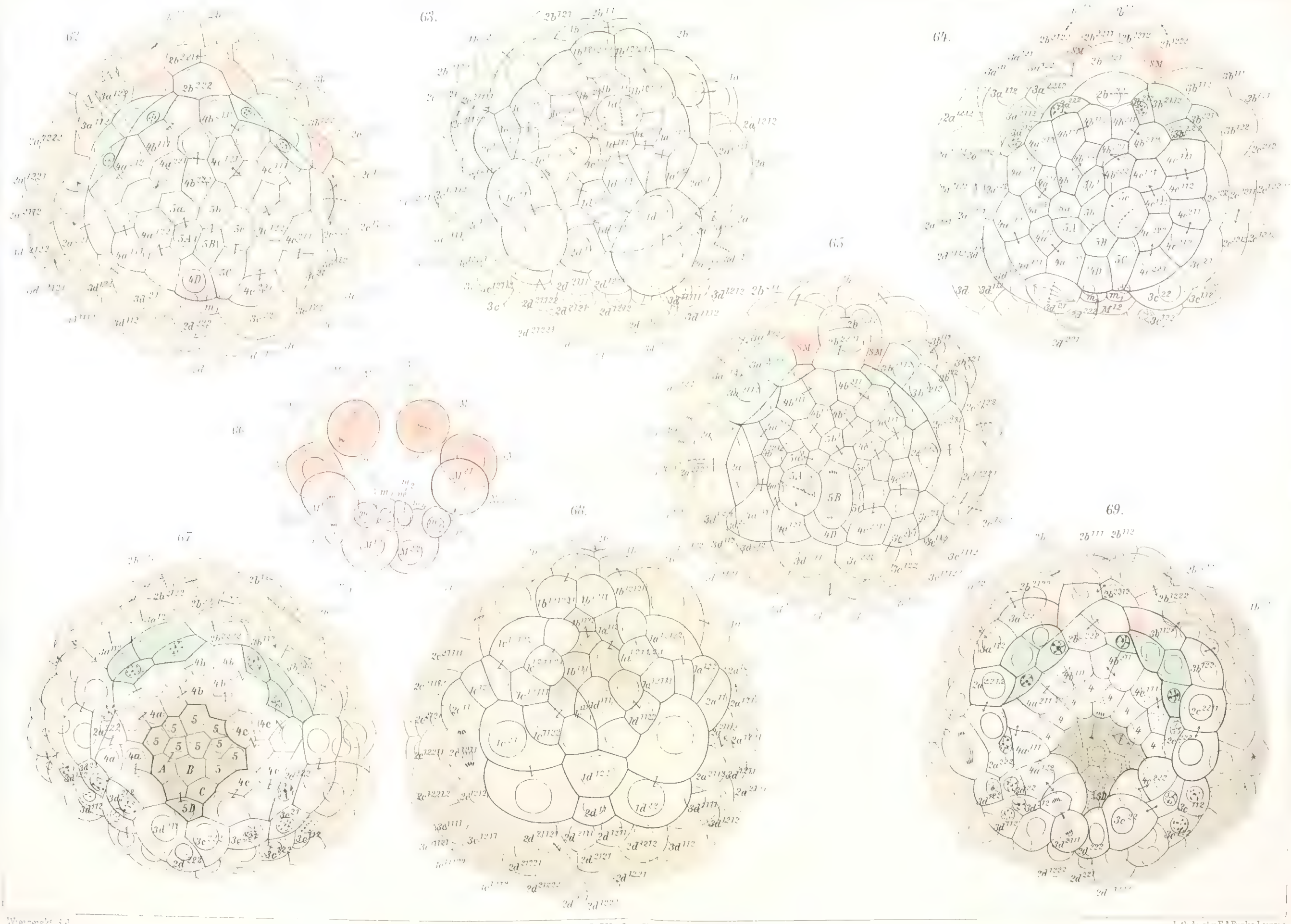






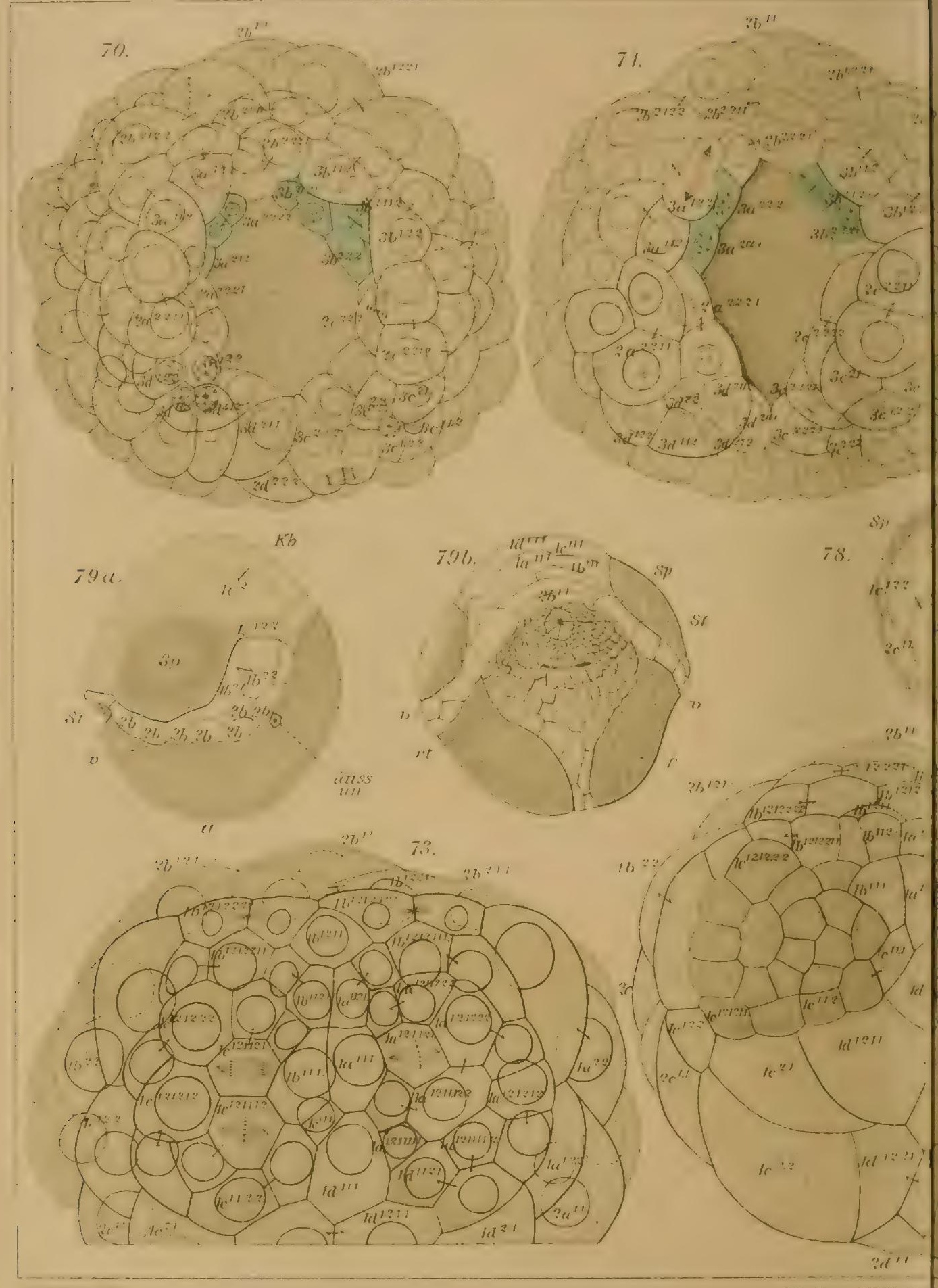

Verlag $v$. Wilhelrn 


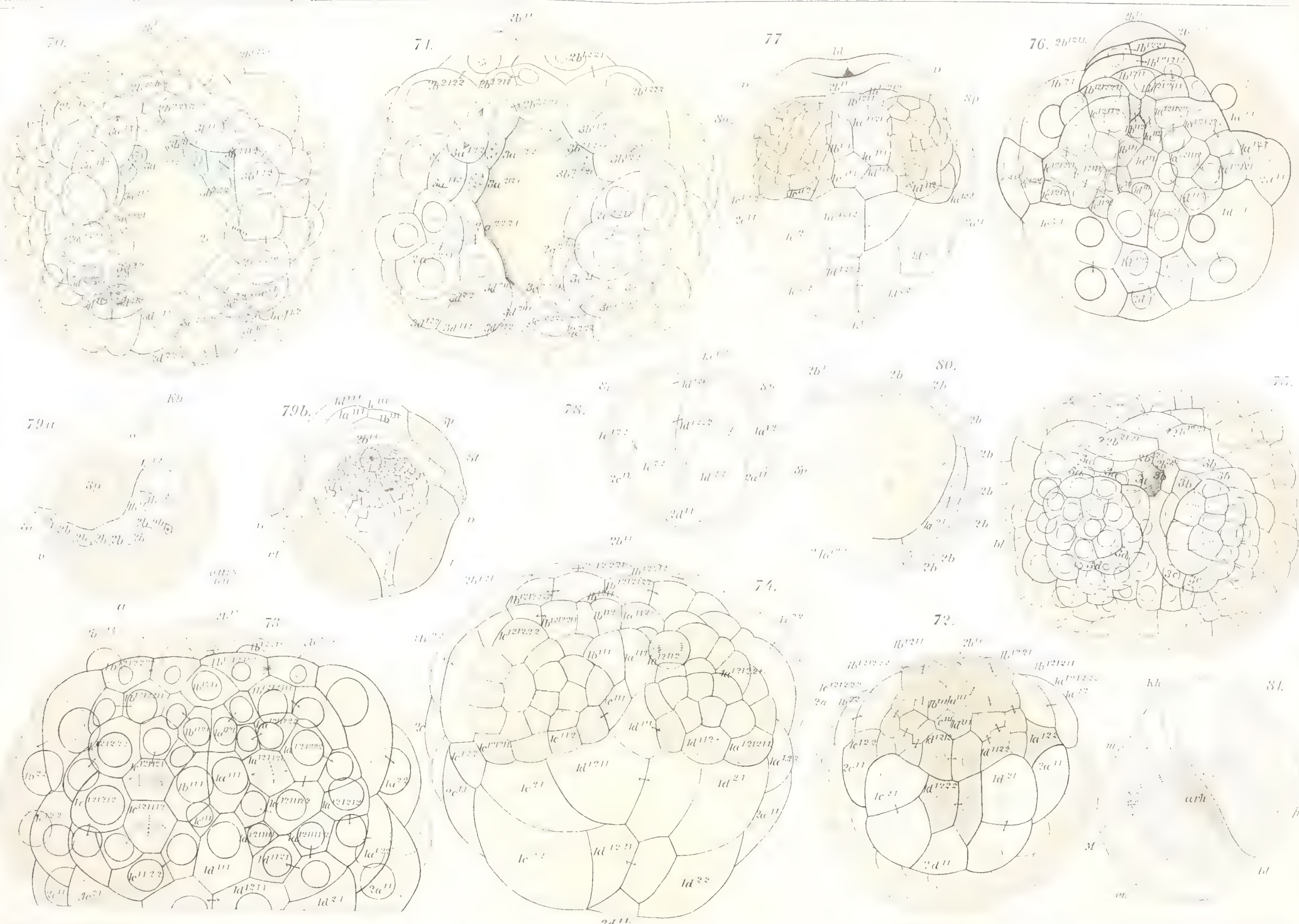

,
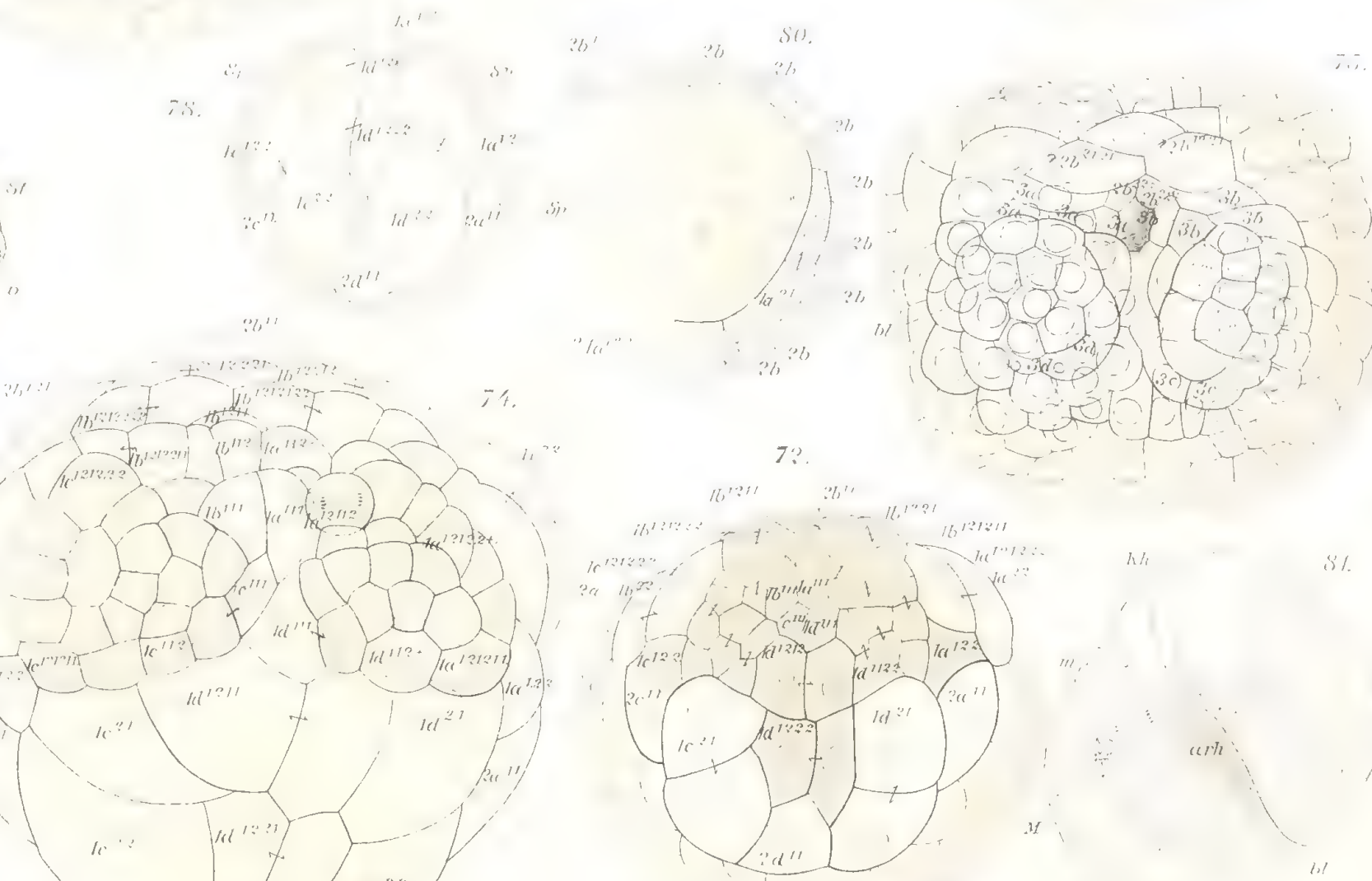




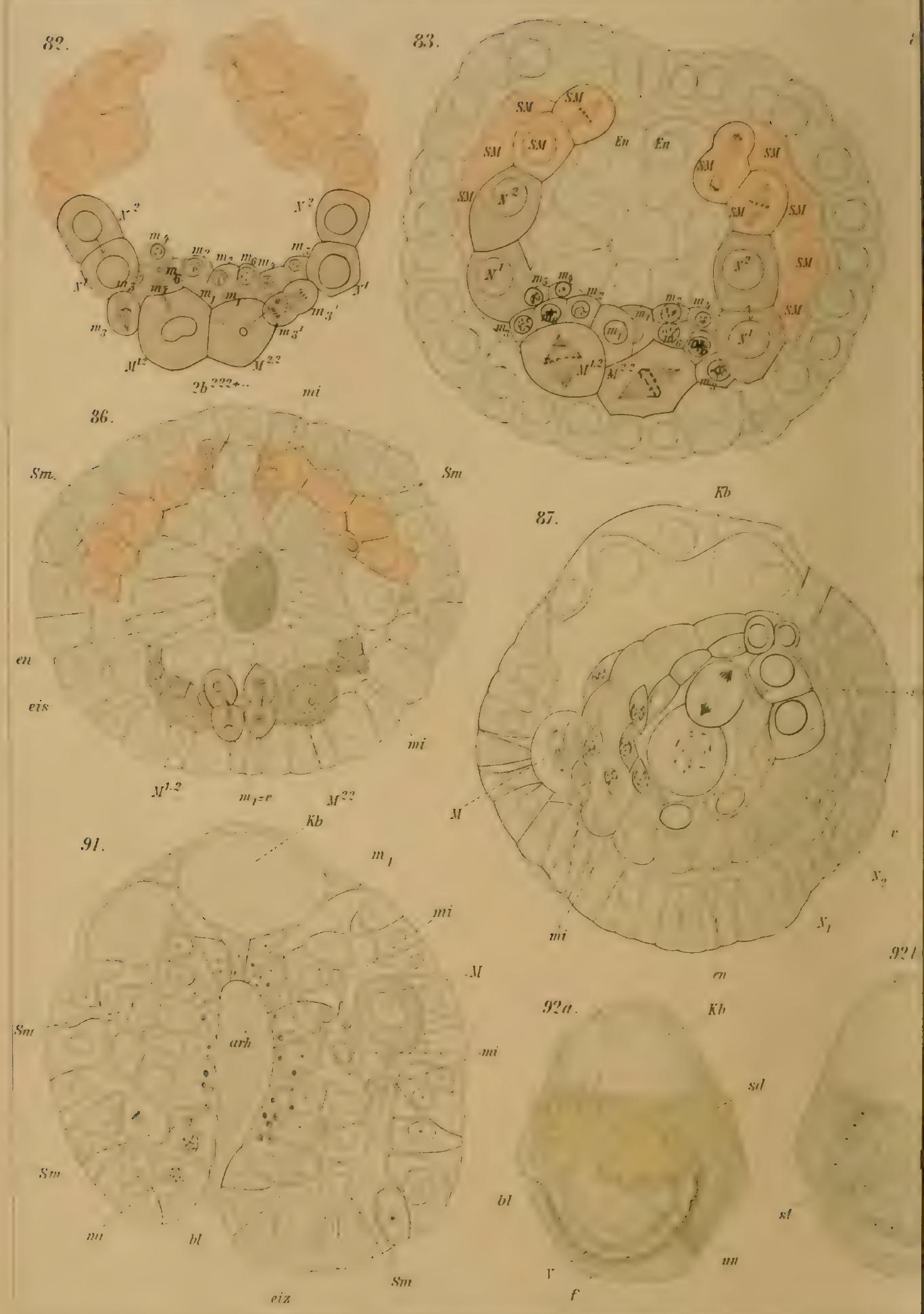





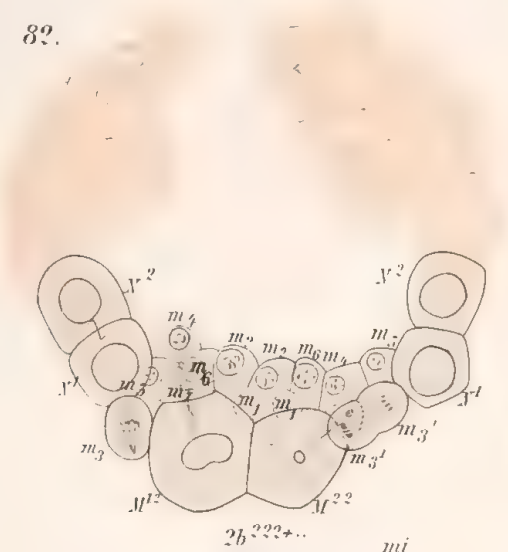

36. $s i m$

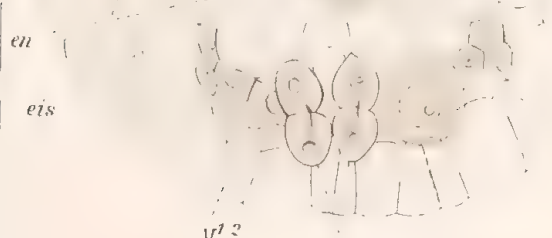

91.

$k b$

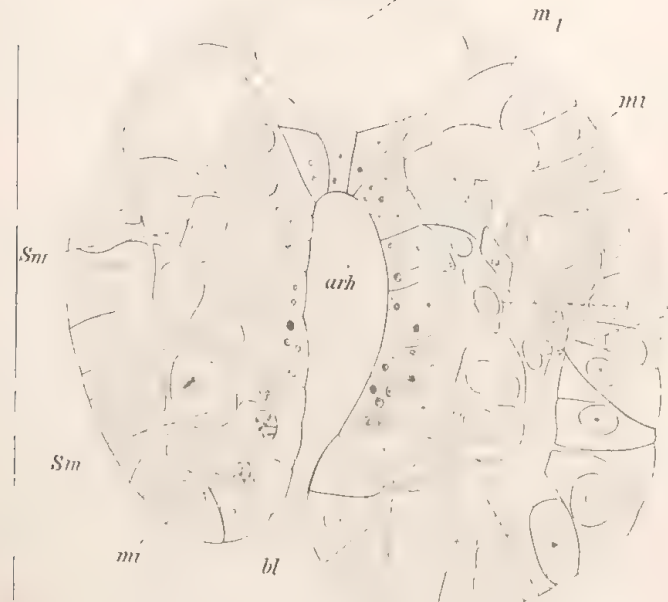

$s m$
8.3.

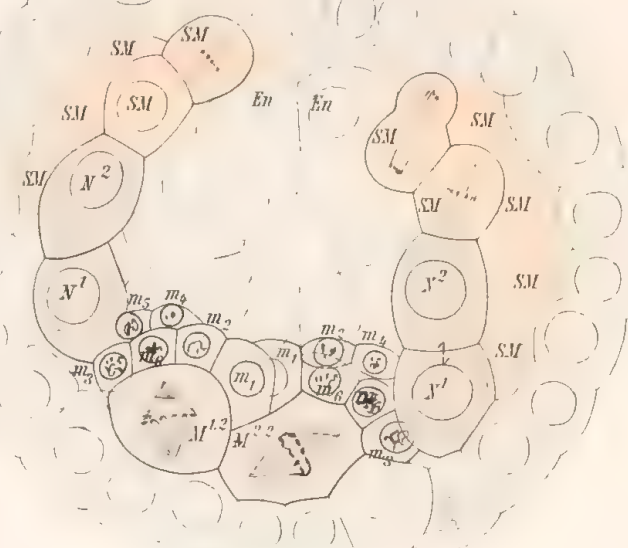

$S \operatorname{sim}$

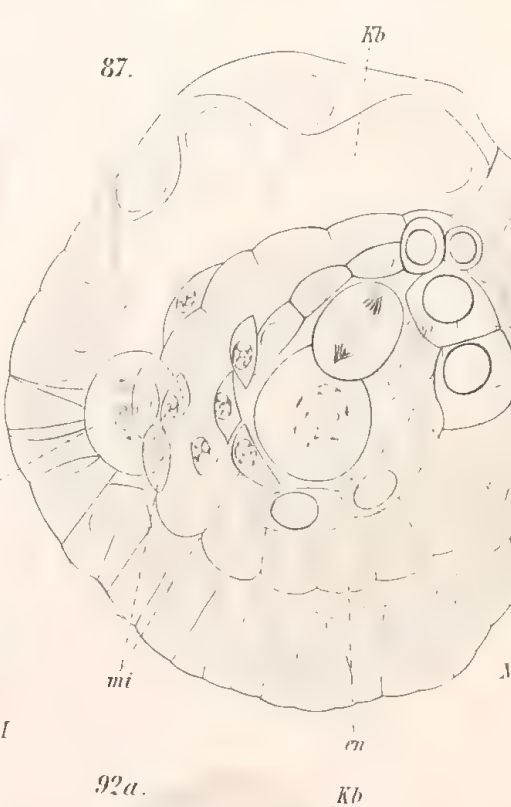

bi

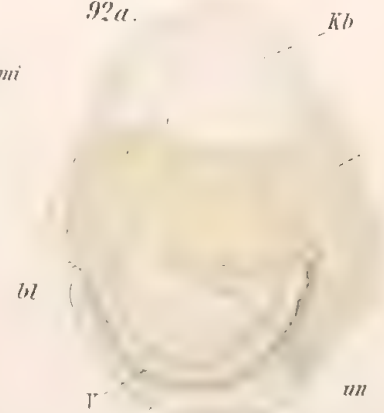

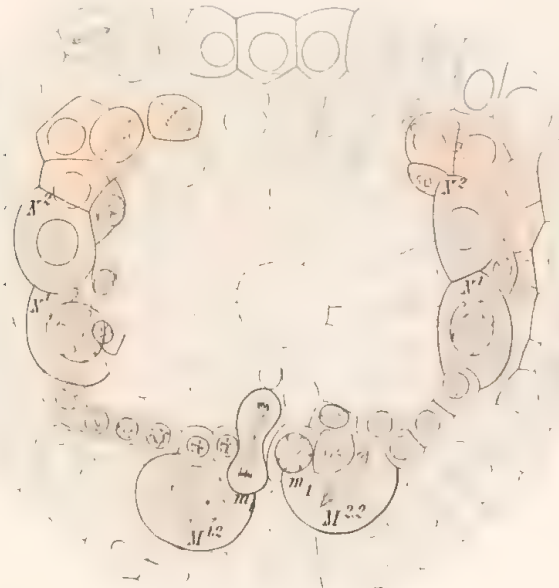

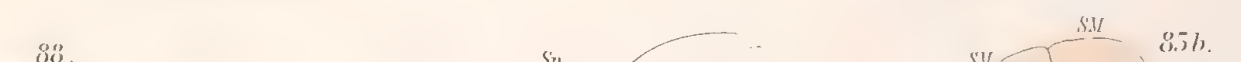
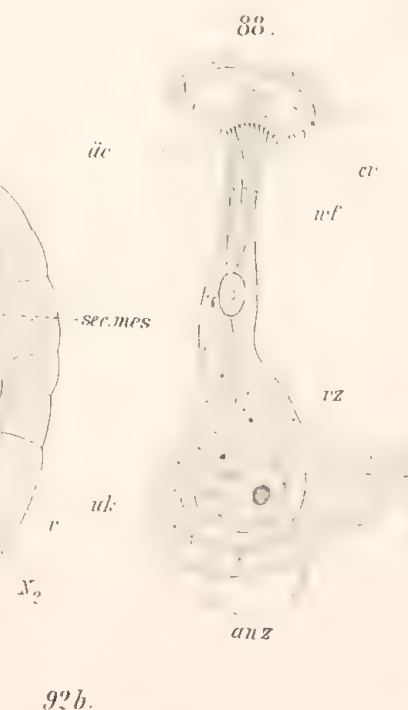

8.94
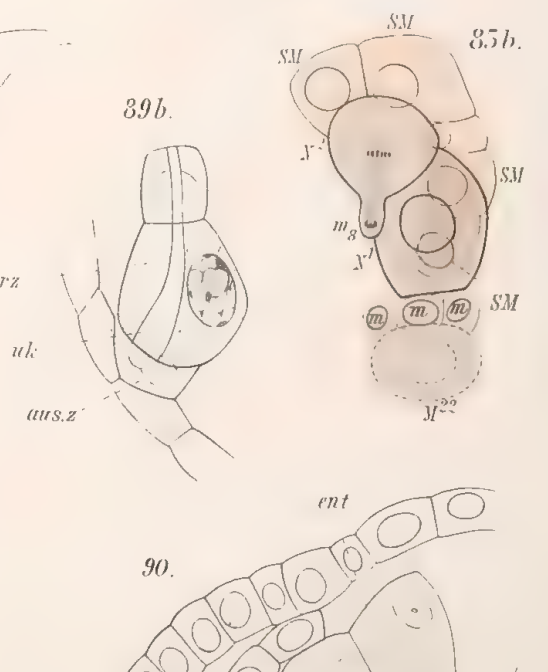

9

9?c.

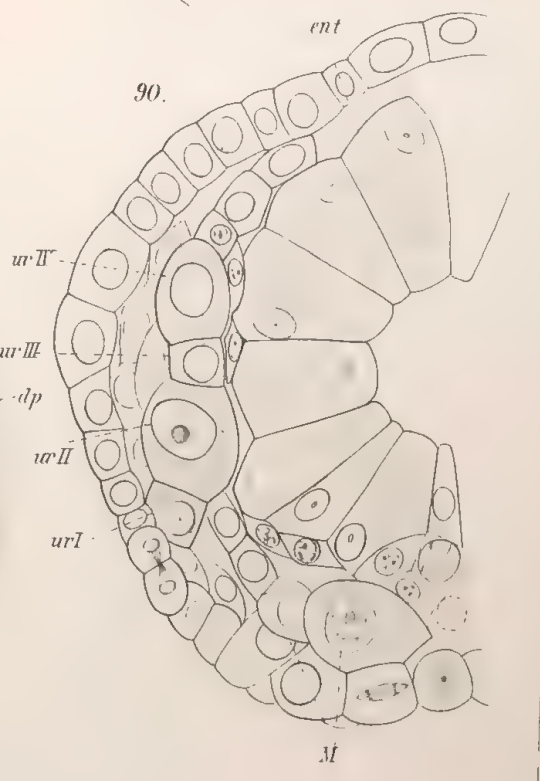




Zeitschrift fin riss Zooloyie Bd. LALXIII.

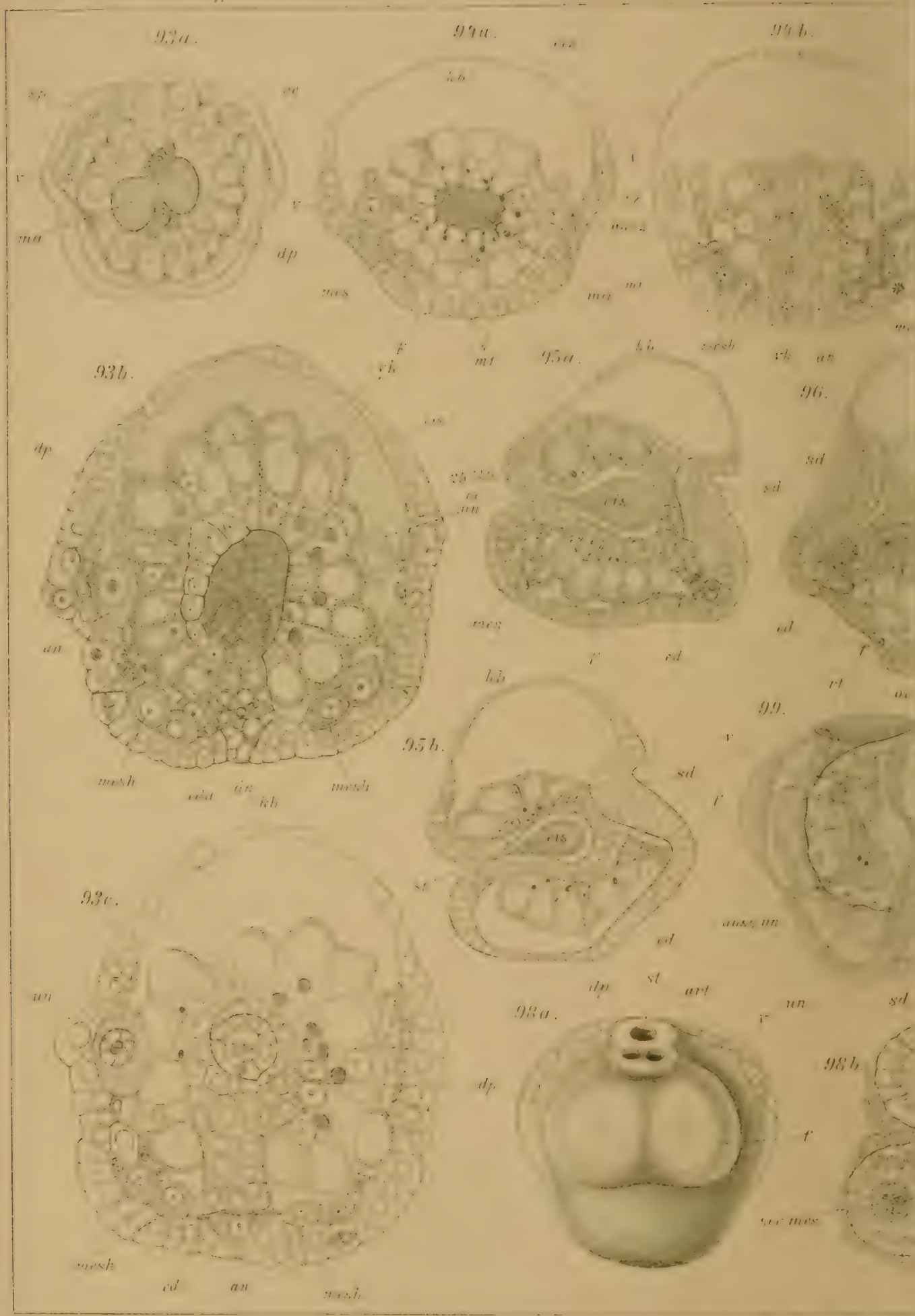




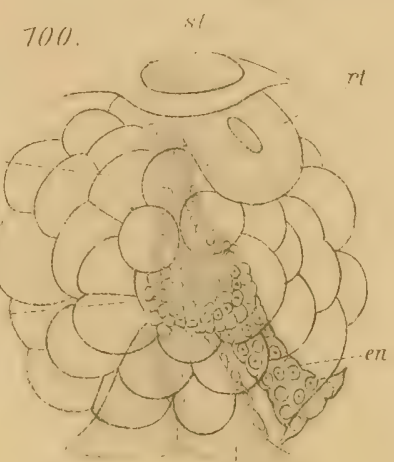

(1) i $\quad 10$ mesh

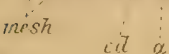

97.

oe

$104 x$.

sil

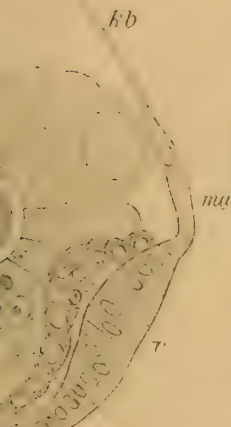

sicimes.
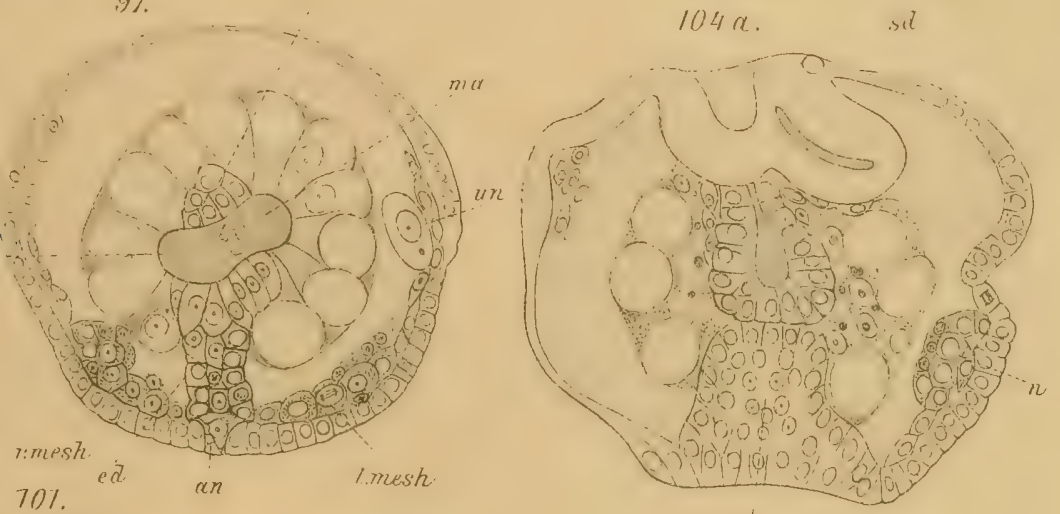

$70 \%$
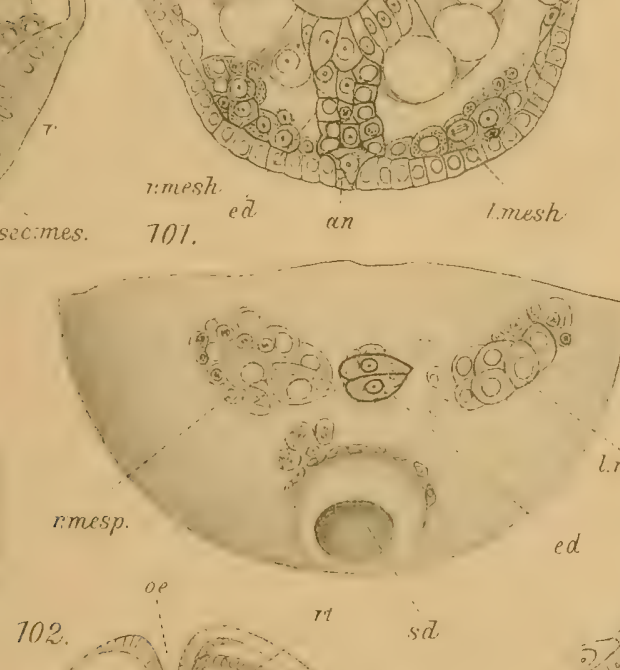

Imesh

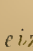

$7046 . \quad$ sid

eiz
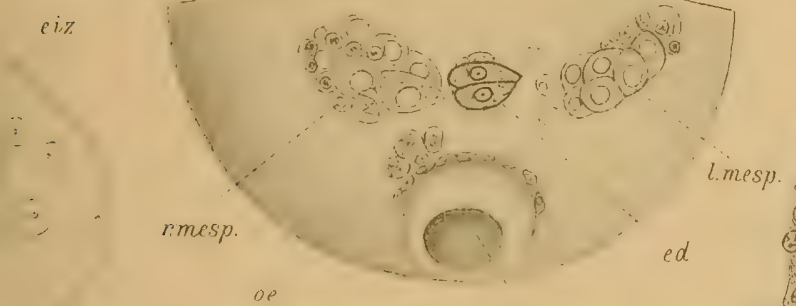

st

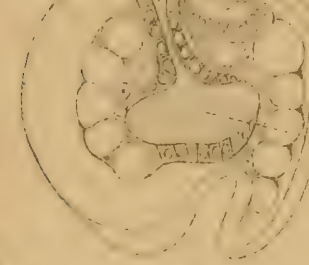

$s d$
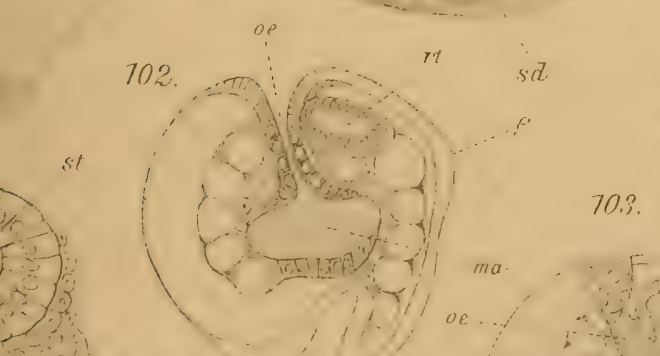



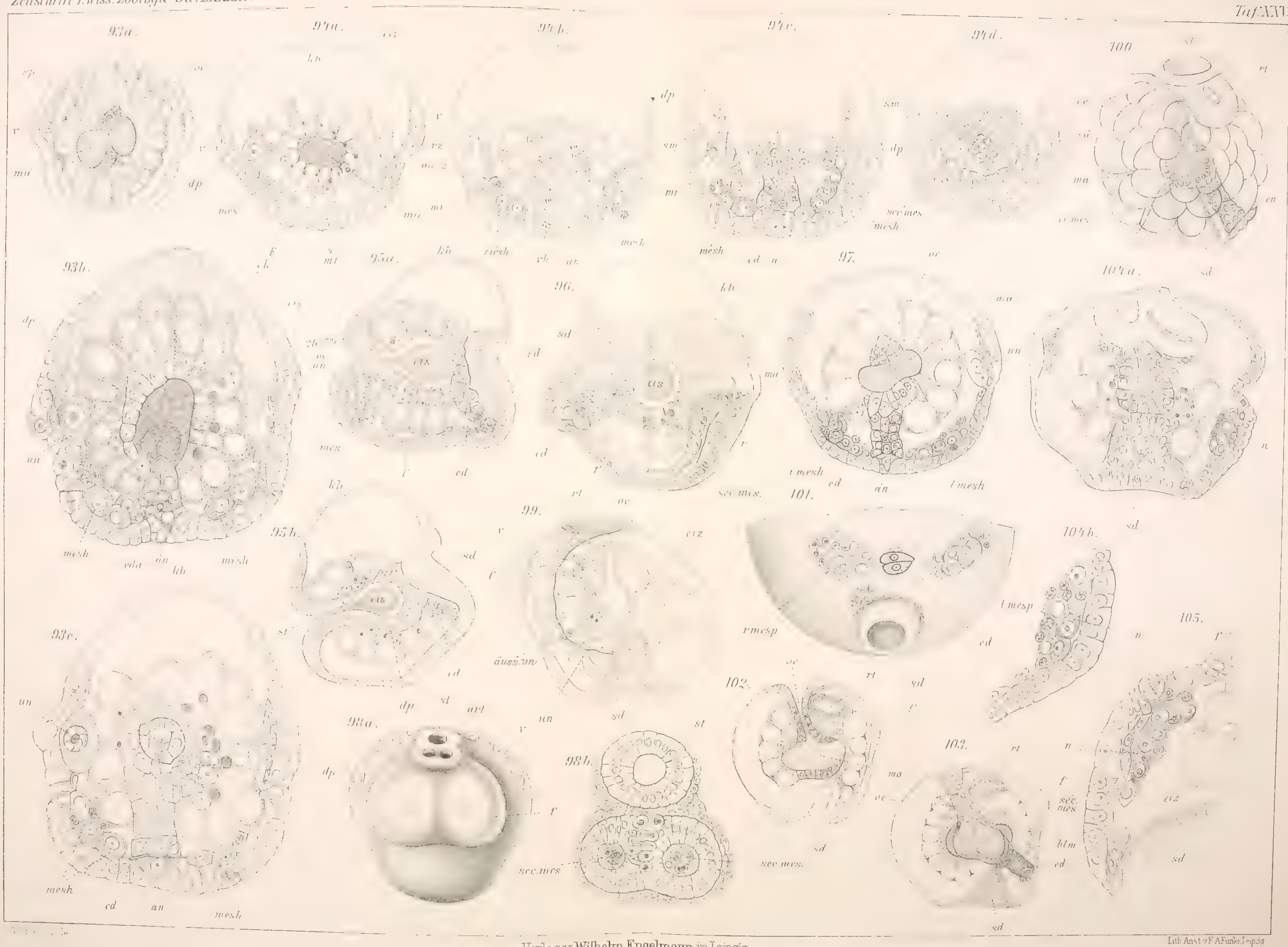





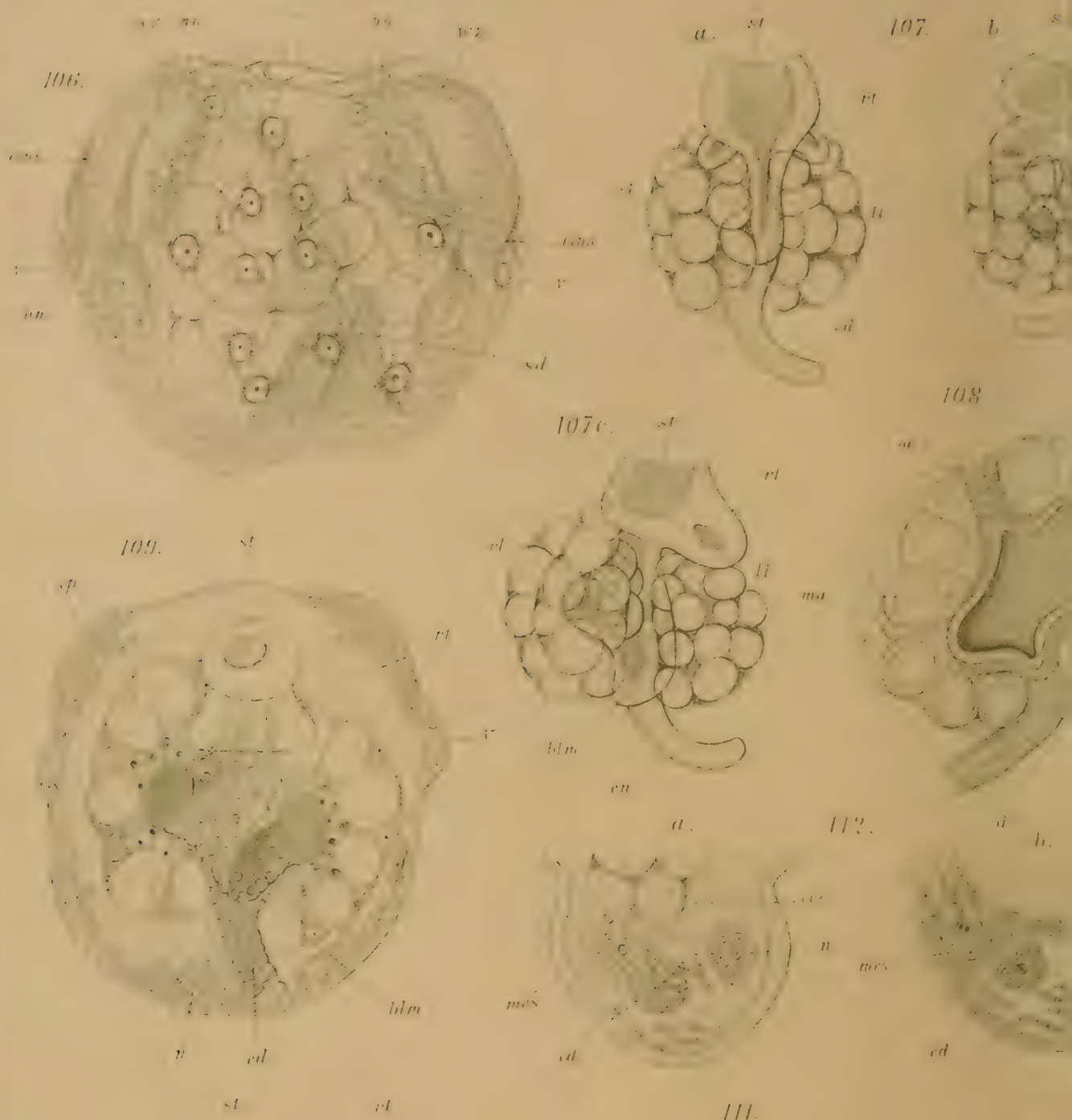

III:
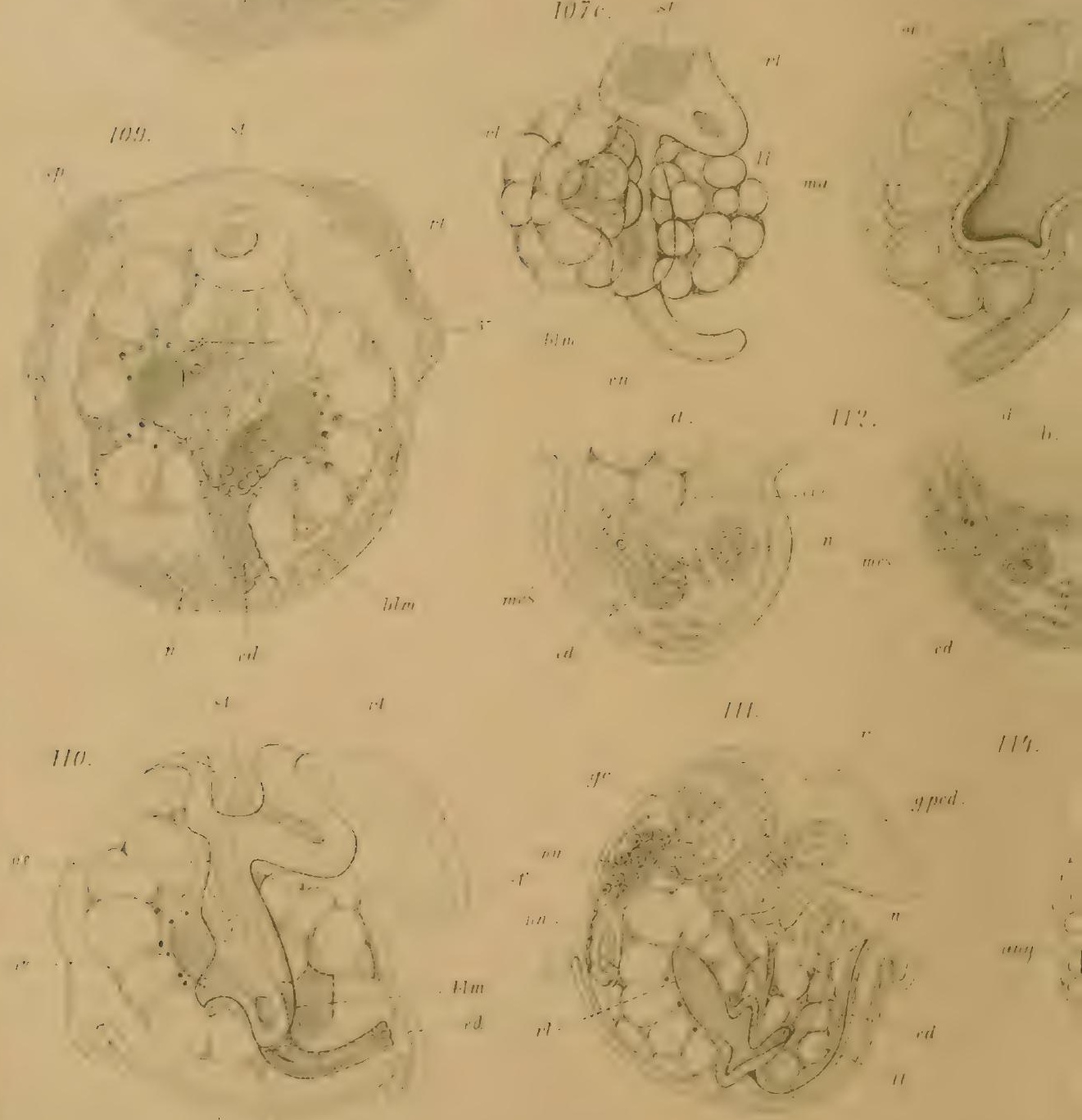

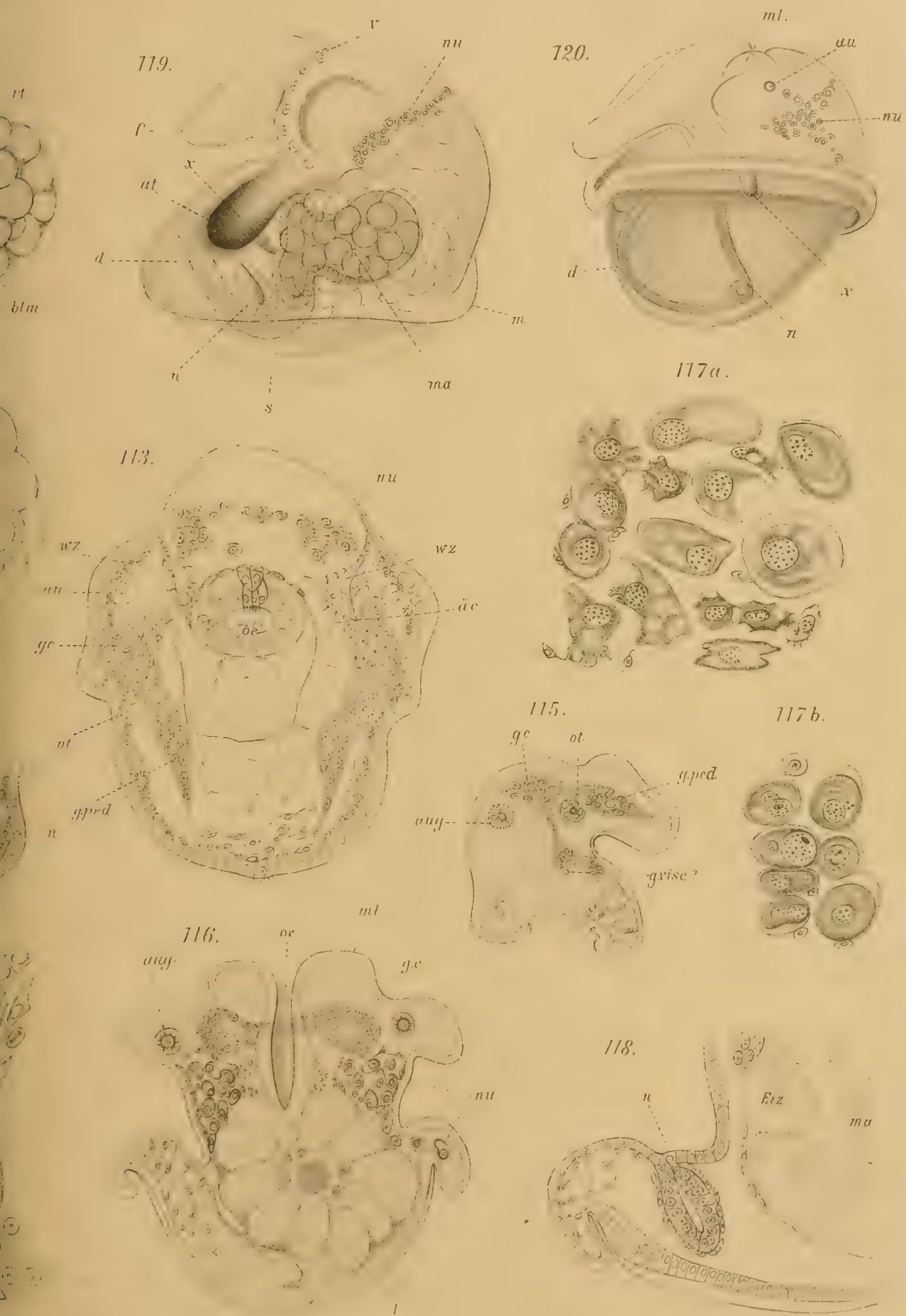



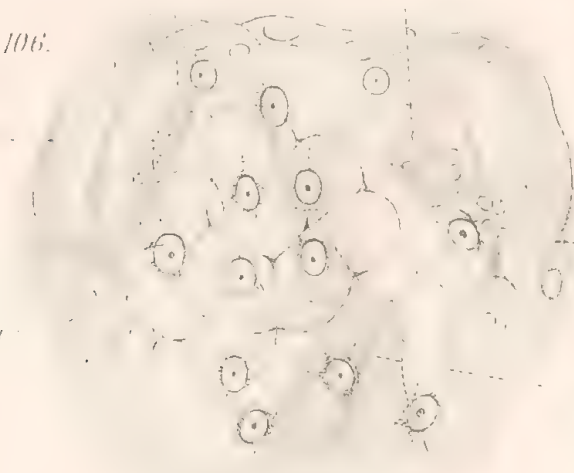

(11).
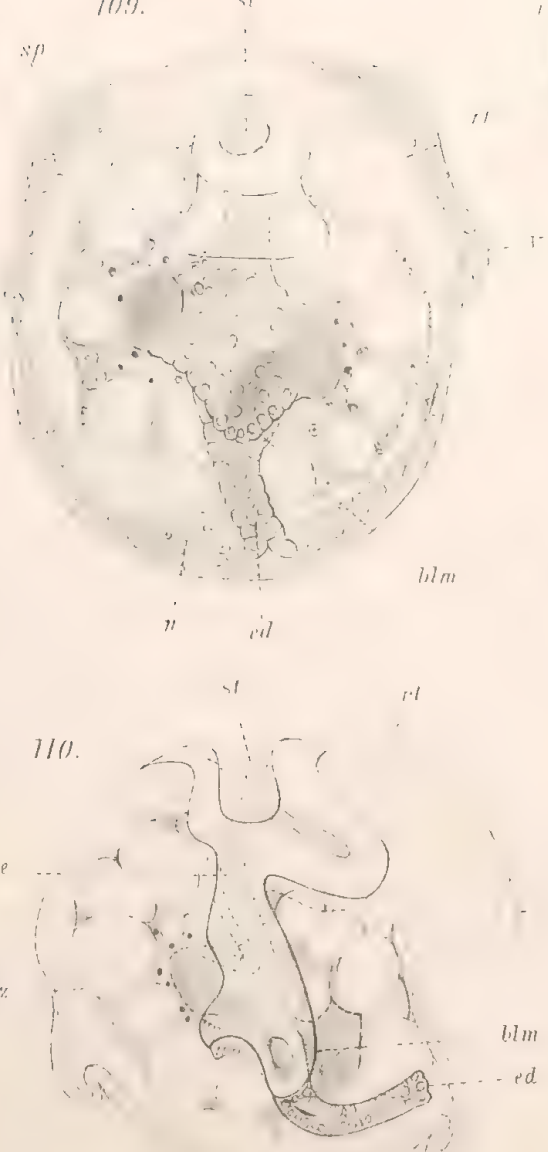
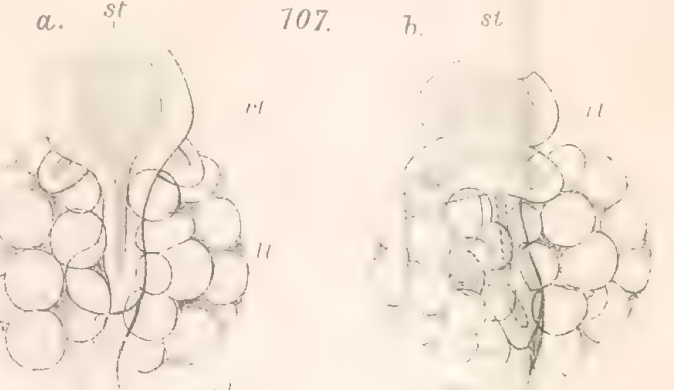

$\because-$
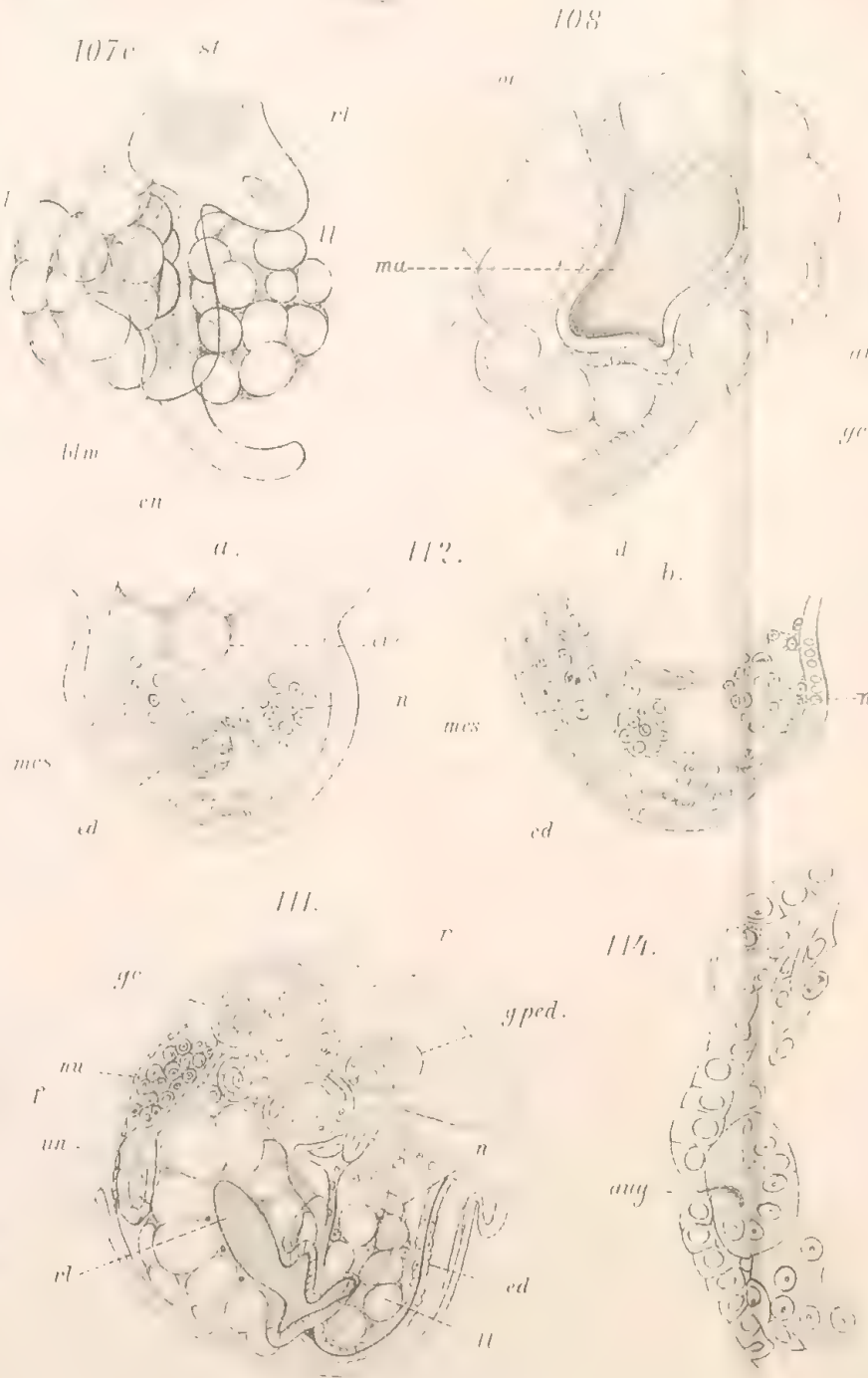
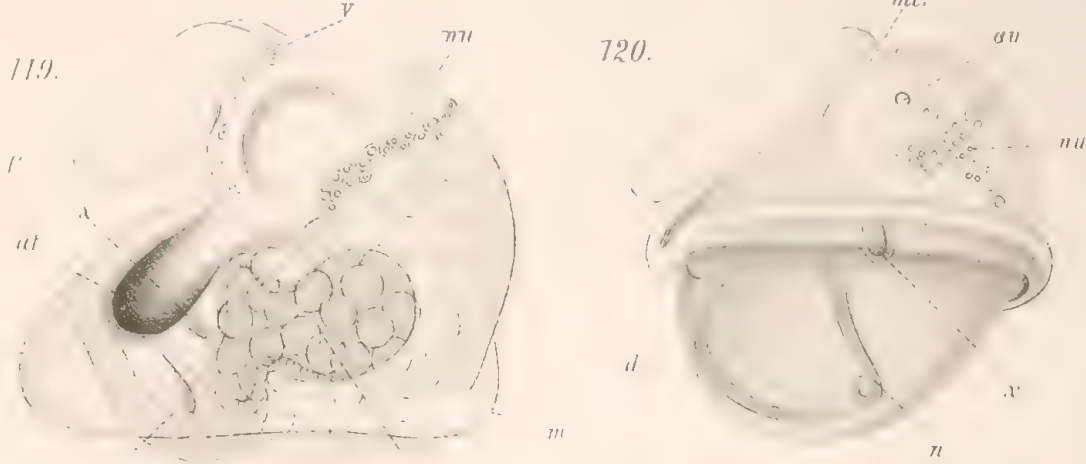

ia
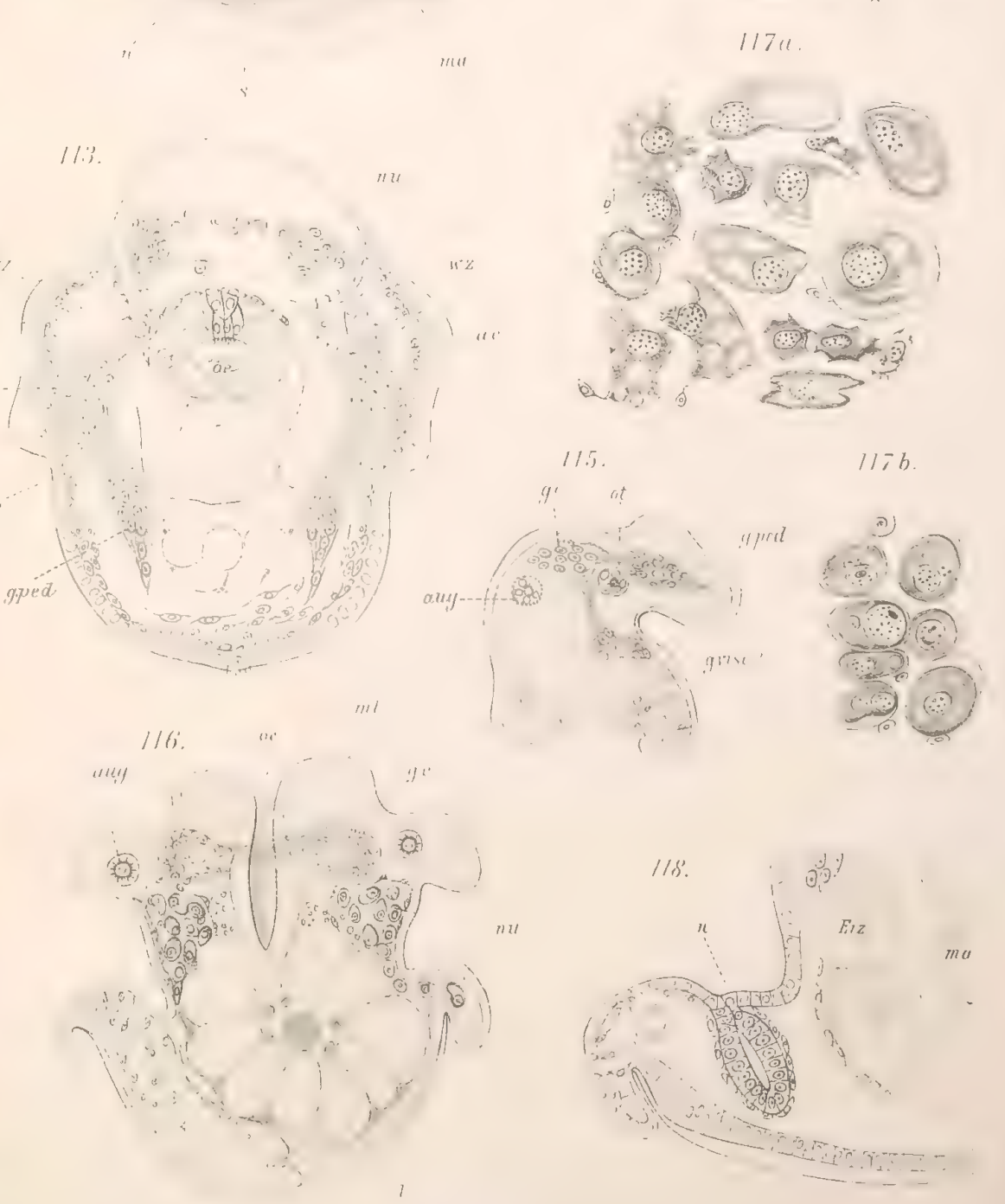



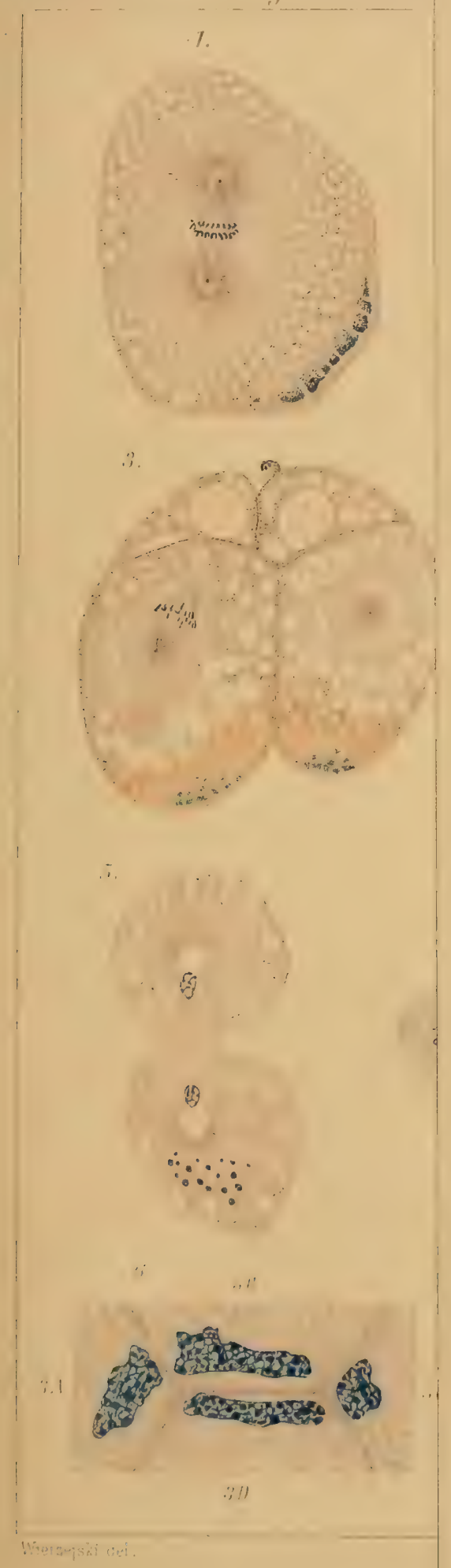





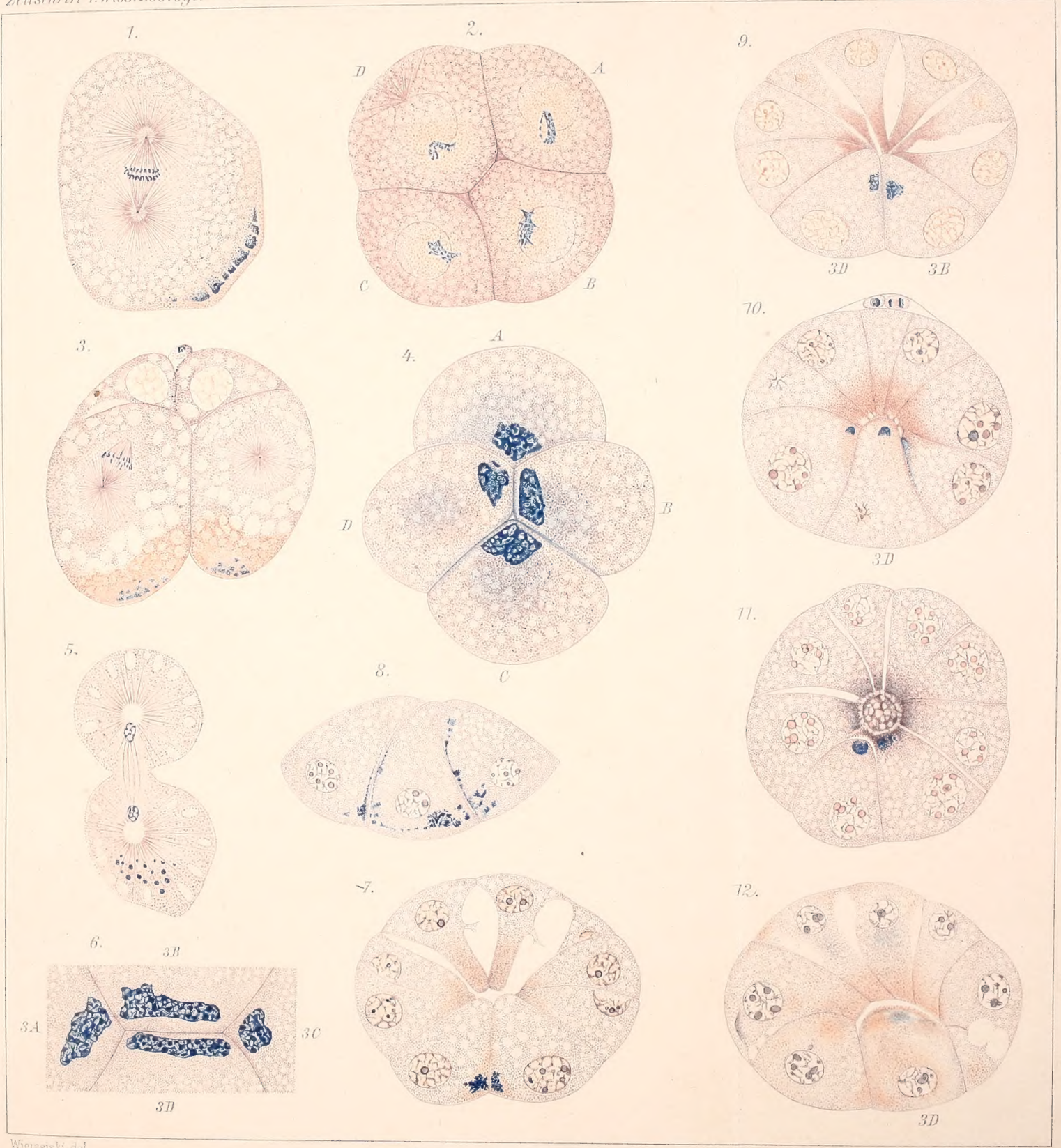




